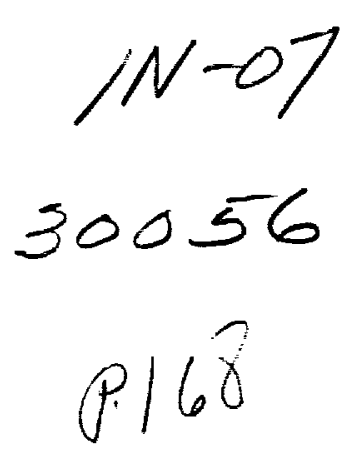

NASA Contractor Report 187137

$$
\begin{gathered}
30056 \\
0.168
\end{gathered}
$$

\title{
Detonation Duct Gas Generator Demonstration Program
}

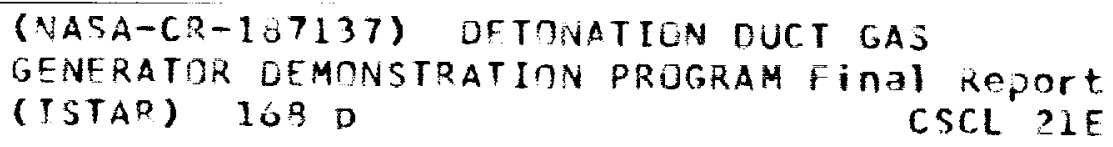

Unclas

63/07 0030056

Andrew Wortman, Gayl A. Brinlee, Peter Othmer, and Michael A. Whelan

ISTAR, Inc.

Santa Monica, California

June 1991

Prepared for

Lewis Research Center

Under Contract NAS3-25453 
This program demonstrated experimentally the feasibility of generation of detonation waves moving periodically across high speed channel flow. Such waves are essential to the concept of compressing the outflow from a low pressure compressor with the objective of reducing conventional compressor requirements and increasing the engine thermodynamic efficiency through isochoric energy addition. By generating transient transverse waves, rather than standing waves, shock wave losses are reduced by an order of magnitude. The ultimate objective is to use such detonation ducts downstream of a low pressure gas turbine compressor to produce a high overall pressure ratio thermodynamic cycle.

A 4 foot long, $1 " x$ " 12 " cross-section, detonation duct was operated in a blow-down mode using compressed air reservoirs. Liquid or vapor propane was injected through injectors or solenoid valves located in the plenum or the duct itself.. Detonation waves were generated when the mixture was ignited by a row of spark plugs in the duct wall. Problems with fuel injection and mixing limited the air speeds to about Mach 0.5 , frequencies to below $10 \mathrm{~Hz}$, and measured pressure ratios of about 5-6. The feasibility of the gas dynamic compression was demonstrated and the critical problem areus were identified. 
TABLE OF CONTENTS

1. INTRODUCTION . . . . . . . . . . . . . . 1

1.1 Fundamental Thermodynamic Considerations. . . . . 3

1.2 Detonation wave Theory..............10

1.3 Detonation and Expansion of Gases . . . . . . . . .14

1.4 Availability of Energy. . . . . . . . . . . . . . .22

1.5 Applications to Gas Turbines. . . . . . . . . .24

2. Detonation WAVES . . . . . . . . . . . . . 28

2.1 Ignition. . . . . . . . . . . . . . . .28

2.2 Transition to Detonation. . . . . . . . . .29

2.3 Detonation wave Characteristics........ . .30

2.4 Detonation wave Reactors. . . . . . . . . . . . .31

3. APPARATUS, EQUIPMENT, AND INSTRUMENTATION. . . . . . 33

3.1 Air Supply system . . . . . . . . . . . . . .35

3.2 Detonation Duct................ . .40

3.3 Fuel Injection. . . . . . . . . . . . . . . .59

3.4 Injection-Ignition control system . . . . . . .67

3.5 Data Acquisition and Instrumentation. . . . . . .73

4. RESUlTS. . . . . . . . . . . . . . . . .75

4.1 Detonation Waves. . . . . . . . . . . . . .75

4.2 Pressure Measurements . . . . . . . . . . . 77

5. DISCUSSION OF THE RESULTS: . . . . . . . . . . . 86

6. CONCLUSIONS AND RECOMMENDATIONS. . . . . . . . . . 90

LIST OF SYMBOLS. . . . . . . . . . . . . . . . . . .91

REFERENCES .. . . . . . . . . . . . . . . . . . 94

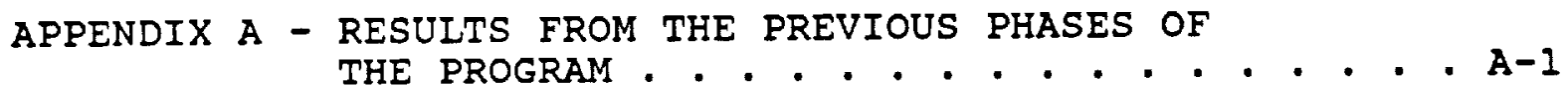

A.l First Feasibility Tests . . . . . . . . . . A-I

A. 2 Demonstration Studies ........... A-4 
APPENDIX B - SUPPORTING EXPERIMENTS. . . . . . . . . . . . B-I

B.1 Ignition Tests. . . . . . . . . . . . . . . B-I

B.2 Detonation Tube Tests... . . . . . . . . . B-3

B. 3 Shock Tube Experiments. . . . . . . . . . . B-6

B.4 Flow studies. . . . . . . . . . . . . . . . B-9

B.5 Original Duct Tests . . . . . . . . . . . . B-17

B.6 Valve Response. . . . . . . . . . . . . . . B-20

B.7 Combustion Bomb................. . . B-22

B.8 Pressure Transducers Flame Tests. . . . . . . . B-25

APPENDIX C - DESIGN OF THE PROTOTYPE GAS

GENERATOR UNIT. . . . . . . . . . . . . . c-1

C.1 Prototype Design. . . . . . . . . . . . . . . c-1

C. 2 Cost Estimates. . . . . . . . . . . . . . . C-7

C.3 Model of the Prototype. . . . . . . . . . c-8

APPENDIX D - EXPERIMENTAI DATA . . . . . . . . . . . . D-I 


\section{INTRODUCTION}

Power cycles are used to convert heat into mechanical energy in a sequence of thermodynamic processes which returns the system to its initial state. Considerations of the second law of thermodynamics have led to attempts at approximations of the carnot cycle. This has led to the optimizations of the elements of the cycle, with the present effort being an example of a more efficient energy addition.

In general, the processes which can be realized in practice are represented by ideal models whose elements are isobaric, isochoric, isothermal, and isentropic paths on thermodynamic diagrams. The work elements are generally achieved by mechanical or aerodynamic components. This report describes a part of a research and.development effort to demonstrate the feasibility of employing detonation waves to compress gases and to increase their temperature in an essentially constant volume process. In contrast with the supersonic combustion ramjets, which employ standing detonation waves and thus require high supersonic Mach numbers, the present concept initiates detonation waves at a wall and propagates them across a transonic stream. Thus, instead of incurring the very high total pressure loss corresponding to the Mach No. $4-6$ standing waves, the idea investigated here has at least an order of magnitude lower loss due to the Mach 2 shock waves generated by the sudden expansion of the detonation products of the transverse waves.

The concept described here is a completely new departure from existing approaches in that transverse detonation waves are used to generate volumes of high pressure and temperature gas without mechanical valves. only small total pressure losses are caused by shock waves induced by the expansion of the detonation products. These waves are attenuated in the highly variable cross-section flow areas of the transition sections of the plenum chambers at both ends of the rectangular cross-section detonation duct. In effect, the device whose feasibility was demonstrated here is a gas dynamic compressor-burner capable of extremely flexible operation because both the air flow rate and the frequency of the detonation waves can be varied over very wide ranges.

Principles of the thermodynamic cycle which approximates that of current gas turbines have been known for over a century, but practical applications appeared only about 50 years ago. In aircraft propulsion, various forms of gas 
turbines power all larger aircraft. only the smallest private aircraft are still using the piston engine powerplants. Large gas turbines are used in powerplants to augment the main steam turbines during periods of peak demand. Gas turbines dominate larger land installations such as petroleum pumping plants and are the primary power units on oil platforms. In marine propulsion, gas turbines are used to power smaller warships and are used in conjunction with Diesel engines in some commercial vessels. The thermodynamic cycle of current gas turbines approximates the ideal Brayton cycle in which compression and expansion are accomplished isentropically and heat is added and rejected isobarically. The useful output, which is the excess of turbine work over that of the compressor, is extracted in the form of pure jet propulsion, mechanical drive of propellers or shrouded fans, some combinations of jet and mechanical power, and electromechanical power units. The efficiency of gas turbines depends on the efficiencies of the system components and increases with operating temperatures and pressure ratios. With the development of high temperature materials, the turbine inlet temperatures have been rising and the pressure ratios have increased correspondingly. current aircraft gas turbines have axial compressors with up to 20 stages and overall pressure ratios of 32 . The specific fuel consumption of high bypass aircraft engines is now approaching 0.3 pounds of fuel per hour per pound of thrust, and large turboshaft units are beginning to compete with Diesel engines. Progress in the last 40 years has been extremely rapid, but further increases in efficiency will be more gradual because the current engines are now operating in the less sensitive portion of the thermodynamic efficiency curve.

It was realized very early that, in analogy with the operation of Otto and Diesel cycles, the efficiency at a given pressure ratio could be increased if heat were to be added isochorically rather than isobarically. This was exploited by Humphrey, who substituted the heat addition isobar of the Brayton cycle with a constant volume process. In 1910 Holzwarth built a gas turbine with periodic isochoric combustion in chambers with intake and exhaust valves. Holzwarth also attempted to enhance efficiency by employing a regenerator in which heat from the expanded gas was transferred at constant pressure to the compressed gas. The engine built by Holzwarth was not practical because of the low efficiency of the compressor and expander elements, the weight of the chambers, and the complexity of the valve gear. 


\subsection{Fundamental Thermodynamic considerations}

Current gas turbines attempt to approximate the Brayton cycle by employing constant pressure combustors. In contrast, the proposed engine, whose feasibility was studied here, employs detonation waves to achieve an essentially constant volume heat addition. In the interest of clarity and brevity, initial discussions will employ ideal gas models and processes. More realistic performance estimates will be presented in the following sections of the report.

The ideal Brayton and Humphrey cycles are shown in pressure-volume and temperature-entropy diagrams in Figure 1.1-1
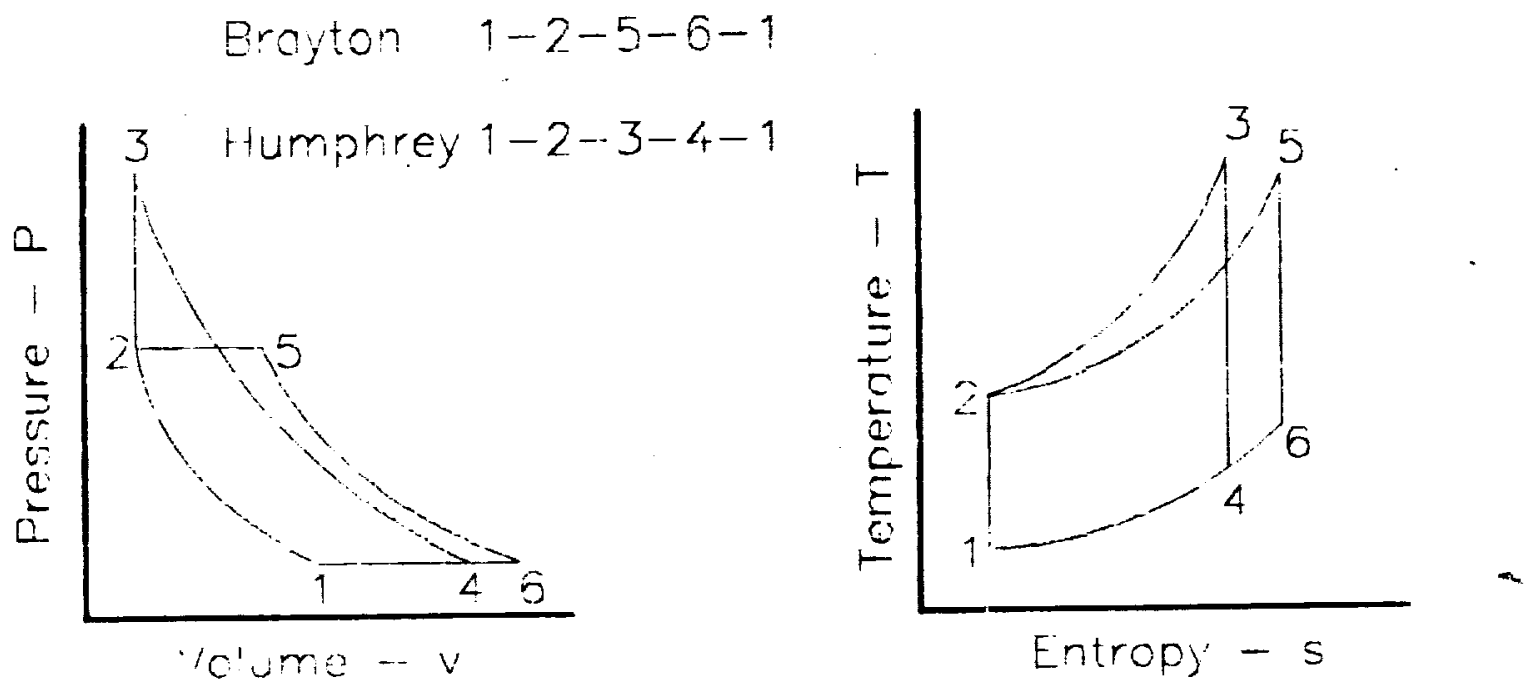

Figure 1.1-1. Ideal Brayton and Humphrey Cycles

The Brayton cycle is discussed in numerous thermodynamics texts. Probably the best discussion is in Reference 1 here it is shown that the cycle thermal efficiency is given by:

$$
e_{t h}=I-R^{-G}
$$


with all symbols being defined in the list of symbols at the end of the report. The symbols are:

$$
\begin{aligned}
& k \quad-\text { isentropic exponent } \\
& G \quad-\quad(k-1) / k \\
& R \quad-\quad \text { cycle pressure ratio }
\end{aligned}
$$

of particular interest in the exposition in Reference 1 are the analyses of various schemes for enhancing the efficiency of the basic cycle. Analyses of the Humphrey cycle are more difficult to find in American texts and the relation for efficiency is taken from Reference 2 which gives it as

$$
\begin{aligned}
e_{t h} & =1-k^{-G}\left\{\left[\left(T_{3} / T_{2}\right)^{1 / k}-1\right] /\left[\left(T_{3} / T_{2}\right)-1\right]\right\} \\
& =1-k^{-G}\left\{\left[\left(T * / R^{G}\right) 1 / k-1\right] /\left[\left(T * / R^{G}\right)-1\right]\right\}
\end{aligned}
$$

with

$$
T^{*}-T_{\max } / T_{1} \text {, limiting cycle temperature }
$$

If the Brayton cycle is analyzed with accounting for allowable temperatures then it is possible to limit the fuel/air ratio. The cycle elements are:

Compression work, $w_{C}$

$$
w_{C}=c_{V} T_{I}\left(R^{G}-I\right)
$$

Expansion work, during heat addition, $\mathrm{w}_{e}$

$$
W_{e}=(I+f) R_{g a s}\left(T_{5}-T_{2}\right)
$$

Expansion work in the expander, $W_{t}$

$$
W_{t}=(1+E) c_{V} T_{5}\left(1-R^{-G}\right)
$$

Compression work during heat rejection, $\mathrm{w}_{\mathrm{hr}}$

$$
W_{h r}=(1+f) R_{\text {gas }}\left(T_{6}-T_{1}\right)
$$

with

$$
R_{\text {gas }} \text { - gas constant }
$$


Heat addition per unit mass of air, $H$ is

$$
H=f h=c_{p}(l+f)\left(T_{5}-T_{2}\right)
$$

with

f - fuel/air ratio

$h$ - heat released by a unit mass of fuel

Elementary, but tedious, algebraic operation yield the result

$$
e_{t h}=\left(1-R^{-G}\right)\left[1+\left(R^{G} / k Q\right)\right]
$$

with

$$
Q=h / c_{p} T_{1}=\begin{aligned}
& \text { dimensionless fuel energy constant } \\
& \text { parameter which determines } \mathrm{T}_{5} / \mathrm{T}_{1}
\end{aligned}
$$

It should be noted that the fuel/air ratio does not appear explicitly, but is contained within the parameter $Q$. The value of $Q$ is about 10 so that the difference between this relation and the basic Brayton cycle equation is minor.

It is also a some interest to study a Humphrey cycle in which the whole flow is compressed by a Brayton cycle using only the fraction $b$ of the air while the remainder, (1-b), goes through a constant volume heat addition. This is an idealized but realizable representation of a possible engine since the Brayton component. could be started and operi.ted with arbitrary level of augmentation by the Humphrey cycle. The primary interest here is in detonation wave compression, and thus it will be assumed initially that the constant volume process is achieved with stoichiometric fuel/air mixtures. Such a condition could correspond to using the flow from constant volume combustion in a propulsion nozzle, which might tolerate such high temperatures. A more realistic assumption is that the maximum temperature will be limited to $T^{*}$ by operation at less than stoichiometric fuel/air ratios. The compression work is given in Equation 3. The heat added air per unit mass is

$$
H=f_{s} h=c_{v}\left(T_{3}-T_{2}\right)
$$

with

$$
f_{s} \text { - stoichiometric fuel/mixture fraction }
$$


and therefore

$$
\mathrm{T}_{3} / \mathrm{T}_{1}=\mathrm{R}^{\mathrm{G}}+\mathrm{kf}_{\mathrm{s}} \mathrm{Q}
$$

The cycle pressure ratio for the (1-b) fraction of the flow is therefore

$$
P_{3} / P_{1}=\left(T_{3} / T_{1}\right) R^{1 / k}
$$

The net work per unit mass is the difference between turbine expansion and the compression during the heat rejection process so that

$$
w_{N}=c_{v} T_{3}\left[1-\left(k P_{31}\right)^{-G}\right]+c_{v} T_{1}(k-1)
$$

with

$$
P_{31}=P_{3} / P_{1}
$$

Total energy added, from Equation 1.1 .9 , is $H$ and the Brayton cycle heat input $\mathrm{H}_{B}$, which is derived from the energy balance

$$
H_{B}\left(1-R^{-G}\right)=(1-b) C_{V} T_{1}\left(R^{G}-1\right)
$$

The total heat added is therefore

$$
H=(1-b) m c_{v} T_{3}
$$

and the thermal efficiency is

$$
e_{t h}=1-\left(k P_{31}\right)^{-G}+(k-1) / T_{31}
$$

The fraction of flow going through the Brayton cycle is found from the relation

$$
b^{-1}-1=k\left[\left(T_{5} / T_{1}\right) R^{-G}-1\right]
$$


and the overall fuel/air ratio $m_{f} / m, F$, for the Brayton cycle is

$$
F=b\left(T^{*}-R^{G}\right) / Q
$$

Here it was assumed that the Brayton cycle will be operated at maximum allowable temperature $T^{*}$ to maximize the flow to the constant volume combustion. Comparison of the Brayton cycle and Humphrey cycle, with temperature limited to $T^{*}$, combined Brayton-Humphrey cycle, with stoichiometric isochoric combustion, and the combined cycles, with temperature ratio limited to $T^{*}$, are shown in Figure $1.1-2$ for $k=1.4$, $\mathrm{T}^{*}=8$, and $\mathrm{Q}=10$.

\section{GAS TURBINE CYCLES \\ Comparison of Efficiencies}

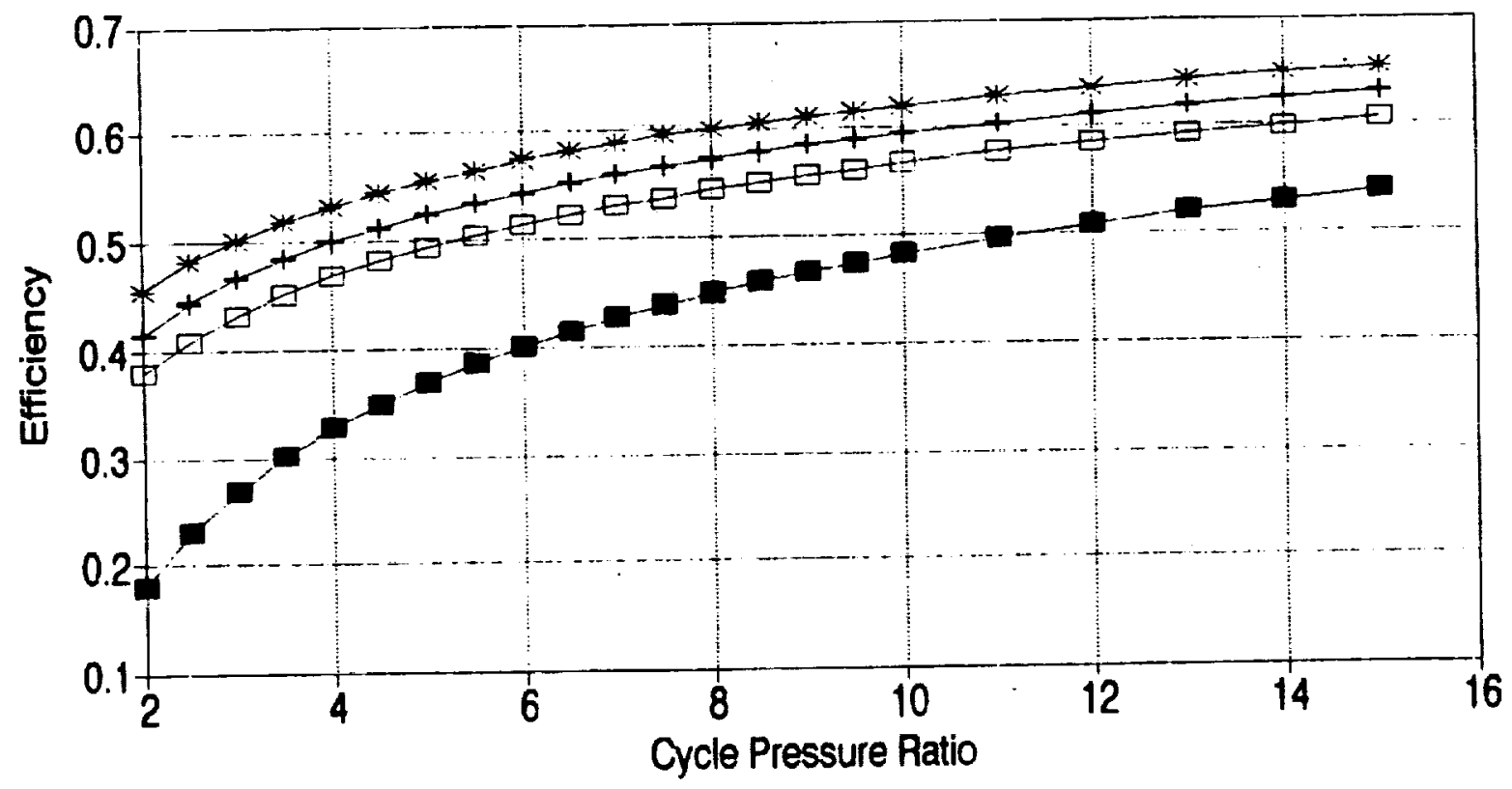

$\rightarrow$ - Brayton + Humphrey *-H-B Stoi $-\square-$ H-B Lim

Figure 1.1-2. Thermal Efficiencies of Brayton, HumphreyTemperature Iimited, Humphrey-Brayton Stoichiometric, and Humphrey-Brayton Temperature Limited Cycles 
A parameter, of considerable interest in the analysis of engine cycles, is the specific power which is defined here as the power output referred to the power in the flow, or

$$
\mathrm{P}^{*}=\mathrm{H} e_{t h} / m c_{v} T_{I}=(1-b) e_{t h}\left(T_{3} / T_{1}\right)
$$

The principal parameters of a combined cycle engine, in which the total output of the Brayton cycle compresses the air for the Humphrey cycle limited to operation at $T^{*}=8$, are shown in Figure 1.1-3. In the Figure $H-E f f$ is the combined cycles efficiency, B-Eff the Brayton cycle efficiency, Mass-B the mass fraction in the Brayton cycle and P-Spec the specific power.

\section{GAS TURBINE CYCLES Performance of Combined Cycles}

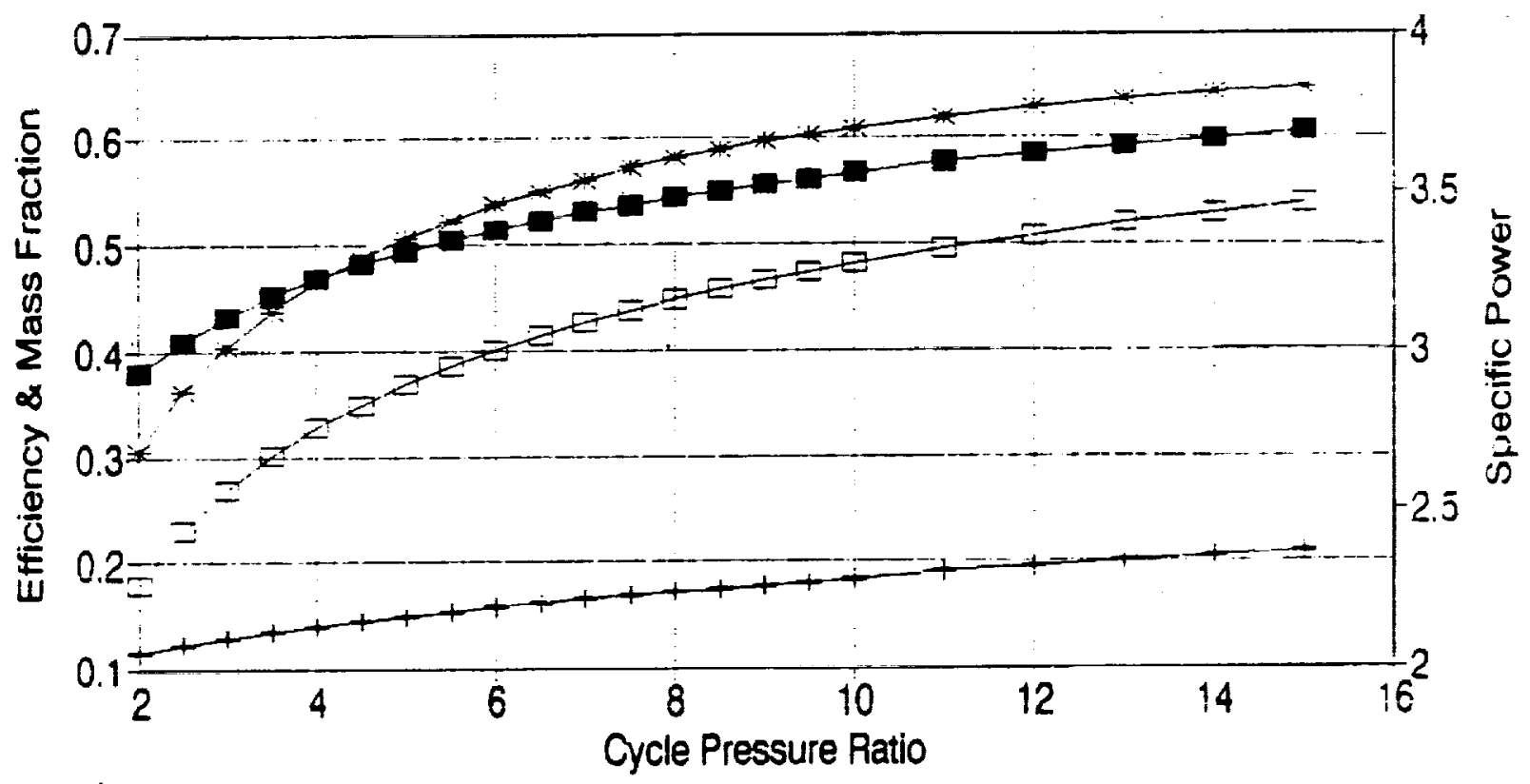

Figure 1.1-3. Temperature Limited Combined Cycles Parameters 
It should be noted that the greatest advantage of the combined cycles occurs at lower Brayton cycle pressure ratios. This is of particular interest here since detonation wave compression is intended to not only increase the overall cycle efficiency but also to reduce compressor requirements. As an example, flow compressed by a centrifugal compressor to a pressure ratio of $5: 1$ would be compressed again by the detonation waves to a pressure ratio of $8: 1$ to yield an overall pressure ratio of $40: 1$.

The combined cycle considered here is shown schematically in Figure 1.1-4.

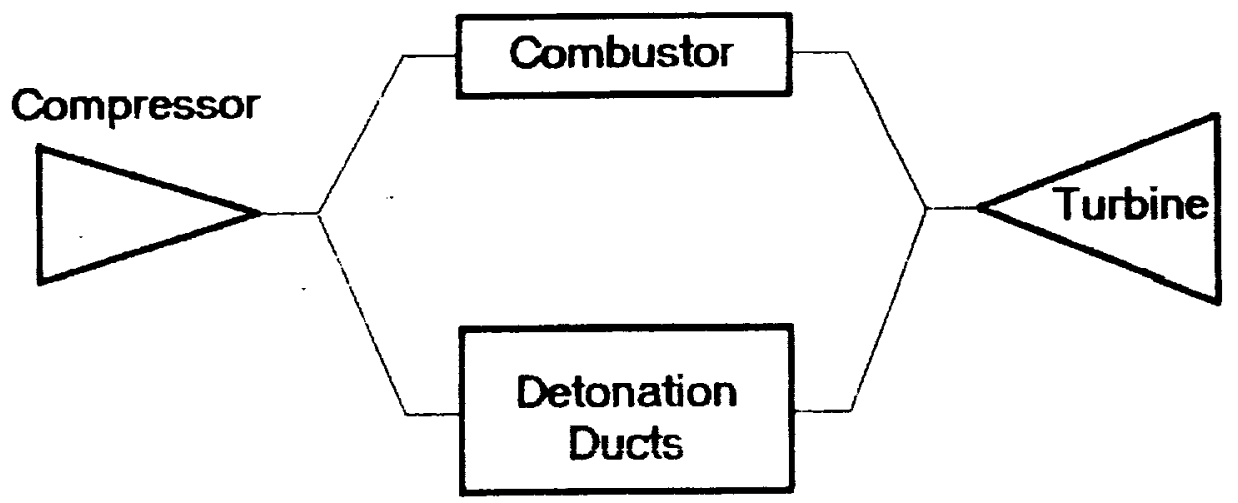

Figure 1.1-4. Combined Brayton-Humphrey Cycles

The Brayton cycle is necessary for starting, but it $15^{\text {m }}$ conceivable that a pure Humphrey cycle engine could be realized. With the highly simplified model of the flow being split downstream of a single compressor, less than 208 would be used in normal combustors and the remainder would go to a number of detonation ducts which would be fired in sequence to minimize pulsation of pressure. Stable detonations can be achieved only with almost stoichiometric fuel/air ratios which would yield temperatures far in excess of turbine temperature limits. This would be a relatively minor problem if the duct flow was expanded in a nozzle and used directly for jet propulsion. If the stream was used in a turbine then temperature would be regulated by the frequency of the detonations which would be adjusted to yield the appropriate energy input for tolerable turbine temperatures. The turbine could then be used to drive shrouded fans or mechanical components in ground installations. clearly, a great variety of combinations of cycles and power outputs could be imagined and implemented with practical devices. 


\subsection{Detonation wave Theory}

Studies of propagation of flames were started in 1880 by French physicists, chiefly vielle, Berthelot, Le Chatelier, and Mallard. It was found that combustion initiated at one end of a tube generally propagated into the combustible mixture with a velocity of a few meters per second. In some circumstances, the flame front accelerated and the reaction propagated, at velocities of a few thousand meters per second. An explanation for these phenomena was given in 1899 by Chapman and later, independently, by Jouguet. In the simplest models, the chemical reaction is assumed to occur on sharp-fronts where a given quantity of chemical energy is released. When the reaction front moves slowly, the pressure changes are relatively small and the process is referred to as deflagration. During a transition to high velocity propagation a shock wave is formed ahead of the combustion front. This shock wave compresses the unburnt mixture which therefore burns more rapidly and the combustion front accelerates. Ultimately, the shock and combustion fronts may be assumed to coalesce although, in reality, the chemical reaction follows the shock. This process is known as a detonation. It has been established that turbulence in the unburnt mixture can reluce the distance of transition from deflagration to detonation by an order of magnitude, but the actual process is not completely understood.

The analysis presented here follows the expositions of courant and Friedrichs ${ }^{3}$ and Stanyukovich who discuss in detail the theoretical aspects of propagation of reaction fronts. The relations for the conservation of mass, momentum, and energy are

$$
\begin{aligned}
& d_{0} u_{0}=d_{1} u_{1}=m \\
& p_{0}+d_{0} u_{0}^{2}=p_{1}+d_{1} u_{1}^{2} \\
& E_{0}+p_{0} v_{0}+u_{0}^{2} / 2=E_{1}+p_{1} v_{1}+u_{1}^{2} / 2
\end{aligned}
$$

Here $E$ is the total internal energy which is given by

$$
E=e+h=\text { internal }+ \text { heat release }
$$

with

$$
\begin{aligned}
& d \text { - density } \\
& p \text { - pressure } \\
& u \text { - velocity }
\end{aligned}
$$

subscripts 0 and 1 denote ahead and after the wave respectively 
The first two equations yield

$$
\left(p_{1}-p_{0}\right) /\left(v_{1}-v_{0}\right)=-d_{0}^{2} u_{0}^{2}=-a_{1}^{2} u_{1}^{2}
$$

This relation shows that the pressure and density increase and decrease in the same direction. In dtonations, pressure and density increase and in deflagrations, they decrease. The first two relations also yield

$$
\left(p_{1}-p_{0}\right) /\left(u_{1}-u_{0}\right)=-d_{0} u_{0}
$$

In the case of a detonation, $p_{1}>p_{0}$, the gas is retarded relative to the wave. The opposite is true in a deflagration where the pressure decreases and the gas is accelerated away from the wave.

When the velocities are eliminated from the conservation equations, the result is the Hugoniot relation

$$
E_{1}-E_{0}=-\left(p_{1}+p_{2}\right)\left(v_{1}-v_{2}\right) / 2
$$

which may also be written as

$$
I_{1}-I_{0}=\left(p_{1}-p_{0}\right)\left(v_{1}+v_{0}\right) / 2
$$

with I being, analogously to $E$, the total enthalpy. It is convenient to define a Hugoniot function

$$
F_{H}=E-E_{0}+\left(p+p_{0}\right)\left(v-v_{0}\right) / 2
$$


for the general points on the hyperbolic curve shown in Figure 1.2-1.

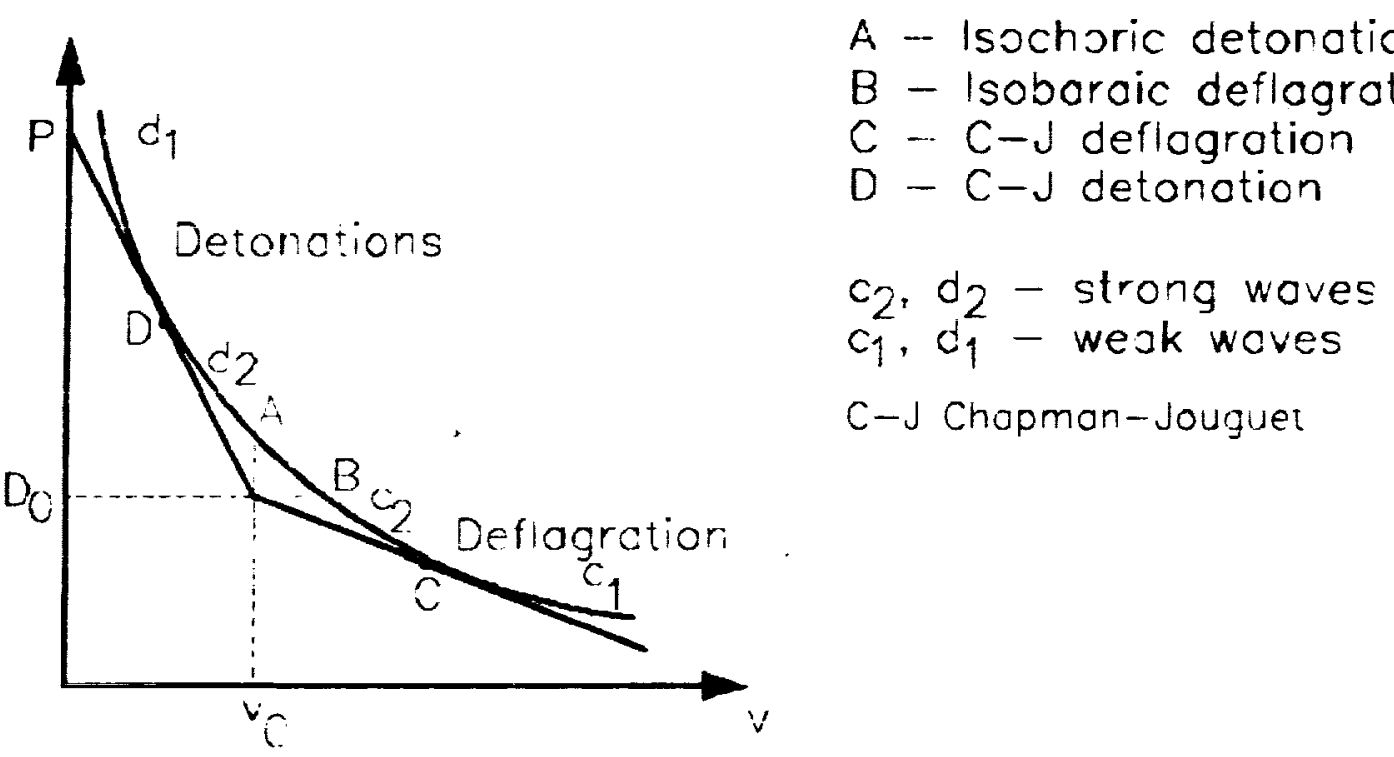

Figure 1.2-1. Hugoniot Curve for Reaction Fronts

The points of tangency, $C$ and $D$, correspond to Chapman Jouguet processes which yield stationary value for the velocity front relative to the unburnt gas. It is shown in Courant and Friedriechs that for Chapman-Jouguet detonations, the wave speed and the entropy of the burnt gas have minimum values, while for Chapman-Jouguet deflagrations, these quantities are relative maxima. It should be noted that for the Chapman-Jouguet relations

$$
d p / d v=\left(p-p_{0}\right) /\left(v-v_{0}\right)
$$

The sound speed is given by

$$
a^{2}=-v^{2} d p / d v
$$


Combination of Equations 4,9 , and 10 yields

$$
a=u_{1}
$$

which means that the burnt gas moves at the speed of sound relative to the reaction front.

It is shown by stanyukovich that if the isentropic exponent $k$ is constant then

$$
D / a_{0}=M_{D}=[1+(k+1) Q / 2]^{1 / 2} \pm[(k+1) Q / 2]^{1 / 2}
$$

with + and - signs corresponding to detonations and deflagrations respectively. Also, for detonations

$$
p_{1} / p_{0}-1=k M_{D}^{2}\left[1-\left(M_{D}\right)^{-2}\right] /(k+1)
$$

and

$$
1-v_{1} / v_{0}=\left[1-\left(M_{D}\right)^{-2}\right] /(k+1)
$$

The velocity of the detonated gases is

$$
u_{H} / a_{O}=M_{D}\left(1-M_{D}^{-2}\right)
$$

For very large $Q$

$$
D / a_{0}=[2(k+1) Q]^{0.5}
$$

for detonations, and

$$
D / a_{0}=[2(k+1) Q]^{-0.5}
$$


for deflagrations. Also, for a large energy release parameter $Q$, detonation wave parameters are

$$
\begin{aligned}
& \mathrm{p}_{1} / \mathrm{p}_{0}=2 \mathrm{kQ} \\
& \mathrm{u}_{\mathrm{H}} / \mathrm{a}_{0}=[2 \mathrm{Q} /(\mathrm{k}+1)] 0.5 \\
& \mathrm{~d}_{1} / \mathrm{d}_{0}=\mathrm{k} /(\mathrm{k}+1)
\end{aligned}
$$

It is also of some interest to note that for large $Q$, stanyukovich shows that the ratios of detonation wave to constant volume combustion temperatures and pressures are

$$
\left(c_{v} T\right)_{D} /\left(c_{v} T\right)_{r}=2 k /(k+1)
$$

and

$$
\mathrm{p}_{\mathrm{D}} / \mathrm{p}_{\mathrm{r}}=2
$$

Subscripts $D$ and $r$ denote detonations and isochoric reactions respectively.

Temperatures and pressures immediately behind the detonation front are higher than those in a constant volume reaction. These differences disappear with distance from the front because of the rarefaction waves which decelerate the burnt gases.

\subsection{Detonation and Expansion of Gases}

The detonation wave compression concept under consideration here avoids the very high total pressure losses of standing detonation waves which incur losses corresponding to Mach 4-6 shock waves. In the present scheme, the detonation is initiated on one side of a large width to height ratio duct. Ignition takes place on one of the small sides to provide adequate length for transition from deflagration to detonation and to ensure an essentially planar wave. Because of the high turbulence in the flow, the induction distance is far less than has been observed in the endlessly repeated published results for detonations in tubes where the gas is stagnant. In some experiments in the present program, pressure ratios of $4-5$ were observed at distances of $3-5$ cm from the igniters. The rapid propagation of the detonation wave creates a volume of high pressure and temperature gas 
which expands longitudinally. Because of the rapid expansion of the detonation products, shock waves are generated and these propagate in the upstream and downstream directions. The situation is shown schematically in Figure 1.3-1.

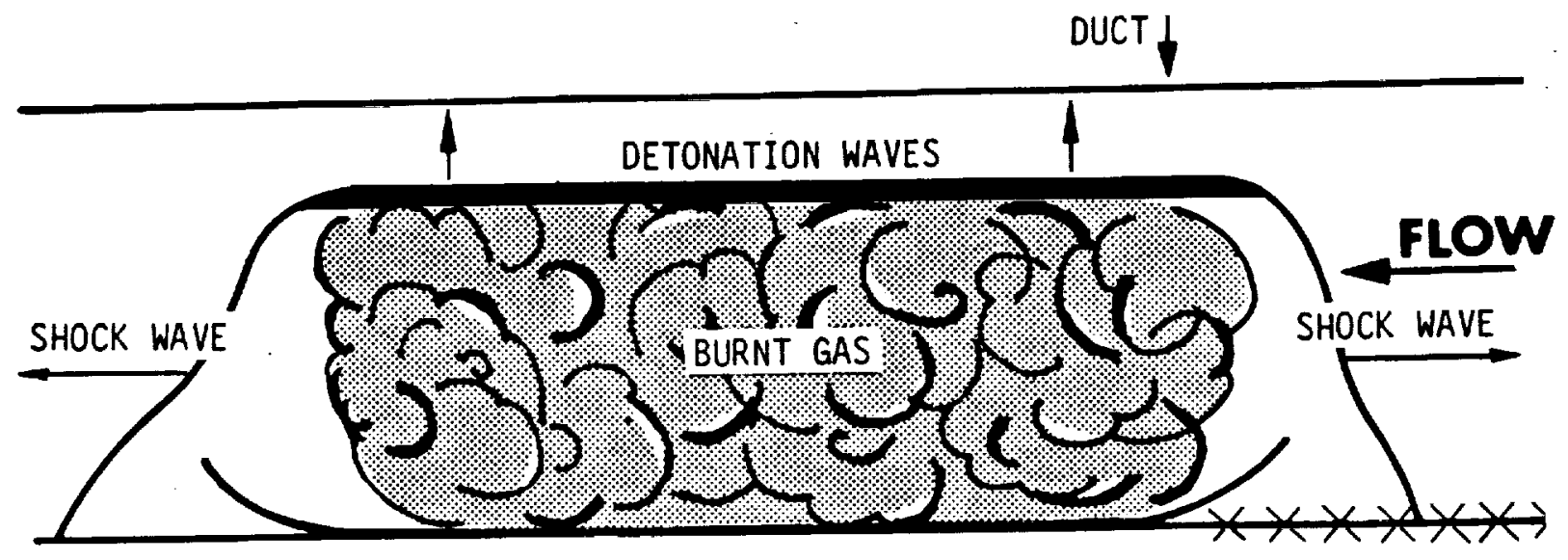

Figure 1.3-1. Expansion of the Detonation Products

During the expansion process, the system of shock waves, rarefaction wave trains, burnt gases, and shocked flow is translating downstream at speeds which ultimately are expected to approach Mach 1 . Since the detonation wave moves at Mach numbers of 4-6, the traverse time is relatively small and the expansion process may be modelled by the Riemann problem, or a snock tube, except that in this case the high. pressure gas is released at both ends. Because of symmetry, this is equivalent to the problem of a single diaphragm at a distance of half the length of the combustion gases. A highly simplified representation of the system of waves in the $x-t$ plane is shown in Figure 1.3-2. The initial expansion of the detonation products generates shock waves and rarefaction waves. When the latter reach the contact surfaces on the opposite side of the detonation products, they retard it and the transmitted waves then continue towards the shock wave which they weaken considerably. In the proposed configuration, the shock waves are weakened even further by the rapid area expansion at both ends of the detonation duct. 

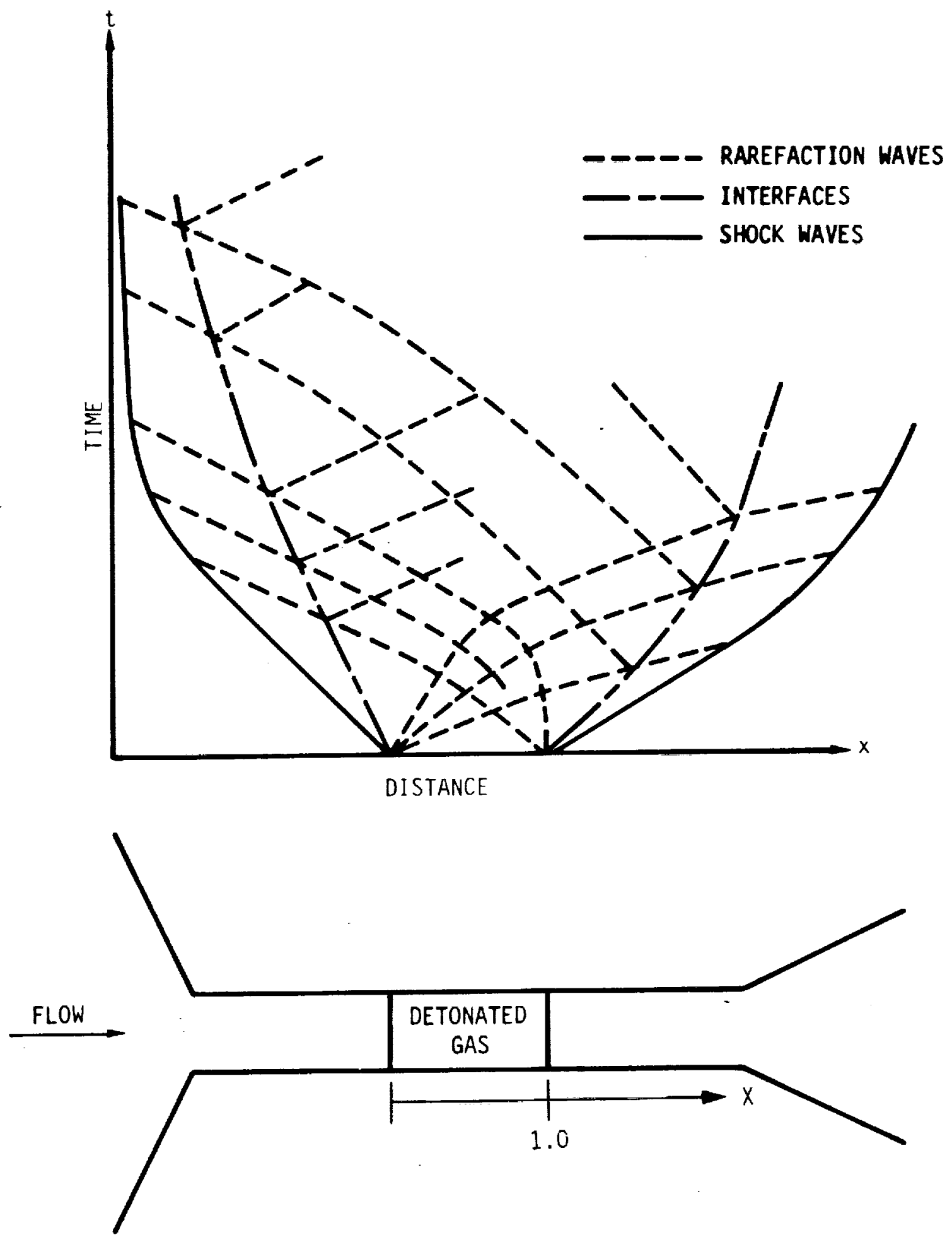

Figure 1.3-2. Simplified $x-t$ Diagrams for the Idealized Expansion of the Detonation Gas 
The initial wave system and the gas dynamics of a shock wave entering an expanding cross-section duct are shown in Figure $1.3-3$.

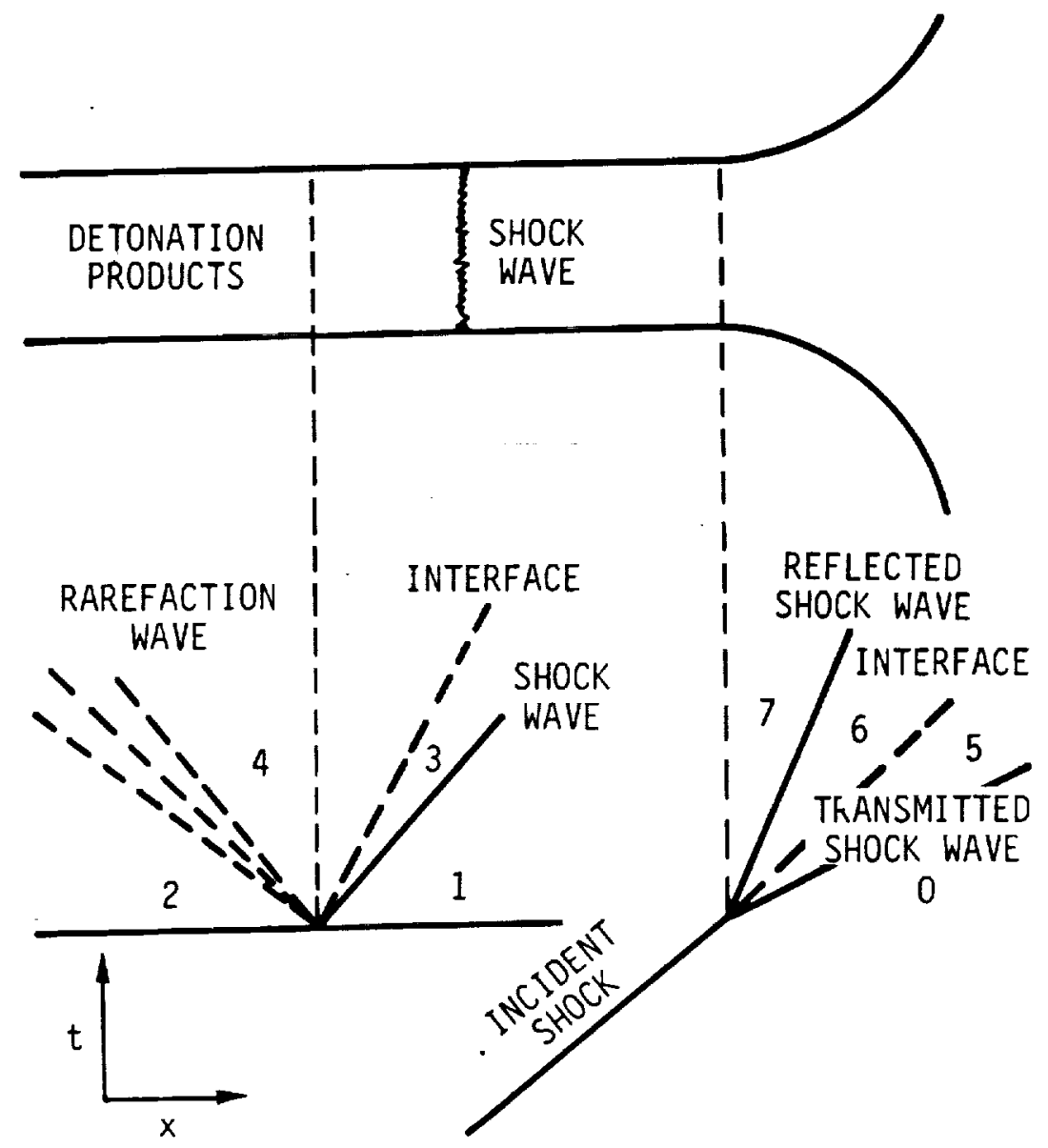

Figure 1.3-3. Simplified $x-t$ Diagram for the Idealized Expansion of the Detonation Gas

Detailed calculations of the interactions of the wave systems created by a sudden expansion of detonation products in a duct flowing at Mach 1 were presented in Reference 3 . In Figure 1.3-4, which is reproduced from Reference 3 , the flow is from right to left and the $x-t$ (distance-time) coordinates are dimensionless. It should be noted that the shock wave propagating in the upstream direction is very 
quickly overtaken by the rarefaction waves from the downstream boundary of the detonation products. The upstream contact surface initially moves upstream, but it is decelerated by the rarefaction waves and begins to move downstream after only a short travel upstream. The rapid decay of the upstream shock wave is shown in Figure 1.3-5. This is of considerable importance because the shock wave represents a loss of available energy.

It is quite easy to estimate the locations of the critical points in the gas expansion-shock wave propagation process. A very simple analysis may be found in stanyukovich ${ }^{4}$. Expansion of the detonation products is symmetric about the center so that the problem is exactly equivalent to a shock tube with chamber length equal to half the length of the burnt gas. If half-length of the detonation is denoted by $I_{0}$ then the intersection of the aft end of the initial rarefaction fan by the head of the reflected rarefaction wave is given by

$$
\begin{aligned}
& a_{D} t_{I} / L_{0}=\left(a_{D} / a_{e}\right)^{I / 2 g} \\
& x_{I} / L_{0}=\left[2 /(k-1)-\left(a_{e} / a_{D}\right) / g\right]\left(a_{D} t_{I} / L_{0}\right)
\end{aligned}
$$

with

$$
\begin{aligned}
& a_{D}-\text { acoustic velocity at the wave front } \\
& g-(k-1) /(k+1) \\
& L_{0}-\text { characteristic length } \\
& t_{1}-\text { time of intersection } \\
& x_{1}-\text { location of intersection }
\end{aligned}
$$

Isentropic component $k$ is associated with the detonation products. The expanded conditions, which are denoted by the subscript $e$, are calculated using the shock tube computer code specially developed for this program. This computer code solves the shock tube problem for arbitrary gas constants, acoustic speeds and pressure ratios. 


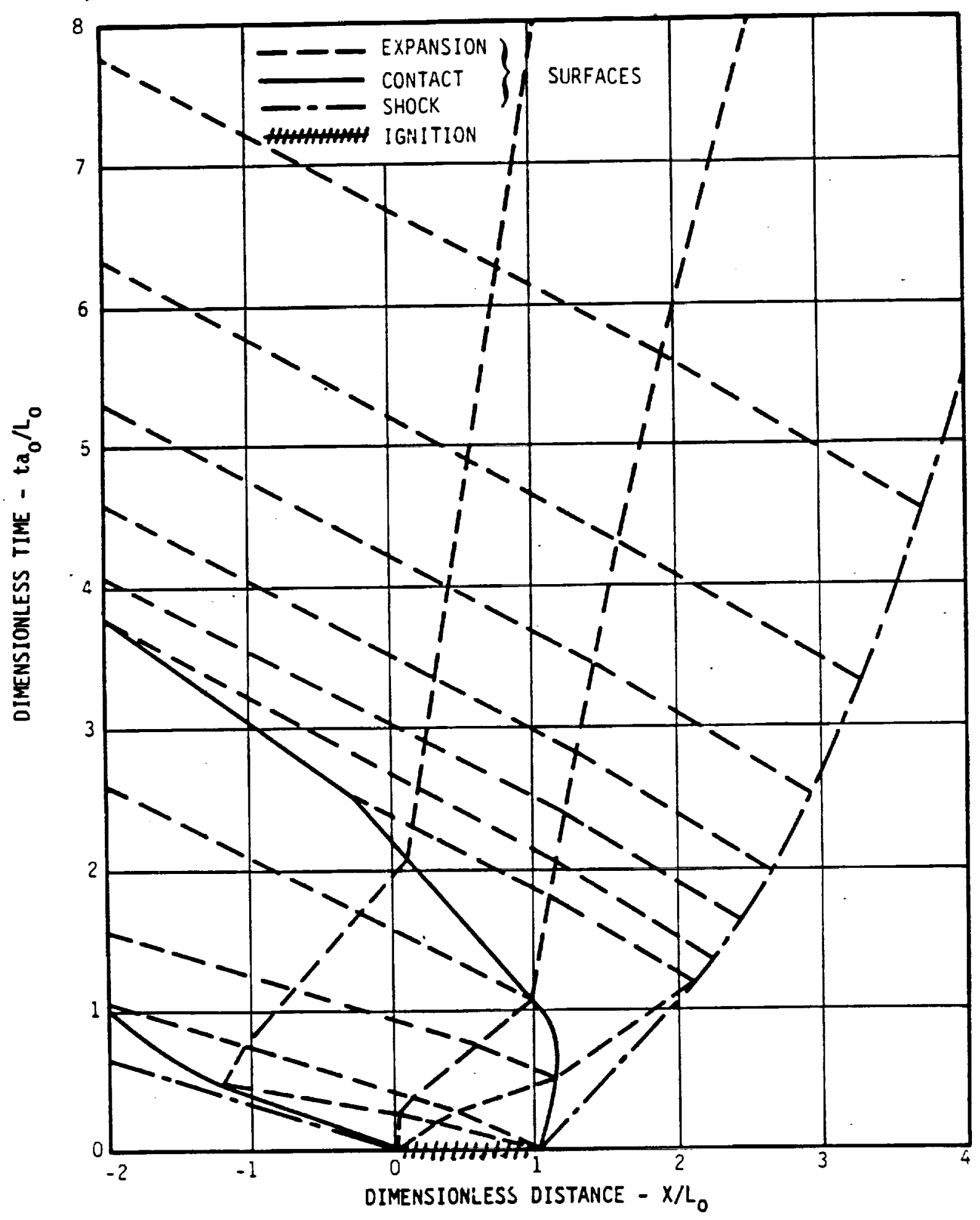

Figure 1.3-4. Calculations of the wave system for Expansion in a Mach 1 Flow 


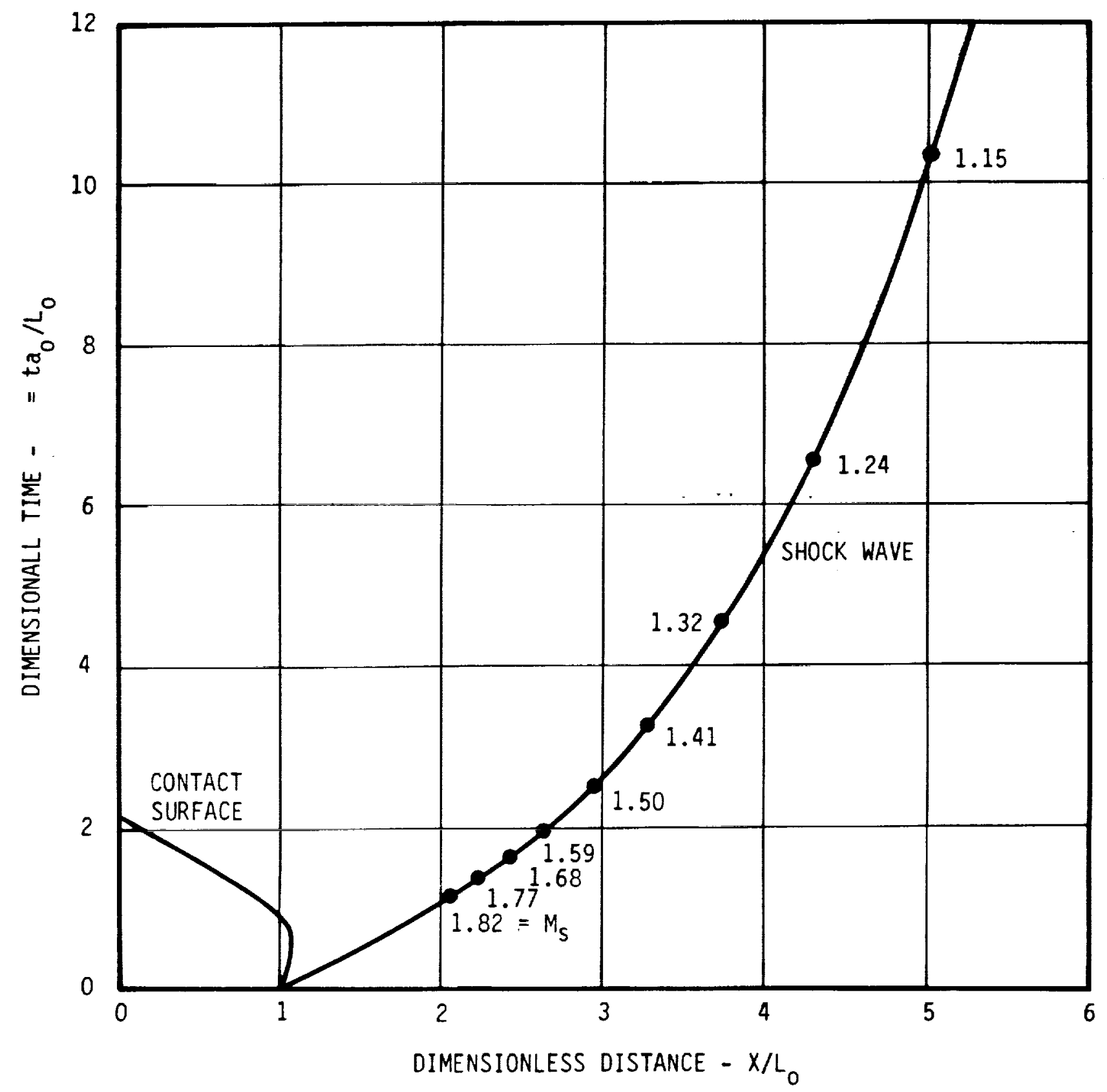

Figure 1.3-5. Motion of Discontinuities in Inertial coordinates 
The intersection of the head of the reflected rarefaction wave with the contact discontinuity occurring at time $t_{2}$ and distance $x_{2}$, is given by

$$
\begin{aligned}
& t_{2}=2 t_{1} \\
& x_{2}=2 u_{y} t_{1}
\end{aligned}
$$

with $u_{y}$ being the speed of the shocked gas in inertial coordinates. The initial intersection of the head of the reflected rarefaction wave with the head of the shock wave occurring at time $t_{3}$ and distance $x_{3}$, is given by

$$
\begin{aligned}
& t_{3}=2 a_{1} t_{1} /\left(u_{y}+c_{1}-D\right) \\
& x_{3}=2 D c_{1} t_{1} /\left(u_{y}+c_{1}-D\right)
\end{aligned}
$$

A representative example of a detonation is,

$$
P_{D O}=9 \quad a_{D} / a_{0}=3 \quad k_{D}=1.25 \quad k_{0}=1.4
$$

which results in a shock tube solution with

$$
\begin{aligned}
& \mathrm{D} / \mathrm{a}_{0}=2.07, \quad \mathrm{P}_{10}=4.84, \quad \mathrm{~T}_{10}=1.75, \\
& \mathrm{~d}_{1} / \mathrm{d}_{0}=2.77, \quad \mathrm{u}_{\mathrm{y}} / \mathrm{a}_{0}=1.32
\end{aligned}
$$

When it is assumed that $a_{0}=1120 \mathrm{ft} / \mathrm{s}$ and $1=0.6 \mathrm{ft}$, it is found that

$$
\begin{array}{ll}
t_{1}=2.4 \times 10^{-4} \mathrm{~s} & x_{1}=-0.36 \mathrm{ft} \\
t_{2}=4.8 \times 10^{-4} \mathrm{~s} & x_{2}=0.71 \mathrm{ft} \\
t_{3}=1.1 \times 10^{-3} \mathrm{~s} & x_{3}=1.54 \mathrm{ft}
\end{array}
$$

The distances $x$ are measured from the initial boundary of the detonation products. It is thus seen that the expansion phenomena occur very rapidly and in relatively small distances. 


\subsection{Availability of Energy}

An estimate of the availability of the energy may be made by considering the situation when the initial rarefaction fan reaches the center plane of the detonation products. In the interests of simplicity and brevity, the rarefaction will be approximated by a single wave, as shown in Figure $1.4-1$.

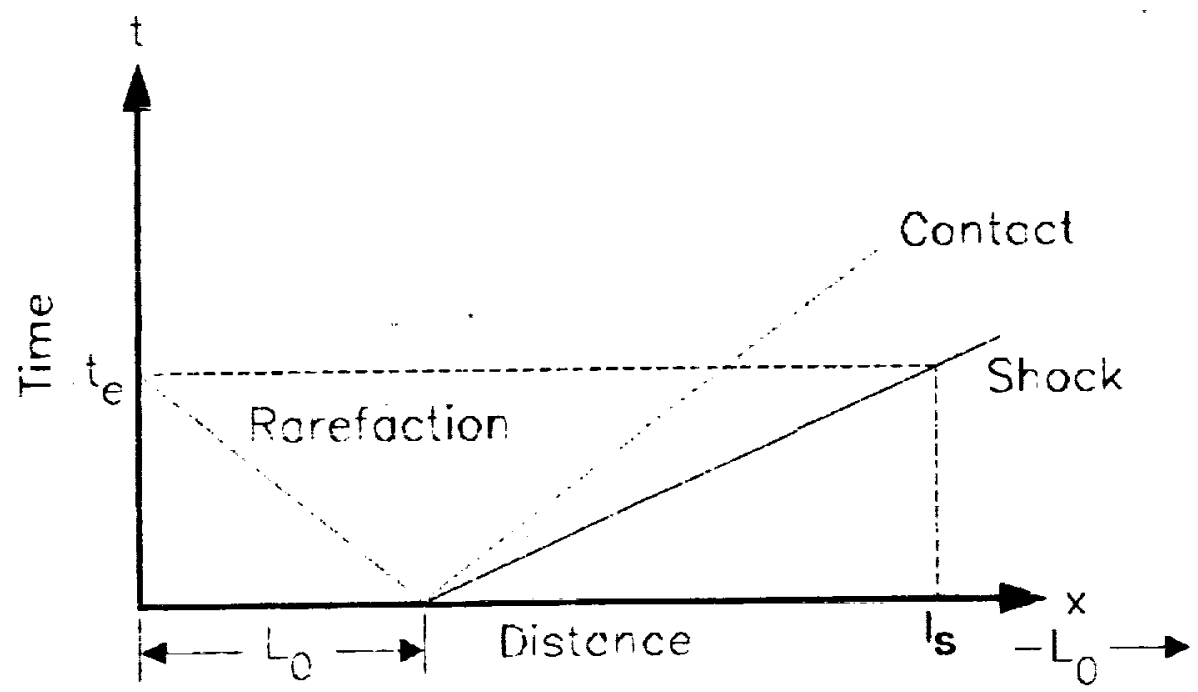

Figure 1.4-1. Highly Simplified Expansion Process

The extent of the expanded detonation products $I_{D}$, is

$$
I_{D}=I_{0}+u_{e} t_{e}
$$

with $u_{e}$ and $t_{e}$ being the velocity of the contact surface and time for the rarefaction wave to intersect the left boundary.

The extent of the shocked flow is

${ }_{1}=\left(D-u_{e}\right) t_{e}$
with $l_{S}$ being the location of the shock wave at $t_{e}$. 
and

$$
t_{e}=L_{0} / a_{D}
$$

The mass of the detonation products is

$$
m_{D}=L_{0} P_{D} / R_{g a s} T_{D}
$$

and that of the shocked flow

$$
m_{S}=d_{0} D L_{0} / a_{D}
$$

Energy of the expanded detonation products is

$$
E_{D}=m_{D}\left(c_{v} T_{D}\left(P_{D e}\right)^{G}+u_{e}^{2 / 2}\right)
$$

and the energy added to the shocked flow is

$$
E_{S}=m_{S}\left[c_{v}\left(T_{1}-T_{0}\right)+u_{e}^{2 / 2}\right]
$$

The initial energy of the detonation products is given by

$$
E_{D, 0}=L_{0} p_{D} /(k-1)
$$

When the calculated values from the shock tube solution are used in the above equations, it is found that

$$
E_{D} / E_{D O}=0.89 \text { and } E_{S} / E_{D O}=0.11
$$

This shows that at the time of the reflection of the rarefaction wave, about $90 \%$ of the energy is in the expanded detonation products. Of course, with increasing time, the proportion of the shocked flow will increase but if the attenuation of the shock is started at this moment, then most of the energy will be in the detonation products. 
Actual availability, relative to that of initial products of detonation, is estimated quite readily from elementary isentropic relations. For the expanded detonation products

$$
M=0.47 \quad P_{D T}=4.87 \quad T_{T} / T_{0}=7.26
$$

For the shocked flow

$$
\mathrm{M}=1.0 \quad \mathrm{P}_{\mathrm{T} 0}=5.1 \quad \mathrm{~T}_{\mathrm{T}} / \mathrm{T}_{0}=2.1
$$

The subscript $T$ denotes total, or stagnation conditions. The energy which could be extracted corresponds to isentropic expansion to ambient pressure. The ratio of that energy to the energy which could be extracted from direct expansion of the detonation products is found to be 0.82 .

These estimates are presented here to indicate the high potential recovery of useful work from detonation products. This contrasts with the very high losses of standing detonation waves in supersonic combustion.

\subsection{Applications to Gas Turbines}

Exploitation of the high temperature and pressure gas generated by detonation waves can be implemented in a large variety of realistic engine configurations. In the section which presented the thermodynamic advantages of the concept, it was assumed that the detonation wave products could be used directly. In the discussion on availability of the detonation wave energy, it was shown that shock wave losses were relatively smali. Here, attention will center on realistic engine applications. For simplicity, and in the interest of deriving conservative estimates of performance, it is assumed that the detonation wave products and the combustor output are mixed in an ejector. The results shown here are taken from Reference 5 .

The simplest application is in the case of a jet engine in which detonation ducts located circumferentially around a combustor supply high energy gas in accordance with the demand. A schematic representation of such an engine is shown in Figure 1.5-1. 


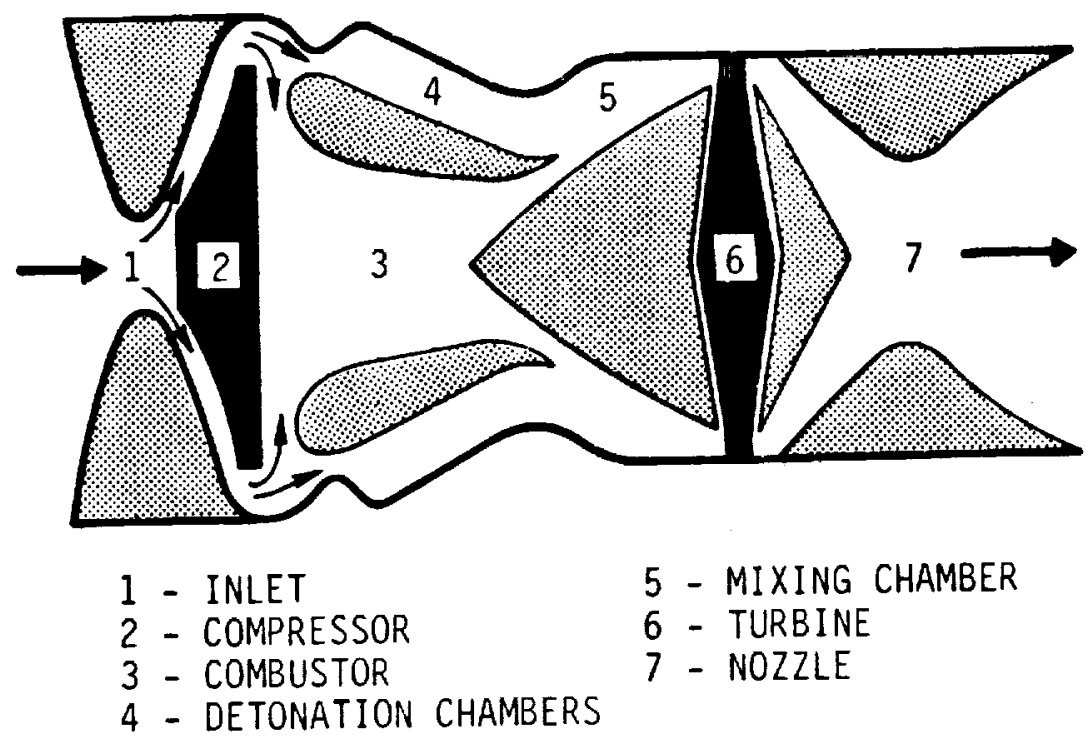

Figure 1.5-1. Detonation Duct Augmented Jet Engine

Since stable detonation waves are achieved most easily with essentially stoichiometric fuel-air mixtures, the output of the detonation ducts would be varied through the frequency of firings. Pressure fluctuations at the turbine would be minimized by sequential firing of the ducts. Here, it is assumed that the detonation ducts are fired at maximum frequencies which in Reference 5 were found to be of the order of $200 \mathrm{~Hz}$. It should be noted that ejector-type mixing incurs high losses in availability. Much more efficient means of using the detonation products could be envisioned for more detailed engine design studies. Performance of an engine with ejector mixing is shown in Figure 1.5-2. A possible configuration of a jet engine, which avoids the mixing losses and pulsating flow into the turbine, is shown in Figure 1.5-3. Because of the high temperature and pressure of the detonation duct bypass flow, the jet velocity would be very high so that high propulsion efficiency could be achieved only in very high speed aircraft. 


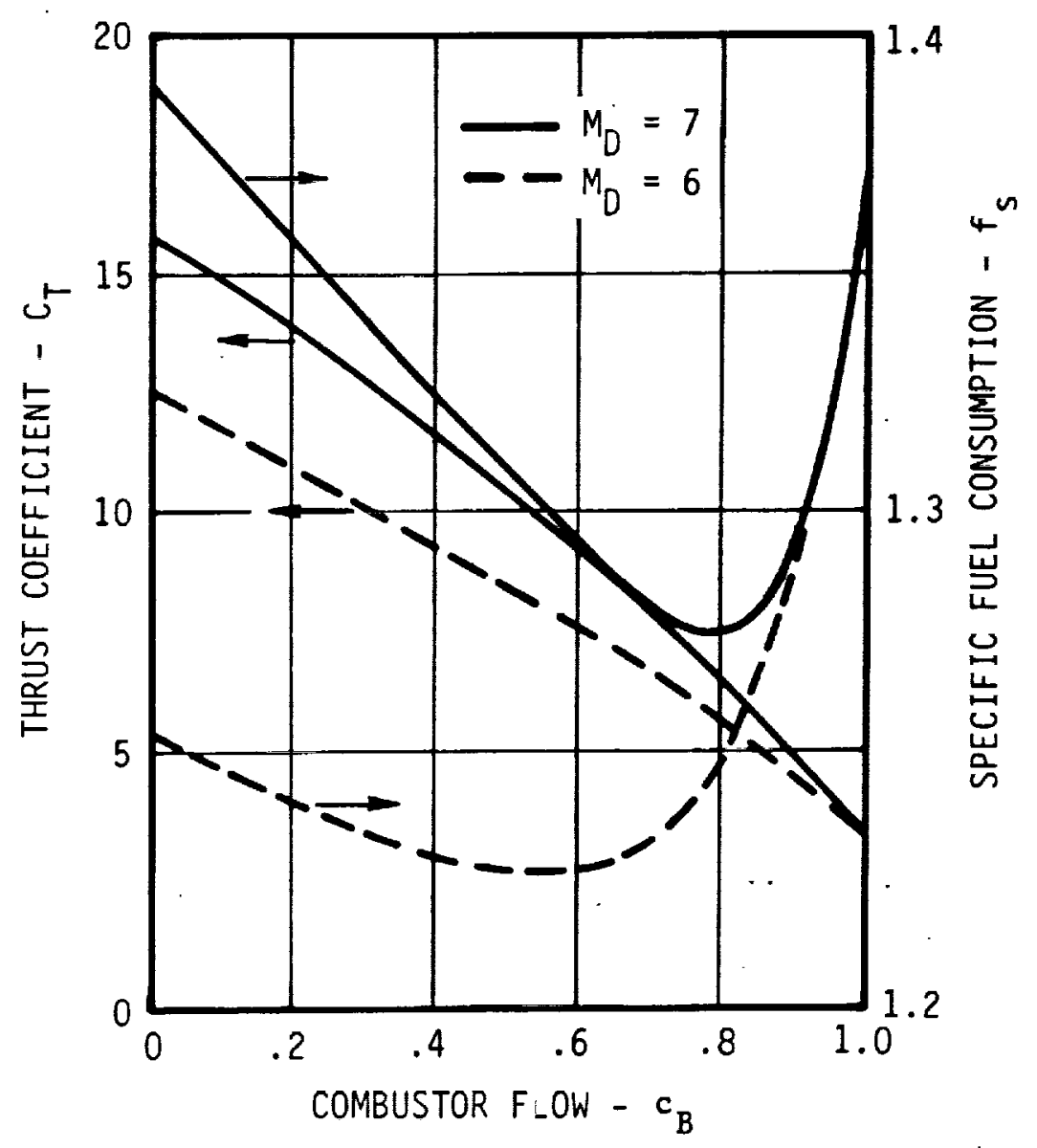

Figure 1.5-2. Performance of a Detonation Wave Augmented Jet Engine

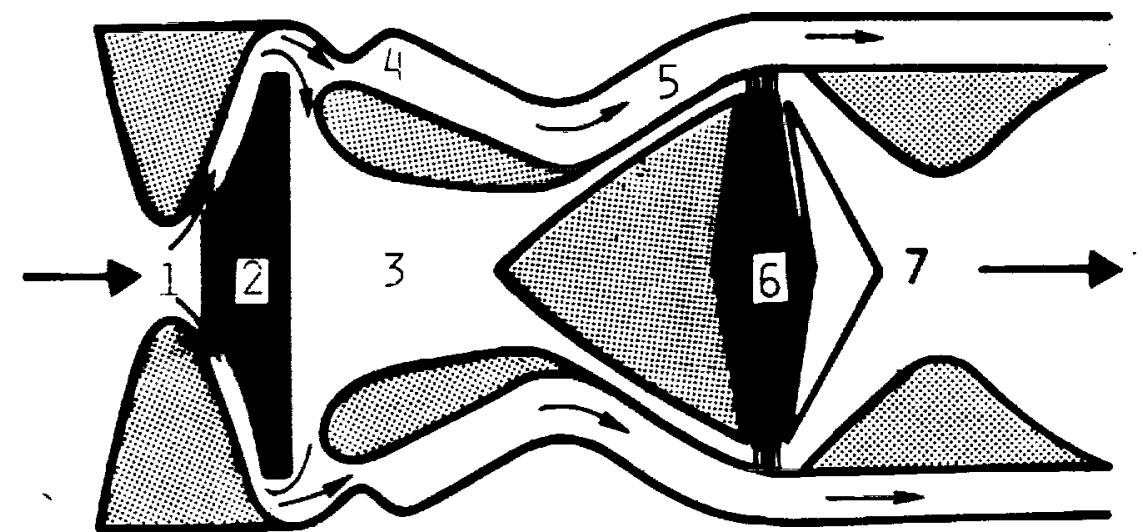

Figure 1.5-3. Bypass Flow Detonation Duct Augmented Jet Engine 
A turbofan application is shown schematically in Figure $1.5-4$.

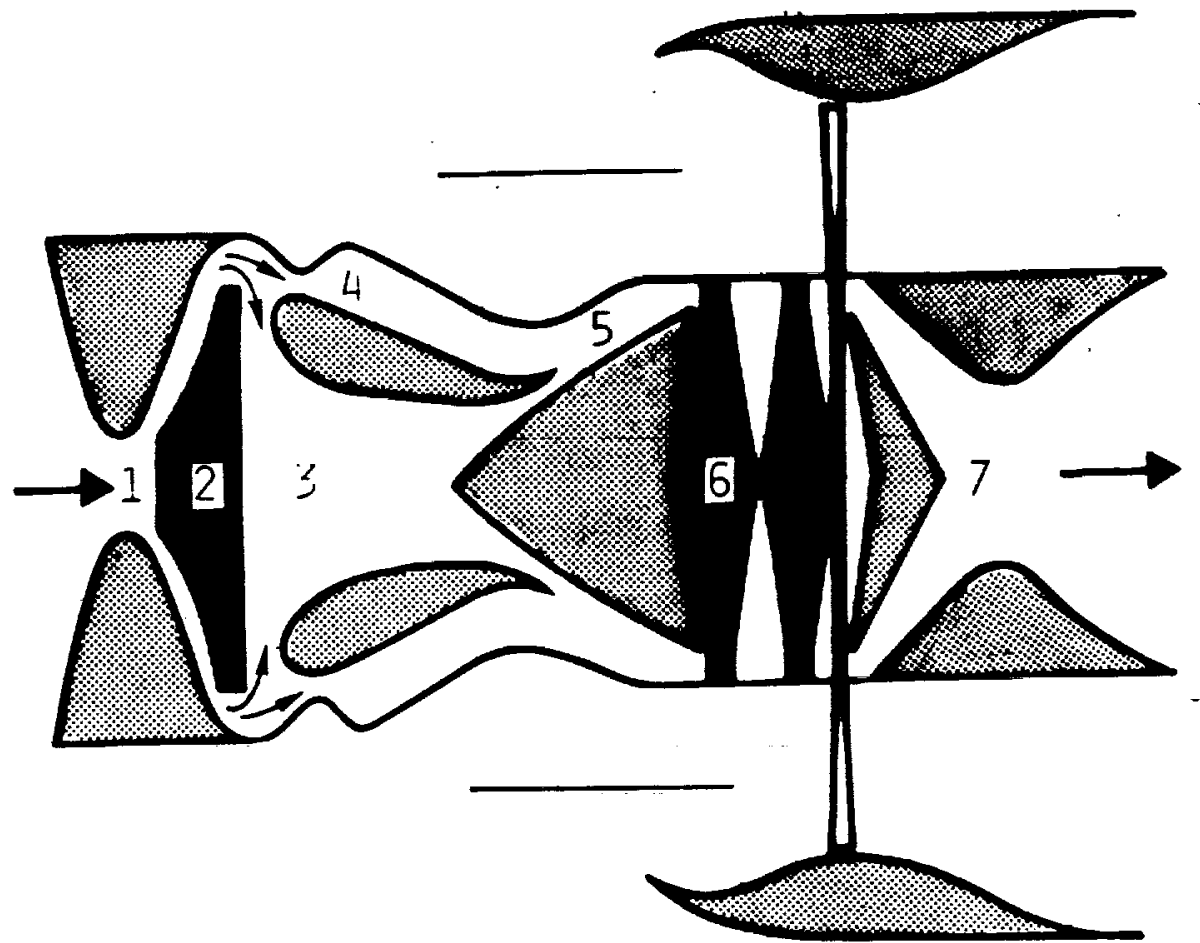

Figure 1.5-4. Turbofan Engine

This is an example of using detonation ducts to augment a gas turbine whose output is primarily in the form of shaft power. 


\section{DETONATION WAVES}

The phenomenon of transition from the commonly encountered combustion to rapidly propagating detonation waves was discovered independently by Berthelot and Mallard and LeChatelier ${ }^{7}$. Theoretical explanations of the detopation wave phenomena were presented by Chapman ${ }^{8}$ and Jouguet ${ }^{9}$ who postulated that the combustion products moved at sonic velocities relative to the detonation wave. Most of the current work in detonations centers on detailed studies of the gas dynamics and chemistry of a wide range of fueloxidant-diluent mixtures. While such studies are of fundamental importance in the development of a basic understanding of the phenomena, they are only of secondary interest here because the objective of the present program is the exploitation of detonation waves in generation of hot compressed gases, and not research in detonation wave phenomena. Actually, the concept of employing transverse detonation waves in transonic flows is a completely new departure in the field of detonation wave studies. The idea is so different from the conventional endlessly repeated studies of detonations in stagnation gases, or standing detonation waves in supersonic combustion, that it was found appropriate in Reference 5 to cite reviews of the basic concept by DOE experts who expressed the opinion that such waves could not be formed.

In view of the fact that the existence of detonation waves is well established, and that a wave traversing a flow could only be translated linearly at the flow velocity, there is little to be gained from a detailed survey of the field. Consequentiy, only a brief outline of some of the more relevant studies of the salient features of the phenomena will be presented here with, references for more thorough studies.

\subsection{Ignition}

It is well known (e.g., Penner and Mullins ${ }^{10}$ ) that most combustible mixtures can be ignited in a wide range of fuel/oxidizer ratios but stable detonations can be achieved only with nearly stoichiometric mixtures. A very interesting study of ignition of propane-pxygen mixtures by a hot wire is given by Gudkovich, et alli who develop the fundamental parameters of the problem. In the case of ignition of an almost stoichiometric mixture near a solid surface, it is known that a detonation wave will be formed and its characteristics will be independent of the details of the ignition mechanism. 


\subsection{Transition to Detonation}

The extensively studied problem of transition from deflagration to detonation is still imperfectly understood, but the vast amount of data has shown the principal functional relationships. Most of the transition studies have concentrated on the determination of the effects of ignition mechanism, size, surface roughness, residual turbulence, and the thermodynamic state of the explosive mixture. In Jost ${ }^{2}$, it is shown that the distance from ignition to detonation wave formation becomes independent of the tube diameter at diameters greater than about $25 \mathrm{~mm}$. Increase of the combustible mixture temperature from $15^{\circ} \mathrm{C}$ to $180^{\circ} \mathrm{C}$ increases the induction distance by about $30 \%$, but the doubling of the pressure, at constant temperature, reduces it by $40 \%$. It therefore appears that the induction distance is primarily a function of the mixture density.

The effect of turbulence on the shortening of the induction distance is brought and by sokolik ${ }^{13}$ who cites data which indicate that roughening of the tube walls with sand reduces the induction distance by a factor of 2. Even more dramatic acceleration of the flame are indicated by sokolik when obstacles are placed in a tube. Lee, et al 14 indicate spiral coil is placed near the igniter. Peraldi, et al 15 performed experiments in tubes filied with $43 \%$ blockage ratio orifices spaced 1 tube diameter apart and showed that transition to detonation occurred when the wave speed reached Mach 1. In nearly stoichiometric propane-air mixture in a $30 \mathrm{~cm}$ tube, a speed of about $1500 \mathrm{~m} / \mathrm{s}$ was reached in about 3 meters. An extremely interesting attempt to predict the induction distance can be seen in the analysis of Nikolaev 16 . Brinkley and Lewis 17 showed that turbulence can reduce the induction distance by an order of magnitude and also showed that in short closed tubes the precursor pressure waves generated by the flame front can compress the unburnt mixture to a pressure ratio of 5. With sufficient levels of turbulence and closed tubes detonation can be reached in 3-5 characteristic transverse dimensions.

In the very high speed bulk flows studies in this program, the turbulence is so intense that transitions to detonations have been observed in as little as $3-5 \mathrm{~cm}$. 


\subsection{Detonation Wave Characteristics}

The simple planar wave theories of detonation waves which were outlined in the Introduction are clearly great simplifications which may be used in approximate analyses, but not in detailed studies of detonation wave formation, propagation and structure. It has been known for some time (e.g., Sokolik ${ }^{13}$ ) that detonation waves propagate in tubes in a spinning motion with a definite cell structure. such details are of minor interest here because of the relatively large dimensions of the apparatus and the extreme turbulence of the flow through which the detonation waves are propagated.

In contrast with. the simple gas dynamic model of detonations, it is known that detonations can be realized only within certain limits. As an example, hydrogen will detonate when its fraction is $0.15-0.90$ in oxygen, or $0.18-0.59$ in air (Jost ${ }^{2}$ ). For propane, the detonation limits in oxygen are $0.032-0.37$ (Jost 12 ).

Experiments show that a stoichiometric hydrogen-oxygen detonation wave propagates at $2806 \mathrm{~m} / \mathrm{s}$ with a pressure ratio of 18.05 and a temperature of $3583^{\circ} \mathrm{K}$ (Jost ${ }^{2}$ ). In stoichiometric propane-air mixtures vasilev, et allo calculate pressure ratios of 18.64 , temperature of $2813{ }^{\circ} \mathrm{K}$ and a propagation velocity $01800 \mathrm{~m} / \mathrm{s}$. Pressures behind a reflected detonation wave are of considerable importance here and it is of interest to note that for stoichiometric mixtures in oxygen sokoliki3 gives for hydrogen a propagation velocity of $2820 \mathrm{~m} / \mathrm{s}$ and a reflected wave pressure ratio of 67.4 , with propane values of $2530 \mathrm{~m} / \mathrm{s}$ and 195 , respectijely. For stoichiometric propane-air mixtures, Eisen, et al 19 calculate $M_{D}=5.31$, pressure ratio $=18.3$ and a temperature of $5090^{\circ}$. For hydrogen-air mixtures, the values are given as $M_{D}=4.83$, pressure ratio of 15.6 and a temperature of $5310 \% \mathrm{R}$. It is clear that in some cases calculations and experimental data can differ considerably.

The unsteady nature of detonation waves is discussed by ulyanitskij and a discussion in terms of cell structures is given by Vasilev, et al 2 . The effect of initial temperature on the detonation wave cell structure is analyzed by vasilev, et al 2. Stability of detonation waves was considered by Dynin $23^{\circ}$ who showed that finite width detonation waves are stable when viscous effects are included. 
Numerous other studies have been published but because of their peripheral interest to the objectives of this program they will not be cited here. Interested readers are referred to the serial publications in which the cited references may be found.

\subsection{Detonation Wave Reactors}

Considerable work has been done in the soviet Union to develop commercial units of detonation wave reactors. A very elegant annular configuration reactor is shown by Bykovskii and Mitrofanov ${ }^{24}$. The apparatus is shown schematically in Figure 2.4-1.

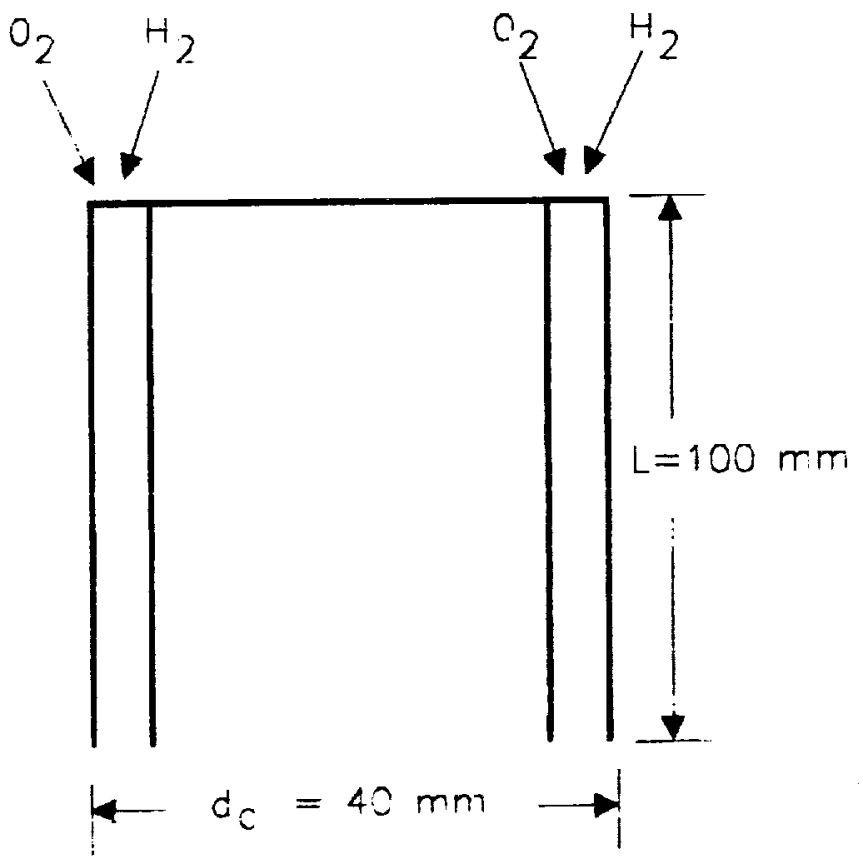

Figure 2.4-1. Annular Detonation Wave Reactor

oxygen and fuels, such as hydrogen, acetylene, propane, and methane, are injected and mixed at the closed end. Ignition by a high voltage discharge at $35 \mathrm{~mm}$ from the closed end initiates a detonation which produces "transverse detonation waves in a definite direction." It appears from the descriptions in the paper that transverse detonation waves could be produced repeatedly. 
Much more common detonation wave reactors are of the type shown in Figure 2.4-2.

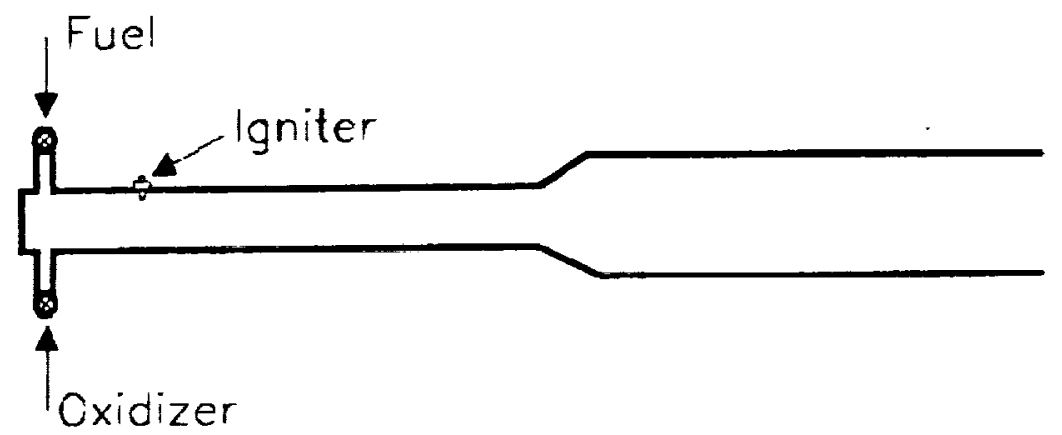

Figure 2.4-2. Iinear Detonation Wave Reactor

A reactor of the type shown is Figure $2.4-2$ was used by Korovin, et al25. The reactor, operated on methane and air, was used to produce nitrogen oxide and hydrogen. It operated at $100 \mathrm{~Hz}$ for 2000 hours. A similar device is described by Baklanov, et al 26 who used methane-oxygen mixtures and measured detonation wave velocities of $2340 \mathrm{~m} / \mathrm{s}$. They also used gasoline-air mixtures and measured detonation wave velocities of $2250 \mathrm{~m} / \mathrm{s}$ for stoichiometric ratios, and 1500 $\mathrm{m} / \mathrm{s}$ for $70 \%$ lean mixtures. Detonations of gasoline-air mixtures in similar apparatus, but with a diaphragm were studied by Lobanov, et al 27 .

A completely different approach was taken by Edwards 28 who produced traveliing detonation waves in a toroida:chamber. This work was performed at Rolls-Royce, but appears to have been abandoned.

It is of some interest to note the work of Ponizy 29 on pulse combustors. While the treatment is limited to deflagrations, it is a detailed analysis of many features of the phenomena involved and could serve as the basis for an extension to detonation waves. 


\section{APPARATUS, EQUIPMENT, AND INSTRUMENTATION}

The experiments were performed in a facility leased by ISTAR Inc. at 402 Princeland court, \#2, Corona, CA 91719 . The leased space was a bay in a light industrial building in a complex of buildings used by small businesses in the area. It may be some interest to note that it is extremely difficult to lease a facility if it is admitted that a U.S. Government contract is involved. The most common concern expressed openly was that an inspection of the whole complex might be involved and that an enormous amount of administrative effort will be necessary. The second problem was with the fact that an R\&D project was involved. The general perception appears to be that extremely dangerous weapons are being developed and the facility might be damaged as a result of accidents. The third problem is in the area of insurance because insurance companies have no category for small $R \& D$ projects. A real estate agent found the facility after a 4 month search only because he represented our project as an engine testing business and insured it as a truck engine repair shop. The facility was located approximately 45 miles south-east of Los Angeles and 64 miles from the ISTAR Inc. base in santa Monica,. A general layout of the facility, which had to be prepared for the corona fire department, is shown here in Figure 3.0-1. 


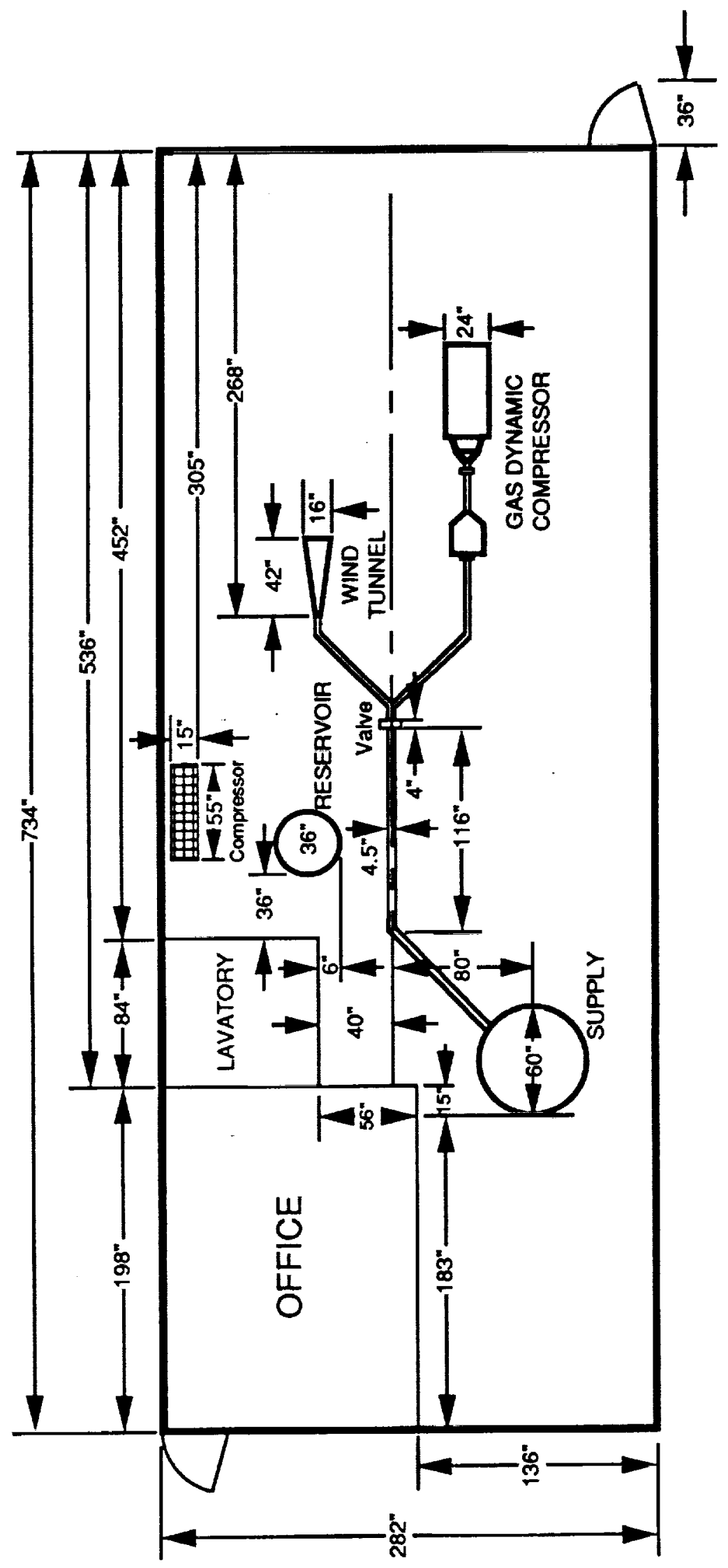

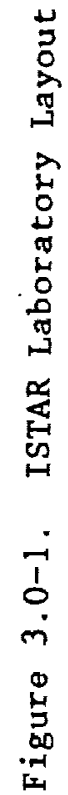




\subsection{Air Supply system}

The air supply system consisted of a $7.5 \mathrm{hp}$ air compressor which supplied a 500 gallon reservoir at pressures up to $175 \mathrm{psig.} \mathrm{The} \mathrm{reservoir} \mathrm{was} \mathrm{connected} \mathrm{through} \mathrm{a} \mathrm{schedule} 40$, 4" diameter line and a pneumatically actuated butterfly valve to a 1400 gallon tank which was generally operated below its rated pressure of 125 psig. A plan view and an elevation of the tank and supply lines is shown in Figure 3.1-1. Flow from the supply tank was controlled by a pneumatically operated butterfly valve located immediately ahead of a Y-junction which split the flow into a wind tunnel leg and the detonation duct channel (Figure 3.1-2). Flow in the two channels was regulated by means of manually operated ball valves.

The open, ejector-type, blow-down, wind tunnel was used very briefly for a DOE project of testing aerodynamic fairings over air conditioning heat exchangers on roofs of tall buildings. The costs of the $Y$-junction and the additional manual ball valve were allocated to the DOE program.

The butterfly and ball valves are shown installed in the air lines in Figure 3.1-3. Flow rates were measured with a metering venturi tube placed in the outlet line. It proved very difficult to achieve repeatable partial opening of the butterfly valves and therefore the flow to the wind tunnel or detonation duct channels was regulated with the ball valves. The pneumatic actuators of the butterfly valves were operated from separate low and high pressure tains. The control or instrument air was supplied by a small 20 psig tank and regulators were used to deliver the air to the actuators at 10-16 psig. At the lowest instrumentation-air pressure, the opening was erratic and at 16 psi the butterfly valve opened completely in less than 1 second. At intermediate pressures, the valve initially opened completely and then returned to some intermediate position. The operating air for the actuators came from a small tank maintained at a pressure of 90 psig. The metering venturi and the butterfly valve actuator air supply tanks are shown in Figure 3.1-4. The initially high opening of the butterfly valves caused some concern because quite frequently it was necessary to transfer air from the reservoir at 175 psig to the supply tank which may have been depleted to $45 \mathrm{psig.} \mathrm{The} \mathrm{highly} \mathrm{audible} \mathrm{shock}$ loading of the supply tank was accompanied by a noticeable distension of its walls. In the future, a restricting orifice or a manual valves should be used to avoid damage to the tank, which in this case was the property of USAF. 

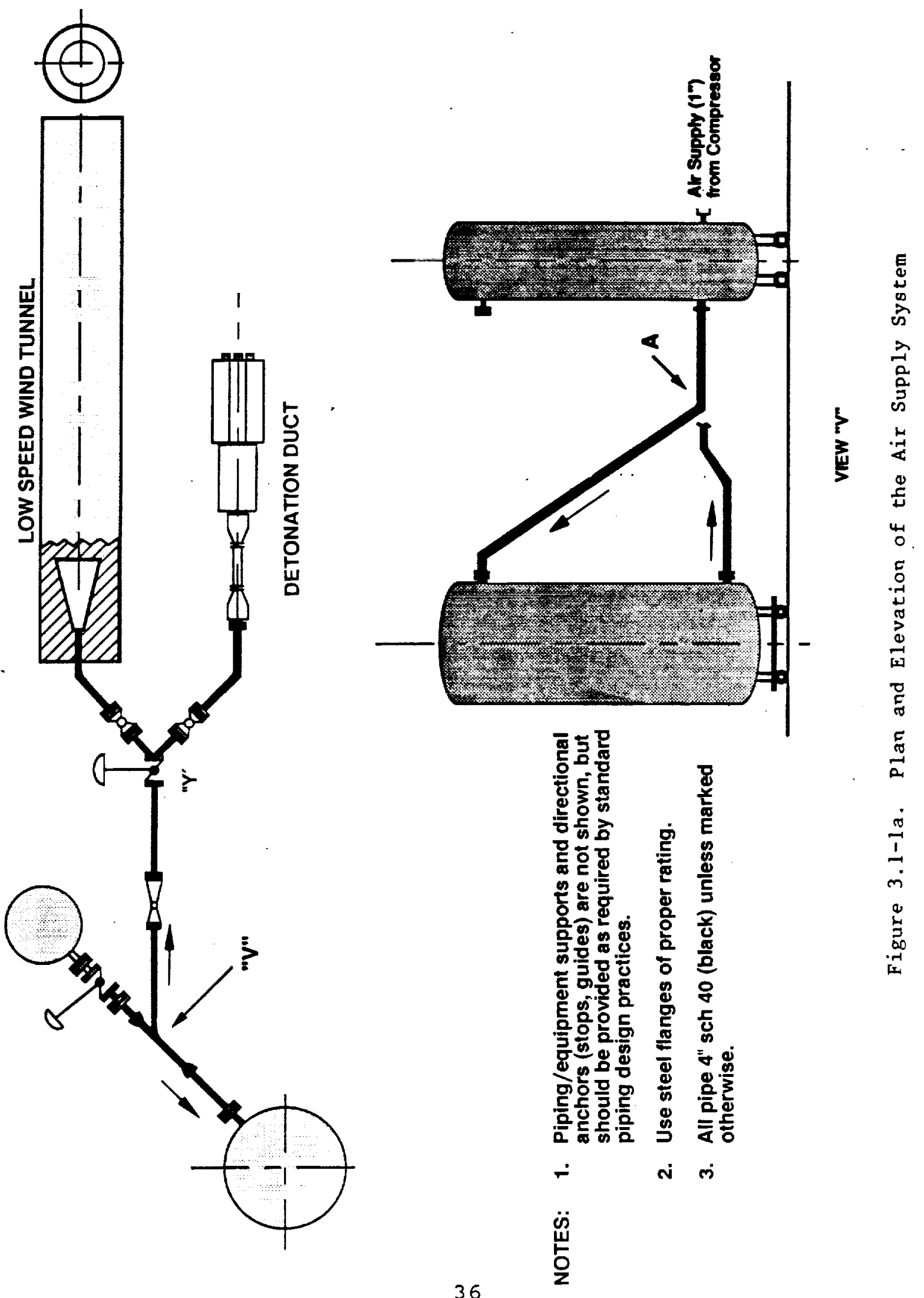


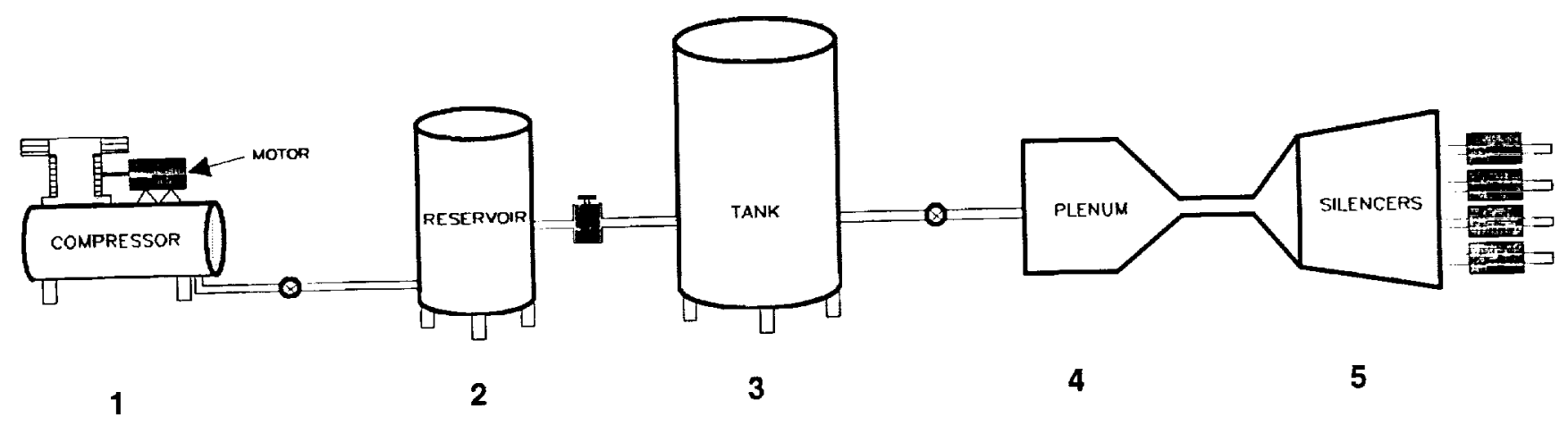

Figure 3.1-1b. Air supply Flow Schematic
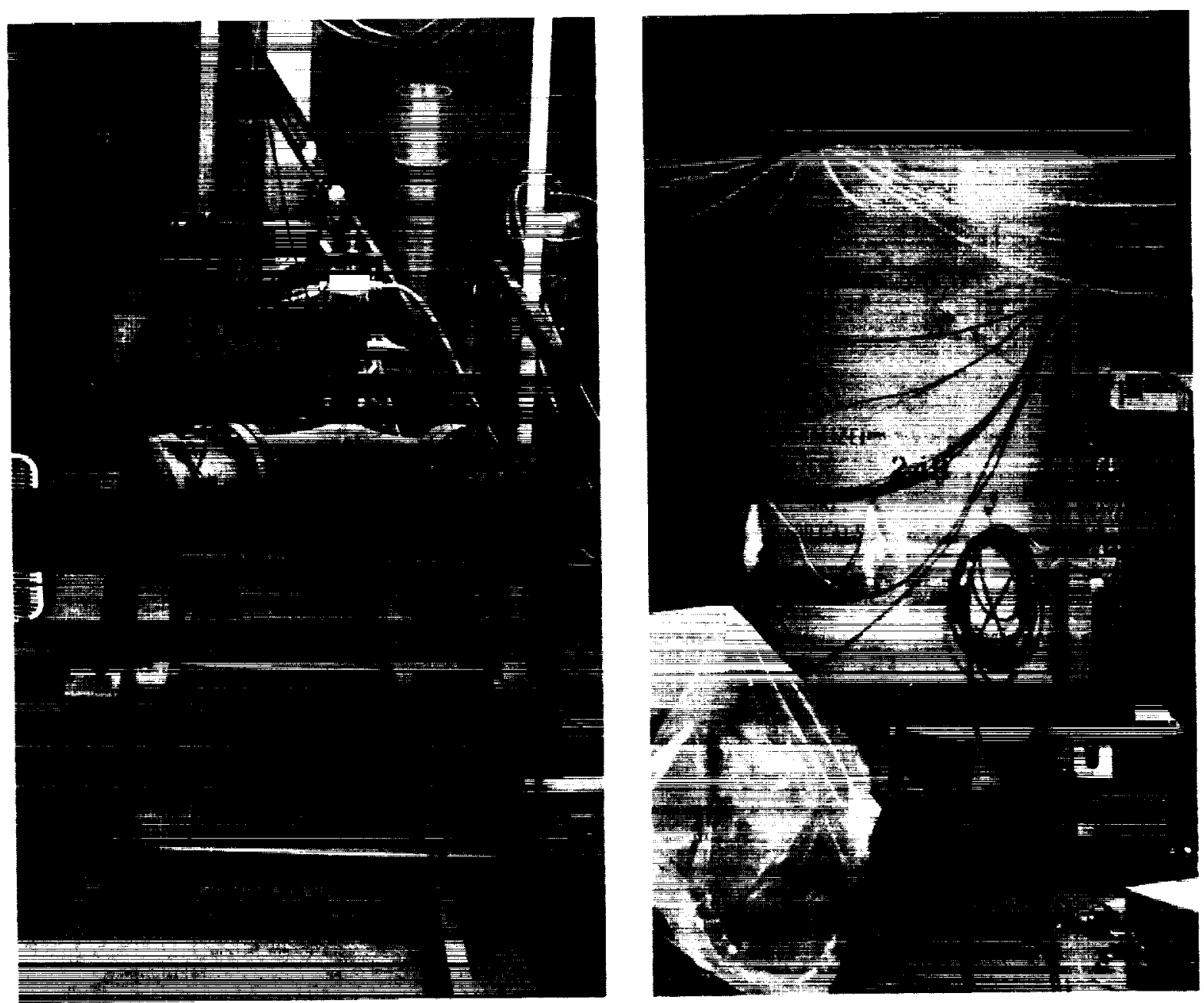

Figure 3.1-2. Supply Tank, $Y$-Junction, and Valves 

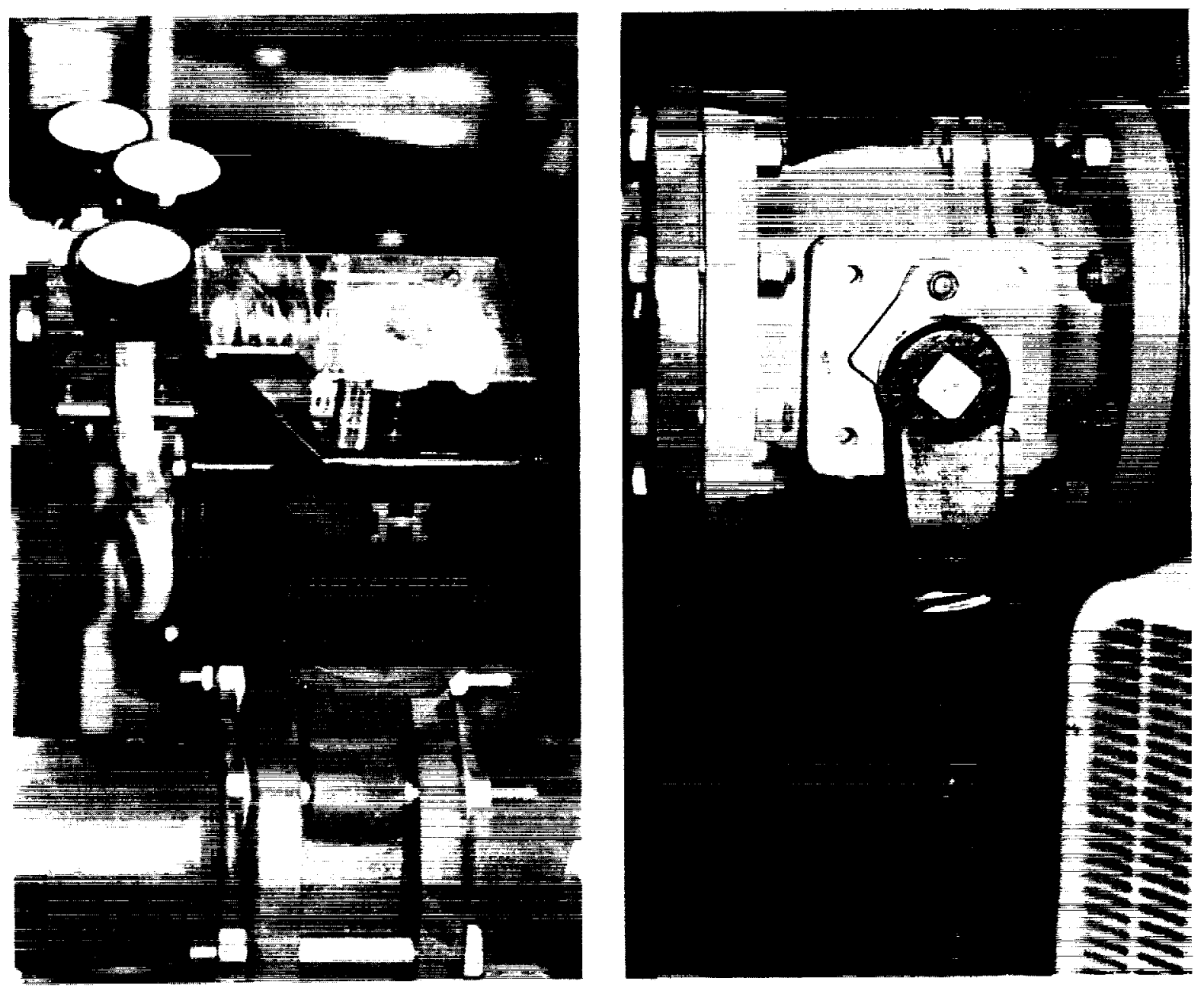

Figure 3.1-3. Butterfly and Ball Valves 


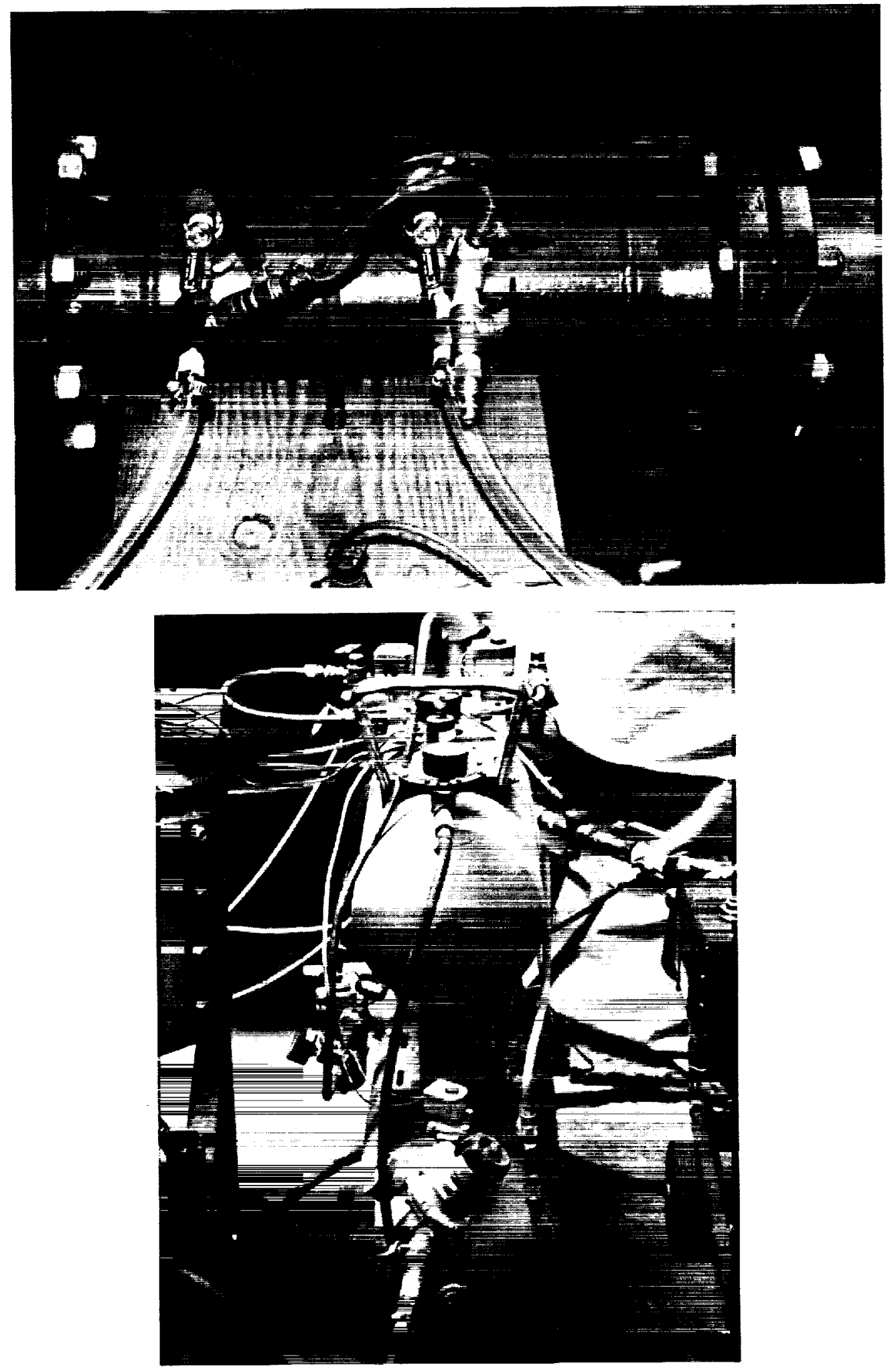

Figure 3.1-4. Venturi and Valve Actuators Air Supply Tanks 
The control air to the actuators of the butterfly valves was supplied through solenoid valves operated from a central control panel. This panel also controlled the supply of air to the instrument and operating air supply tanks so that in case of total depletion of the system the butterfly valves could be operated for some time. A schematic representation of the control system for the valves is shown in Figure $3.1-5$.

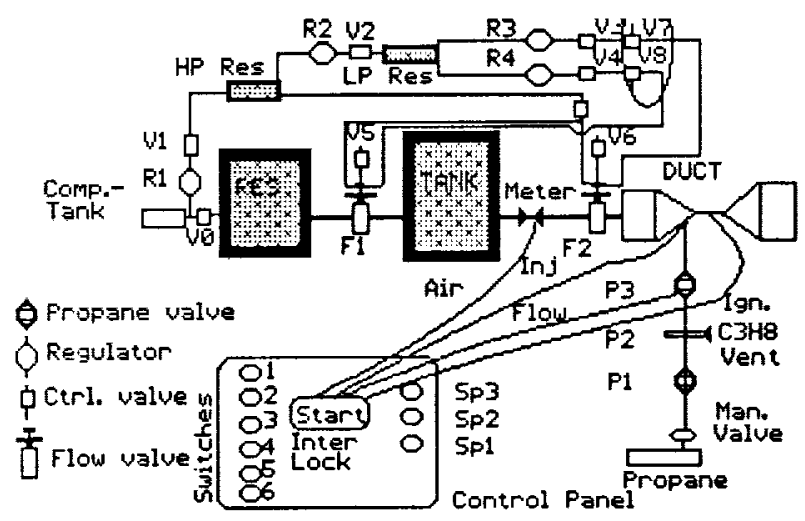

Figure 3.1-5. Schematic Representation of the Valve control system

\subsection{Detonation Duct}

Two completely different detonation duct configurations were used in this program, with a variety of fuel injection systems and ignition locations in each one. Initial tests were conducted with the plenum and shortened detonation duct from the program described in Reference 30. Some descriptions of the equipment used in that program and a summary of the principal results are attached here as Appendix $A$ which also presents some of the very early work done in support of the theoretical studies reported in Reference 5 .

Schematic representation of the plenum, duct, and the collector used here in the initial tests are shown in Figure 3.2-1. Photographs of the assembly are shown in Figure 3.2-2. Details of the collector and the truck mufflers used for silencing are shown in Figure 3.2-3. 
The collector and the mufflers were packed in fiberglass insulation, held in place by a light aluminum sheet. A $1 / 8$ " thick, $8 \mathrm{ft}$ long, $7 \mathrm{ft}$ high scatter shield was placed around the duct, collector, and the mufflers. The scatter shield was lined with a fire resistant acoustic foam. The shield and the acoustic packing are shown in Figure 3.2-4. Also shown as an illustration is an extension tube on one of the mufflers because it was found that in case of a misfire, the exhaust flames would ignite the acoustic foam which would then emit dense black clouds of acrid smoke. Because of misfirings, the mixture frequently exploded in the mufflers and created noise which not only brought complaints from the neighboring businesses, but also attracted the attention of the Corona fire department, which visited the facility with undesirable frequency.

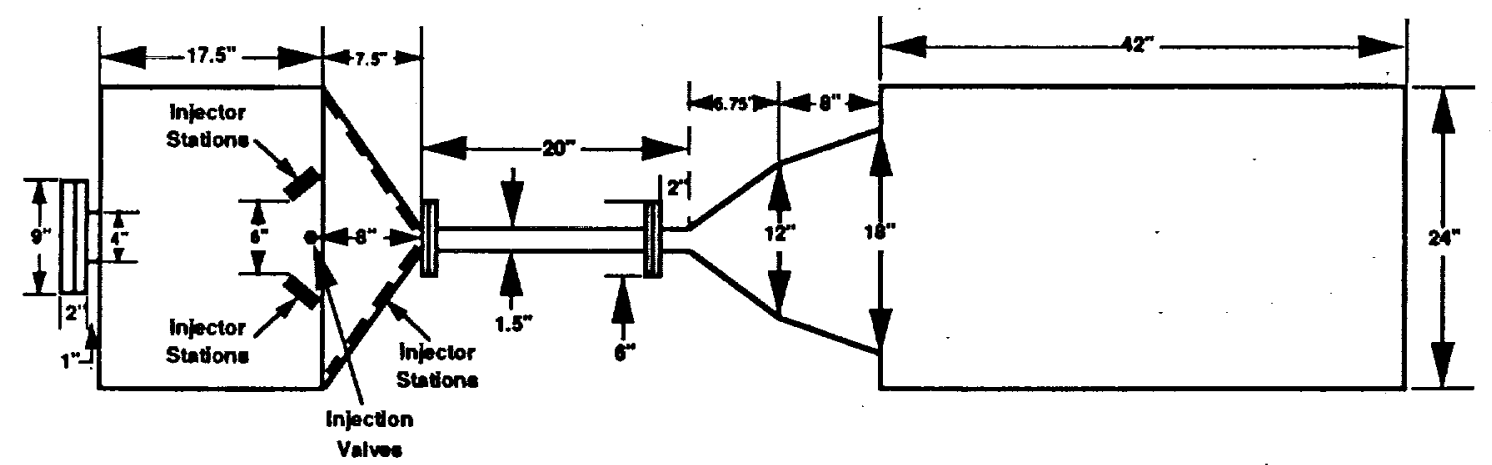

Figure 3.2-1. Plenum, Duct, and the collector 

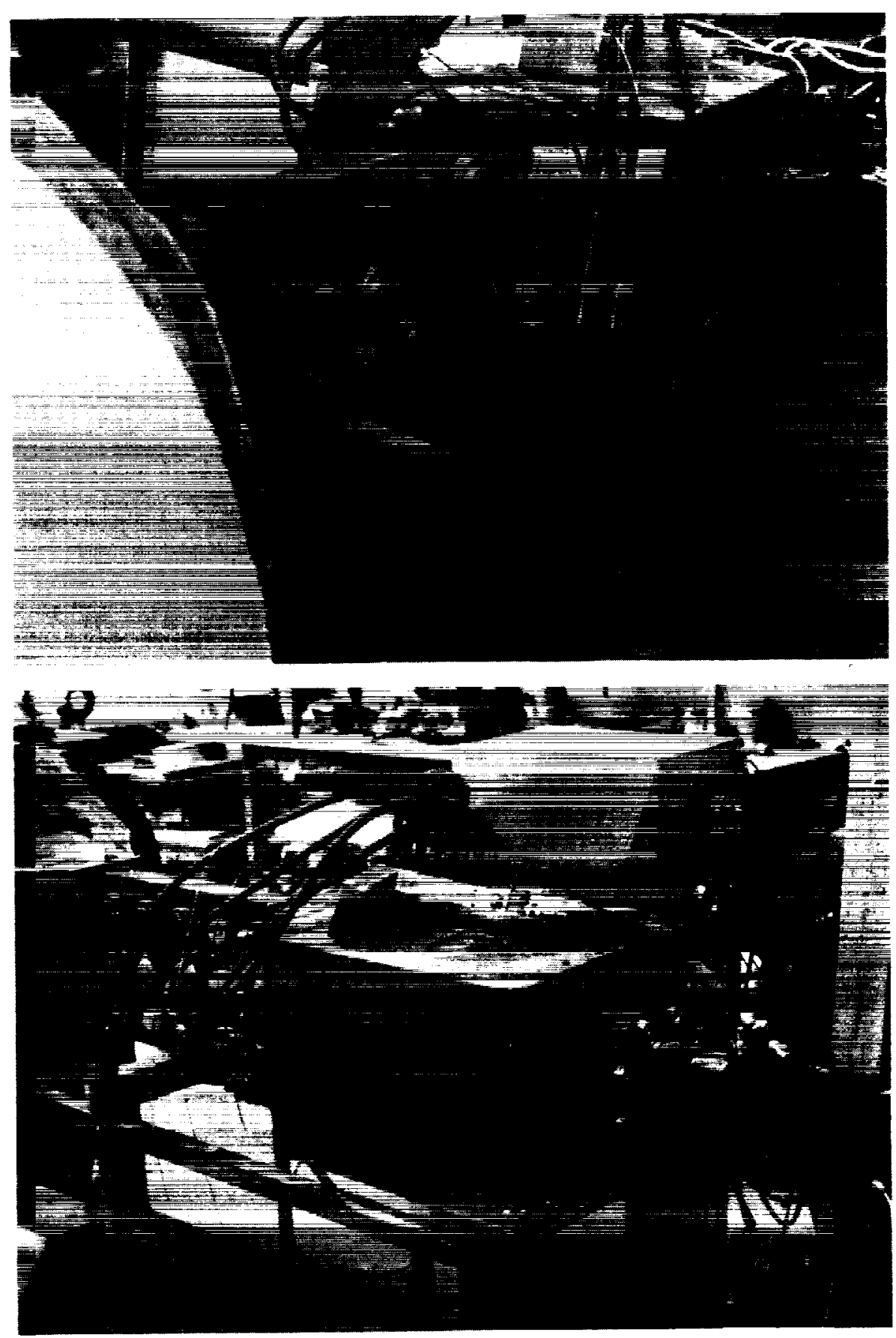

Figure 3.2-2. Plenum, Duct, and Collector Assembly 

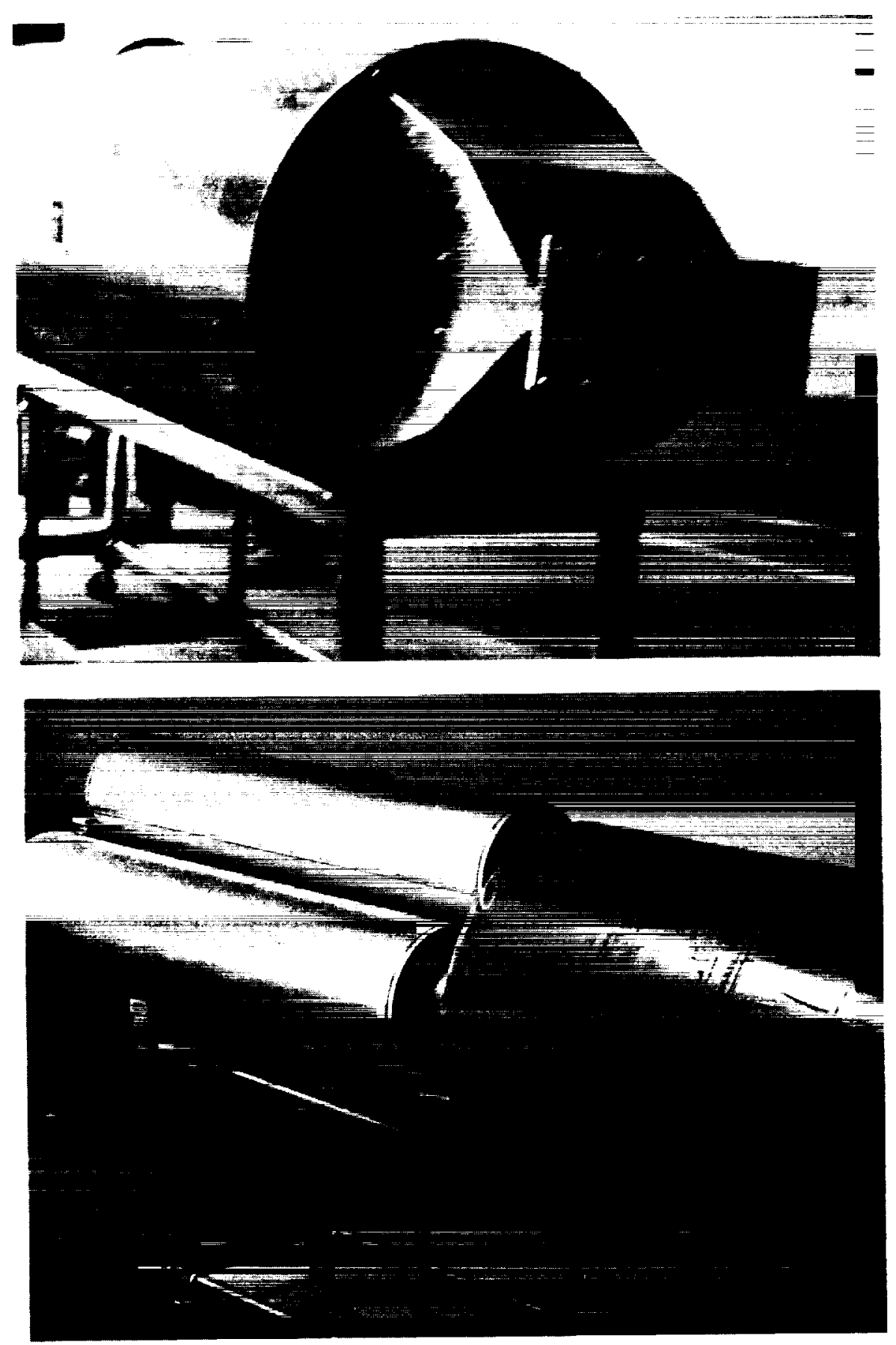

Figure 3.2-3. Collector and Mufflers

ORIGINAL PAGE 

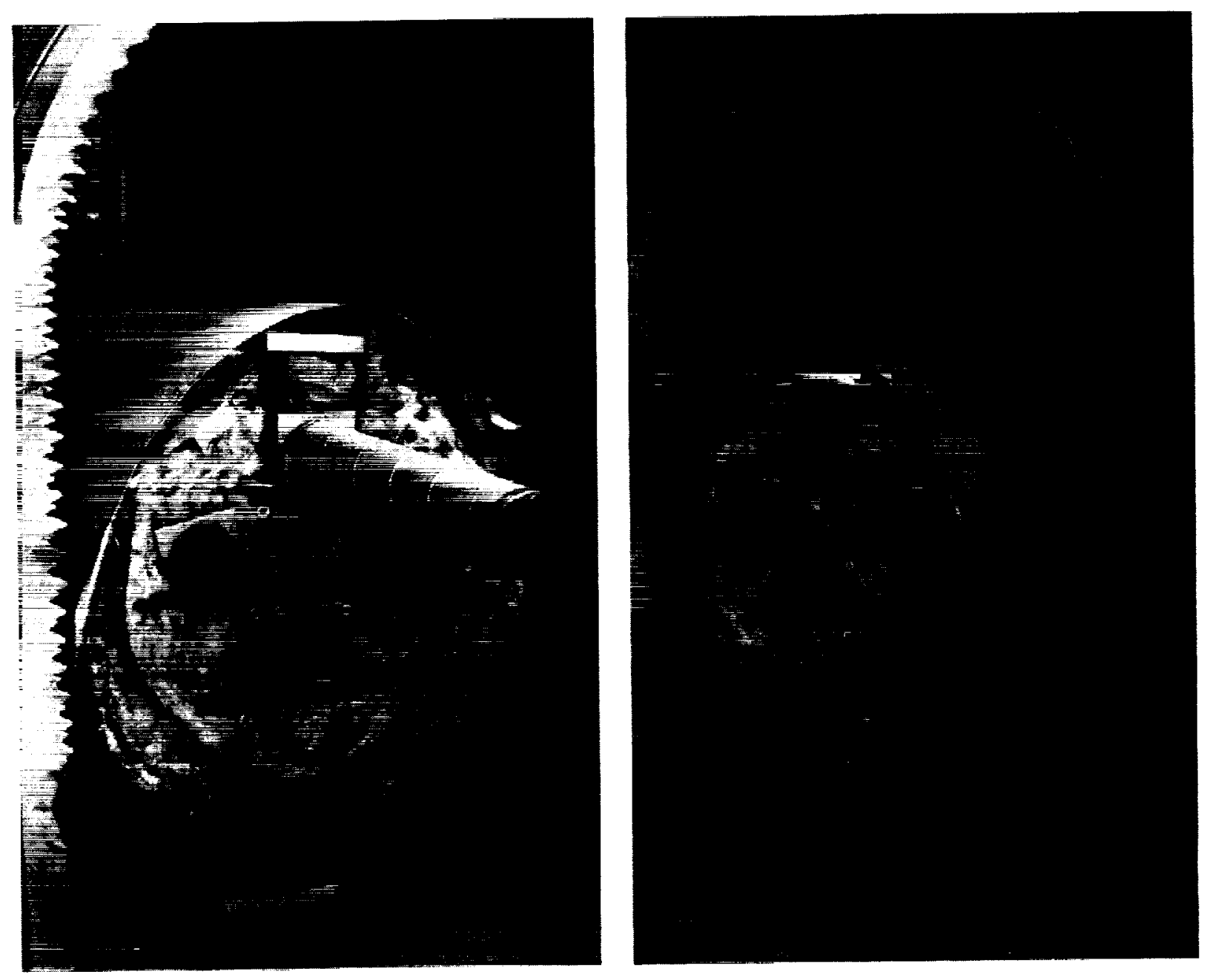

Figure 3.2-4. Acoustic Packing and Foam Iined Scatter Shiela

\author{
ORIGIHAL PAGE
}

B. ACK AND WHITE FHOTCKIALH 
An acoustic module was designed and fabricated. The mufflers exhausted into the module which consisted of an internal frame of steel grating wrapped with 4"-6" of fiberglass wool and encased in a 4 ft $x 4 \mathrm{ft} x 8 \mathrm{ft}$ reinforced plywood box: An internal baffle with about $75 \%$ blockage was placed $2 / 3$ of the distance into the module. A view of the module and the baffle is shown in Figure 3.2-5.

The details of the locations of the instrumentation plugs and the spark plugs are shown in Figure 3.2-6. Also shown are the three external locations for the fuel injectors at the entrance to the detonation duct. It should be noted that one of the fuel rails is removed with its fuel supply hose still attached. This arrangement permitted rapid relocation of fuel injectors, as the need arose.

It was found that the solid baffle plate at the inlet of the plenum created large vortices which were swirling the injected fuel in the plenum and caused frequent explosions which damaged the plenum structure. The baffle plate was drilled as shown in Figure 3.2-7 and the problems were alleviated considerably.

Several variations on the basic duct configuration were tried in an attempt to increase the pressure ratios and to diminish the transmission of pressure pulses into the plenum. some of these are shown in Figure 3.2-8. In the triangular cross-section configuration, the ignition was at the bottom in an attempt to propagate the detonation wave into a decreasing area channel and thus to create a super-compressed wave. No significant differences between this configuration and the basic rectangular one could be observed. Restriction at the entrance to the detonation duct was intended to diminish the strength of the pressure pulses entering the plenum. This proved ineffective because the restriction created a jet which reduced the mixing area and caused the ignition to occur far downstream. The wedge insert was intended to reflect the wave in the downstream direction and thus to reduce the transmission of pressure into the plenum. Some improvements were noticed but these were not considered to be significant enough to warrant further efforts in this direction. 

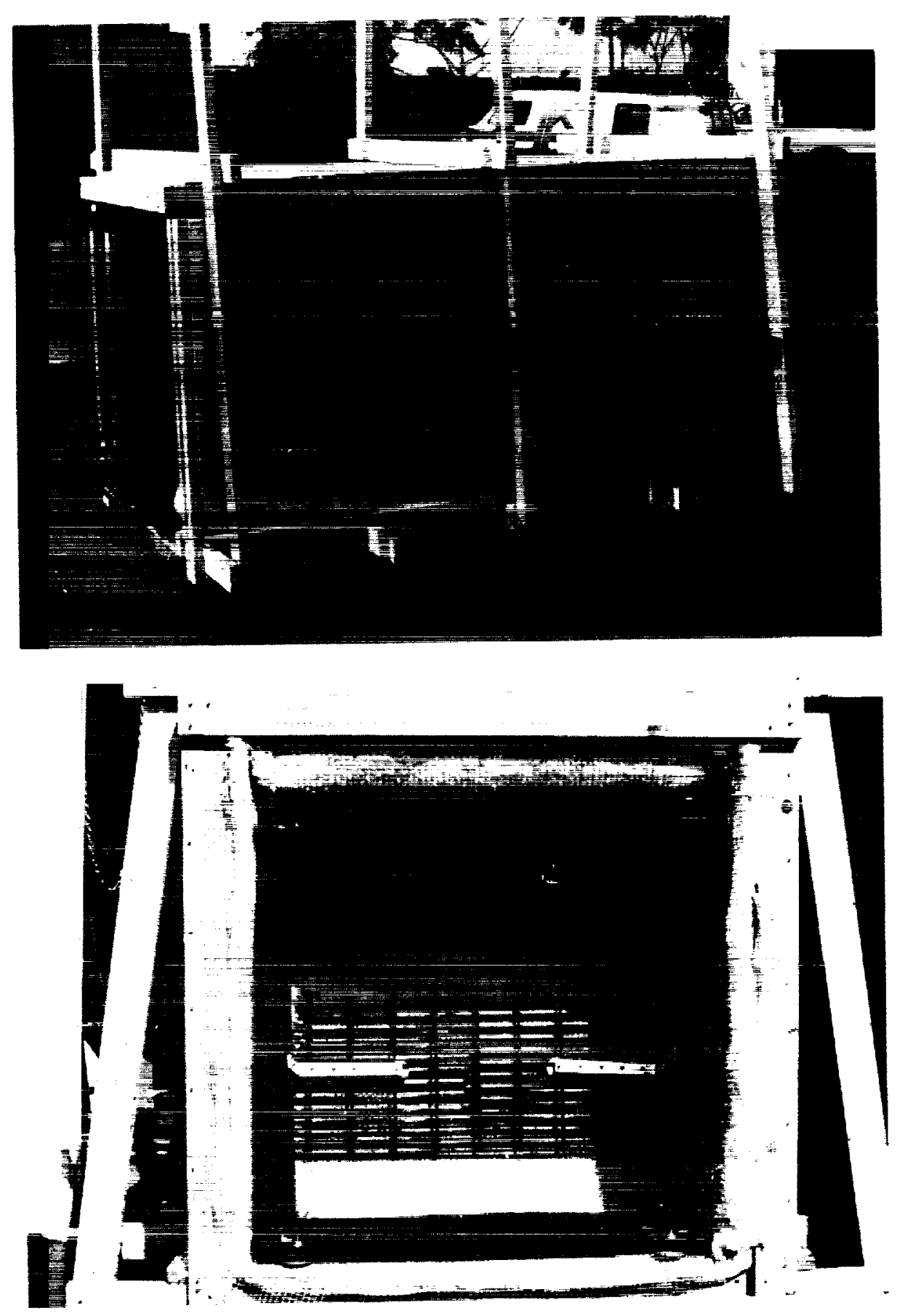

Figure 3.2-5. Acoustic Module 

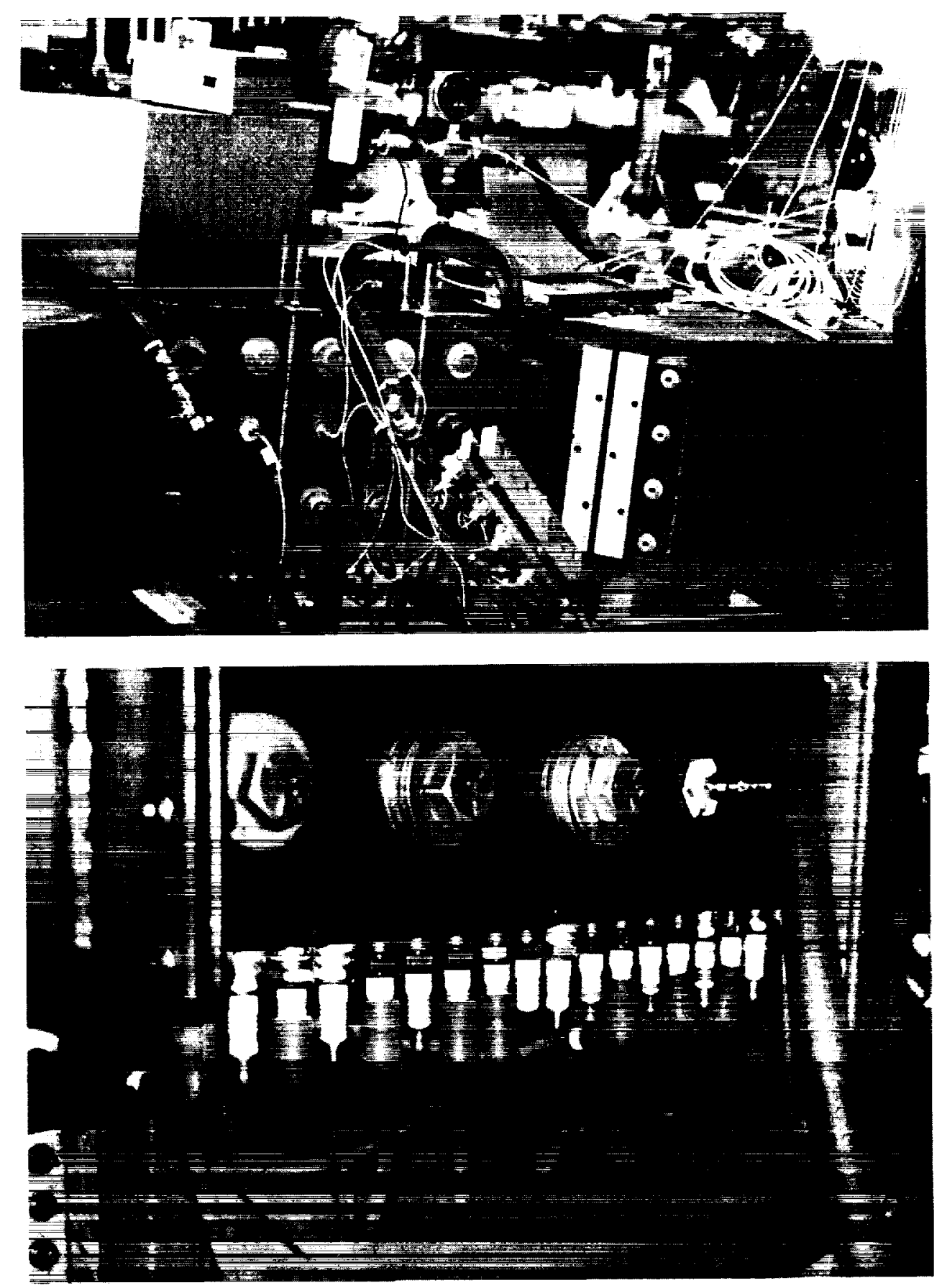

Figure 3.2-6. Fuel Injection Ports, Fuel Rail, and Spark Plugs 

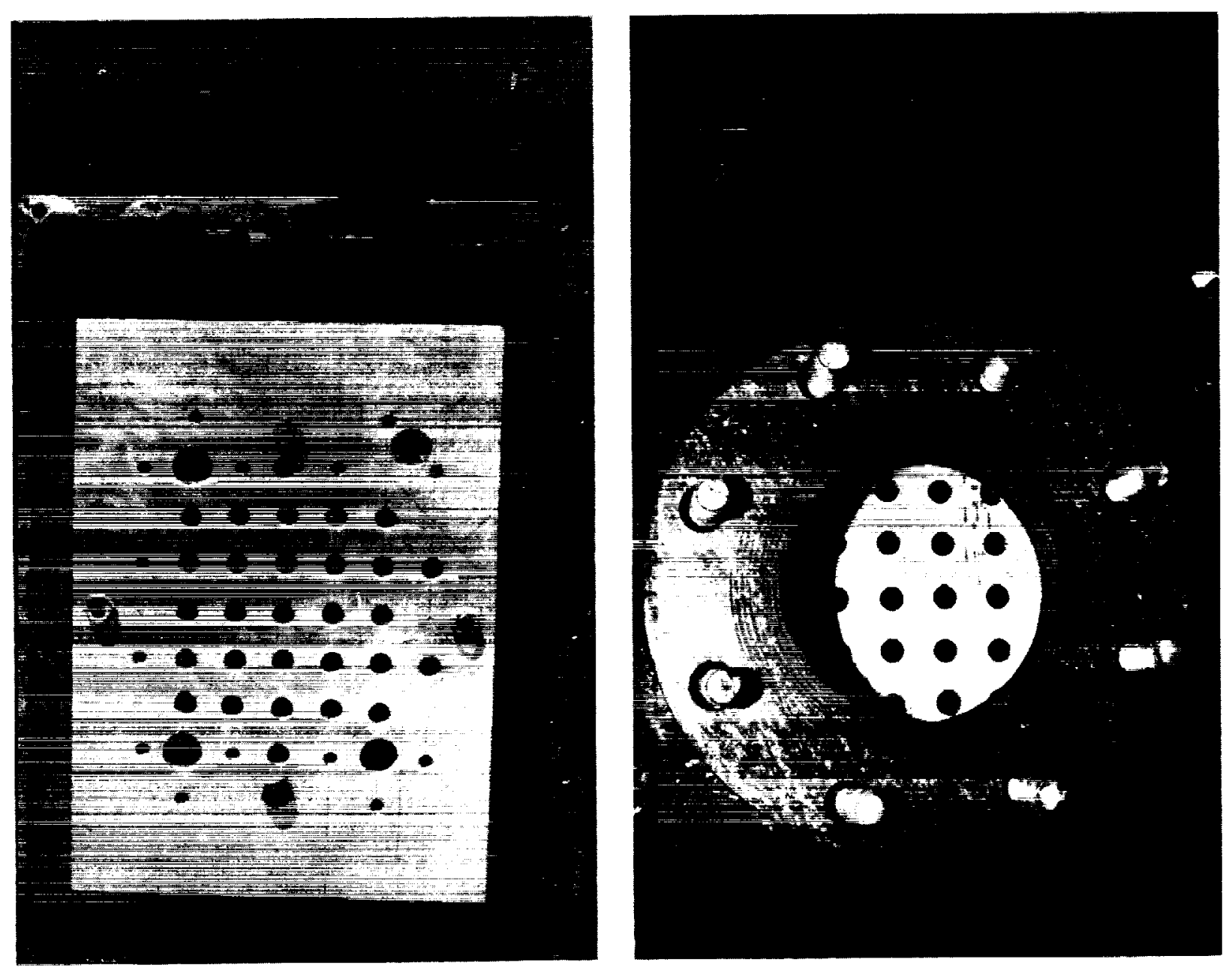

Figure 3.2-7. Baffle Plate and Inlet to the Plenum

ORIGINAL FR:- 

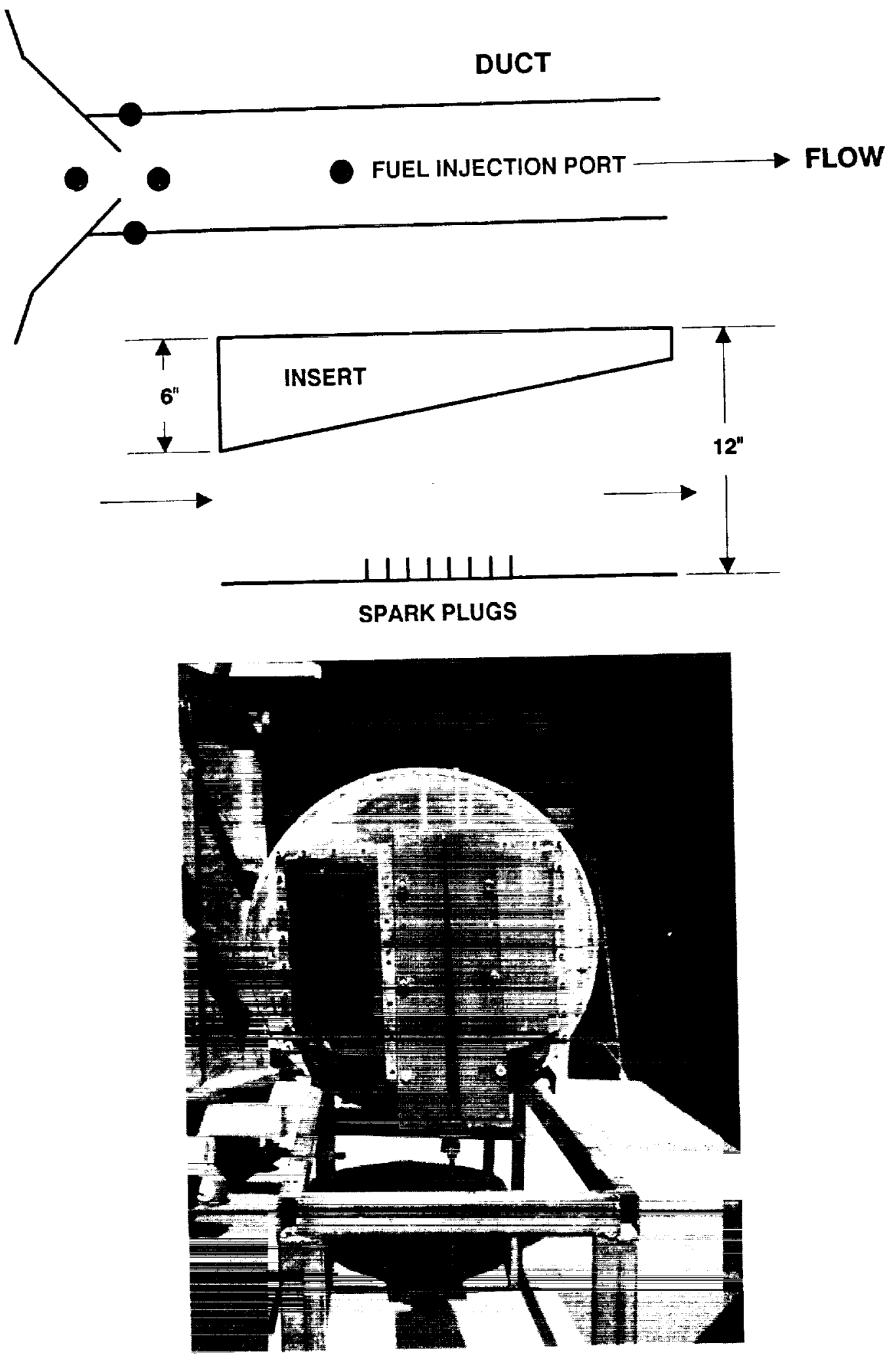

Figure 3.2-8. Variations on the Basic Duct Configuration 
Progressive disintegration of the plenum, resulting from explosions within it, necessitated a major redesign of the apparatus. A flexible design was developed which allowed the duct width to be varied from .25" to 1.5". A length of 4 ft was chosen in an attempt to alleviate the mixing problems of the shorter duct. Injection ports were provided in vertical and inclined arrays near the entrance. The $5 / 8$ " $x 12$ " $x 48$ " aluminum side plates were held in place by a bottom channel and tension bolts between the inlet and outlet transition sections. Vertical tension bolts were used to hold the channel and the plate in place. Lateral dimensions were maintained with aluminum spacers and bolts. The duct assembly is shown in Figure 3.2-9 and the side plate dimensions are given in Figure 3.2-10. The bottom channel is shown in Figure 3.2-11. The fuel injector rails attached to plates which were bolted to the sides of the duct plates. The duct side plates and a view of the vertical and horizontal tension bolts are shown in Figure 3.2-12. Details of the transition sections are shown in Figure 3.2-13. A detailed view of the transition section flanges and the duct, transition section, and muffler assembly is shown in Figure 3.2-14. Further views of the side plates with the bottom channel, top spacer, and horizontal tension bolts are shown in Figure 3.2-15. Views of the complete duct assembly, with the fuel injector rails and the 4 in-line mufflers, are shown in Figure 3.2-16.

Except for variations in the methods and locations of fuel injection systems, this was the configuration which was used in the last 4 months of testing and with which most of the test data were obtained. 

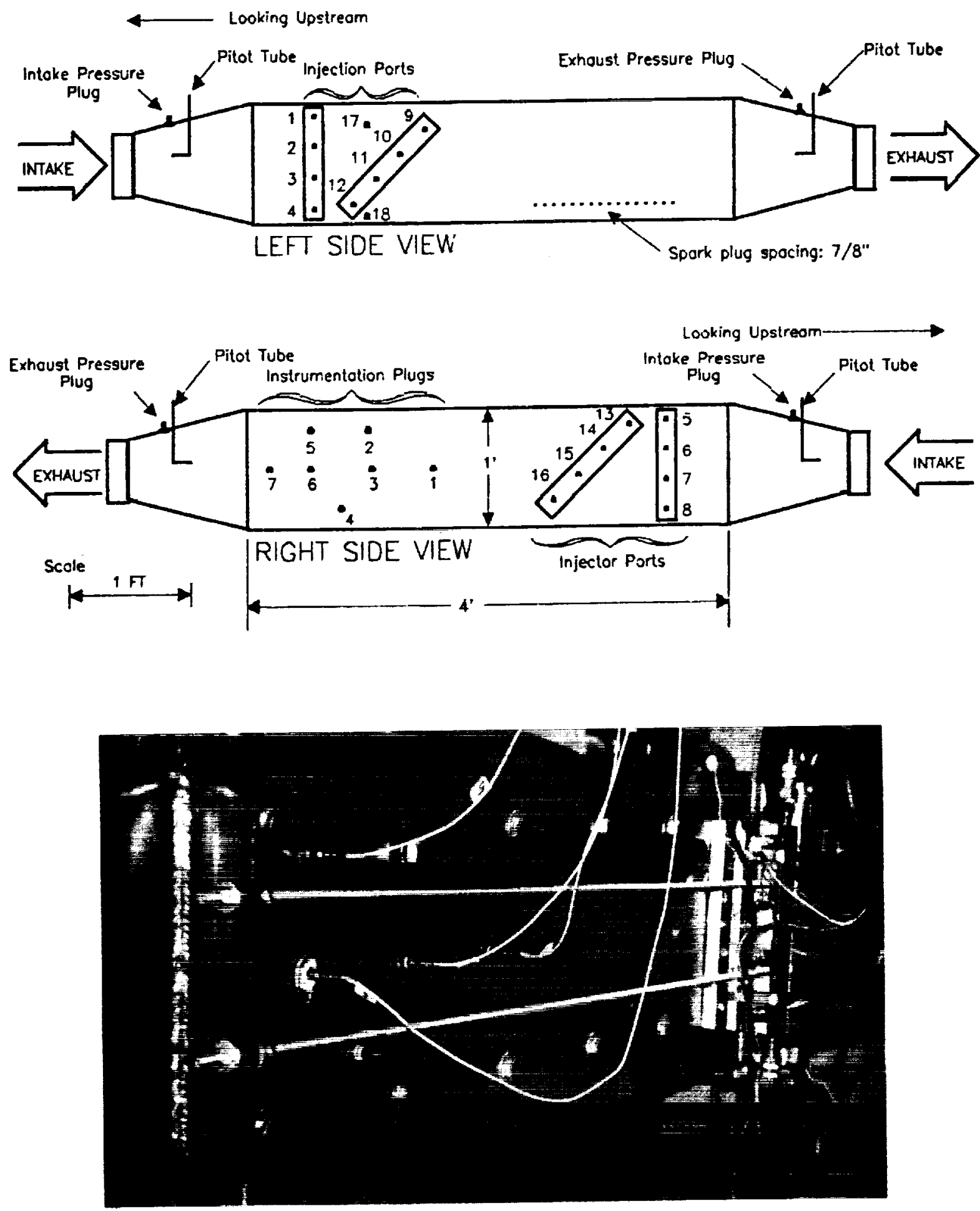

Figure 3.2-9. Detonation Duct Assembly (Right side view looking forward from rear. Note instrumentation and also fuel injector system.) 

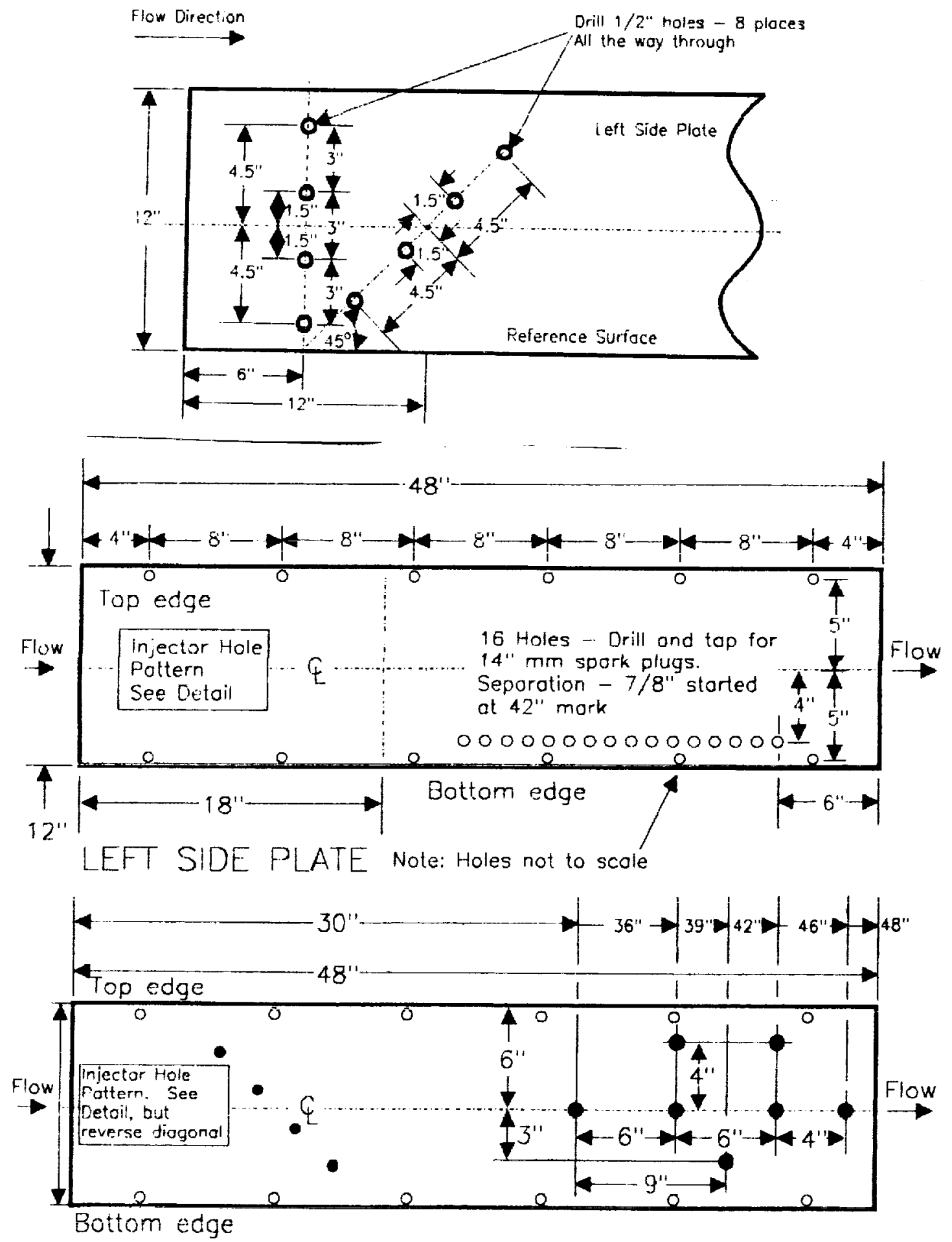

RIGHT SIDE PLATE

45. Injection holes drilling pattern as per left hand side plate - but reverse

Figure 3.2-10. Side Plates 


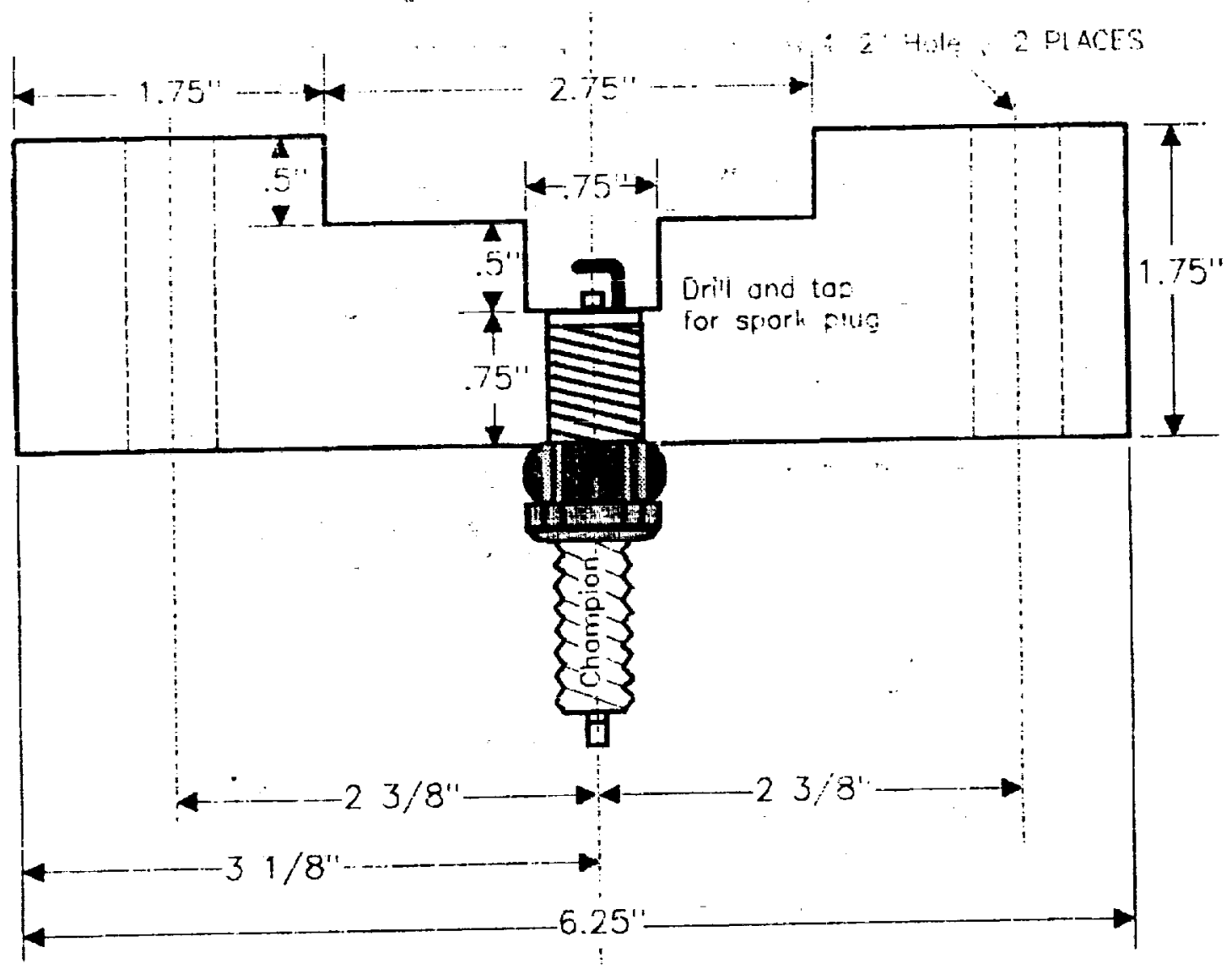

TOP VIEW

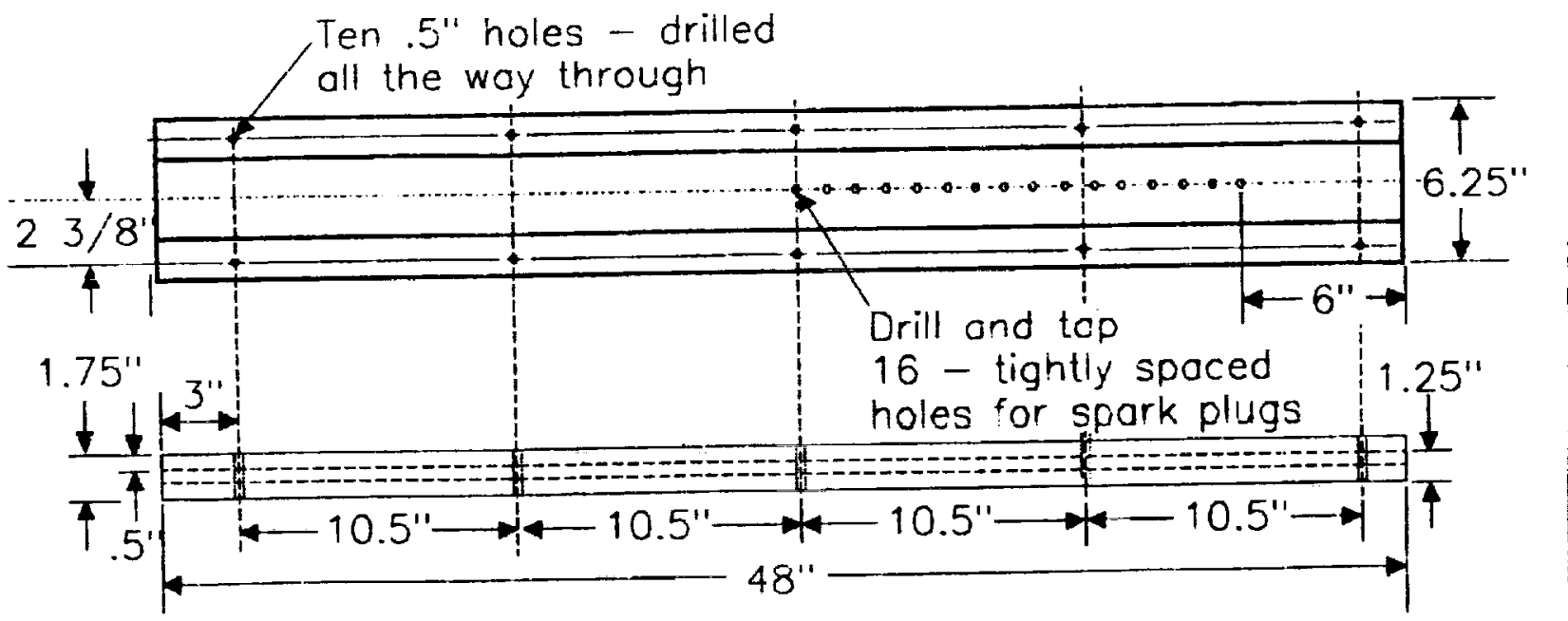

EDGE VIEW

Figure 3.2-1i. Bottom Channel 
VERTICAL $(90 \mathrm{deg})$ MODEL

Material - 6061 Aluminum Piote - 1/4" thick
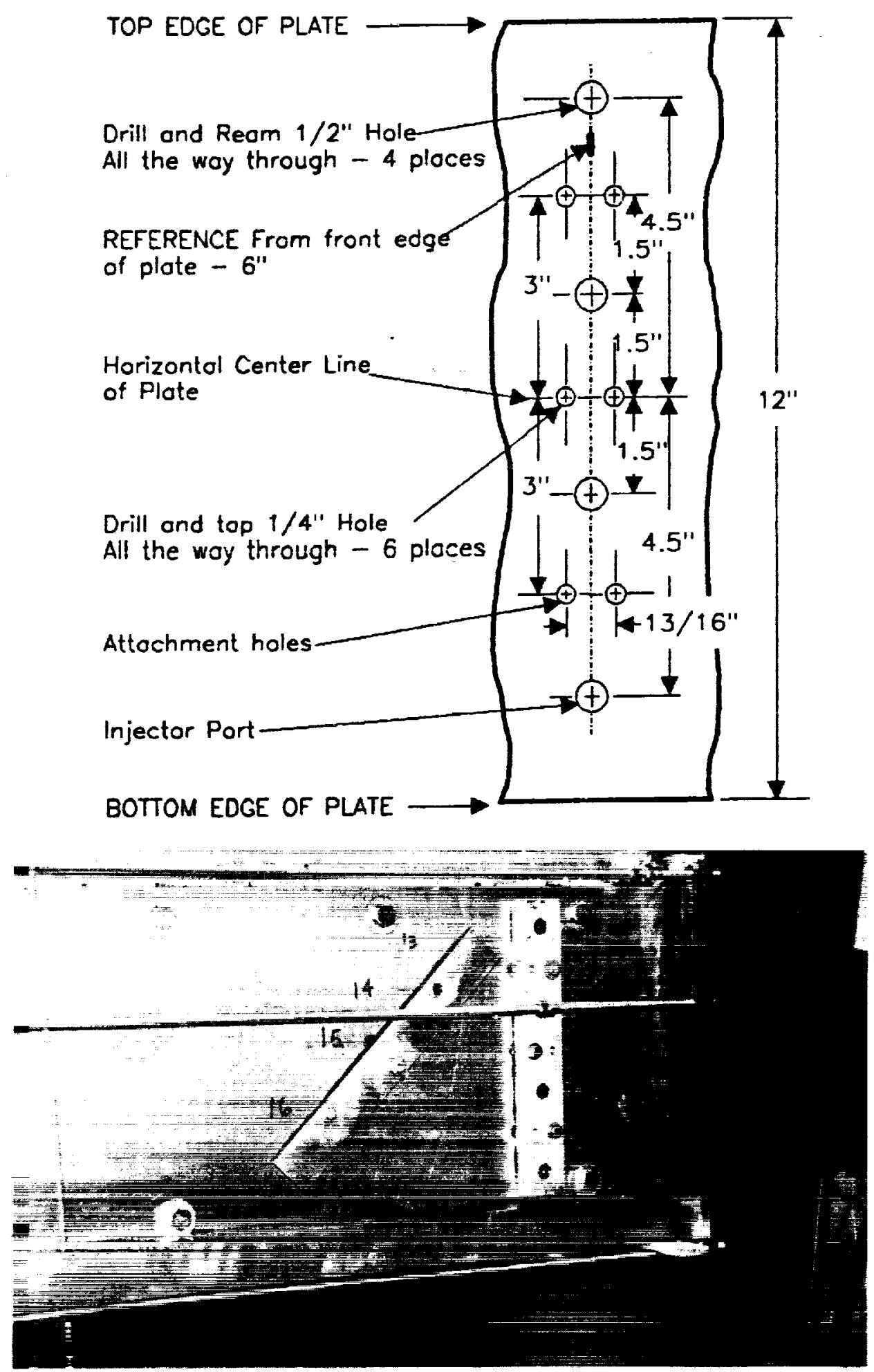

Figure 3.2-12. Fuel Rail Plates and Tension Bolts 


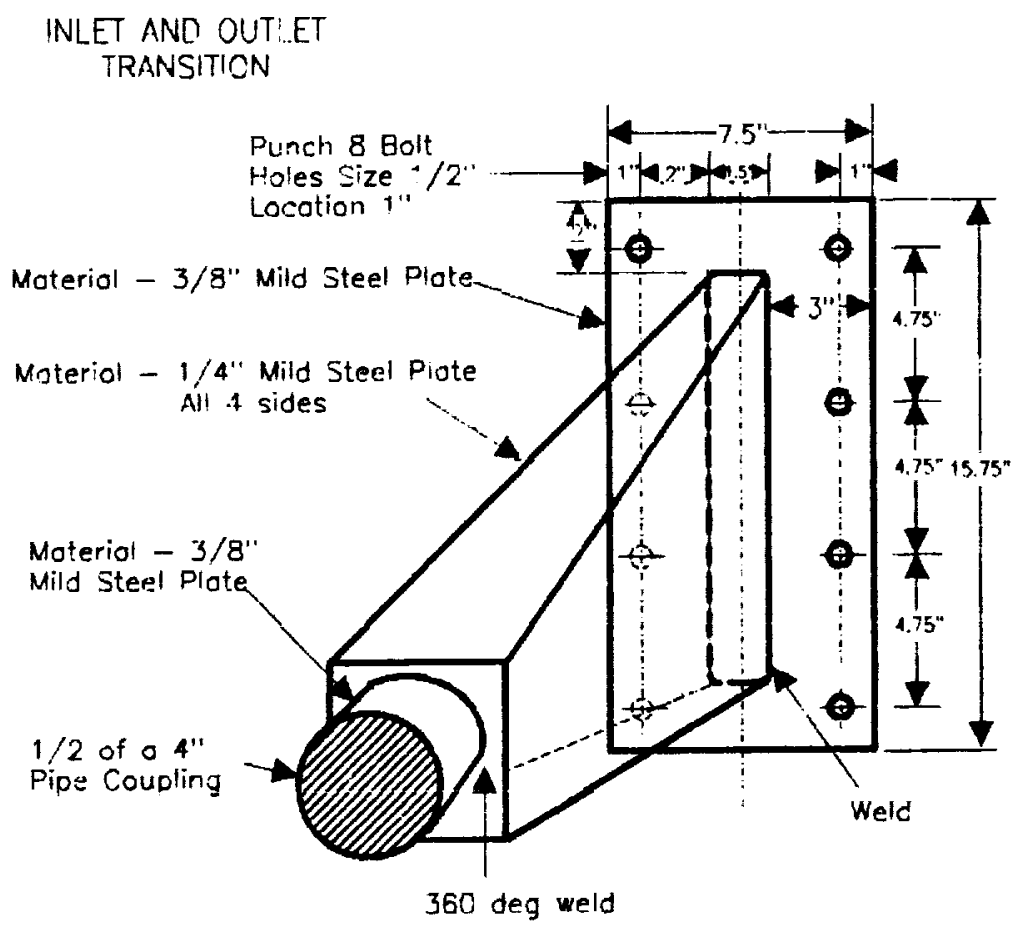

Moximum System Pressure - 125 psig

Operating Pressure - 10-20 psig

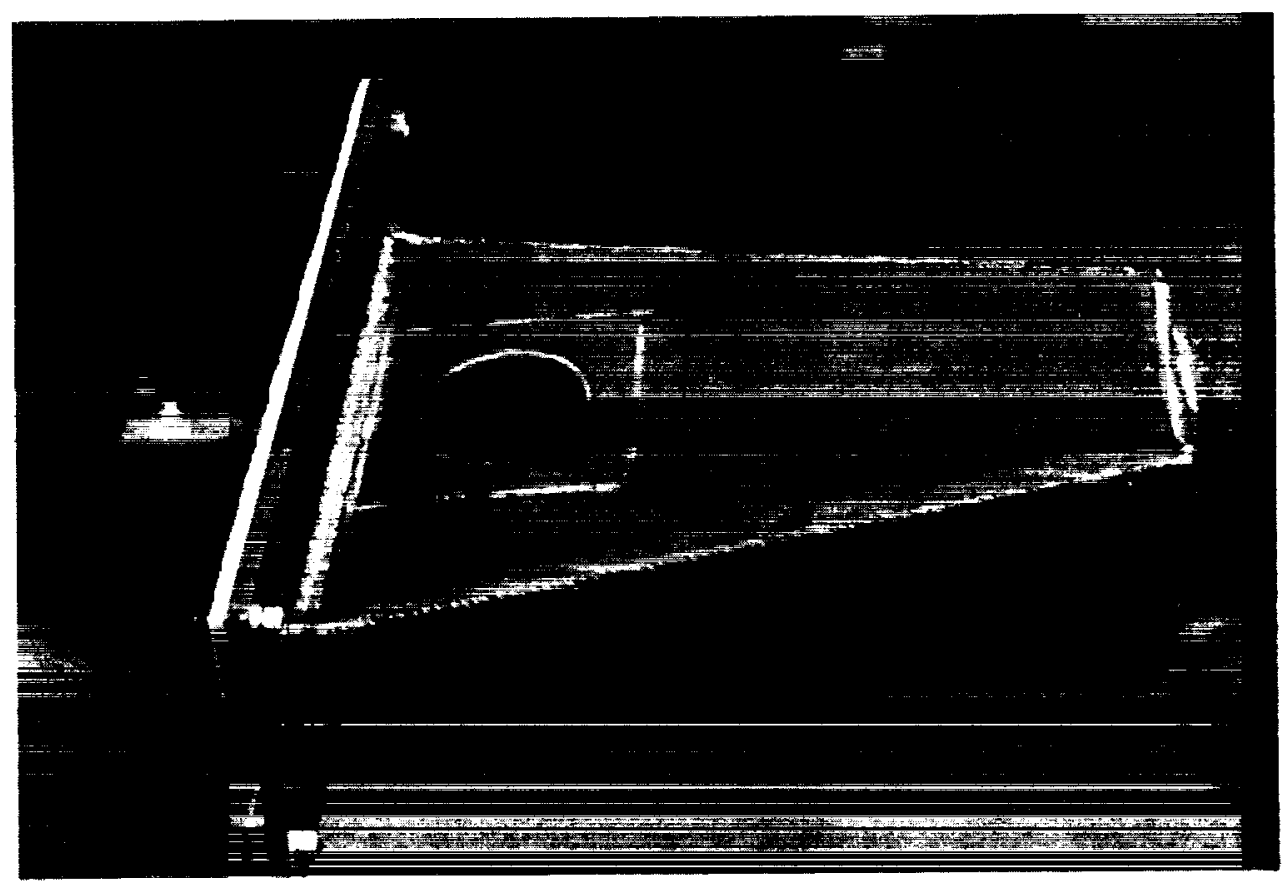

Figure 3.2-13. Details of the Transition section 

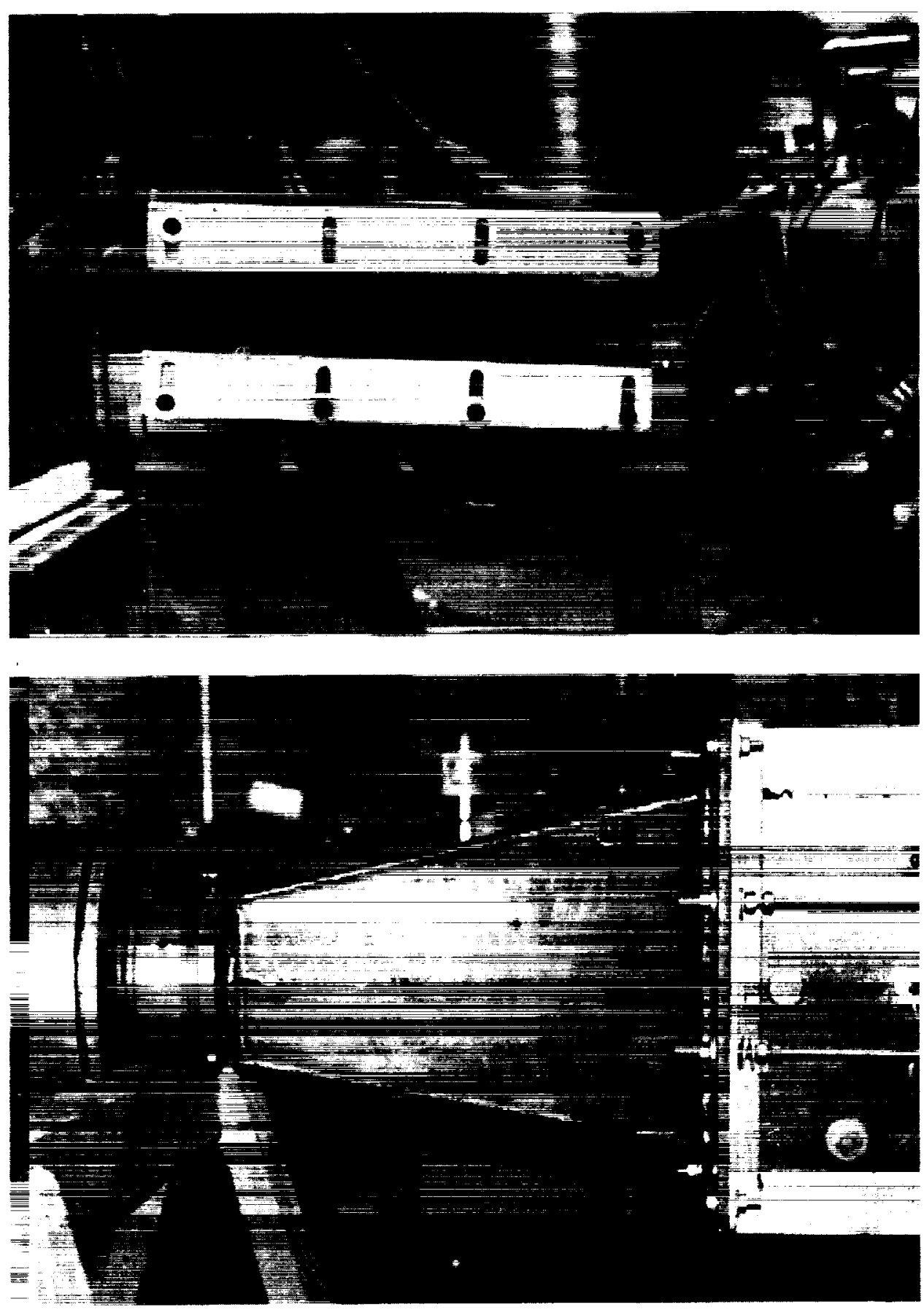

Figure 3.2-14. Details of the Transition section Flange and Duct Exit Assembly 

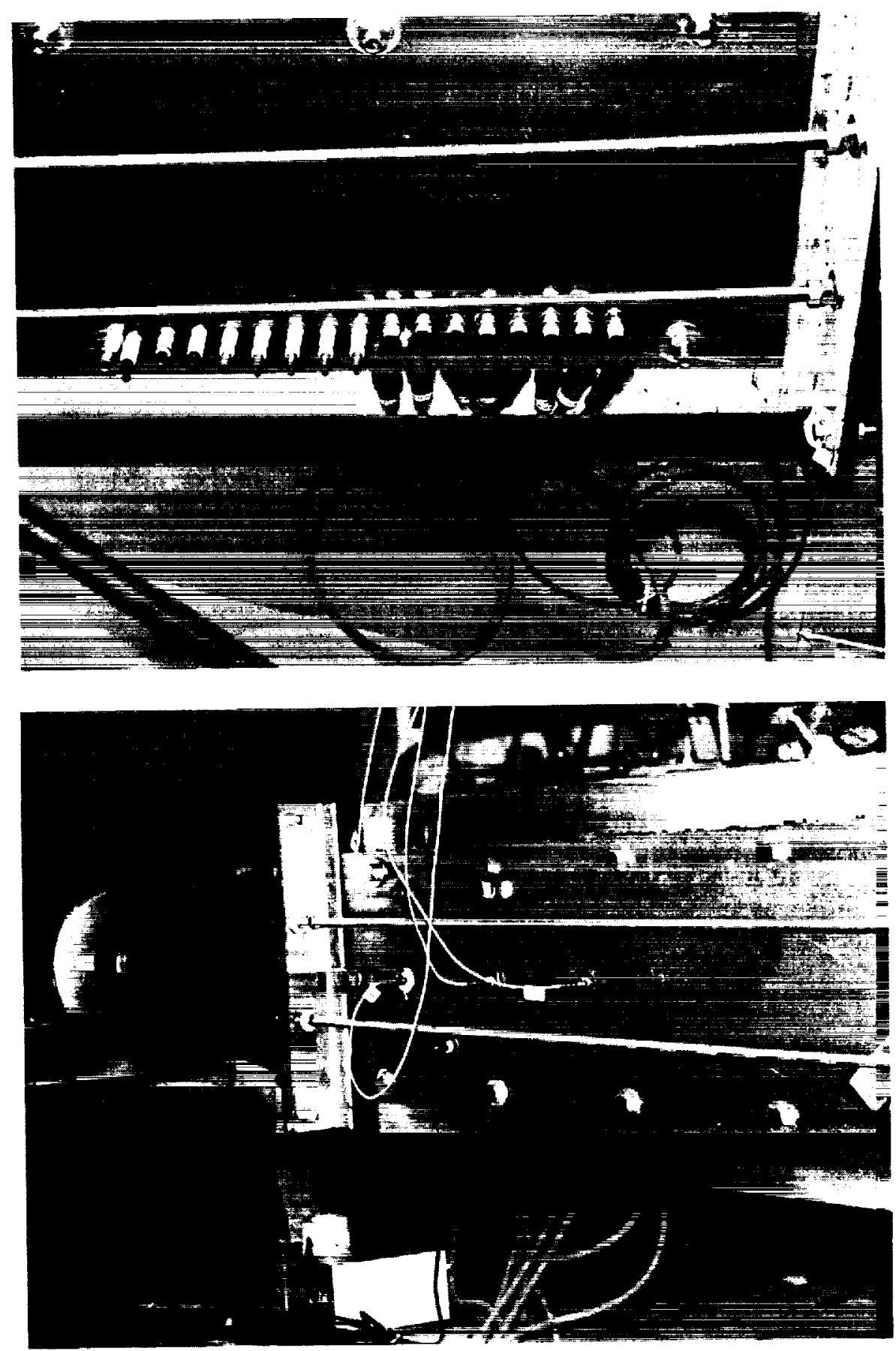

Figure 3.2-15. Views of the Duct Side Plates 

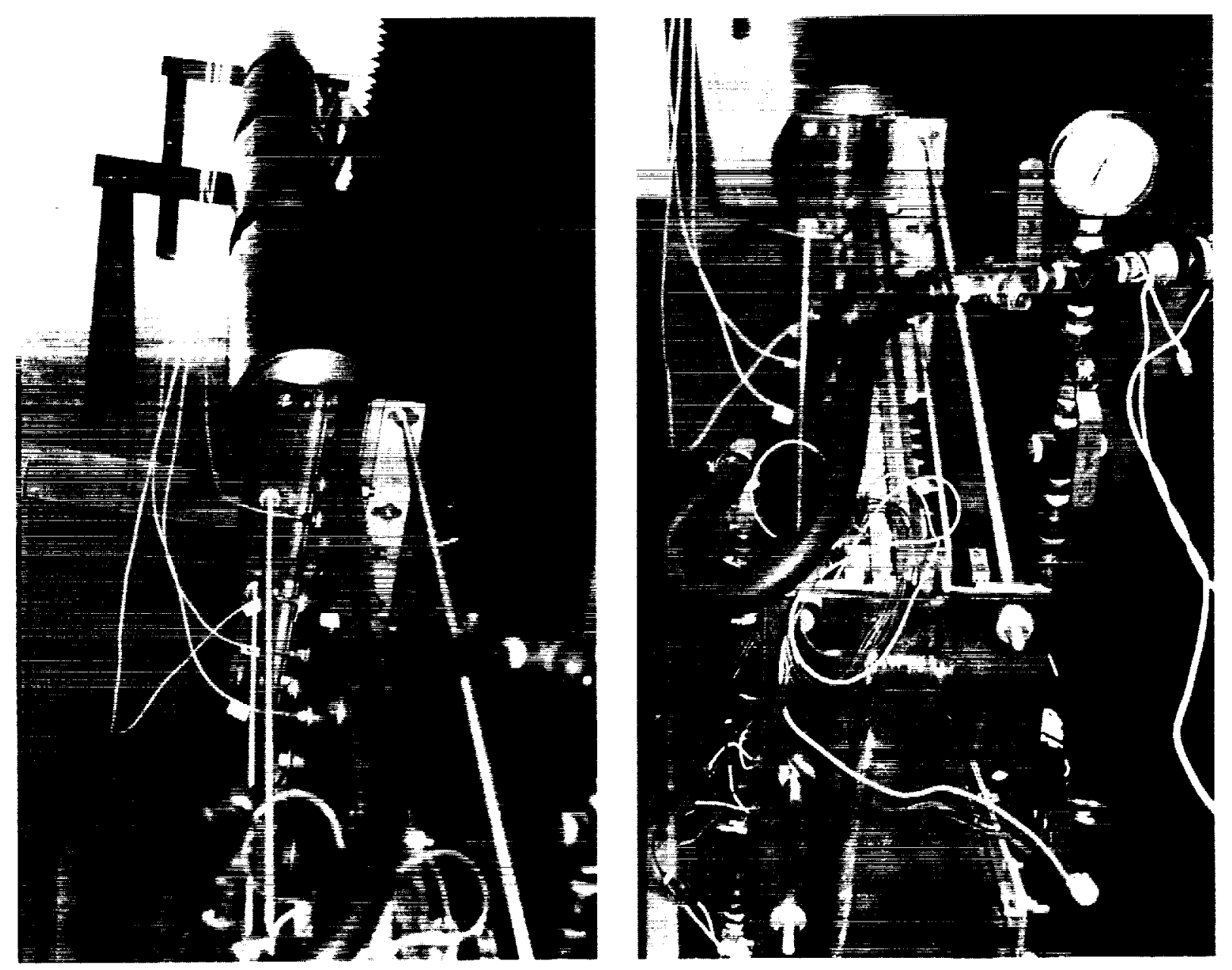

Figure 3.2-16. Longitudinal Views of the Duct Assembly

ORIGINAL PAGE

BLACK AND WHITE PHOTOGRAPH 


\subsection{Fuel Injection}

Several fuel injection systems were tried in the numerous attempts to increase the pressure ratios in the detonation waves, and the firing frequency. The basic fuel injection system consisted of 8 automotive fuel injectors which, in the initial experiment, were mounted in the walls in the converging section of the plenum at the inlet to the detonation duct.

The availability of adequate fuel flow rate was based on the use of these injectors in racing 350 in $^{3}$ engines which operate at speeds up to $9000 \mathrm{rpm}$. With a reasonable estimate of volumetric efficiency, the air flow rate through such an engine is about $1 \mathrm{lb} / \mathrm{s}$. Since the fuel/air mixture is slightly rich, the fuel flow rate is about $0.068 \mathrm{lb} / \mathrm{s}$, or $0.0085 \mathrm{lb} / \mathrm{s}$ for each injector. It is of interest to note that the injectors are sometimes pulsed twice during the intake stroke so that their frequency rating is at least 150 $\mathrm{Hz}$, and that they can easily be operated at twice that frequency. With 75 fuel pulses/second, each injector delivers about $0.00011 \mathrm{lb} /$ pulse. If the pulse period is taken as equal to the inlet stroke, or $1 / 300$ seconds, then the fuel flow rate through an injector $1 \mathrm{~s} 0.034 \mathrm{lb} / \mathrm{sec}$. In this case, the fuel was liquid propane which is about $2 / 3$ the density of gasoline, but was operated at about 3 times the fuel pressure found in racing engines. The flow rate of propane through the injector, while it was open, was therefore estimated at $.05 \mathrm{lb} / \mathrm{s}$. With 8 injectors the fuel flow rate was $0.4 \mathrm{lb} / \mathrm{s}$ and the required air flow rate for stoichiometry was 6.3 $1 \mathrm{~b} / \mathrm{s}$. With the $2 " \mathrm{x} 12^{\prime \prime}$ detonation duct flowing at a pressure of 1 atmosphere absolute, the corresponding air velocity was about $560 \mathrm{ft} / \mathrm{s}$, or Mach number of 0.5 . In view of the projected operation at Mach 1, provisions were made for the installation of 16 injectors, with only half that number being used initially. The disposition of the external injectors, and the subsequently added internal fuel rails, is shown schematically in Figure 3.3-1. 


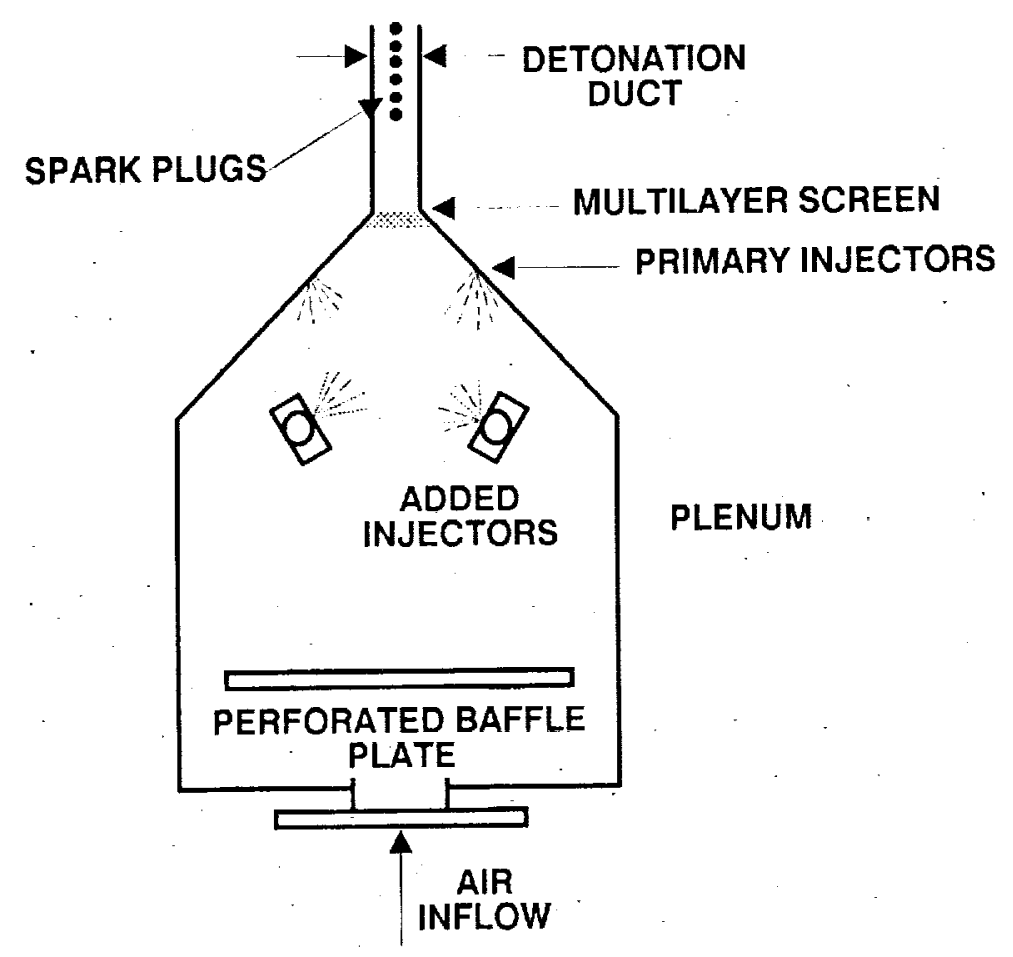

Figure 3.3-1. Disposition of the Fuel Injectors

The multilayer screen was tried in an attempt to improve mixing but had to be abandoned because it proved to be an excellent flameholder which caused explosions in the plenum.

The fuel injectors were mounted on rails so that changes of location would not require the opening of any of the fuel lines. The location of the three sets of fuel injection ports in the plenum and a fuel injector rail are shown in Figure $3 \cdot 3-2$.

The fuel injection system worked erratically because the opening of the injectors created volumes of vapor which could only be removed by frequent venting of the highest points of the fuel injection system. Flow test of the external injectors and of the internal fuel injector rails are shown in Figure 3.3-3. In this test, the injectors were virtually new so that they responded correctly to each signal. It should be noted that the upper 4 external injectors are not operational because of the presence of vapor in the fuel lines. 


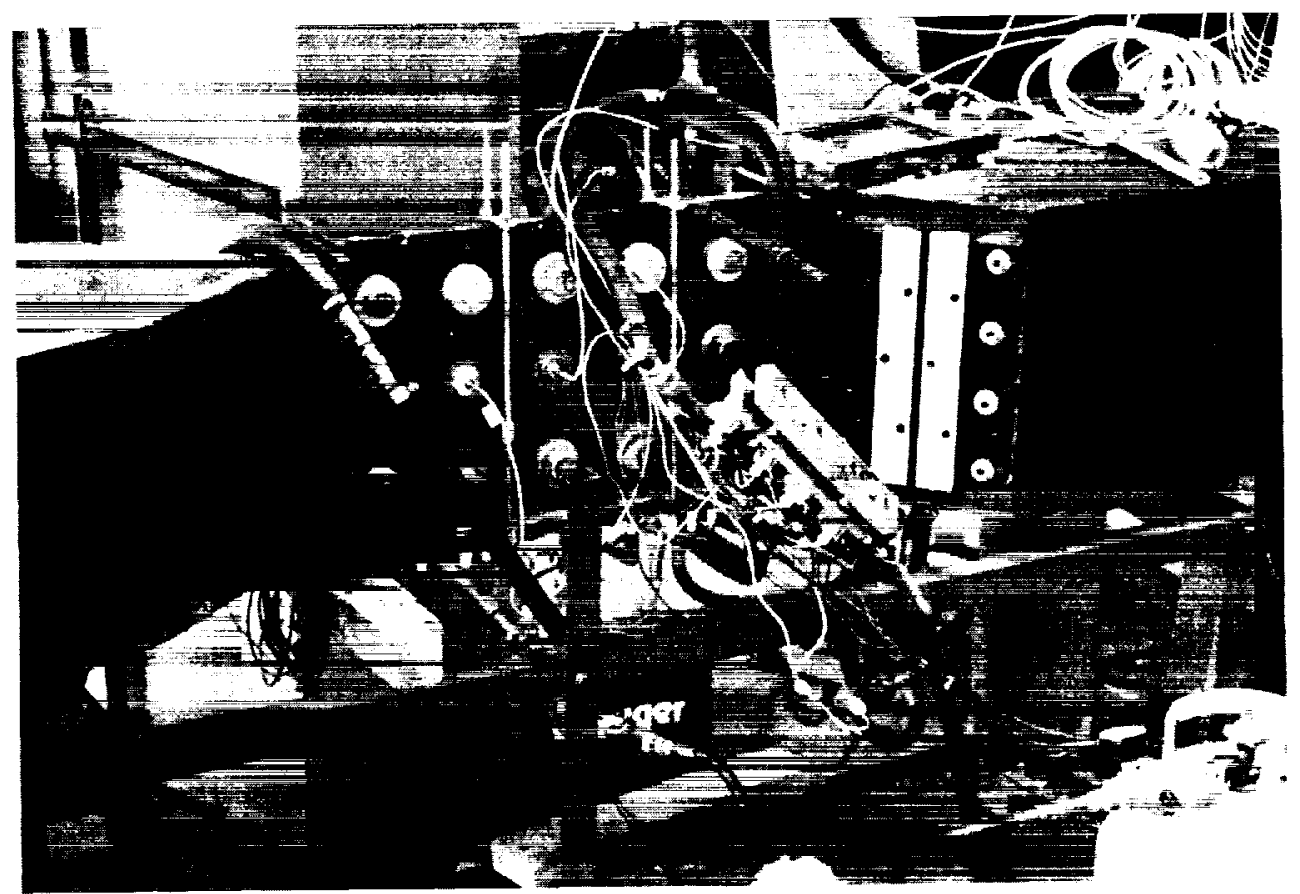

Figure 3.3-2. Fuel Injector Rail and Three Sets of Ports in the Plenum

Even with 16 injectors, it proved very difficult to ignite the mixture at higher air velocities. It appeared that the injectors were not delivering the predicted fuel flow rates because the solenoids could not overcome the propane pressure which was 4-5 times the design value. This was particularly noticeable with the aging of the injectors. Not only were the solenoids and return springs fatiguing but also the plastic tips of the injectors burned and obstructed the flow of fuel.

Tests were performed with a used injector and an omega 1/8" solenoid valve rated at $50 \mathrm{~Hz}$. Examples of spray patterns are shown in Figure 3.3-4. The very weak, diffuse patterns of the injector is caused by partial pintle opening, obstruction of the flow by the damaged plastic tip, and the small size of the liquid propane droplets. The 6 foot plume from the valve is due to the virtually unobstructed passage through the channel and relatively large sizes of droplets. It is of interest to note that expansion of propane gas from 150 psig results in a Mach 2.2 jet moving at a velocity of $1600 \mathrm{ft} / \mathrm{s}$. This jet propels the liquid propane droplets to great distances. It should also be noted that the evaporation of liquid propane in a stoichiometric fuel/air mixture reduces the temperature by only $3^{\circ} \mathrm{F}$. When the solenoid valve was used for fuel injection into the detonation duct, its output was throttled to reduce the size of the jet. 
ORIGINAL PAGE

BLACK AND WHITE PHOTOGRAPH
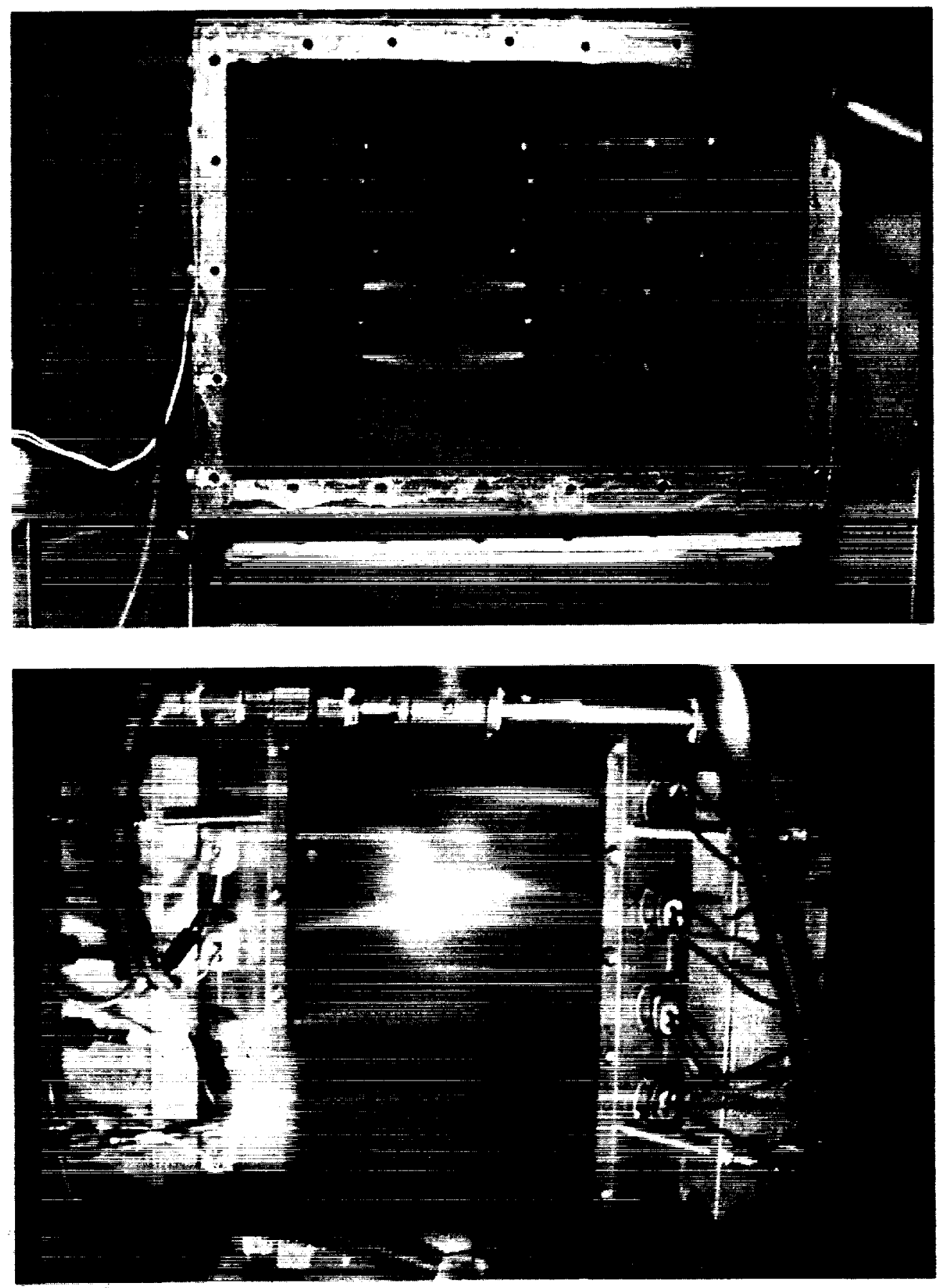

Figure 3.3-3. Fuel Injection Tests with an Open Plenum 


\section{ORIGINAL PAGE \\ BLẢCK AND WIHITE PHOTOGRAPH}
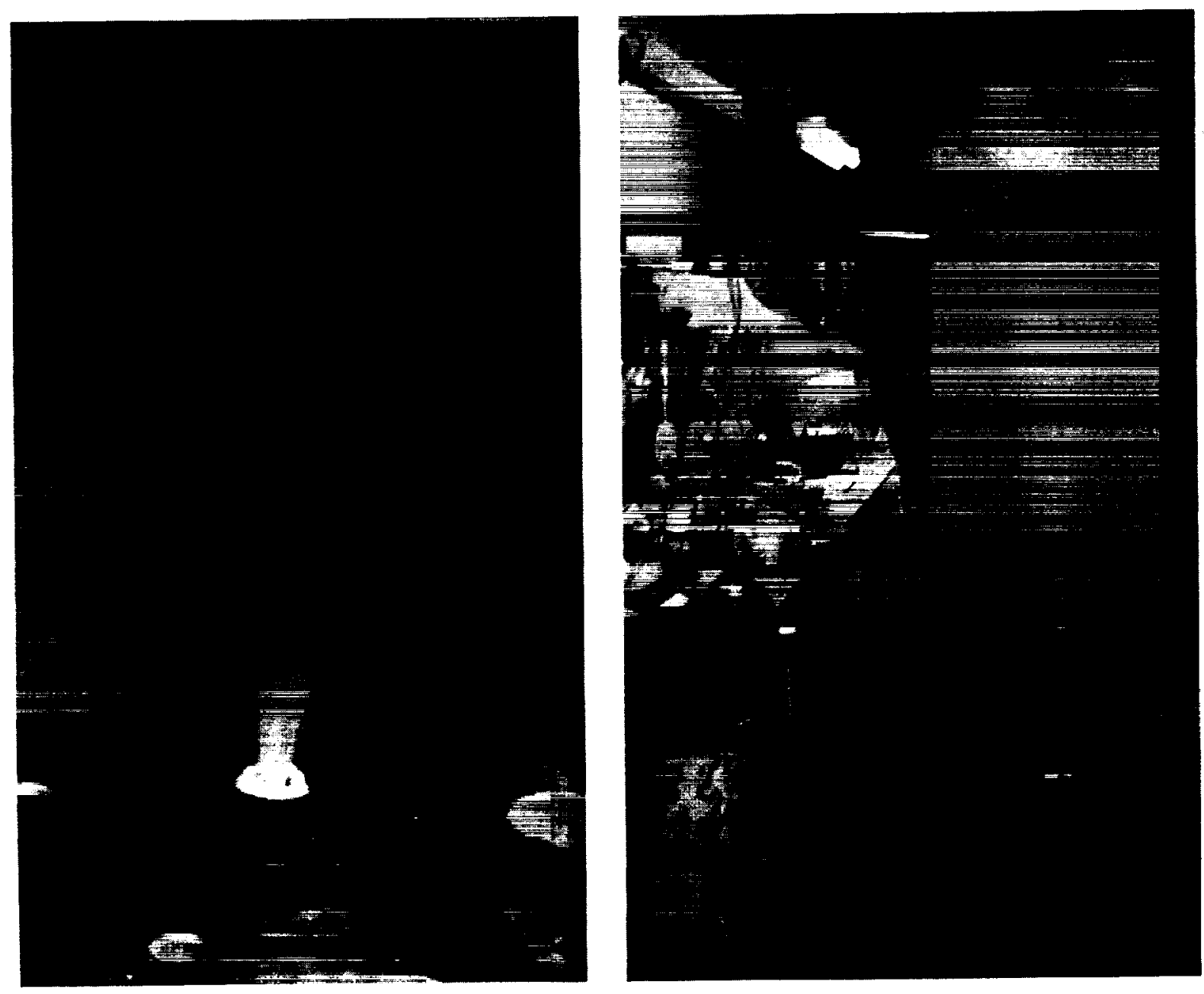

Figure 3.3-4. Spray Patterns from an Injector and a Solenoid Valve 
The very large plume generated by the valve could not be tolerated and several nozzles were developed to improve the dispersion. Examples ranging from perforated tubes to NASA-supplied stainless steel nozzles are shown in Figure 3.3-5. These nozzles were installed in the detonation duct. Even with the dispersion of the fuel by the nozzles, some droplets were carried into the plenum which exploded quite frequently.

With the very large flow rate through the valve, attempts were made to inject propane vapor at various supply pressures, but these met with limited success since at high pressures the Mach 2.2 jet spread rapidly and blocked the duct air flow while at low pressures the quantities of fuel were not sufficient to form a detonation wave. Attempts to inject premixed stoichiometric, or slightly rich propane-air mixtures and thus to duplicate the previous successes (Reference 30 ) failed because, at the higher duct air velocities in the present program, the mixture was dispersed rapidly and generally failed to ignite.

Fuel injection by means of the automotive injectors was tried in the new duct with channel widths of $1 / 4$ " and $1 / 2 "$, but detonations were produced irregularly, even at extremely low air velocities. When the duct width was set at I", the automotive injectors could not supply enough fuel and fuel had to be supplied through the omega valve and a nozzle. As before, this produced only limited success because the propane jet blocked the air flow. The most successful configuration was that in which liquid propane was injected through a nozzle transversely to the air stream through a nozzle located in Port \#9 (see Figure B.4-1) while an air jet was directed across it and in the direction of the spark plugs. The fuel injector rail and the valve injection-air blast arrangement are shown in Figure 3.3-6.

The one insurmountable problem with solenoid valve injection is that long after the valve is closed, the lines downstream of it are still loaded with fuel. This caused afterburning and occasional explosions. While this approach increased the success rate in obtaining detonations, it necessitated very low frequency firings. Because of the schedule, achievement of high pressure ratio detonations was considered to be more important than frequency and the nozzle flow-air blast fuel injection system was the ultimate configuration in this program. 

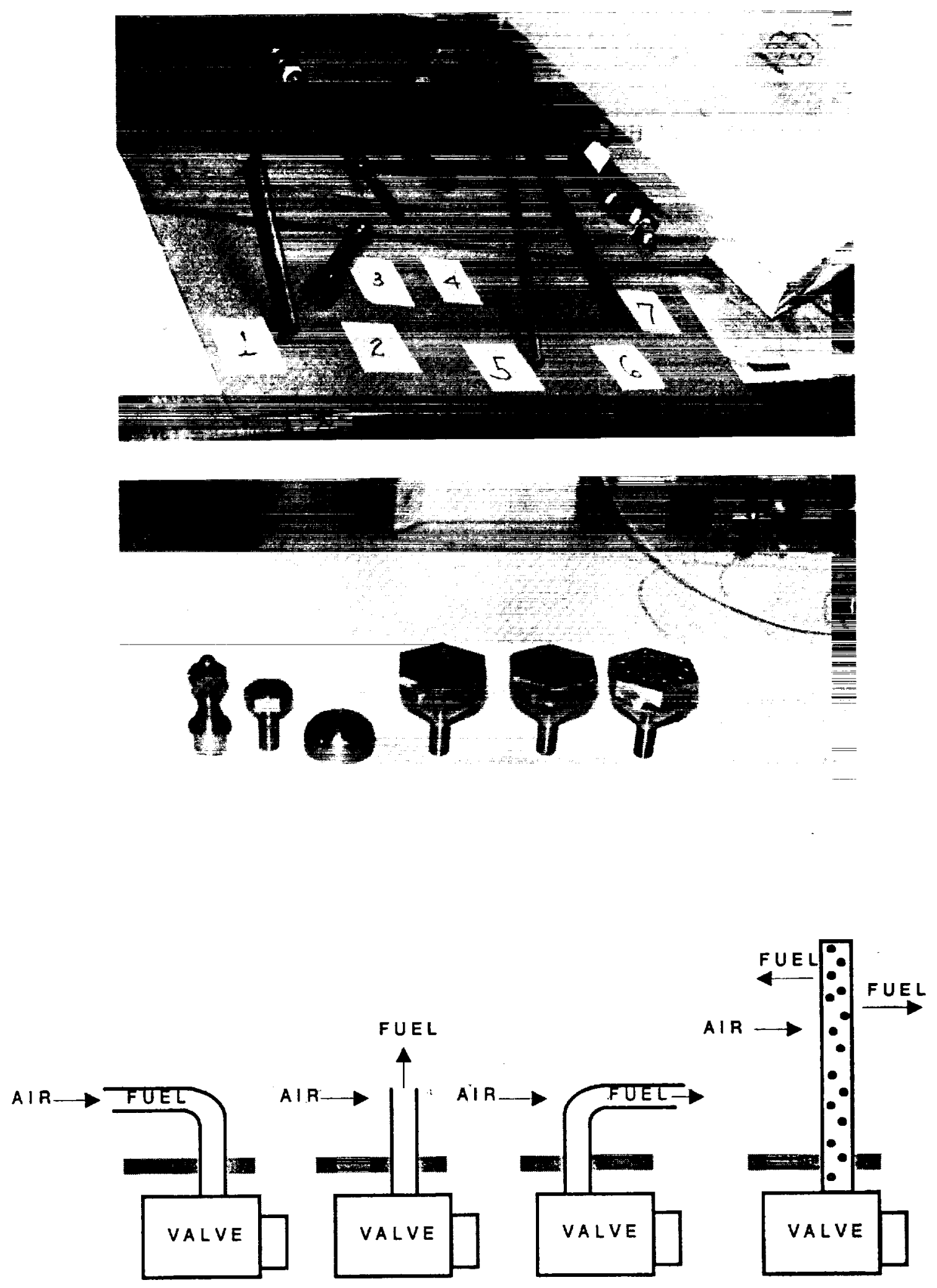

Figure 3.3-5. Injector Nozzles and their Installation 
ORIGINAL PAGE

BLACK AND WHITE PHOTOGRAPH
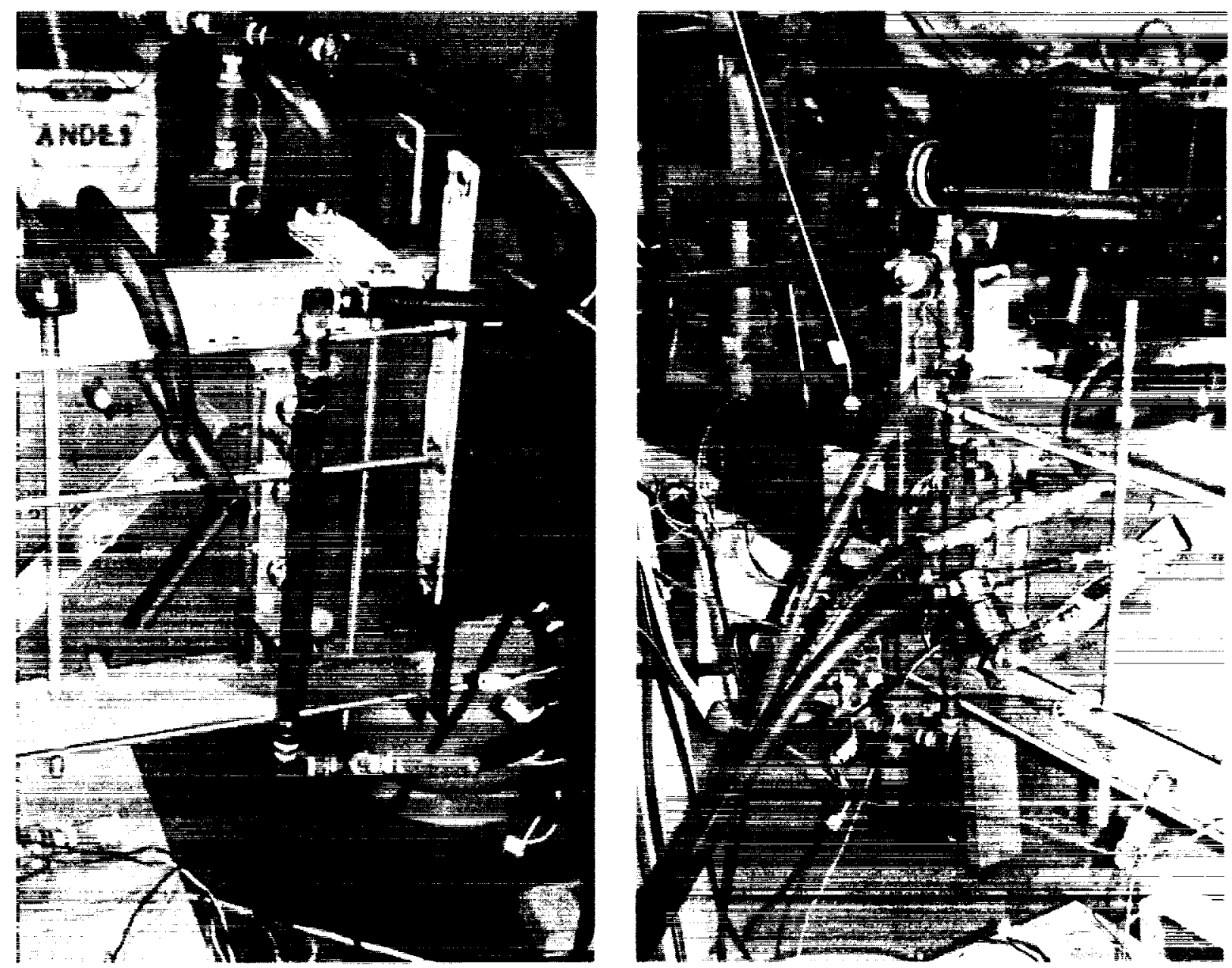

Figure 3.3-6. Fuel Injector Rail and the Nozzle-Air Blast Fuel Injection system 


\subsection{Injection-Ignition Control System}

The injection-ignition control system was designed to operate at frequencies of $300 \mathrm{~Hz}$, although such high firing rates were never contemplated in this program. Both the injection and ignition pulses were obtained from signal generators with the latter having an arbitrary delay. Because of the unique demands of this program, it was necessary to design and develop a completely new system. Component and development costs were minimized through the use of standard equipment such as commercially available function generators, amplifiers, and standard automotive injectors and ignition coils. In effect, one signal generator pulses the injectors while the second one, after a selected delay, pulsed the ignition coils.

Provisions were made to operate the second pulse generator independently at very high frequencies so that an effectively continuous line of sparks was delivered. When it was found that the detonation duct occasionally misfired and the pulse generators continued to function during a pre-set operating period, a safety switch was added to allow fuel to flow only when the operator depressed the contact button. Also, as a reminder that the system was armed and ready, bright warning lights were added.

The general logical scheme for the control system is shown in Figure 3.4-1. Schematic representation of the principal components is given in Figure 3.4-2.

The control system is driven by two separate pulse generators which operate the fuel and ignition subsystems. The fuel signal is a pulse train with zero volts being FUEL OFF and negative eight volts signaling FUEL ON. This is true for both the Bosch fuel injectors and omega valve. The spark signal is also a pulse train. Unlike the fuel signal, however, the spark signal should be maintained at +12 volts for SPARK OFF and reduced to zero volts to generate a spark. The spark occurs at the trailing edge (high to low transition) of the spark signal. Further, the spark duration is a function of the discharge time constant of the coils and spark plugs only and is independent of the actual time that the signal voltage is held low. Normally, the SPARK ON signal should be brief, but at least three to five milliseconds, to insure proper operation. 


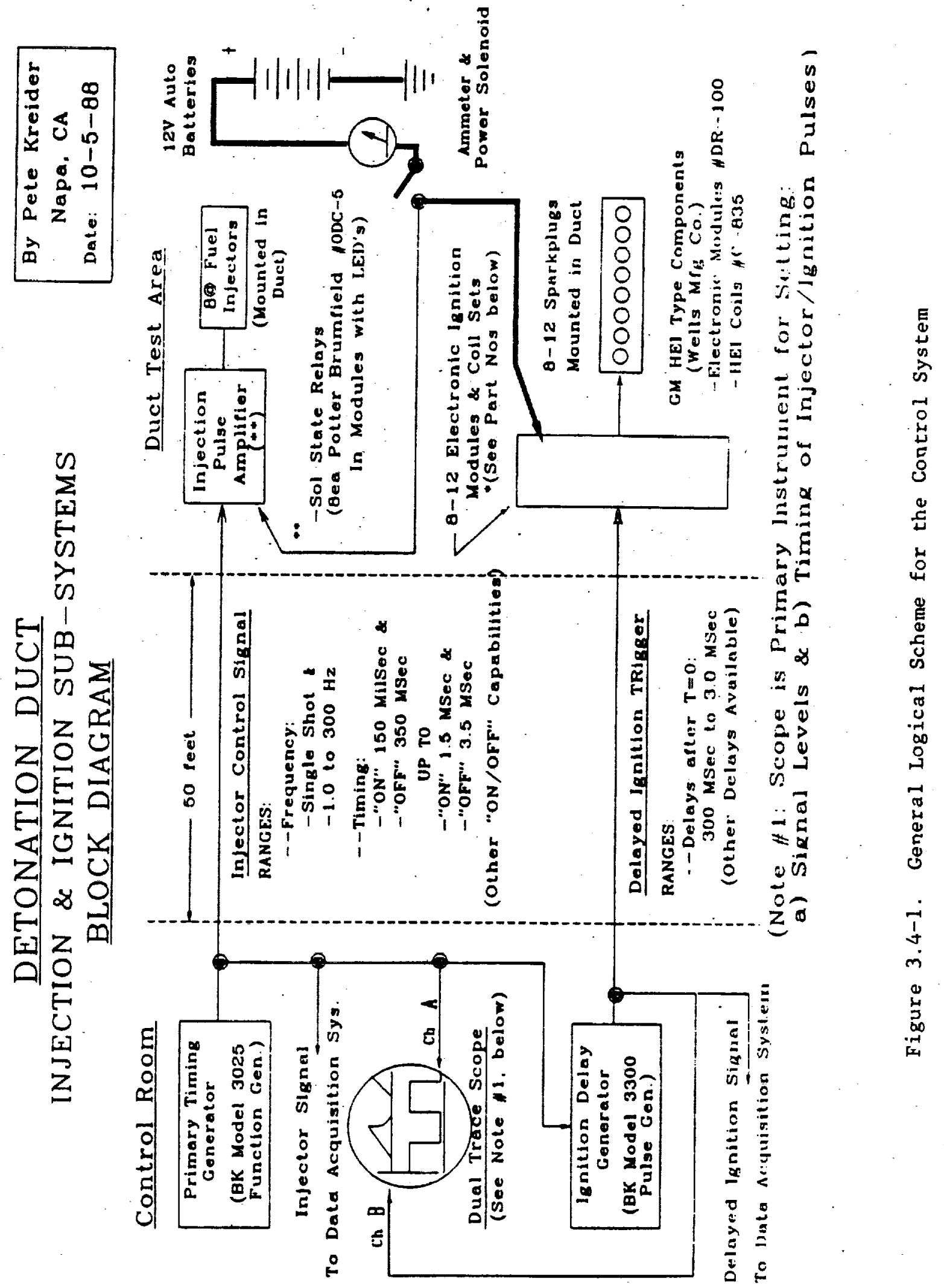




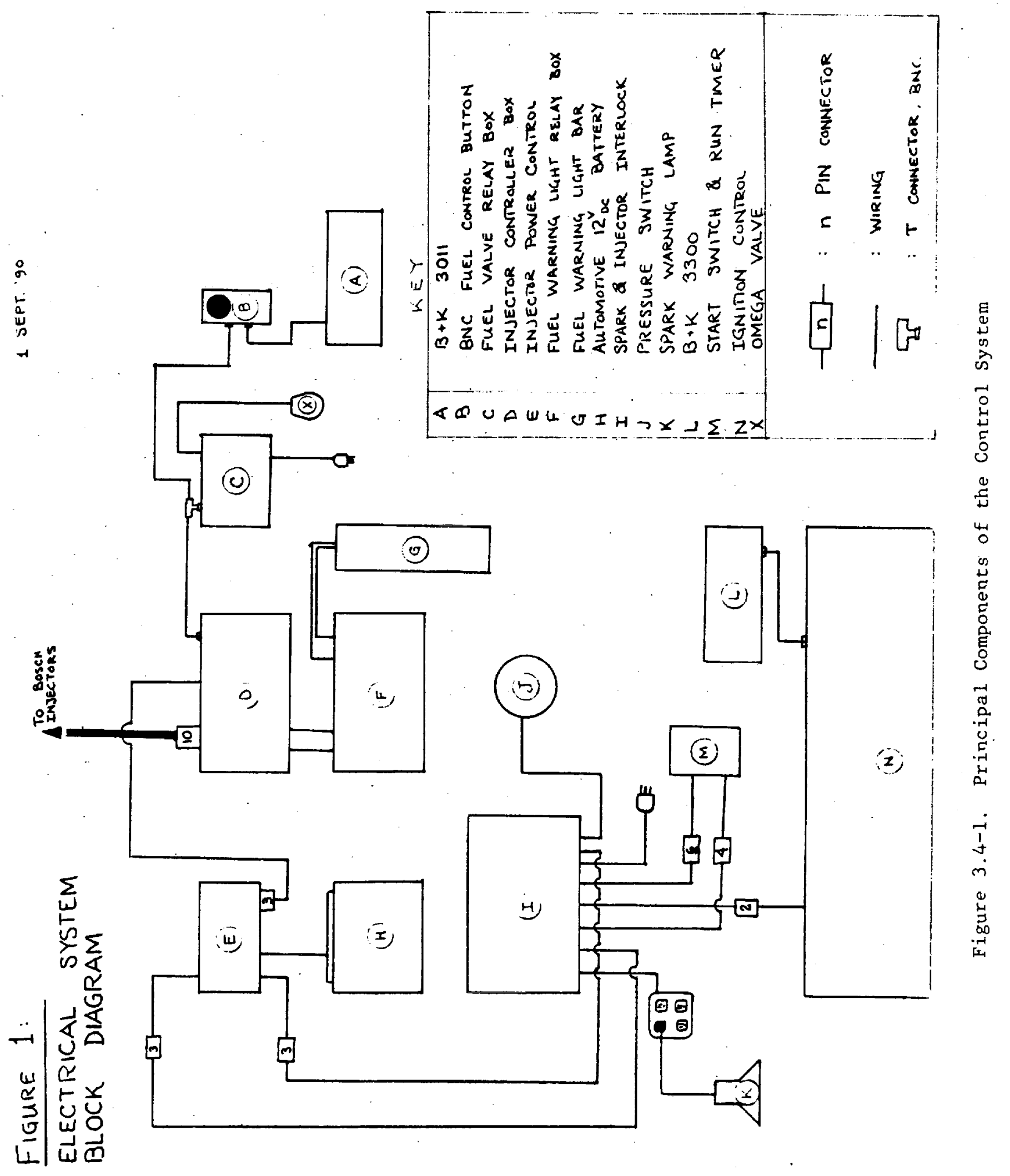


Several important conventions were adopted early in the experiment with regards to the control signals. First, there would be two modes of spark operation, SINGLE SPARK (synchronous mode) and CONTINUOUS SPARK (asynchronous mode). Second, the fuel/spark cycle would be dictated by the fuel signal. That is, the fuel/spark cycle's period is the period of the fuel signal which is defined to start at FUEI ON. Therefore, the SPARK DELAY is the interval between the start of FUEL ON and the start of SPARK ON in single spark mode. The SPARK RATE is the pulse repetition period of the spark signal in continuous spark mode.

Examples of synchronous and asynchronous mode are shown in Figure 3.4-3. The pulse generators, oscilloscope, and the ignition module are shown in Figure 3.4-4.

Operations of the detonation duct was as follows:

1. Air flow is started by the opening of the flow control, air operated, butterfly valve in the main supply line.

2. Simultaneously with the above, a timer (1-10 seconds) is started to enable all circuits and turn the system enabled and armed light on.

3. Air pressure activates the interlock which opens the main propane tank solenoid valve.

4. Pulse generators are started and the spark activation light goes on.

5. Fuel control button is depressed, the fuel warning light goes on, and the final propane solenoid valve is opened so that fuel is injected into the air flow.

6. Release of the fuel control button terminates the test. 
SINGLE, SYNCHRONOUS SPARK

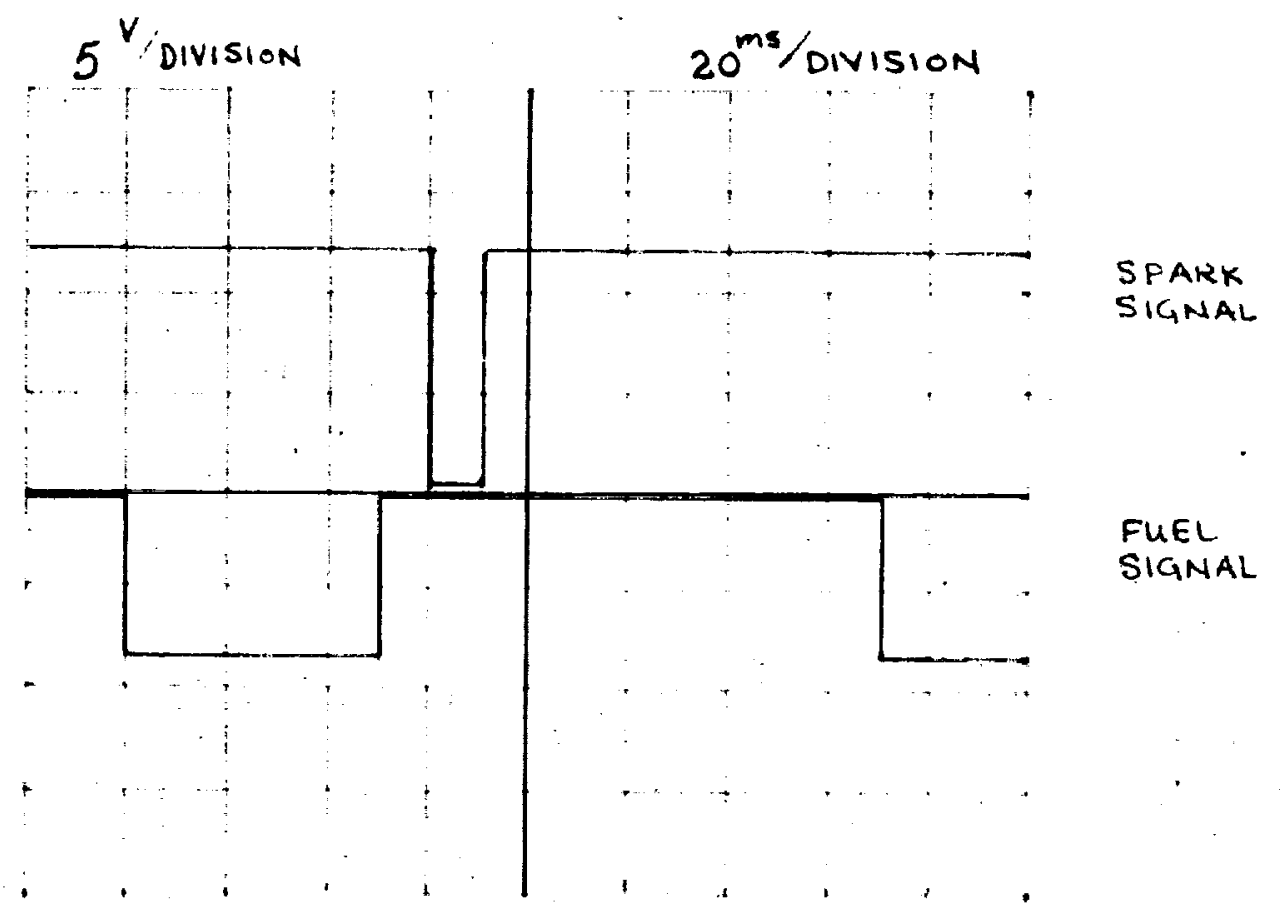

CONTINUOUS, ASYNCHRONOUS SPARK

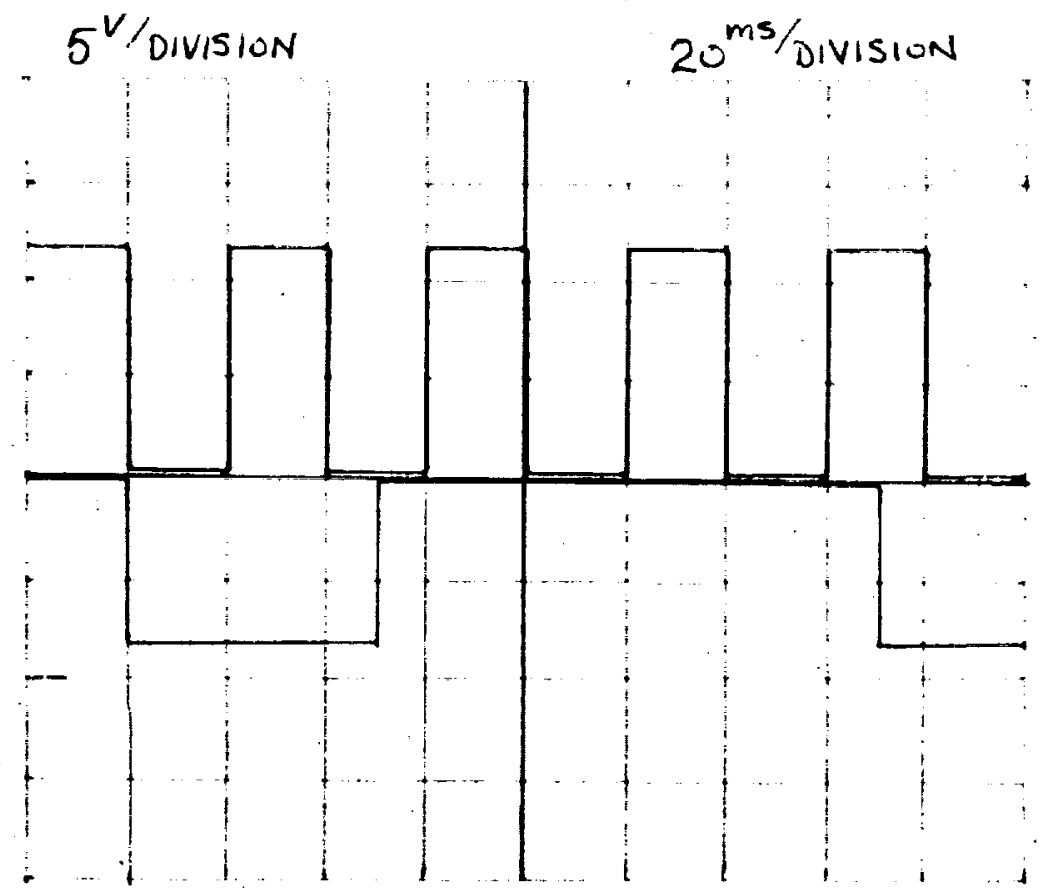

SPARK SIGNAL

FUEL SIGNAL

Figure 3.4-3. Fuel and Ignition Signals

71 
ORIGINAL PAGE

BLACK AND WHITE PHOTOGRAPH
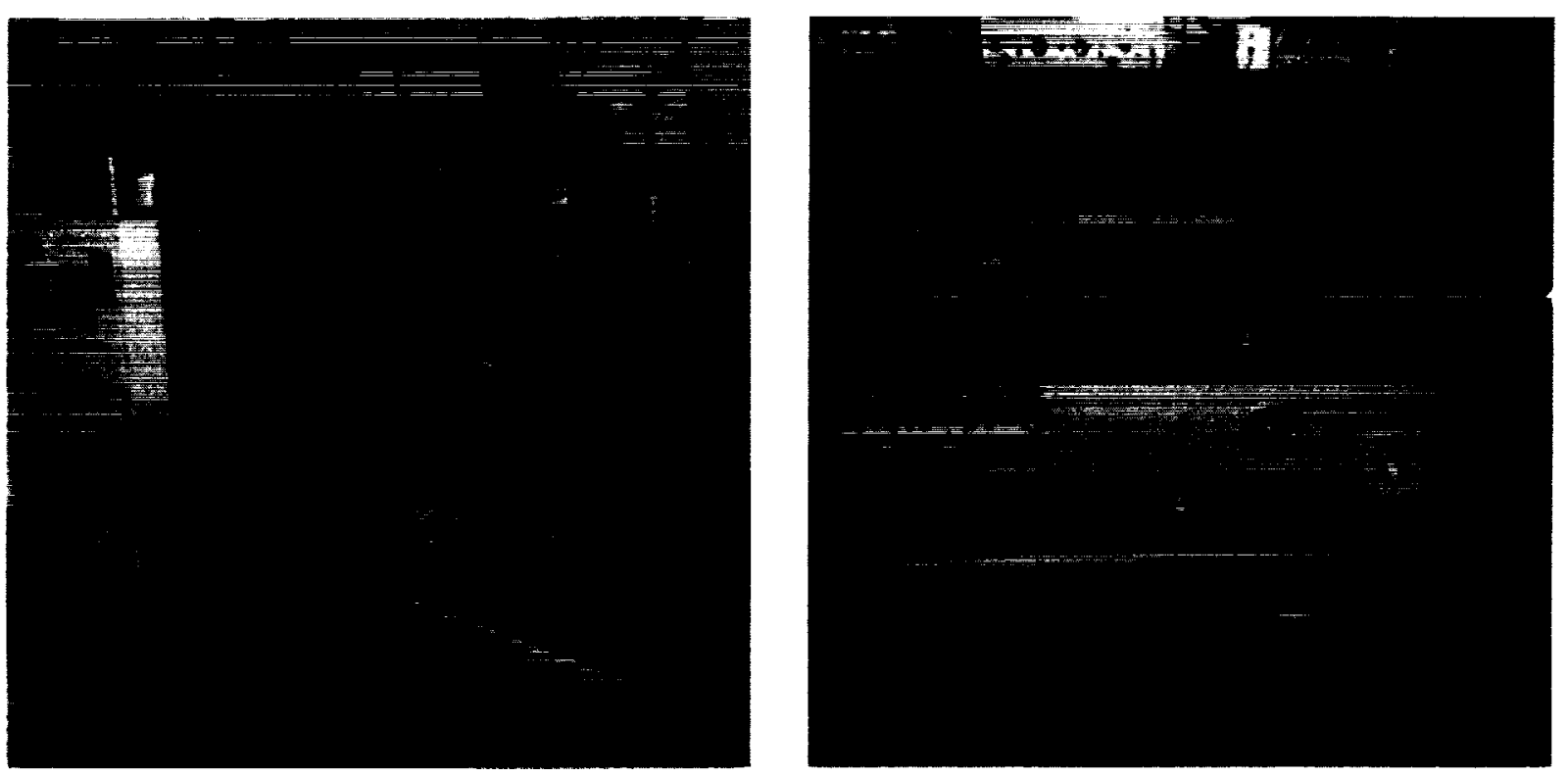

Figure 3.4-4. Controls and the spark Ignition Module 


\subsection{Data Acquisition and Instrumentation}

After several unsuccessful attempts to obtain data acquisition systems on firm, fixed price terms agreed to during the placement of the order, a decision was made to use the oscilloscopes and a small computer to store and process data. The best oscilloscopes for this purpose are the Gould 1604 models which are rated at $10 \mathrm{MHz}$ so that they are far below the usual electronic test equipment requirements and cost, but are more than adequate for any aerodynamics or propulsion testing. These oscilloscopes have 4 channels of $10 \mathrm{kilobytes}$ of memory and a built-in printer/plotter. One of the oscilloscopes was augmented with a Gould Model 260 Waveform Processor Interface and a Processor unit. Both oscilloscopes were equipped with IEEE 488 interface modules and an IEEE 488 card was installed in the computer. Communications between the oscilloscopes and the computer failed with the first Gould software and were only marginal with the new software brought in by Gould 10 days before the termination of the project. It was found that Gould realized that the first software package did not work but could do nothing to improve it because its designer had left Gould to join a competitor. The second rackage was brand new and Gould personnel knew nothing about it. Apparently we were one of the first customers for the new software and even though it could not be made to work properly, we knew more about it than anybody at Gould.

Detonation wave pressures were measured with PCB Type 102A piezoelectric pressure transducers through a 6 channel amplifier. These transducers were rated at $200 \mathrm{kHz}$ so that in principle, adequate resolution of the detonation waves was attainable. A similar PCB transducer installed in a spark plug could not be made to produce believable data. Some doubt was cast on the early results when it was found that that exposure of the transducers to flames could produce a signal which could be interpreted as a pressure wave. sensitivity to combustion was eliminated when the transducer sensing elements were covered with electrical or RTV coating which was able to survive dozens of explosions in the duct. The RTV coating reduced the sensitivity of the transducers, but this was not deemed to be significant in this program. It may be of interest to note that PCB claimed to be unaware of the flame sensitivity of the transducers and had been selling them for engine studies for years. 
Flow measurements were made with validyne DP-15 diaphragm type pressure transducers operating with CD-15 carrier demondulators. These transducers are rated at $1 \mathrm{kHz}$ and are linear over wide ranges of pressures, but unfortunately are extremely sensitive to electromagnetic interference. It proved impractical to use these transducers when the ignition system was functioning.

In addition to the above instruments, which were considered to be of primary importance, a large number of pressure regulators and gages was used in the air supply and control systems. The pressure gages were of the Bourdon type and thus could be used only for steady state, or extremely slowly varying phenomena. 


\section{RESULTS}

The objective of the program was the determination of the frequency and magnitude of detonation waves propagating across transonic flow in a channel. Although it is now known that detonation waves can be initiated at a line or a point, it is most convenient to ignite at a solid surface. In this case the wave, which is formed in a short induction region of transition from deflagration to detonation, is swept downstream by the channel flow while it is propagating transversely to it.

\subsection{Detonation Waves}

The general features of such a flow may be considered in terms of a detonation wave propagating from a solid wall into a stagnant gas because of the invariance of the equations of mechanics under the Newton-Galilei group of transformations. Detonation waves were discussed earlier in this report and here attention will be centered on the field downstream of the wave front. The disiussion here follow's the exposition of stanyukovich for strong detonation waves. In the very strong wave approximation, it can be shown that the principal parameters of the wave are given by:

$$
\begin{aligned}
D / a_{O} & =\left[2\left(k_{1}^{2}-1\right) Q /\left(k_{0}-1\right)\right]^{1 / 2} \\
a_{H} & =k_{1} D /\left(k_{1}+1\right) \\
u_{H} & =D /\left(k_{1}+1\right) \\
p_{H} / p_{O} & =k_{O}\left(D / a_{0}\right)^{2} /\left(k_{1}+1\right)
\end{aligned}
$$

Here, as before, $a, D, p$, and $u$ are acousic and wave velocities, pressure, and gas velocities respectively. Subscript $H$ denotes inertial reference frame.

For stoichiometric propane/air mixture, the fuel fatio is 0.0638 and the heat released is 1270 Btu/lb (Taylor 31 ). With $\mathrm{k}_{0}=1.38, \mathrm{k}_{1}=1.25$, and $\mathrm{Q}=10$, the above quantities are:

$$
\begin{array}{ll}
\mathrm{D} / \mathrm{a}_{O}=5.44 & \mathrm{a}_{\mathrm{H}} / \mathrm{a}_{O}=3.02 \\
\mathrm{u}_{\mathrm{H}} / \mathrm{a}_{\mathrm{O}}=2.42 & \mathrm{p}_{\mathrm{H}} / \mathrm{p}_{\mathrm{O}}=18.2
\end{array}
$$


These are in fair agreement with the results of exact calculations presented elsewhere in this report. A method of characteristics solution for the field between the wave front and the wall, at which the detonation was initiated, yields

$$
\begin{aligned}
& \mathrm{u}=2(\mathrm{x} / \mathrm{t}-\mathrm{D} / 2) /\left(\mathrm{k}_{1}+1\right) \\
& \mathrm{a}=\left[\left(\mathrm{k}_{1}-1\right) \mathrm{x} / \mathrm{t}+\mathrm{D}\right] /\left(\mathrm{k}_{1}+1\right)
\end{aligned}
$$

These equations show that at the mid point of field, $x=D t / 2$

$$
\mathrm{u}=0 \quad \mathrm{a}=\mathrm{D} / 2
$$

which indicates that a rarefaction wave, which is necessary to satisfy the condition $u=0$ at the wall, stagnates the flow up to half the field behind the wave front

$$
a / a_{H}=\left(k_{1}+1\right) / 2 k_{1}=\left(T / T_{H}\right)^{1 / 2}
$$

Therefore, the stationary field is at a pressure and temperature ratios relative to the immediate downstream values of the wave front of 0.81 and 0.35 respectively. The forms of the functions are shown in Figure $4.1-1$.

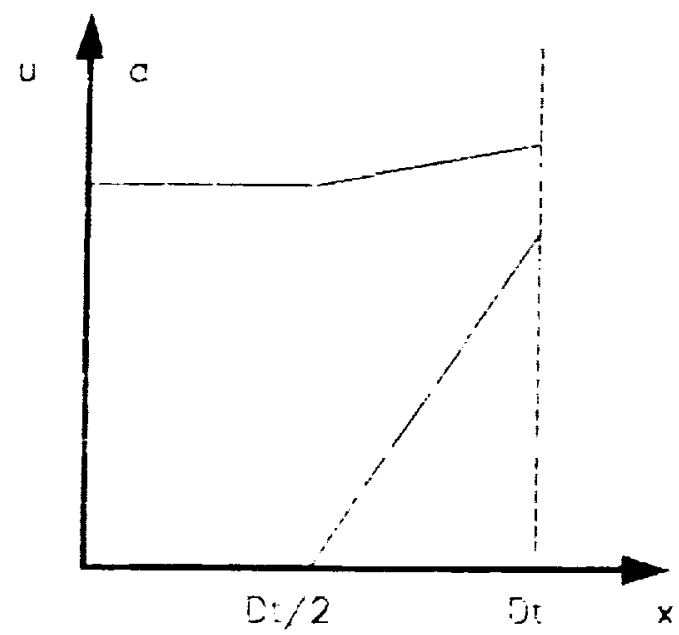

Figure 4.1-1. Forms of the Functions 
It is shown in stanyukovich ${ }^{4}$ that when a strong detonation wave is reflected from the wall, as is the case here, then

$$
\begin{aligned}
& \mathrm{p}_{2} / \mathrm{p}_{\mathrm{H}}=\left(5 \mathrm{k}_{1}+1+\mathrm{K}\right) / 4 \mathrm{k}_{1} \\
& \mathrm{D}_{2} / \mathrm{D}_{\mathrm{H}}=\left(\mathrm{k}_{1}-3 \mathrm{~K}\right) / 4\left(\mathrm{k}_{1}+1\right) \\
& \mathrm{k}
\end{aligned}
$$

with $k_{1}=1.25$

$$
\begin{array}{ll}
\mathrm{p}_{2} / \mathrm{p}_{\mathrm{H}}=2.55 ; & \mathrm{p}_{2} / \mathrm{p}_{0}=46.4 \\
\mathrm{D}_{2} / \mathrm{D}_{\mathrm{H}}=-0.415 ; & \mathrm{D}_{2} / \mathrm{a}_{0}=-2.26
\end{array}
$$

These are initial values which change as the reflected wave moves into non-uniform field in the detonation wave.

In the present program, it proved impossible to discern any reflected waves, even though wave speeds of Mach 2.2-2.7 were measured.

\subsection{Pressure Measurements}

The bulk of the data obtained in this program consisted of the presisure pulses in the detonation duct and the forward and rear plenums, or transition sections. The various experiments performed in support of the main program objectives are presented in Appendix B. Since the pressure transducers were rated at about $200 \mathrm{kHz}$, there were no problems with resolution of the variations of pressures within the duct. Most of the data shown here were obtained with the flow control ball valve at around $80^{\circ}$ which restricted the flow significantly so that the channel Mach number was well under 0.5. As long as the air supply was highly restricted by the ball valve, the flow rates were so low that the pressure in the detonation duct was only slightly above ambient. Under these conditions, the pressure in the supply tank did not seem to influence the results in any discernible way. Because of this, it is not possible to develop any correlations in terms of supply pressure or ball valve opening angles. In general, it was easier to adjust the duration of fuel injection and spark delay at lower frequencies to obtain higher pressure pulses. This is reflected in the trends presented below. 
Because of the difficulties encountered in the procurement of a data acquisition system, the pressure traces exhibited here are taken directly from the oscilloscope printers. An example of $\mathrm{l} \mathrm{Hz}$ tests is shown in Figure 4.2-2. In this case, the flow in the duct was at about Mach 0.5 . The magnitudes of the pressure pulses are somewhat high because at the time of these tests, the protective coatings for the pressure transducers' sensing elements had not been fully developed and the data exhibit the influence of the response of the transducers to the exposure to flames. These data are shown as examples of cyclic operation and are not used in the data base accompanying this report. Tests indicated that single pulse or $1-2 \mathrm{~Hz}$ operation produced essentially identical results. Examples of tests at 7-8 $\mathrm{Hz}$ are shown in Figure 4.2-3. The upper trace shows pressure pulses and the automotive fuel injectors signals. Downward drift of the pressure signals is due to the effect of rising temperatures on the pressure transducers signal levels. Operation of the injectors at higher frequencies produced irregular pressure pulses due to fuel starvation. Examples of single pulse operation with a very short injection period of the solenoid valve opening are shown in Figure 4.2-4. With lower injection period, the valve did not deliver a sufficient quantity of fuel and the pressure pulses were weaker.

All the data from the final phase of the project which were considered to be reliable are summarized in Figure 4.2-5. The data are plotted as pressures against an arbitrary sequence number to display the number of data points for each instrumentation port. The results presented range from misfires with virtually no increase in pressure to explosions in the converging section of the plenum of the old duct (Location \#4). Correlations of pressures at various locations for a particular experiment are given in the data base in Appendix $D$.

The data show considerable scatter and therefore it is of interest to establish variances. This is done for pressures and pressure ratios (referred to 15 psia) for the old and the new duct in Figures $4.2-6$ and $4.2-7$ respectively. In these Figures, the distances are arbitrarily referred to the intake flange at its junction with the bottom of the duct, where the spark plugs were located. With $x$ and $y$ being the axial distance and vertical height respectively, the following dimensions were used: 
Old Duct

\begin{tabular}{|c|c|c|c|c|c|c|c|}
\hline LOC & $x$ & $y$ & $d$ & LOC & $x$ & $y$ & $d$ \\
\hline $\begin{array}{l}4 \\
13 \\
14 \\
17 \\
20 \\
21 \\
\text { Spark }\end{array}$ & $\begin{array}{r}-8 \\
10 \\
10 \\
14 \\
18 \\
18 \\
6\end{array}$ & $\begin{array}{r}10.0 \\
2.0 \\
6.0 \\
6.0 \\
6.0 \\
10.0\end{array}$ & $\begin{array}{r}-12.8 \\
10.2 \\
11.7 \\
15.2 \\
19.0 \\
20.6\end{array}$ & $\begin{array}{c}1 \\
2 \\
7 \\
\text { Int } \\
\text { Exh } \\
\text { Spar }\end{array}$ & $\begin{array}{l}29 \\
35 \\
45 \\
-6.5 \\
56.0 \\
28\end{array}$ & $\begin{array}{r}6 \\
10 \\
6 \\
11 \\
11\end{array}$ & $\begin{array}{r}29.6 \\
36.4 \\
45.4 \\
-12.8 \\
57.1\end{array}$ \\
\hline
\end{tabular}

All distances are in inches and negative values are assigned to the plenum (IOC. \#4) and the transition section (Int.) which are upstream of the reference point. Spark denotes the distance to the first spark plug in a linear, maximum density, array of spark plugs.

The data in Figures $4.2-6$ and $4.2-7$ are displayed as averages and averages plus and minus the standard deviations. The new duct with I" channel width shows higher pressures. Both ducts show maximum pressures short distances downstream of the location of the first spark plug which means that maximum pressures occurred immediately above the array of spark plugs. It is of interest to note that both ducts indicate lowest pressures downstream of the spark plugs and rising pressures in the exhaust sections. 
12 JAN 90

DATE.DE UDU UE

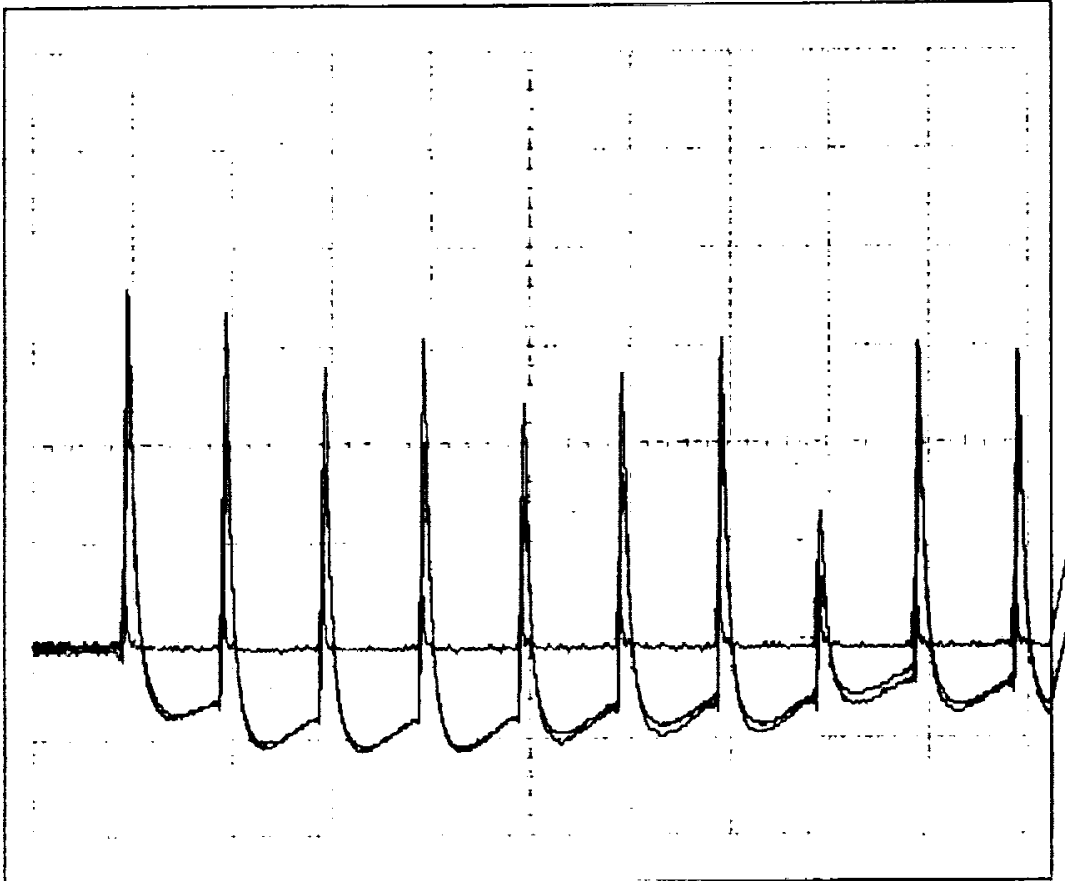

TIME +45

$\mathrm{CH} 1: 02.0 \mathrm{~V}$ : $1 \mathrm{~s}$

50 PSI/DIVISION

$\mathrm{CH} 2: 02.0 \mathrm{OU}: 1 \mathrm{~s}$

SO PSI/DIVISION

CH3: 02.0U : 1s

$10 \mathrm{PSI} / \mathrm{DIVISION}$

FUEL: $100^{\mathrm{ms}}$

SPARK: $80^{\mathrm{ms}}$

PER 10D: $1000 \mathrm{~ms}$

SPARKPLUGS

SPACED

EVERY OTHER

PLuG.

$77 \frac{1}{2}$ VALVE ANILE

12 JANSO

OATE:UE OUE VE
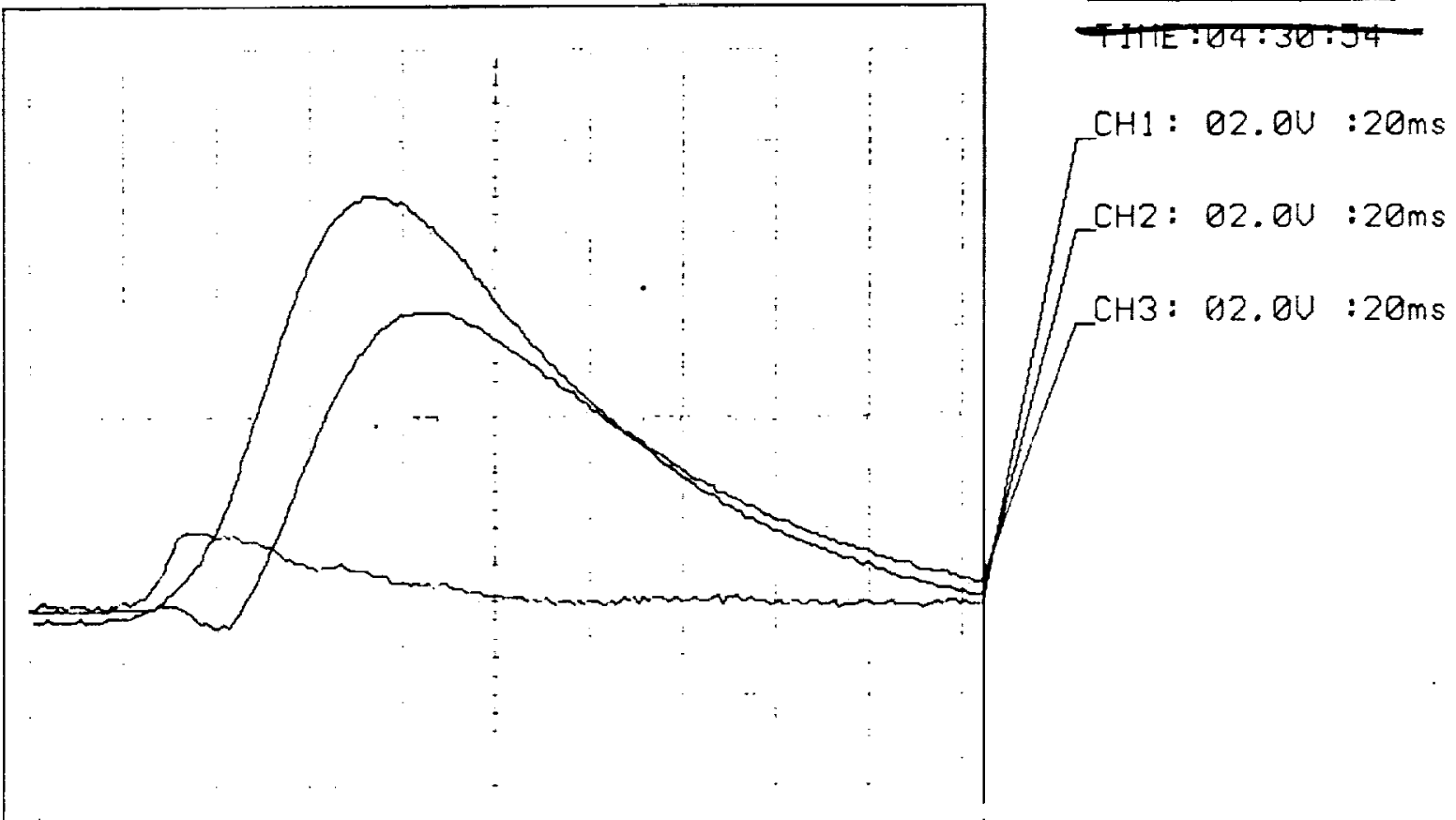

Figure 4.2-2. Example of Low Frequency (I Hz) Duct Operation Pressure Pulses. Lower Figure Shows Expaned Time Scale 
DATE :00 000 00

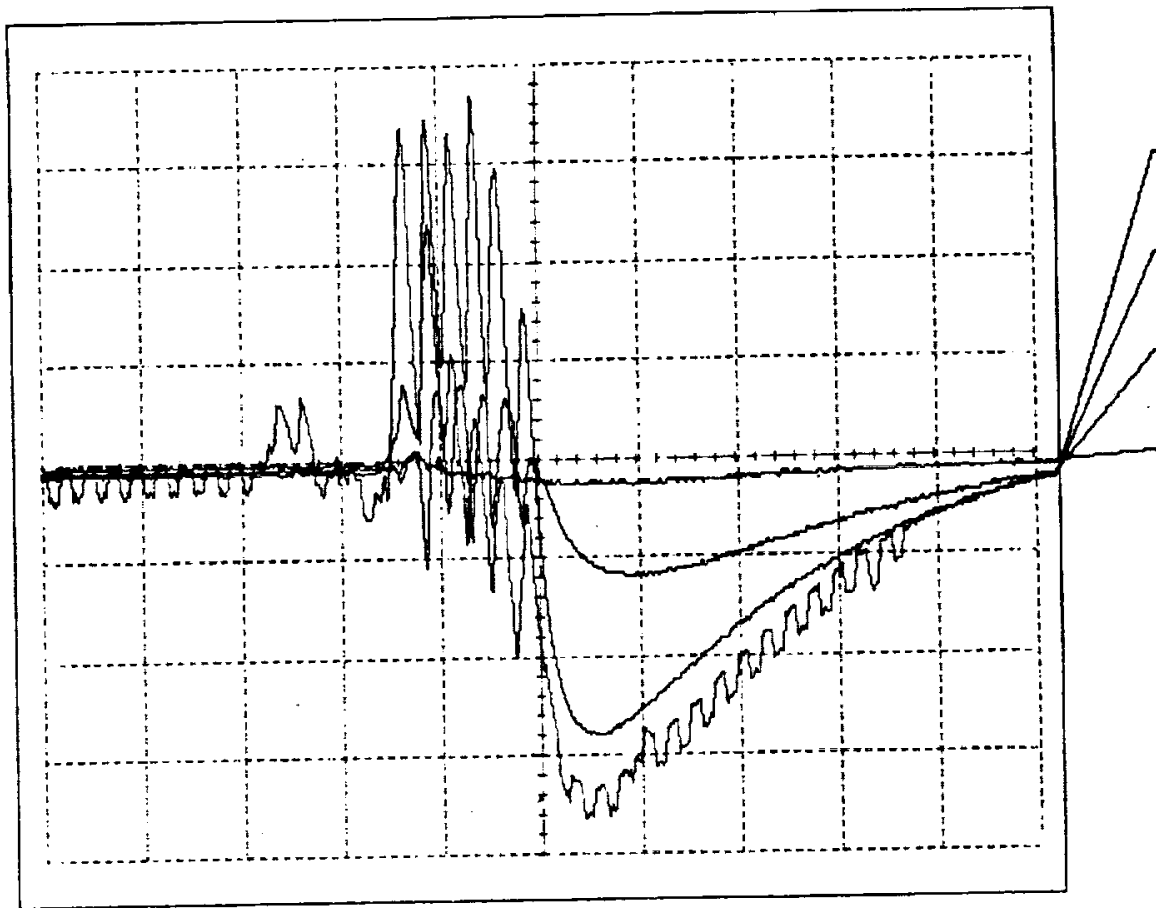

TIME :02:19:47

$\mathrm{CHI}: 1.00 \mathrm{U}: 500 \mathrm{~ms}$ Note 1

$\mathrm{CH} 2: 1.00 \mathrm{OU}: 500 \mathrm{~ms}$ NOTE2

$\mathrm{CH} 3: 1.00 \mathrm{OU}: 500 \mathrm{~ms}$ Note 3

$\mathrm{CH} 4: 1.00 \mathrm{U}: 500 \mathrm{~ms}$ NOTE $A$

\section{0}

\section{प}

DATE: NoU $18 / 89^{\circ}$

TIME : $18: 34: 20$

$\mathrm{CH} 1: 05.0 \mathrm{OU}: 100 \mathrm{~ms}$

NOTE 6

$\mathrm{CH} 2: 05.0 \mathrm{U}: 100 \mathrm{~ms}$ $N$ ore 7

CH3: 22.0U : $100 \mathrm{~ms}$ NOTE 8

$\mathrm{CH} 4: 1.00 \mathrm{~N}: 100 \mathrm{~ms}$ NoTE 9

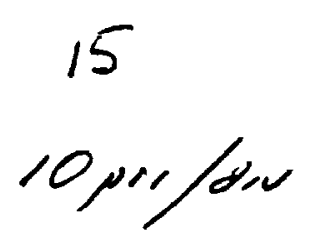

Figure 4.2-3. Pressure Pulses in High Frequency Operation $(7-9 \mathrm{~Hz})$. Lower Figure Shows Expanded Time scale 


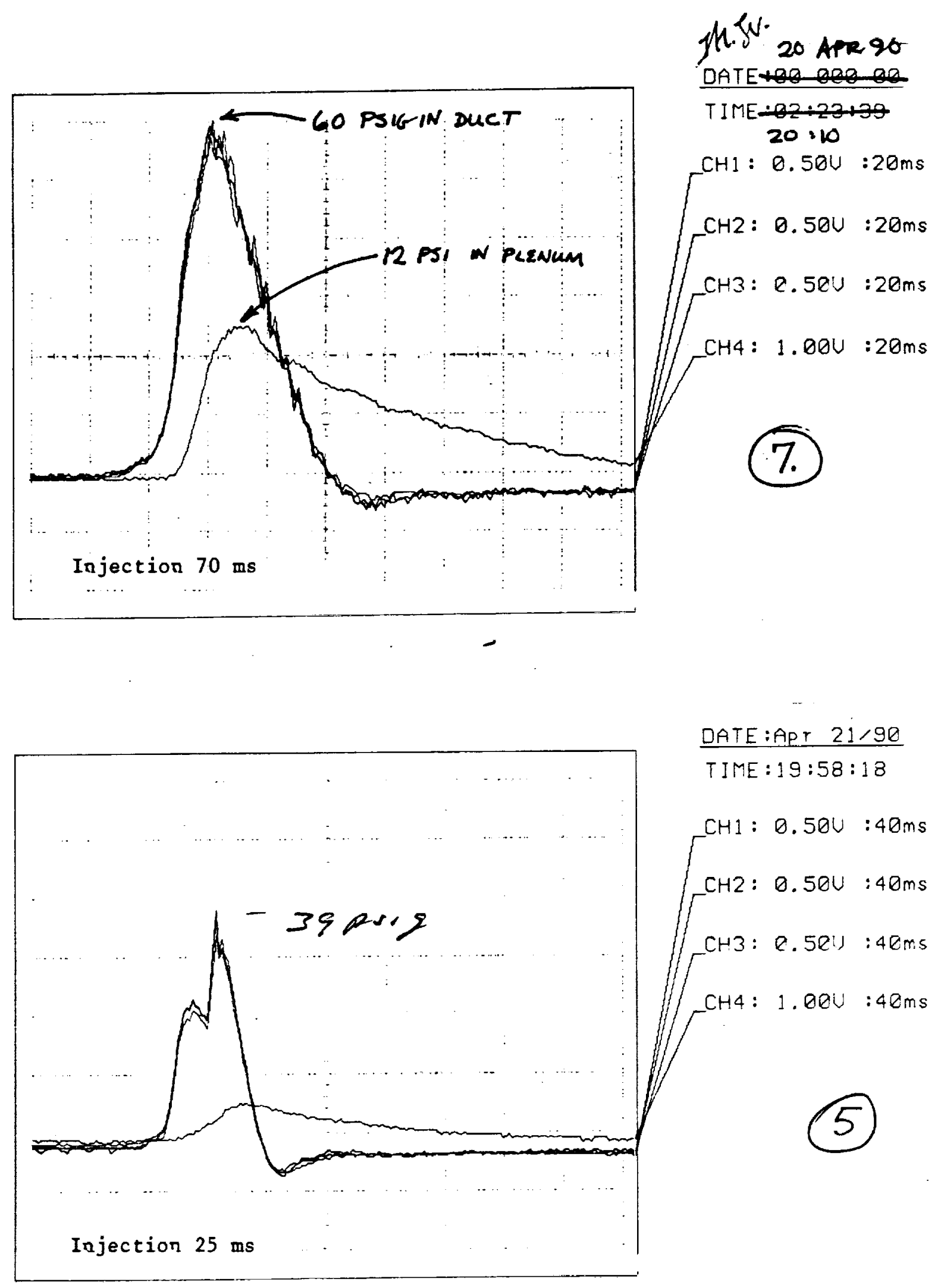

-

Figure 4.2-4. Single Pulse, short Fuel Injection Operation 


\section{IASA DDGG EXPERIMENTS \\ old Duct - Summary}
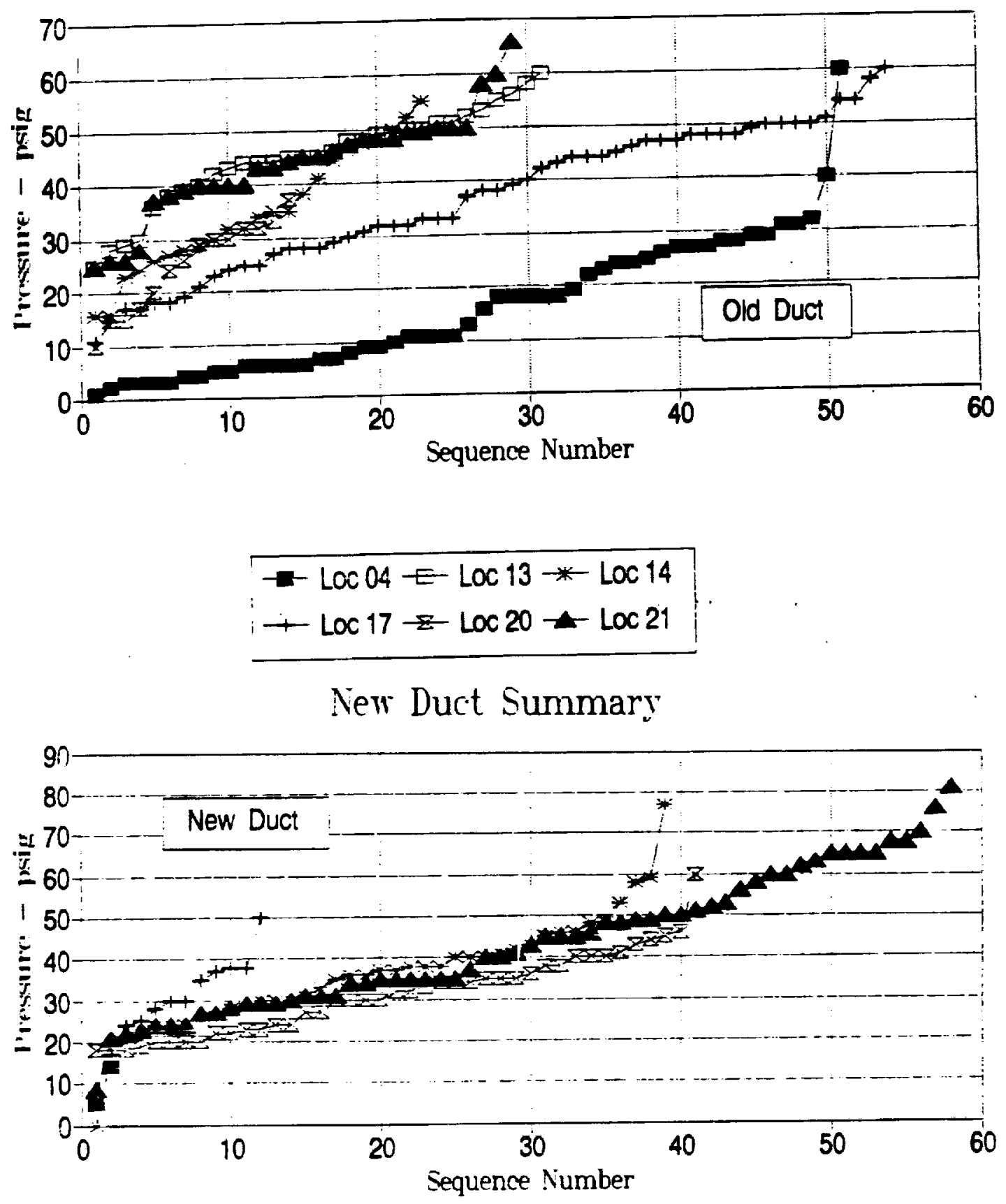

\begin{tabular}{l}
- Pos $\# 1+$ Pos $\# 2 \rightarrow-$ Pos $\# 7$ \\
$\rightarrow$ Int. $\approx$ Exh. \\
\hline
\end{tabular}

Figure 4.2-5. Summary of Maximum First Pulse Pressures at Various Locations 
$\underset{\text { New Duct Configuration }}{\text { NASA DDGG EXPERIMENTS }}$

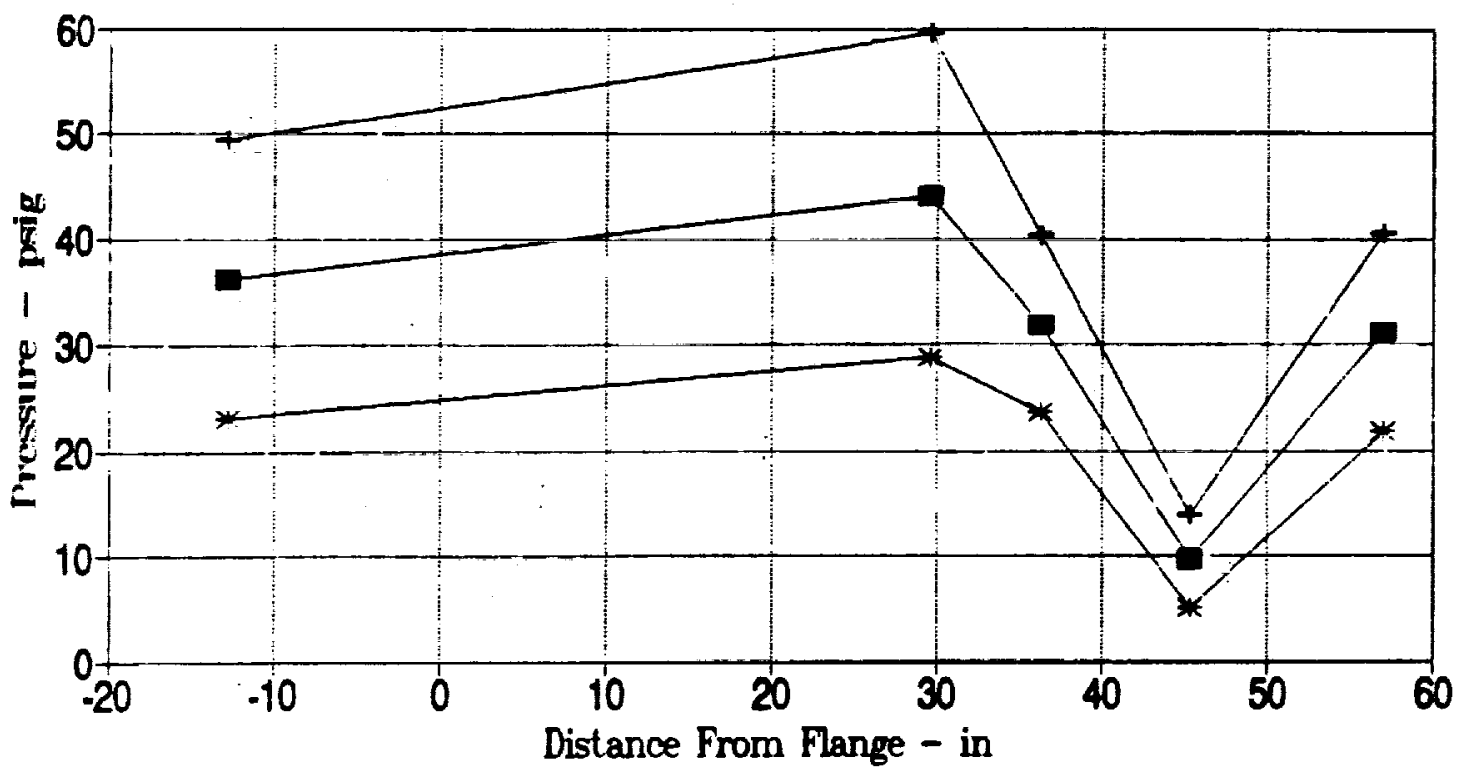

- Ave + Ave + SD $*$ Ave - SD
New Duct Configuration

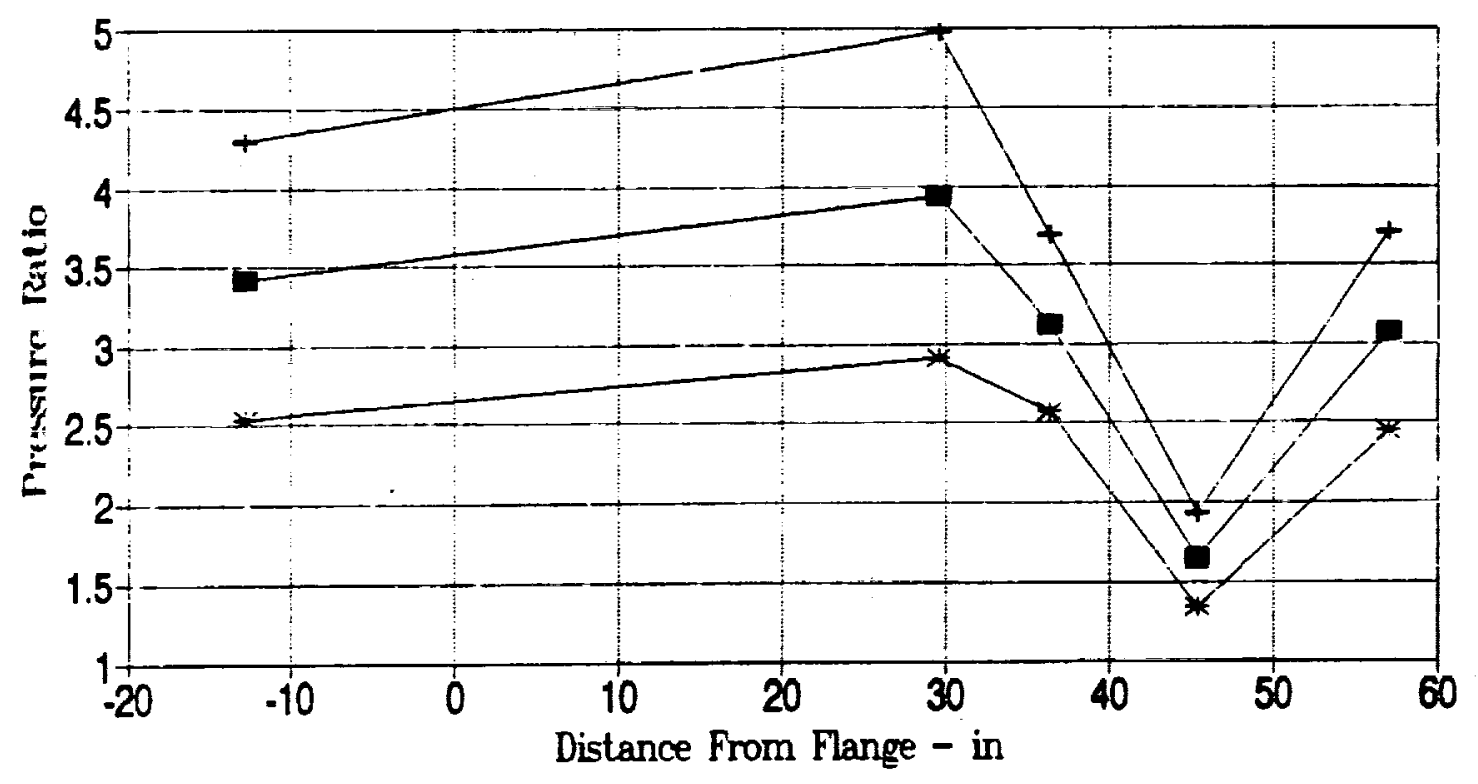

- Ave + Ave + SD * Ave -SD

Figure 4.2-6. Average Pressures and Standard Deviations in the New Duct 


\section{NASA DDGG EXPERIMENTS old Duct Configuration}

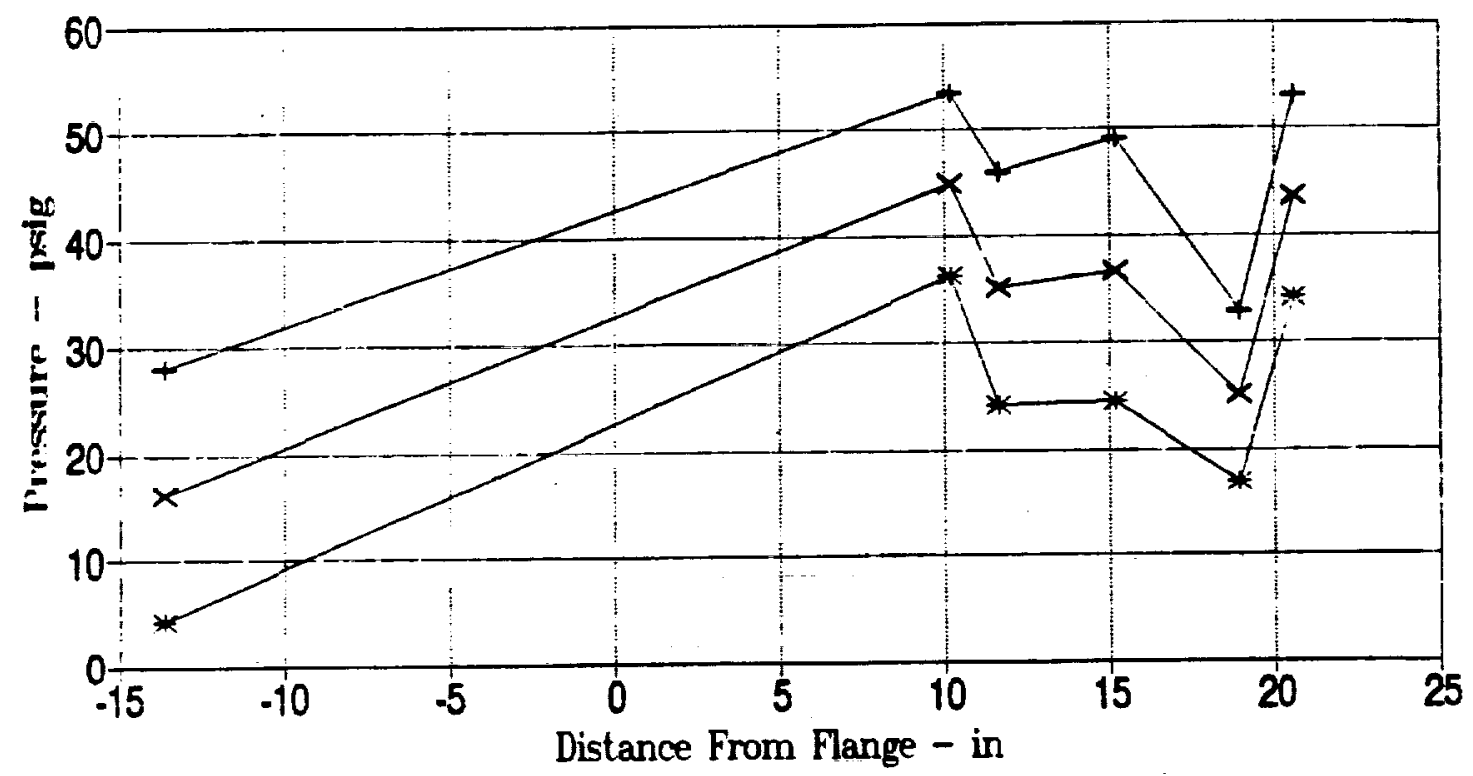

$*$ Ave +Ave + SD * Ave -SD

old Duct Configuration

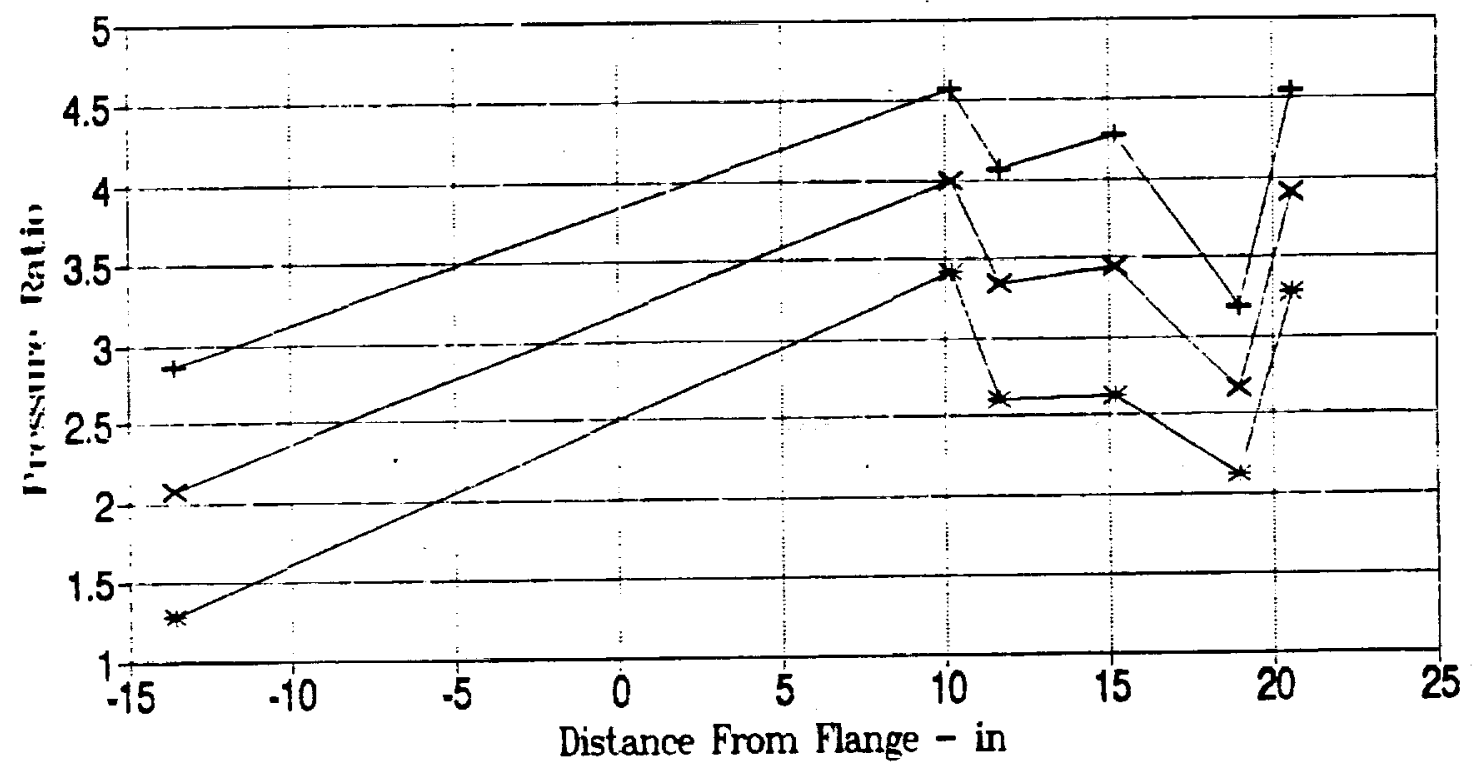

$$
* \text { Ave } \rightarrow \text { Ave }+ \text { SD } \rightarrow \text { Ave -SD }
$$

Figure 4.2-7. Average Pressures and standard Deviations in the old Duct 


\section{DISCUSSION OF THE RESULTS}

The present program was the culmination of a series of projects in the development of the concept of compression of gases by transverse detonation waves in transonic channel flows. Initial studies established the advantages of the concept and described the extremely complex gas dynamic phenomena involved in terms of simplified models which were used to estimate the maximum power output of a transverse wave detonation duct. At the same time, simple experiments were performed which indicated that pressure ratios of 10-12 were attainable. In a preliminary experimental study, higher air speeds were attempted and injection of propane/air mixtures produced encouraging results. In this program, the intent was to establish the air flow at approximately Mach $I$ and to inject liquid propane at frequencies up to $200 \mathrm{~Hz}$. The latter was chosen on the basis of previous studies which showed that the theoretical limit was under $300 \mathrm{~Hz}$.

The only commercially available injectors capable of such frequencies were the standard automotive gasoline fuel sequential injectors. Estimates based on the use of such injectors in very high speed racing engines showed that with propane vapor pressures of around $140-160$ psig at least 16 injectors would be needed to supply sufficient fuel for Mach 1 flows in the $1 " x 12$ " detonation duct. These injectors are designed to operate at fuel pressures of $30-35$ psig and frequencies under $150 \mathrm{~Hz}$. - Racing engines operate these injectors at $60-70 \mathrm{psig}$, but orly for relatively short periods. When operated at around $160 \mathrm{psig}$, the injectors could not open completely and insufficient fuel flow rates were obtained. Also, with high fuel pressures, the response of the injectors proved to be erratic at higher frequencies, particularly as their solenoids started to fail progressiveIy. The plastic tips of the injectors proved to be excellent flameholders and continued to burn long after the injection pulses stopped. This led to frequent explosions when the fuel injection was restarted. When the injectors experienced fatigue of their solenoids and springs, the fuel continued to leak and the burning plastic tips ignited it. The plastic tips were removed so that only steel nozzle and printle were exposed, but the leakage problems of aging injectors could not be rectified and frequent replacements proved to be necessary. A solenoid valve with a 1/8" throat, 200 psig operating pressures, and a frequency rating of $50 \mathrm{~Hz}$ was 
procured as a replacement for the failing fuel injectors. Tests indicated that the valve should have been rated more realistically at $5 \mathrm{~Hz}$ and was completely reliable only when it was opened at about $1 \mathrm{~Hz}$ with injection periods of about $50 \mathrm{~ms}$. Scheduling and resources limitations prevented the development of a reliable large capacity fuel injection valve capable of operating at around $10 \mathrm{~Hz}$. The real imitation on operating frequencies was not so much the valve as the length of line between the valve and the port in the plenum or the duct. After the valve closed, fuel in the line continued to flow into the system and occasionally multiple pressure pulses could be developed from a single fuel injection. This type of work requires a large fuel injector located directly in the duct and closing at its tip to prevent leakage after the injection pulse is terminated. Also, such an injector must be able to generate sprays of extremely fine droplets which will evaporate rapidly.

The high scatter in the data is caused by problems with the fuel injection system and the extreme difficulties encountered with the mixing of propane with air. Injection of propane vapor proved impractical because even with the relatively large valve, it was not jossible to transfer sufficient quantities of fuel to the air stream during the injection period. Liquid injection proved to be extremely difficult because the propane vapor expanding from the nozzle reached speeds corresponding to about Mach 2 and propelled the liquid droplets over very large distances from the injection point. When automotive fuel injectors were used, these droplets were very small and therefore travelled over relatively short distances before they evaporated. The relatively large solenoid valve expelled large droplets which travelled upstream into the plenum where they evaporated and the mixture was ignited by the flames in the detonation duct. Use of a less volatile fuel. such as gasoline or jet fuel is not practical because the evaporation rate is too low and liquid fuel accumulates in the system and ultimately results in very powerful explosions. This would not be a problem if air could be taken directly from the compressor because its high temperature would have evaporated the fuel very rapidly.

Mixing of propane with air proved to be a far greater problem than could have been predicted from the low speed tests performed in the previous experiments. When automotive fuel injectors were used, evaporation of the very small droplets and the mixing of the vapor with air, did not seem to present any problems. However, at higher air flow speeds, 
the injectors could not deliver an adequate flow of fuel and the fuel-lean mixtures could not be ignited. When the injectors were pulsed at frequencies of 25-50 $\mathrm{Hz}$, volumes of nearly stoichiometric fuel/air mixture would be created randomly and the detonations could not be correlated with either the fuel injection, or ignition. Injection through the solenoid valve in the plenum proved impractical because the expanding propane vapor would distribute the propane droplets throughout the plenum and an explosion would follow. This was the cause of the destruction of the plenum and consequent abandonment of the old duct. Injection in the duct created large clouds of propane vapor, which could not mix with the air flowing through the narrow channel. When the mixing finally occurred in the collector or the mufflers, explosions would occur in the exhaust system. This caused the destruction of the acoustic module in the experiment which terminated the program.

High air flow rates could not be attained because the automotive injectors could not supply sufficient fuel and fuel injected through the solenoid valve did not have sufficient time to $\mathrm{mix}$ adequately with air when the ignition occurred. Because of the low air velocities, pressure pulses were able to propagate into the plenum. Attempts to improve mixing by blocking the duct inlet with perforated plates proved unsuccessful because the very high speed jets emanating from the plate openings had very short residence times in the duct and could not $\mathrm{mix}$ with the injected fuel. Equally unsuccessful were attempts to use screens at the duct inlet to generate turbulence which would enhance mixing. These screens retained fuel and flames and caused serious damage to the plenum of the old duct. Deflector plates in the duct were used to generate large volumes of separated flow whose large vortices should have enhanced mixing. No significant improvement in performance was gained with these deflectors. significant improvement in repeatability was achieved when a jet of hot compressed air taken directly from the air compressor's own tank was directed at the injected propane.

Both ducts attained maximum average pressure ratios of about 4 with a standard deviation of about $11 \%$ for the old duct and $20 \%$ for the new one. Because of the much lower area ratio of the new duct, the pressures recorded in the entrance region were much higher than those in the old duct. Both ducts show that maximum pressures occurred in the region immediately above the spark plugs. The mean maximum pressures are a fraction of the values expected from theoretical calculations and previous tests. The measured wave speeds of Mach 2.2 - 2.5 are about half the expected values. These 
values are approximately equal to the pressure ratios measured in the combustion bomb where the theoretical values should have been approximated quite well. Also, these values are $1 / 3$ to $1 / 2$ of those measured in the original duct tests. It is unlikely that there was something wrong with the fuel because propane is sold commercially in fairly pure form.

The combustion bomb tests suggest that the low pressure ratios must have been caused by the fuel or instrumentation. However, shock tube tests indicate that the instruments were operating properly because theoretical values were approximated very closely. At present, no explanations for the low pressures can be suggested. 


\title{
6. CONCLUSIONS AND RECOMMENDATIONS
}

\begin{abstract}
The program demonstrated that transverse detonations can be generated in high speed channel flows. Even though the pressure ratios are less than half of what was expected, careful adjustments of fuel flow and ignition delay would yield trains of regular pressure waves. With the shock tube tests confirming the accuracy of the pressure transducers, the low pressures attained here in the ducts and the combustion bomb are rather puzzling. This is reinforced by the fact that special tests in the original duct showed levels of pressure which were only about half of those measured previously. The possibility of poor fuel quality could be suggested, but it is difficult to accept that premise at this time. Injection of liquid propane through large injectors propels relatively large droplets over large distances and should not be attempted in the future.
\end{abstract}

The program attempted to develop a prototype which could be readily related to components of an advanced gas turbine. While the principal objectives of the program were achieved and trains $0 .:$ detonation waves could be generated, neither the pressure ratios nor firing frequencies, expected on the basis of previous work, were achieved. The problems have been traced to the mechanism of injection and mixing. Further advancement of the concept of detonation wave augmentation of gas turbines requires the solution of the injection and mixing problems.

It is recommended that the next program concentrate on these problems rather than attempt the much more ambitious undertaking of prototype development. 


\section{IIST OF SYMBOLS}

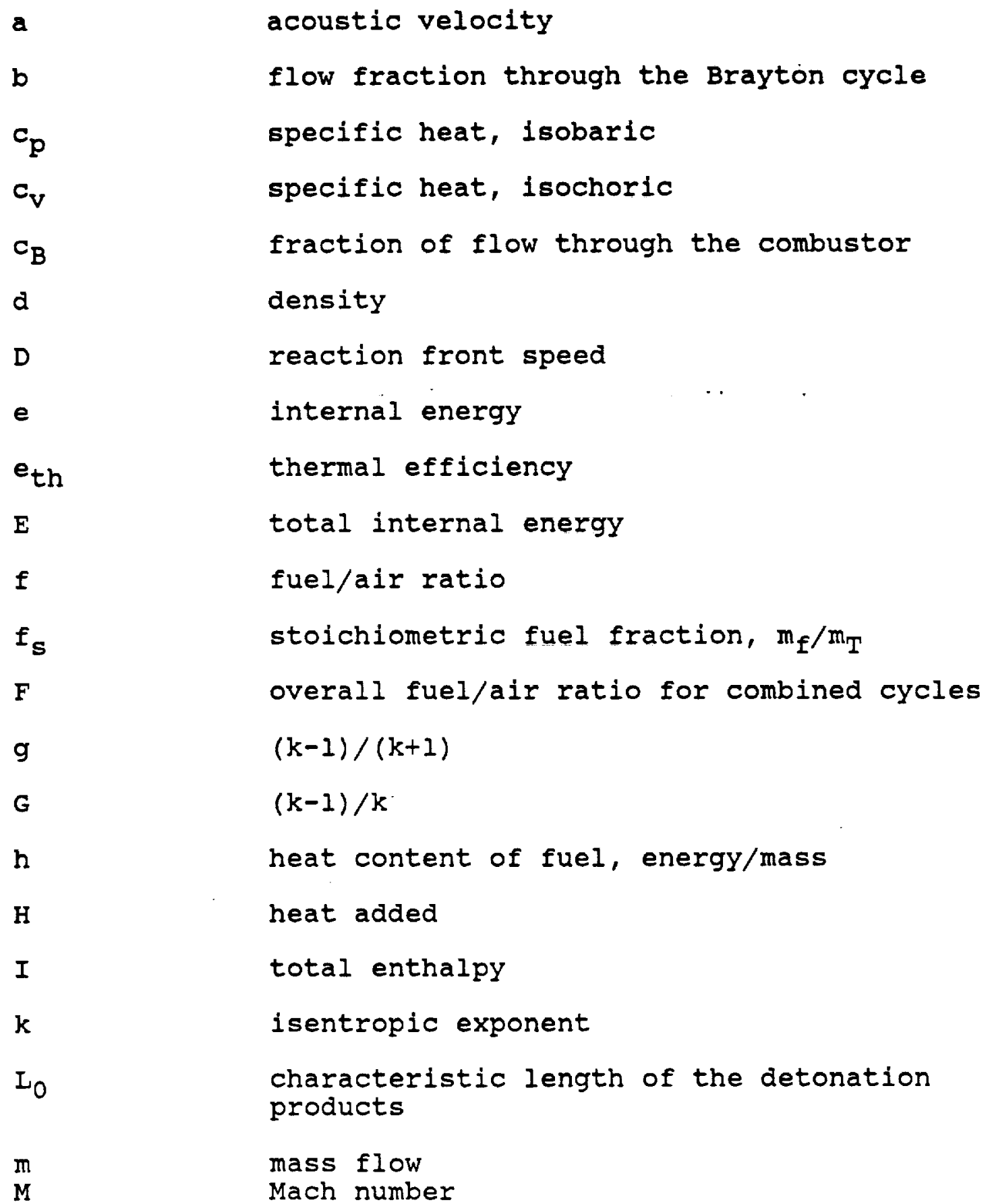




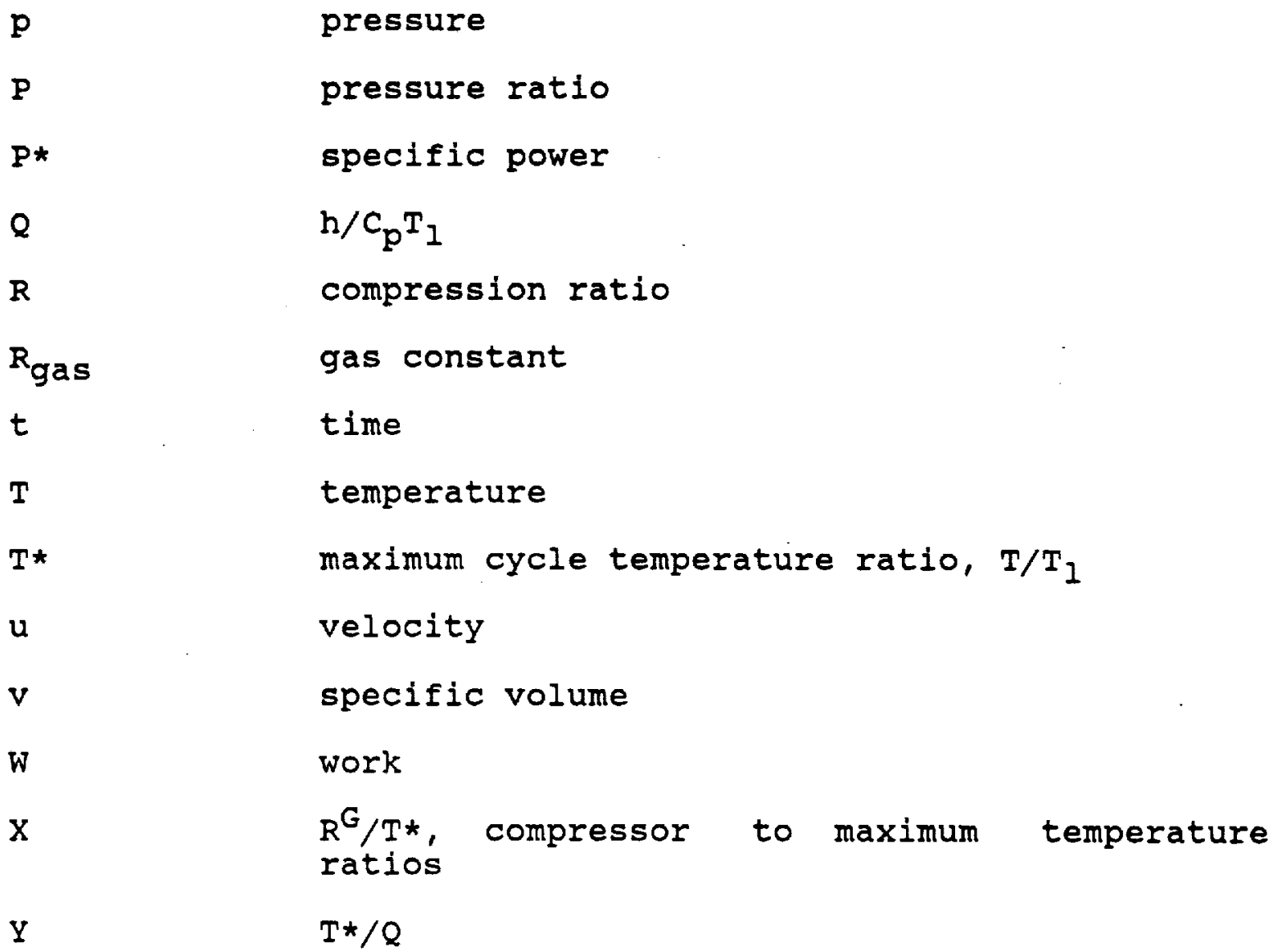




\section{Subscripts}

0

1

$a b$

c

D

e

$\mathbf{f}$

$\mathrm{H}$

N

r

$\mathbf{s}$

S

t

$\mathrm{T}$ upstream

downstream

ratio at a to that at $b$

compressor

detonation

expended detonation products

fuel

inertial coordinate reference

net

reaction

stoichiometric

shock processed flow

turbine

total or stagnation 


\section{REFERENCES}

1. Kirillin, V.A., Sychev, V.V. and Sheindlin, Enqineering Thermodynamics, Mir Publishers, Moscow, USSR, 1981 pp 353-370.

2. Ocheduszko, S., Termodynamika Stosowana, WNT, Warsaw, Poland, 3rd Ed., 1970, pp 520-530.

3. Courant, R. and Friedrichs, K.0., supersonic Flow and Shock Waves, Interscience Publishers, New York, 1948, Ch. III, Pt. E.

4. Stanyukovich, K.P., Unsteady Motion of Continuous Media, Pergamon Press, New York, 1960.

5. Wortman, A., Detonation wave Compression in Gas Turbines, Final Report on NASA Contract NAS3-24854, Report IST-NAS-07-84-01, ISTAR Inc., Santa Monica, CA, 1984 .

6. Berthelot, M., "Sur la Vitesse de Propagation des Phenomenes Explosifs dans les gas," Comptes Rerdus, de l'Academic des sciences, Paris, pp. 18-22.

7. Mallard, E., and Lechatelier, H., "Sur la Vitesse de Propagation de L'inflammation dans les Melanzes Explosifs," Comptes Rendus, de l'Academic des sciences, Paris, pp. 145-148, July 18, 1881.

8. Chapman, "On the Rate of Explosion in Gases," Phil. Mag., 1899, vol. 47, p. 90.

9. Jouguet, E., "Sur la Propagation des Reaction Chimiques dans les Gas," J. Mathematique, vol. 6, No. 1, 1905, p. 347 ; vol. 6 , No. 2 , 1906 , p. 6 .

10. Penner, S. S., and Mullins, B. P., Eds., Explosions, Detonations, Flammability, and Ignition, Pergamon Press, New York, 1959.

11. Gudkovich, V. N., et al, "Ignition of Rich Propane-oxygen Mixtures, Fizika Goseniya i Vzryva, Vol. 16, No. 6, Nov-Dec 1980, pp. 93-97, Plenum Press 1981.

12. Jost, W., Explosion and Combustion Processes in Gases, First Ed., McGraw-Hill, New York, 1946.

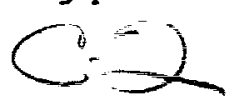


13. Sokolik, A. S., Self-Ignition Flame and Detonation in Gases, Akademiýa Nauk, USSR, Moskva, 1960. Translation from Russian, Israel, 1963.

14. Lee, J.H.S., Knystautas, R., and Freiman, A., "High speed Turbulent Deflagrations and Transition to Detonation in $\mathrm{H}_{2}-\mathrm{Air}$ Mixtures," Combustion and Flame, Vol. 56, No. 2, May 1983.

15. Peraldi, 0., et al, "Criteria for Transition to Detonation in Tubes," 21st Symposium (International) on Combustion, Munich, The Combustion Institute, 1986.

16. Nikoleiev, Yu. A., "Theory of Detonation in Wide Tubes," Fizika Goreniya i' Vzryva, vol. 15, No. 3, May-June 1979, pp. 142-149, Plenum Publishing, 1979.

17. Brinkley, S..R., Jr., and Lewis, F.,."on the Transition from Deflagration to Detonation," Seventh Symposium (International) on Combustion, The combustion Insitute, London and oxford, 1958.

$\therefore$. Vasilev, V. M., et al, "Calculation of Fuel-Air Mixture Detonation Parameters," Fizika Goreniya i Vzrgva, Vol. 16 , No. 3, May-June 1980, pp. 127-134, Plenum Publishing 1980 .

19. Eisen, C. I., Gross, R. A., and Rivlin, T. J., "Theoretical Calculations in Gaseous Detonations," combustion and Flame, Vol. 4, No. 2, June 1960, pp. 137-149.

20. Ulyanitskii, V. Yu., "Galloping Mode in Gas Detonations," Fizika Goreniya i Vzryva, Vol. 17, No. 1 , Jan-Feb 1981, pp. 118-124, Plenum Publishing 1981.

21. Vasilov, A. A., "Analysis of Cell Parameters of Multifront Gas Detonation," Fizika Goreniya 1 Vzryva, vol. 13, No. 3, May-June 1977, pp. 404-408, Plenum Publishing 1977 .

22. Vasilov, A. A., et al, "Effect of Initial Temperature on Gas-Detonation Parameters," Fizika Goreniya 1 Vzryva, vol. 15, No. 6, Nov-Dec 1979, pp. 149-152, Plenum Publishing 1980 .

23. Dynin, E. A., "One Dimensional stability of stationary Compression and Combustion Waves," Fizika Goreniya i Vzryva, Vol. 17, No. 4, Jul-Aug 1981, pp. 85-91, Plenum Publishing 1982 . 
24. Bykovskil, F. A., and Mitrofanov, V. V., "Detonation Combustion of a Gas Mixture in a Cylindrical Chamber," Fizika Goreniya i Vzryva, Vol. 16, No. 5, sept-Oct 1980, pp. 107-117. Plenum Publishing 1981.

25. Korovin, I. N., et al "Combustion of Natural Gas in a Commercial Detonation Reactor," Fizika Goreniya i Vzryva, Vol. 17, No. 3, May-June 1981, pp. 68-71. Plenum Publishing 1981.

26. Baklanov, D. I., et al, "Certain Technical Aspects of Using the Detonation Combustion Mode," Fizika Goreniya $i$ Vzryva, Vol. 12, No. 1, Jan-Feb 1976, pp.47-52, Plenum Publishing 1976 .

27. Lobanov, D. P., et al, "Detonation of Gasoline-Air Mixtures," Fizika Goreniya i Vzryva, Vol. 12, No. 3, May-June 1976, pp. 446-450, Plenum Publishing 1976.

28. Edwards, B., "Maintained Detonation Waves in an Annular Channel: A Hypothesis which Provides the Link Between Classical Acoustic Combustion Instability and Detonation Waves," XVIth International Symposium on Combustion. The Combustion Institute, Pittsburgh, PA, 1977, pp. $1611-1618$.

29. Ponizy, B., and Wojcicki, s., "On Modeling of Pulse Combustors," Combustion Institute 20 th symposium on Combustion, August 1984, pp. 2017-2024.

30. Wortman, A., "Development of Detonation Duct Gas Generator," Final Report on NASA contract No. NAS3-25143, ISTAR Report IST-87-09-002, ISTAR Inc., Santa Monica, CA, October 1987.

31. Taylor, C. F., The Internal combustion Engine in Theory and Practice, 2nd Ed. Rev., The M.I.T. Press, Cambridge, Mass, 1985. 


\section{APPENDIX A}

\section{RESULTS FROM THE PREVIOUS PHASES OF THE PROGRAM}

The present project is the culmination of a multiphase program of theoretical and experimental studies aimed at demonstrating the feasibility of employing transverse detonation waves to generate hot compressed gases for gas turbines. The basic theoretical studies of the advantages of constant volume rather than constant pressure heat addition were performed under contract No. NAS3-24098 and were reported in Reference A.1. This work was followed by extensive, detailed gas dynamic studies, which were done under Contract No. NAS3-24854 and summarized in Reference A.2. Included in this report were the results of some preliminary studies of transverse detonation waves in rectangular ducts. Transverse detonation waves in ducts were studied experimentaily under contract No. NAS3-25143 using a rectangular duct which formed the basis of the device used in the early stages of the present program. This work was reported in Reference A.3.

\section{A.1 First Feasibility Tests}

The first experiments were performed in a rectangular duct of $2 " x$ 12" cross-section with air and propane being supplied in separate jets at the closed end. The propane supply tube was bent at $90^{\circ}$ so that the air jet expanding from 250 psig intersected the propane jet expanding from $30-40 \mathrm{psig.} \mathrm{Due} \mathrm{to} \mathrm{rela-}$ tively low flow rates from the $1 / 4 "$ diameter line and the large cross-section of the duct, which was open to the atmosphere, the initial pressure prior to the detonation was essentially at the ambient level.

The basic configuration is shown schematically in Figure A.1-1 with pressure transducer locations and representative results being shown in Figure A.1-2.

Pressures were measured with Kistler $603 \mathrm{~L}$ piezoelectric transducers rated at $200 \mathrm{kHz}$. These transducers were checked in a shock tube so that the data shown are considered to be reliable. It should be noted that the measured wave speeds were about Mach 3 and pressure ratios generally clustered around 10-12. In contrast, the generaliy accepted theoretical values for propane-air detonations are Mach 5.1 and pressure ratios of 18. Data from calculations in Reference A.4 indicate that a detonation in a stoichiometric propane-air mixture results in a pressure ratio of 18.6 , wave velocity of $1734 \mathrm{~m} / \mathrm{s}$, and detonation 
products temperature of $2813^{\circ} \mathrm{K}$. It has been established that calculations of detonation wave parameters are in good agreement with experimental data so that the above are representative values. As an example, Reference A.5 shows that for $\mathrm{H}_{2}-\mathrm{O}_{2}$ detonations, the calculated and measured wave velocities are 2806 and $2819 \mathrm{~m} / \mathrm{s}$. 


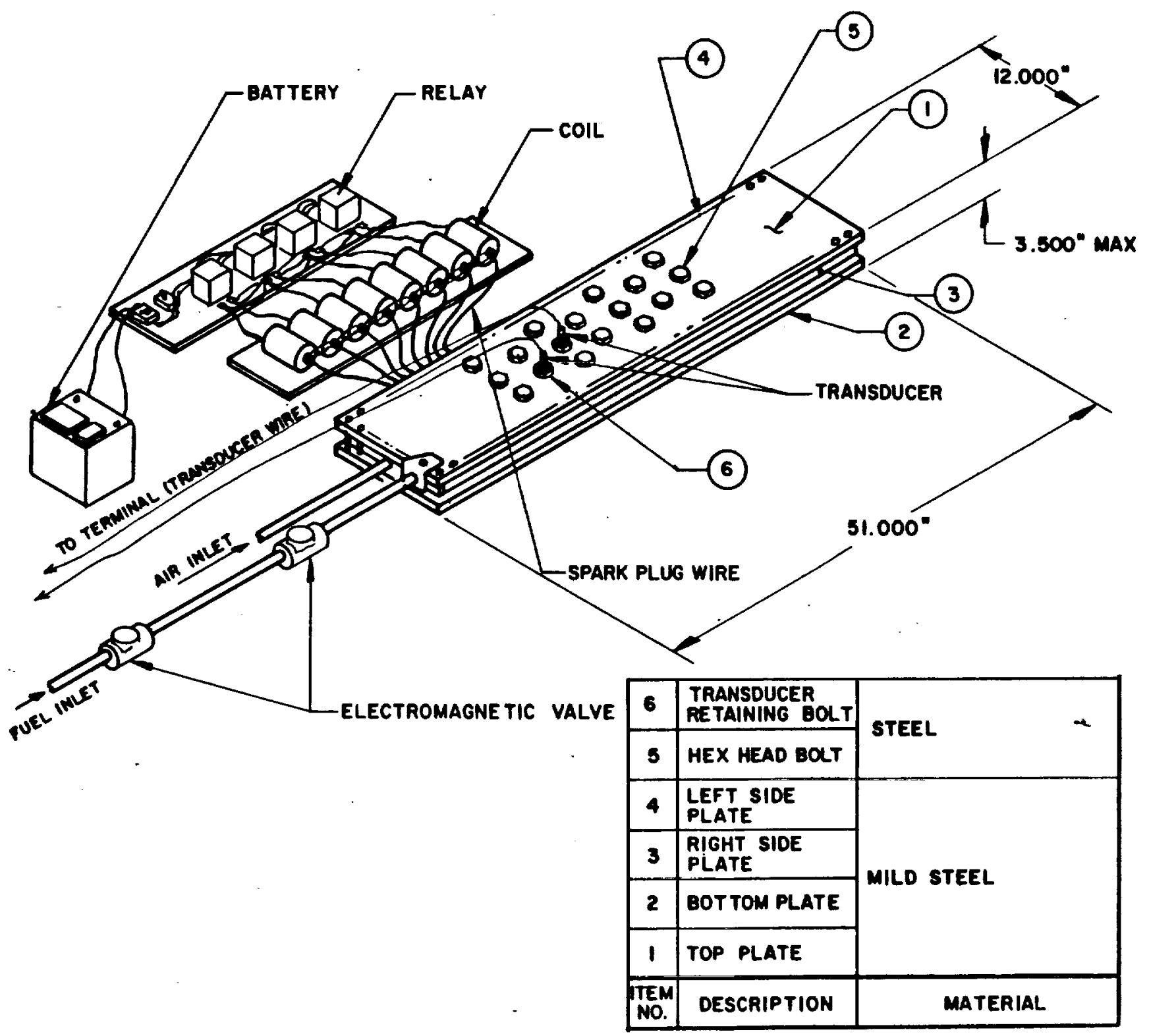

Figure A.1-1. Detonation Duct Used in the Initial Experiments 


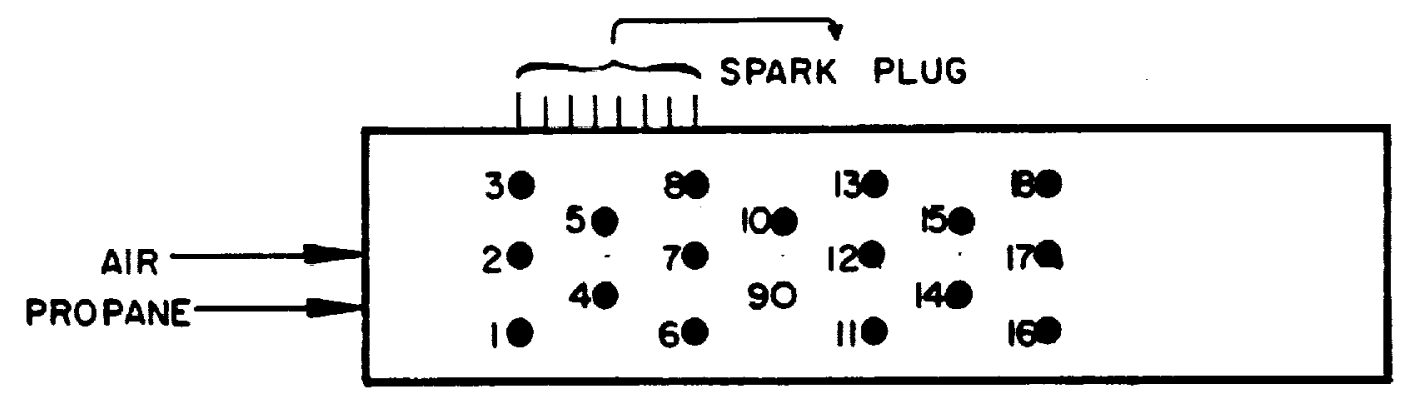

TRANSDUCER ARRAY

\begin{tabular}{|c|c|c|c|c|}
\hline RUN NO. & $\begin{array}{l}\text { TRANSDUCER } \\
\text { LOCATION }\end{array}$ & $\begin{array}{l}\text { PRESSURE } \\
\text { (PSI) }\end{array}$ & $\begin{array}{c}\text { PRESSURE } \\
\text { RATIO }\end{array}$ & $\begin{array}{l}\text { TIME DIFF/ } \\
\text { VELOCITY }\end{array}$ \\
\hline 1 & $\begin{array}{r}7 \\
10\end{array}$ & $\begin{array}{l}200 \\
160\end{array}$ & $\begin{array}{l}13.6 \\
10.8\end{array}$ & - \\
\hline 2 & $\begin{array}{r}7 \\
17\end{array}$ & $\begin{array}{l}200 \\
240\end{array}$ & $\begin{array}{l}13.6 \\
16.4\end{array}$ & - \\
\hline 3 & $\begin{array}{r}7 \\
17\end{array}$ & $\begin{array}{l}140 \\
140\end{array}$ & $\begin{array}{l}9.6 \\
9.6\end{array}$ & $3880 \mathrm{FT} / \mathrm{S}$ \\
\hline 4 & $\begin{array}{r}7 \\
17\end{array}$ & $\begin{array}{l}200 \\
180\end{array}$ & $\begin{array}{l}13.6 \\
12.2\end{array}$ & $2917 \mathrm{FT} / \mathrm{S}$ \\
\hline 5 & $\begin{array}{r}5 \\
11\end{array}$ & $\begin{array}{l}140 \\
200\end{array}$ & $\begin{array}{r}9.6 \\
13.6\end{array}$ & $3646 \mathrm{FT} / \mathrm{s}$ \\
\hline 6 & $\begin{array}{r}5 \\
11\end{array}$ & $\begin{array}{l}180 \\
140\end{array}$ & $\begin{array}{r}12.2 \\
9.6\end{array}$ & - \\
\hline 7 & $\begin{array}{r}5 \\
11\end{array}$ & $\begin{array}{r}170 \\
80\end{array}$ & $\begin{array}{r}11.6 \\
5.4\end{array}$ & - \\
\hline
\end{tabular}

Figure A.1-2. Representative Results from the Initial Experiment

\section{A. 2 Demonstration studies}

The preliminary feasibility experiments were not formally a part of the contract but were done as a minimum effort demonstration of the existence of transverse detonation waves in channel flows. Extensions of the tests to higher channel flow speeds was done in Reference 3 which operated at $1.5^{\prime \prime} \times 12$ " rectangular duct in blow-down mode using a $7.5 \mathrm{hp}$ air compressor and a 500 gallon 
tank air reservoir. Principal components of the equipment are shown in Figure A.2-1. The duct with its array of instrumentation parts is shown in Figure A.2-2. Also shown in this Figure are the fuel injector rail with 8 injectors and a tube which was used as a plenum for the premixed propane-air injection. Injection of liquid propane through the automotive injectors had to be abandoned because it proved impossible to achieve detonations at any reasonable channel flow speeds. Far greater successes were found with propane-air mixture injected through the perforated tube injector shown in Figure A.2-3. Turbulence in the stream was induced by the inclined plate ahead of the distributor which represented a 75\% blockage of the channel cross-section. Such high flow losses could not be tolerated in an actual operating system, but it was necessary to try the large distributor tube and propane-air injection because of limited resources and schedules. It is estimated that flow speeds of Mach 0.3-0.4 were achieved towards the end of the program. Representative results are shown in Figure A.2-4. The scatter in the data is attributed to extremely rapid mixing promoted by the high turbulence which resulted in nonuniform fuel-air mixtures and delays in ignition. Injections of fuel-rich mixtures alleviated some of the problems but significant run-to-run variations in pressure rates persisted. 


\author{
ORIGINAL PAGE \\ BLACK AND WHITE PHOTOGRAPH
}
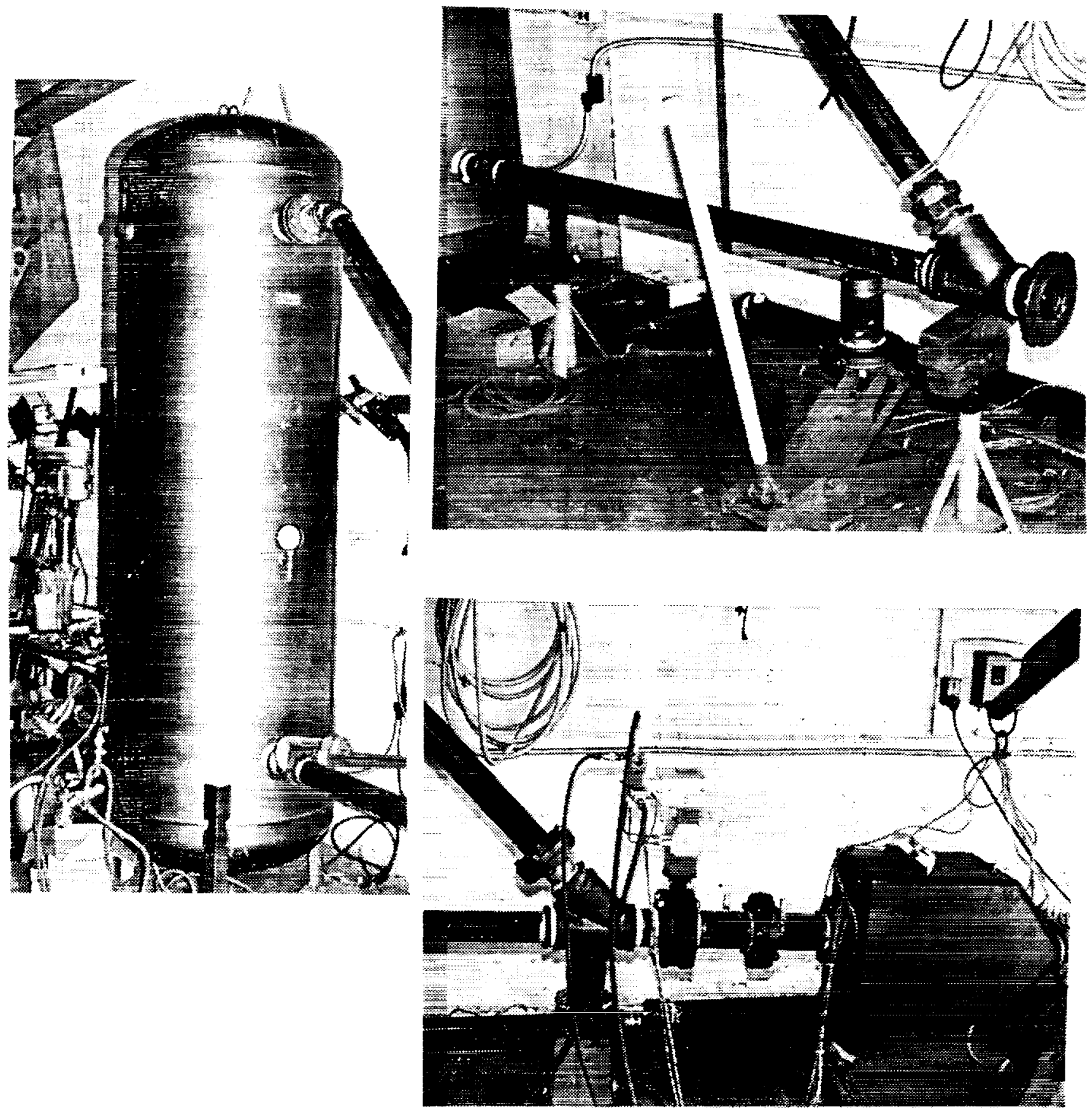

Figure A.2-1. Experimental Equipment used in Reference 3 
ORIGINAL PAGE

BLACK AND WHITE PHOTOGRAPH
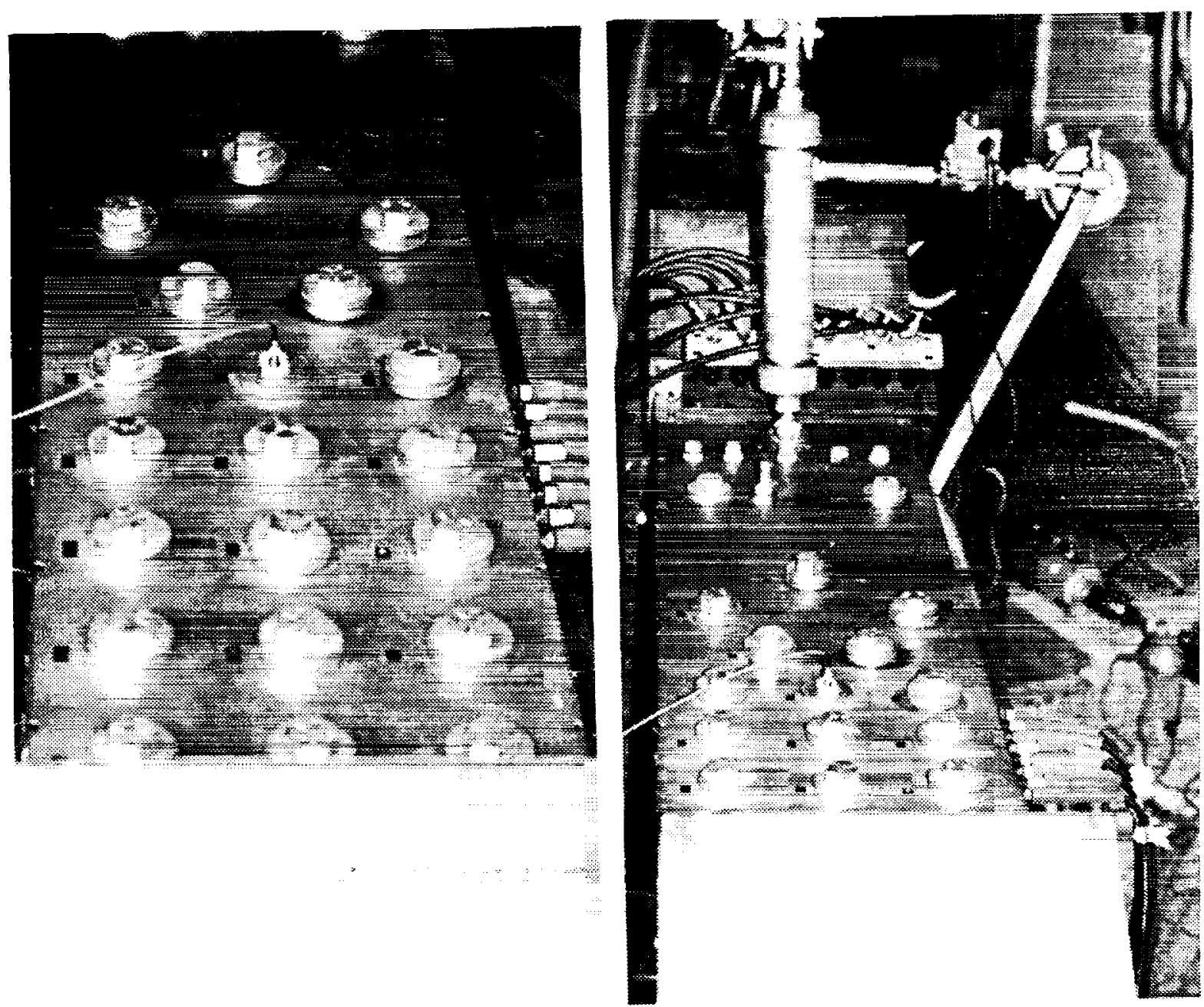

Figure A.2-2. Details of the Duct with Instrumenttion Ports and Fuel Injection 
ORIGINAL PAGE

BLACK AND WHITE PHOTOGRAPH
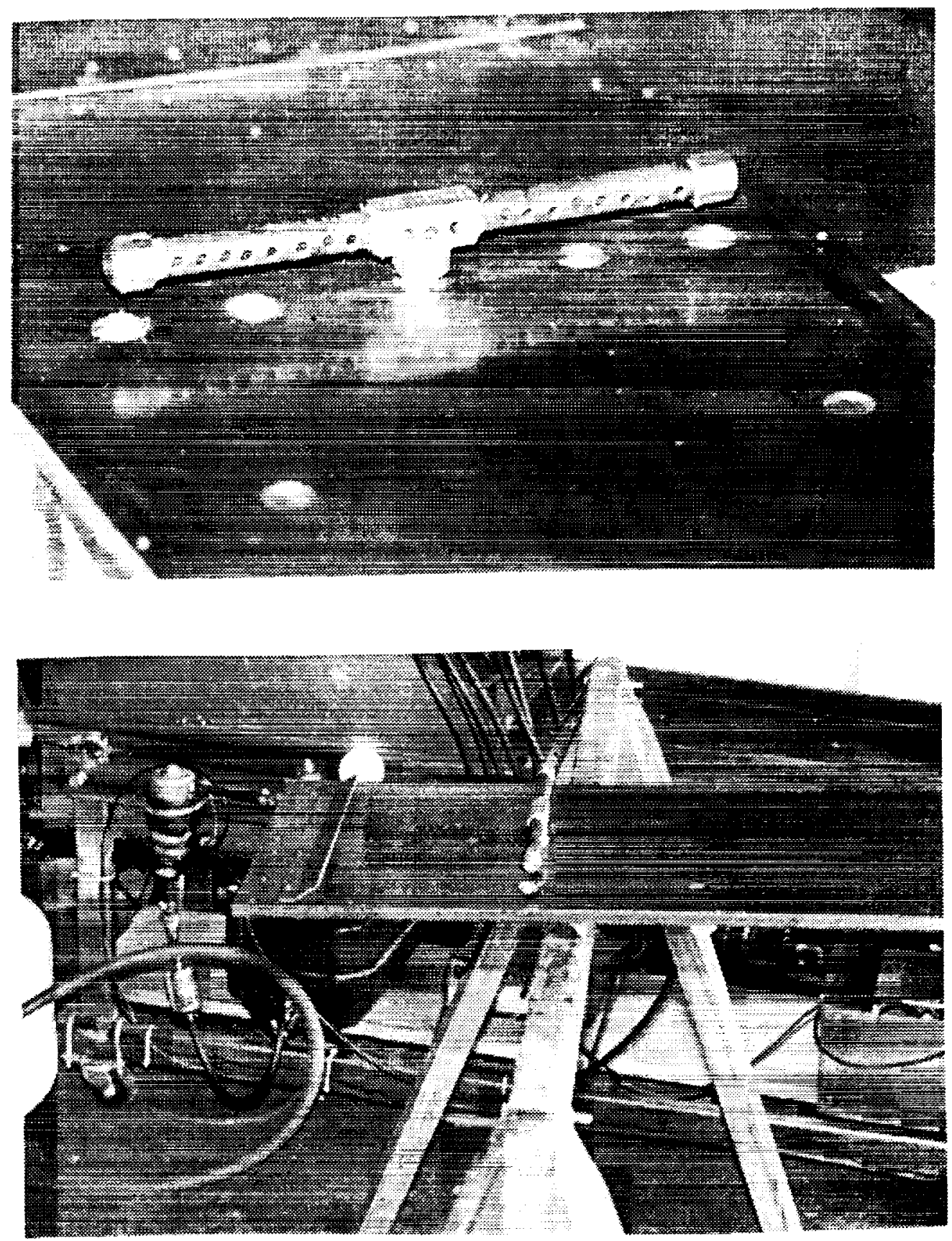

Figure A.2-3. Distributor for the Injection of Propane/Air Mixture 


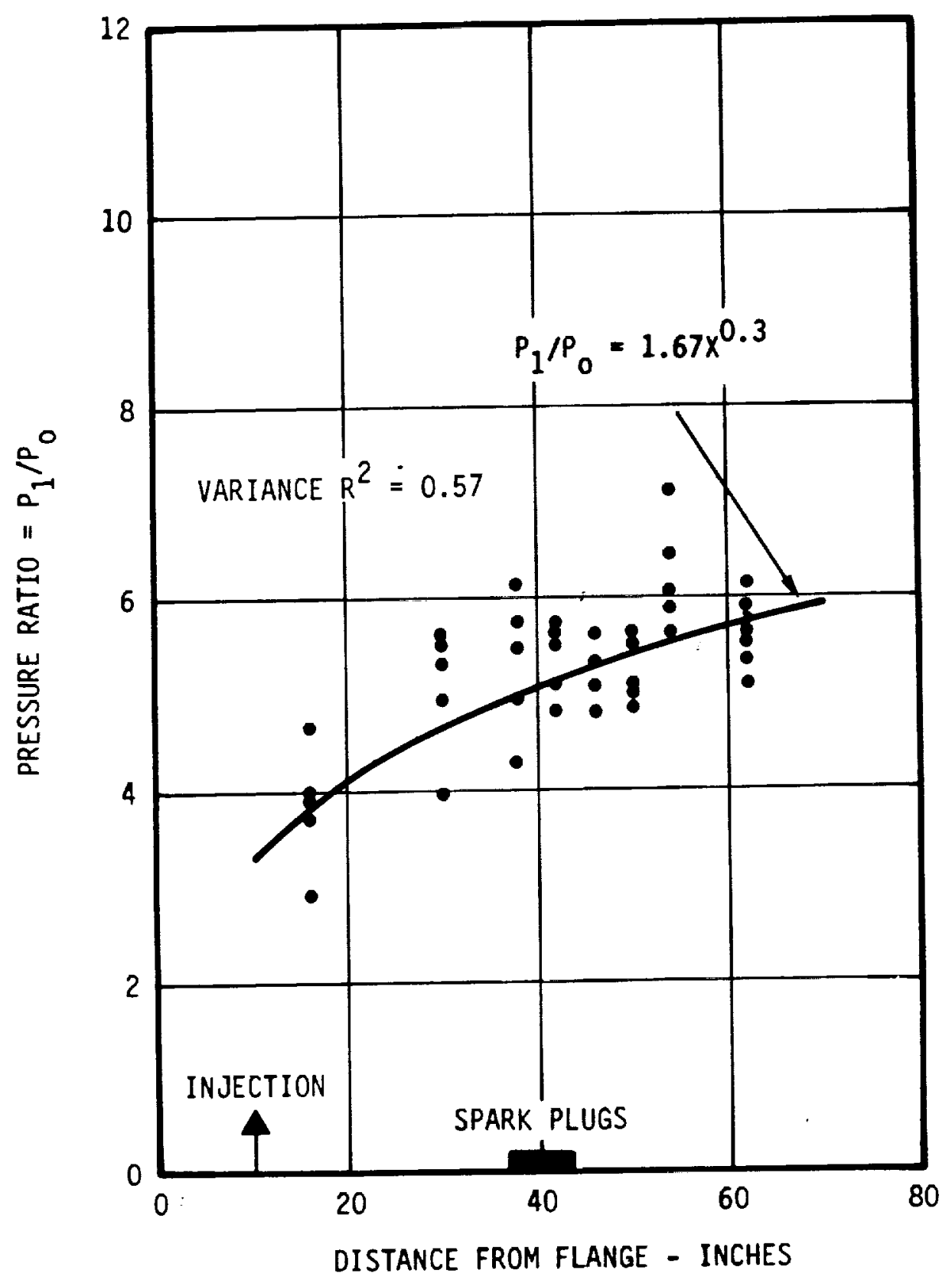

Figure A.2-4. Pressure Ratios Measured in Previous Tests 


\section{REFERENCES}

A.1. Wortman, A., "Detonation Wave Augmentation of Gas Turbines," Final Report on Contract No. NAS3-24098, Report No. ISTNAS-07-84-01, ISTAR Inc., Santa Monica, CA 16 June 1984 .

A.2. Wortman, A., "Detonation Wave Compression in Gas Turbines," NASA Contractor Report 179557, December 1986.

A.3. Wortman, A., "Development of Detonation Duct Gas Generator," Report No. IST-87-09-002, ISTAR Inc., Santa Monica, CA, 15 October 1987.

A.4. Vasilev, V.M., et al, "Calculation of Fuel-Air Mixture Detonation Parameters," Fizika Goreniya i Vzryva, Vol. 16, No. 3, May-June 1980, pp. 127-13. Plenum Publishing, 1980.

A.5. Jost, W., Explosion and Combustion Processes in Gases. Translation, 1st. Ed., McGraw-Hill, New York, 1946. 


\section{SUPPORTING EXPERIMENTS}

The main effort was concentrated on the achievement of highest pressure ratios and firing frequencies, but it was necessary to perform numerous other experiments to verify the basic approaches and accuracy of the instrumentation.

\section{B. I Ignition Tests}

The first tests were performed in the desert area southeast of Los Angeles, before the laboratory facility was leased in corona. These tests were aimed at determining the minimum distance for explosion between injection of liquid propane through an automotive injector and spark ignition. A 4" diameter pipe was drilled and tapped to accept arrays of 6 spark plugs in several planes. Firing of the spark plugs was by means of a standard automotive ignition system with the distributor being rotated by an electric drill. A large fan was used to blow air through the pipe. The experimental equipment is shown in Figure B.1-l. It was found that with the low air flow speed through the pipe, sharp explosions could be obtained every time that the propane was ignited. Manual operation of the injector switch limited the frequency to about $2 \mathrm{~Hz}$. The nearest spark plug array was about I ft from the injector. so that even with the low flow velocity, vaporization and adequate mixing were obviously being achieved quite rapidly. 
ORIGINAL PAGE

BLACK AND WHITE PHOTOGRAPH
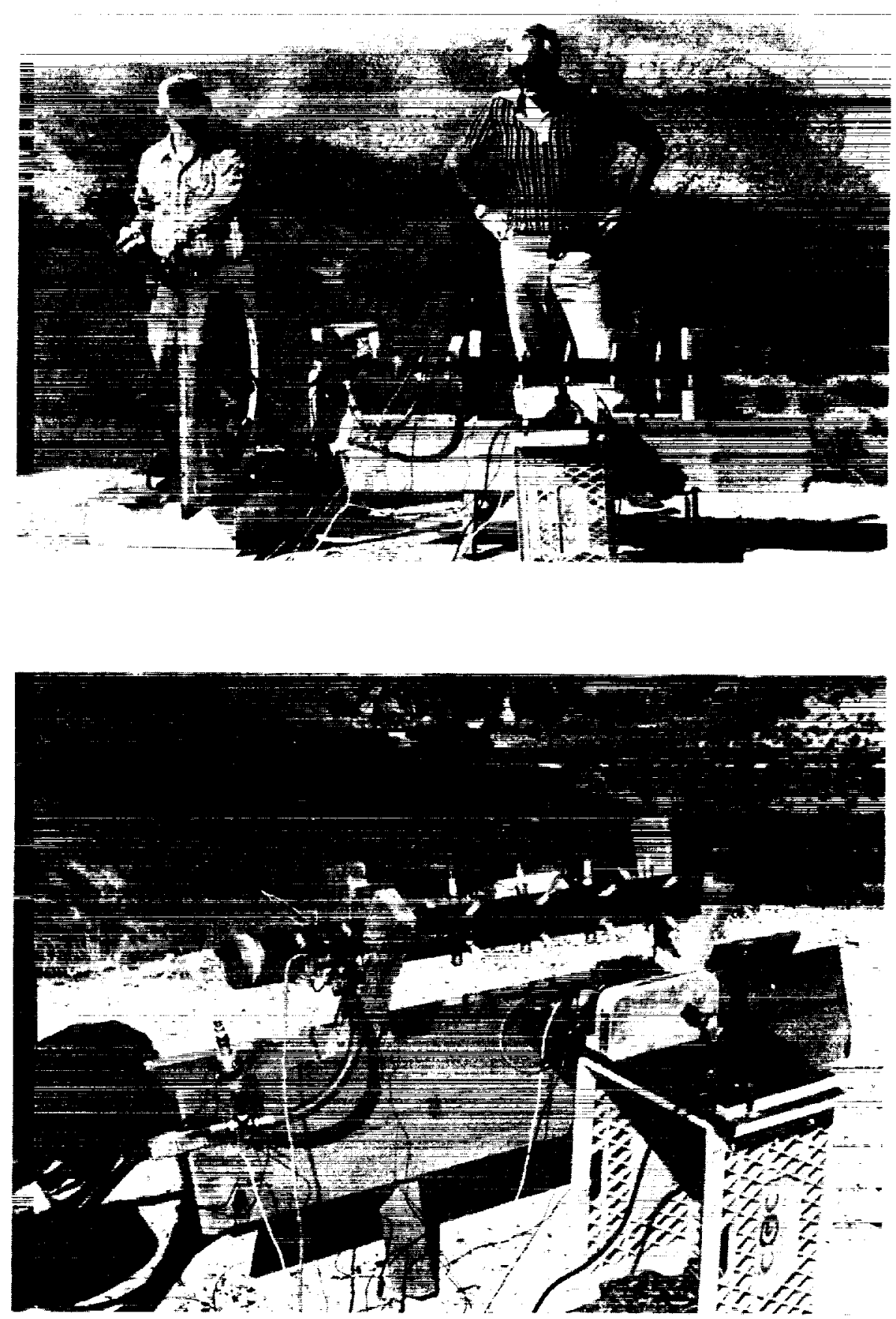

Figure B.1-1. Preliminary Liquid Propane Ignition Tests 


\section{B.2 Detonation Tube Tests}

The difficulties in achieving repeatable detonations in the duct necessitated testing in a closed tube. Schematic representation of the apparatus is shown in Figure B.2-1. Initial tests in the $3 "$ diameter tube produced occasional detonations, particularly at the beginning of each experiment.

Introduction of the wire screens near the igniter increased the pressures but the theoretical initial front pressure ratios of 18 could not be achieved. It was found that draining the tube of the water generated by combustion improved the performance significantly, but the theoretical front pressure ratios, or the subsequent pressures in the products of combustion could never be achieved.

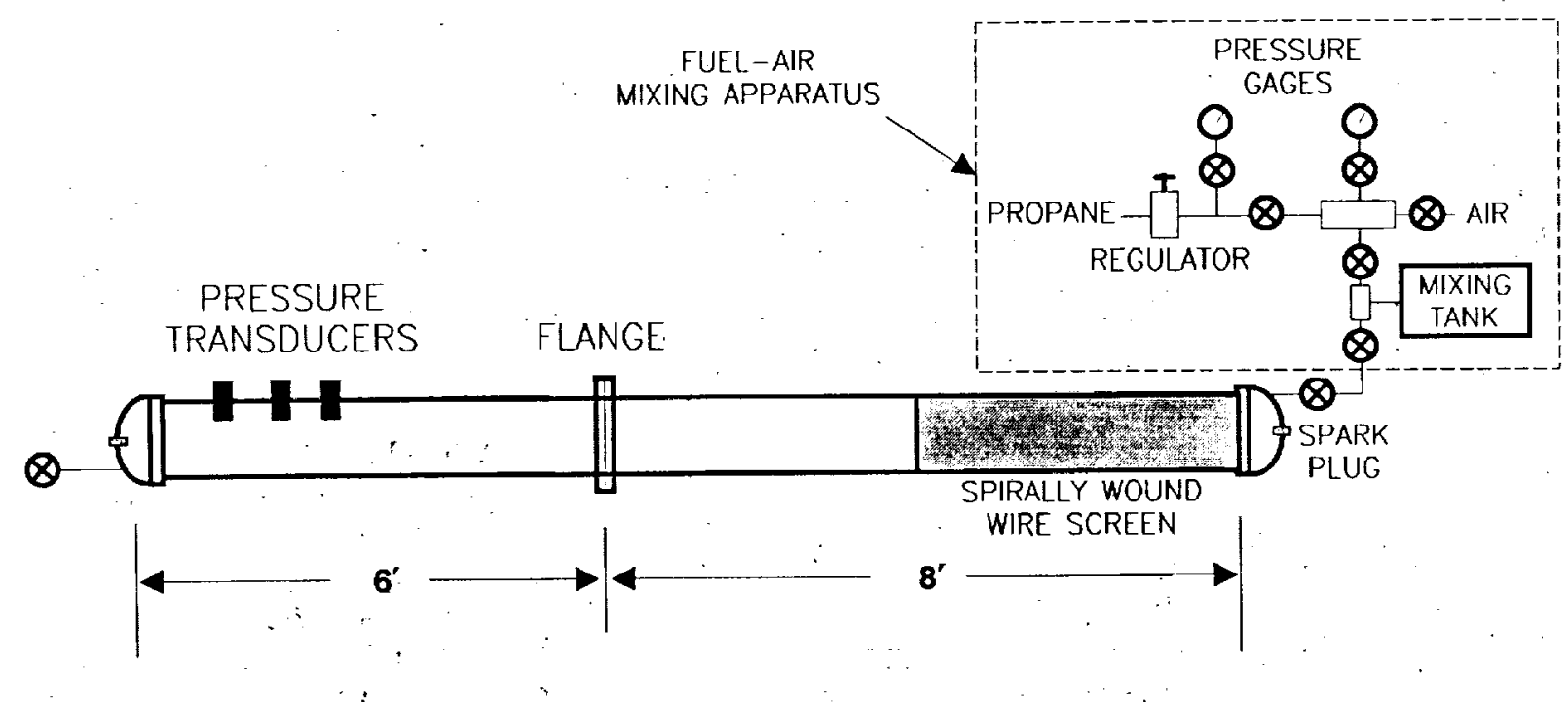

Figure B.2-1. Detonation Tube

The tests indicated that the presence of moisture on the tube walls weakens the detonation wave significantly. Upon reflection, this is quite reasonable since the energy in a tube of gas is

$$
0.25 \pi D^{2} L d_{g} H
$$


with $D, I$ being the tube diameter and length respectively, $d_{g}$ the mixture density, and $H$ its heat of combustion. The energy needed to vaporize a layer of water of thickness $d$ is

$$
\text { DL } \pi d d_{L} H_{W}
$$

with $d_{L}$ being the density of water and $H_{w}$ its heat of vaporization.

The thickness of the water layer, which must be evaporated to reduce the heat released by a fraction $x$, is

$$
\mathrm{d}=.25 \times \mathrm{Xdg}_{\mathrm{g}} \mathrm{H} / \mathrm{d}_{\mathrm{L}} \mathrm{H}_{\mathrm{W}}
$$

For stoichiometric propane-air mixture, $H$ is about 1000 Btu/lb and $s$, is $H_{W}$. With 1 atmosphere, initial pressure $d_{g}$ is 0.08 $1 \mathrm{~b} / \mathrm{ft}^{3}$ and $\mathrm{d}_{\mathrm{L}}$ is $62.4 \mathrm{lb} / \mathrm{ft}^{3}$. If the net heat released is reduced $50 \%$ (i.e., $X=0.5$ ) then the layer of water which must be evaporated in a $3 "$. ID pipe is only $2 \times 10^{-5} \mathrm{ft}$, or about 0.00025 . This is well within the roughness of the commercial pipe which was used for these experiments.

The detonation tube was purged with air after each firing, but the pressures were generally too low. Tests at higher pressure were much more successful because the energy density was higher. An example of a test with a stoichiometric propane-air mixture initially at $120 \mathrm{psig}$ is shown in Figure $\mathrm{B} .2-2$. The overall pressure ratio is 5.75 which suggests that the detonation wave was not estabiished at the time that the combustion front reached the transducers. This is confirmed by the very gradual rise in pressure. 


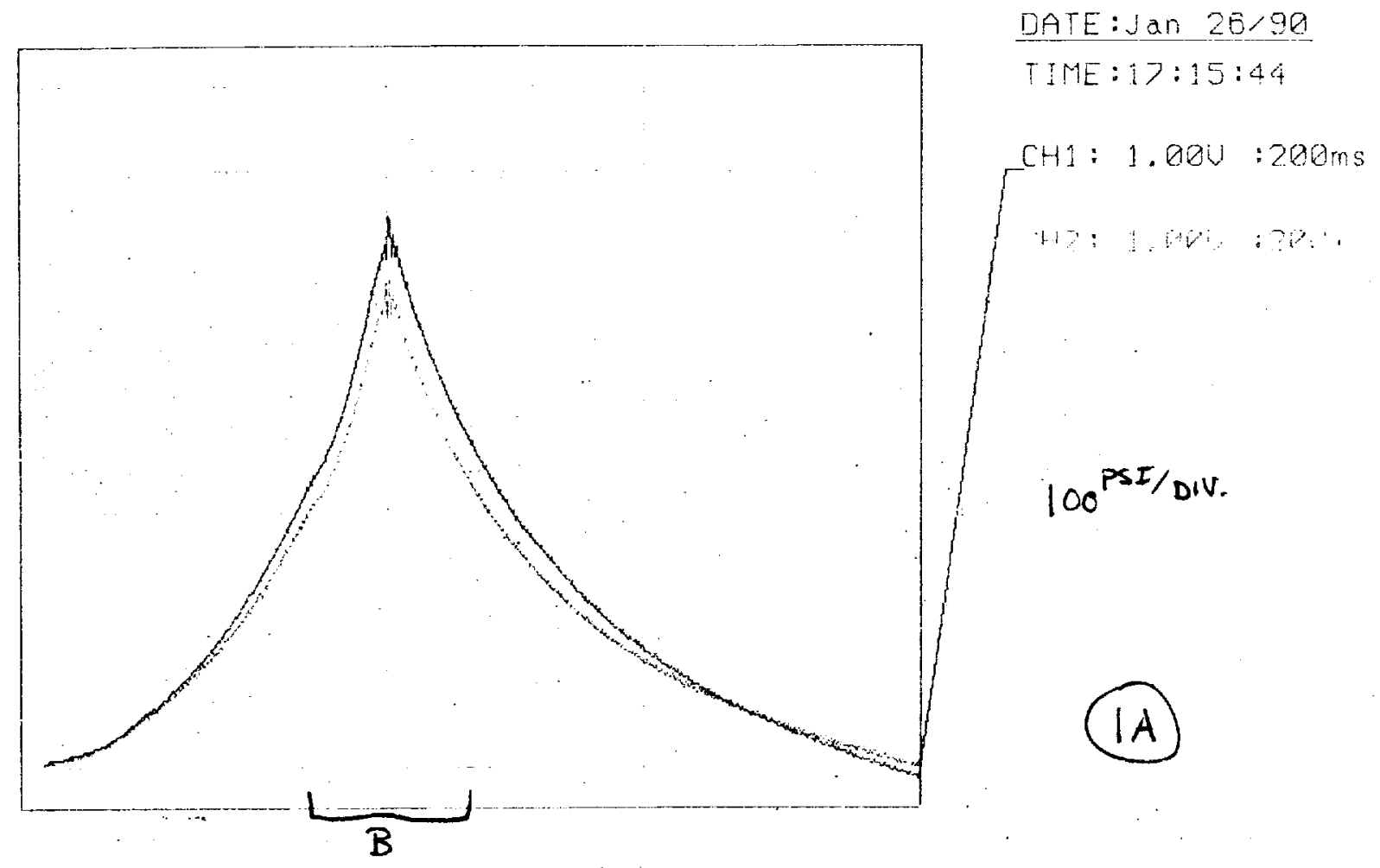

Figure B.2-2. Pressure Rise in the Detonation Tube 


\section{B. 3 Shock Tube Experiments}

Shock tube experiments were performed to obtain calibrations for the $\mathrm{PCB}$ and Kistler piezoelectric pressure transducers. The shock tube was a 3" diameter pipe with the channel open to the atmosphere. Principal dimensions and a view of the air supply fittings are shown in Figure B.3-1. The only available air was from the compressor so that pressure ratios were limited to only about 12 . Vinyl and brass shimstock diaphragms were used, with the latter being scribed to give a sharp burst. Because of the low pressure ratios, the metal diaphragms had to be very thin and a completely satisfactory, sharp, failures were never realized. Representative pressure traces are shown in Figure B.3-2. The Kistler transducers appeared to have serious problems with their cables which seemed to deteriorate very rapidly even with very careful use. New cables were purchased from Kistler but these offered only a marginal improvement in performance. Calibration curves for $P C B$ and Kistler transducers are shown in Figure B.3-3. Because of, the scatter in the calibration data, the use of the Kistler transducers was limited to only occasional checks of the readings of the PCB instruments.
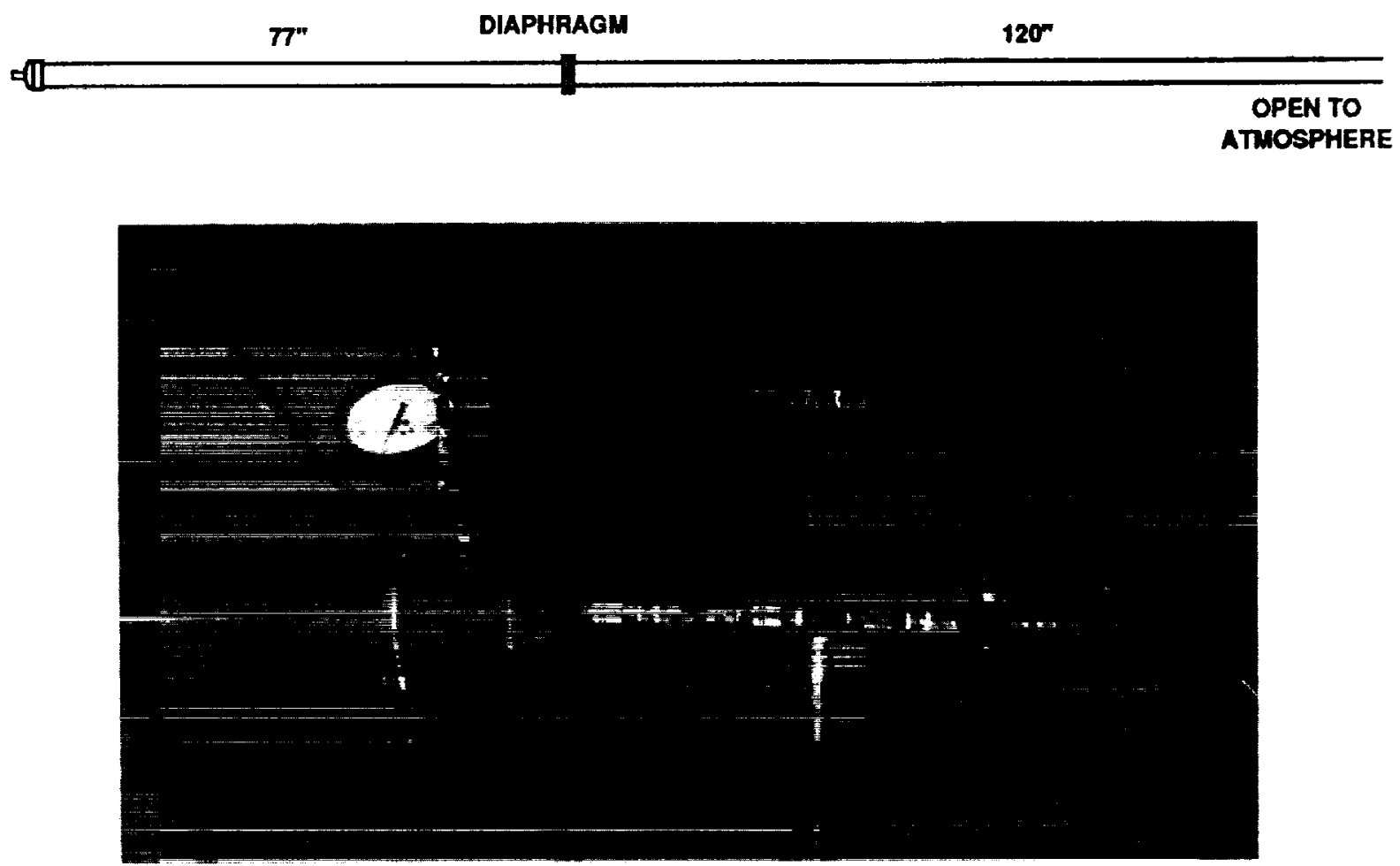

Figure B.3-1. Shock Tube

$$
B-6
$$




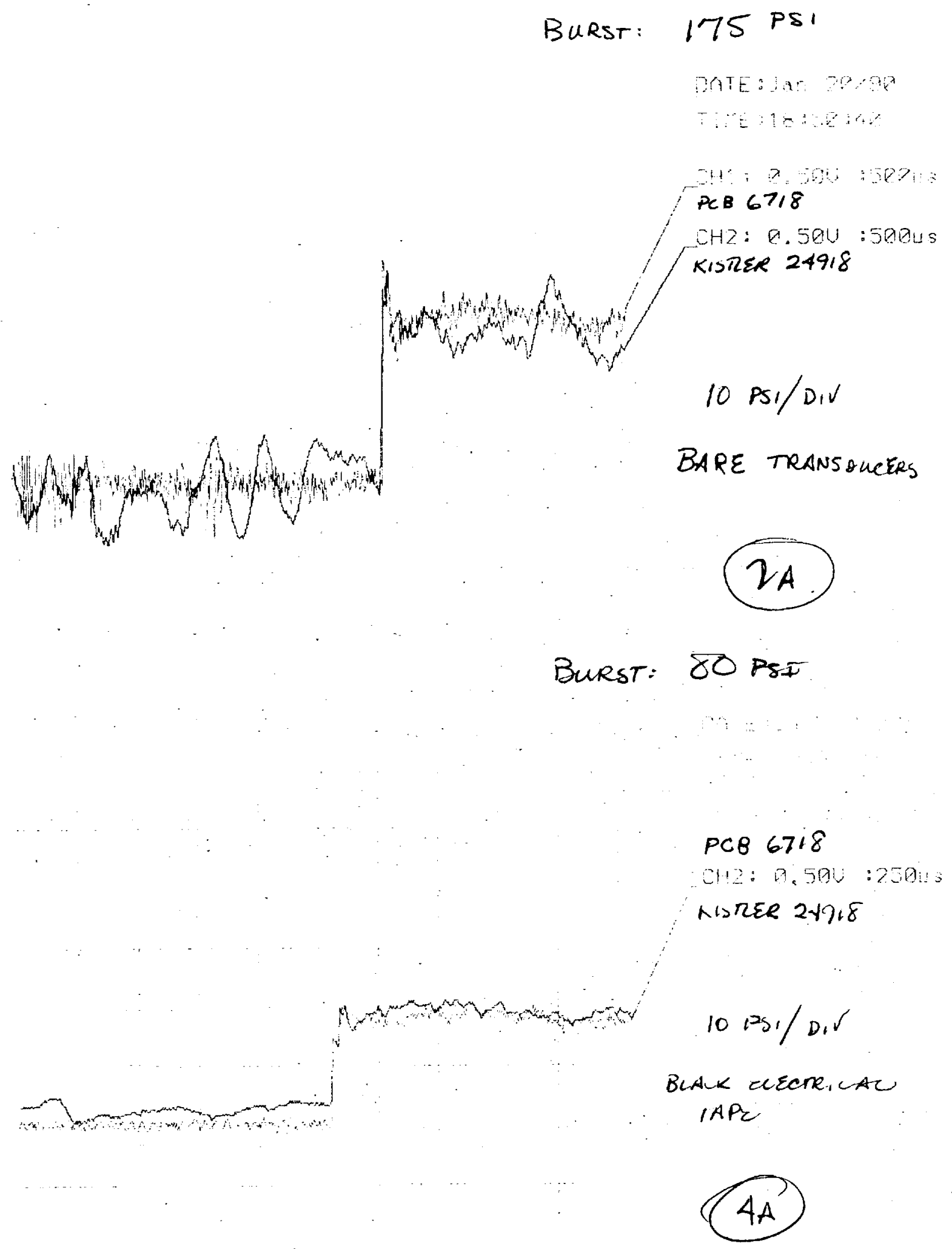

Figure B.3-2. Transducer Response in Shock Tube Tests 


\section{KISTLER TRANSDUCERS Shock Tube Calibrations}
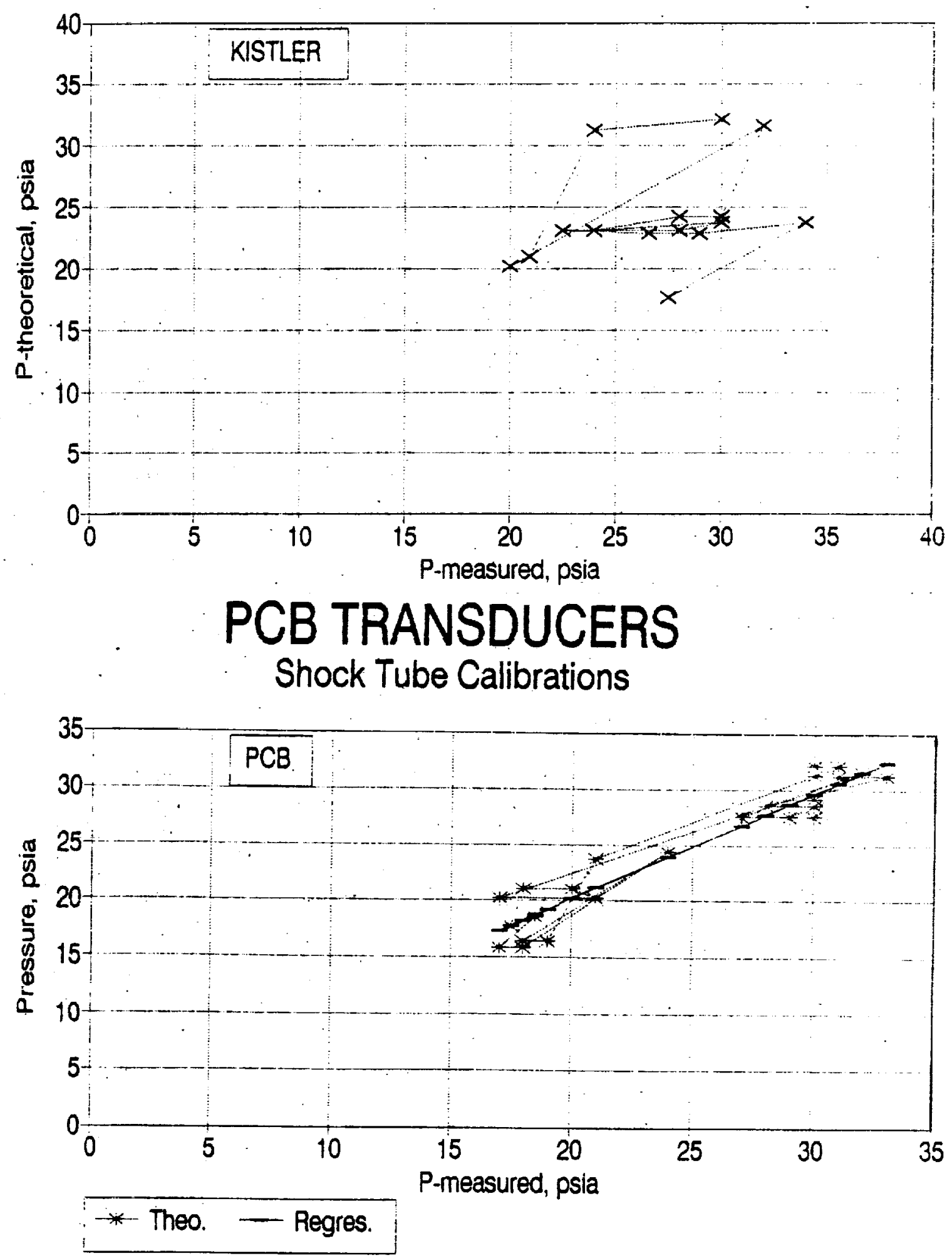

Figure B.3-3. Shock Tube Calibrations of the Pressure Transducers

$$
\text { B-8 }
$$




\section{B. 4 Flow studies}

Because of the difficulties with the procurement of a data acquisition system, it was not practical to measure the air flow rate on each test run. This necessitated the development of calibration curves so that the flow rate could be determined for experiments which were of particular interest to the program. Flow measurements were made using a venturi tube and a pitot-static probe in the detonation duct. These are shown in Figure B.4-1. Validyne DP-15 differential pressure transducers were used for static and differential pressures. Computer codes were developed for compressible flow calculations based on pressure measurements for the venturi tube and the pitot-static probe. 'Comparisons of venturi and pitot probe flow. rate calculations are shown in Figure B.4-2. It should be noted that the duct measurement is $11.5 \%$ lower than the venturi tube value for the $1 / 2 "$ duct, but is $20 \%$ higher for the 1" duct. This is thought to be due to the blockage of flow in the smaller duct and acceleration of flow by the probe in the larger channel.

When the air flow rate is plotted in Figure $B .4-3$ against the duct total pressure, it is seen that straight line relationships exist except at the lowest pressures. Straight line relationships indicate critical flow, or choking, in the system (e.g., Fliegner's formula). This is quite understandable in view of the fact that the 4 in-line truck mufflers in the duct exhaust had large arrays of small perforations which choked the flow. A cross-section of a muffler is shown in Figure B. 4-4.

The ball valve which was used to regulate the flow was extremely nonlinear, particularly at large angles which corresponded to very small openings. Variations of the duct total, pressure with the valve angle are shown in Figure B.4-5. The pitot probe was located near the entrance to the duct so that the 1/2" duct probably was choked near its exit. variations of the flow Mach numbers with the duct total pressure are shown in Figure B.4-6. The lower values for the $1 / 2$ " duct confirm the hypothesis that the flow was choked near the duct exit. Variation of the 1" width duct Mach number with the valve is shown in Figure B.4-7. Again, the data exhibit anomalous behavior at high supply pressures and valve angles around $60^{\circ}$. 
BLACK AND WHITE PHOTOGRAPH
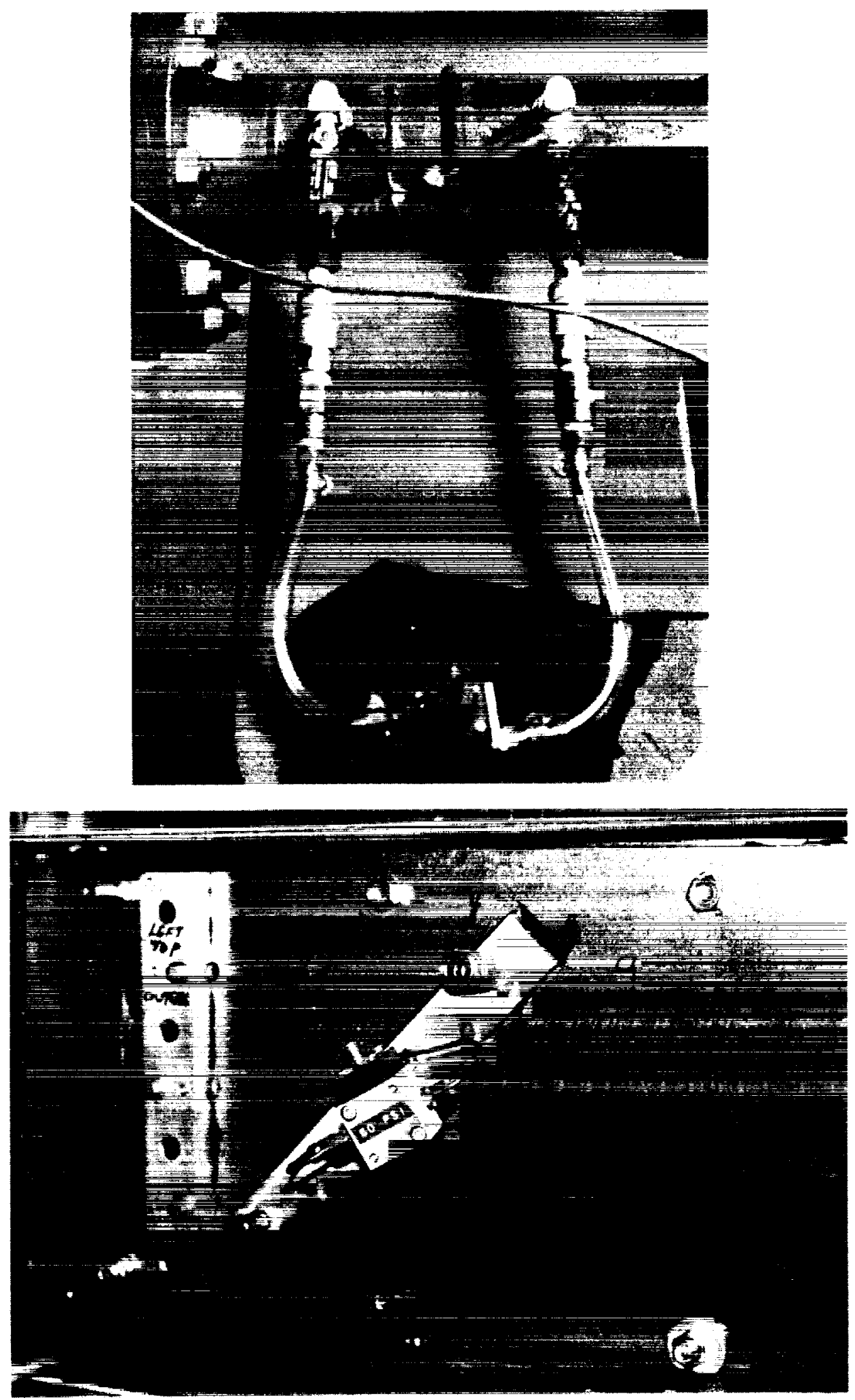

Figure B.4-1. Venturi Tube and Pitot-static Probe Differential Transducer 


\section{DUCT FLOW MEASUREMENTS}

Venturi Tube vs Duct Pitot - 1/2" Duct

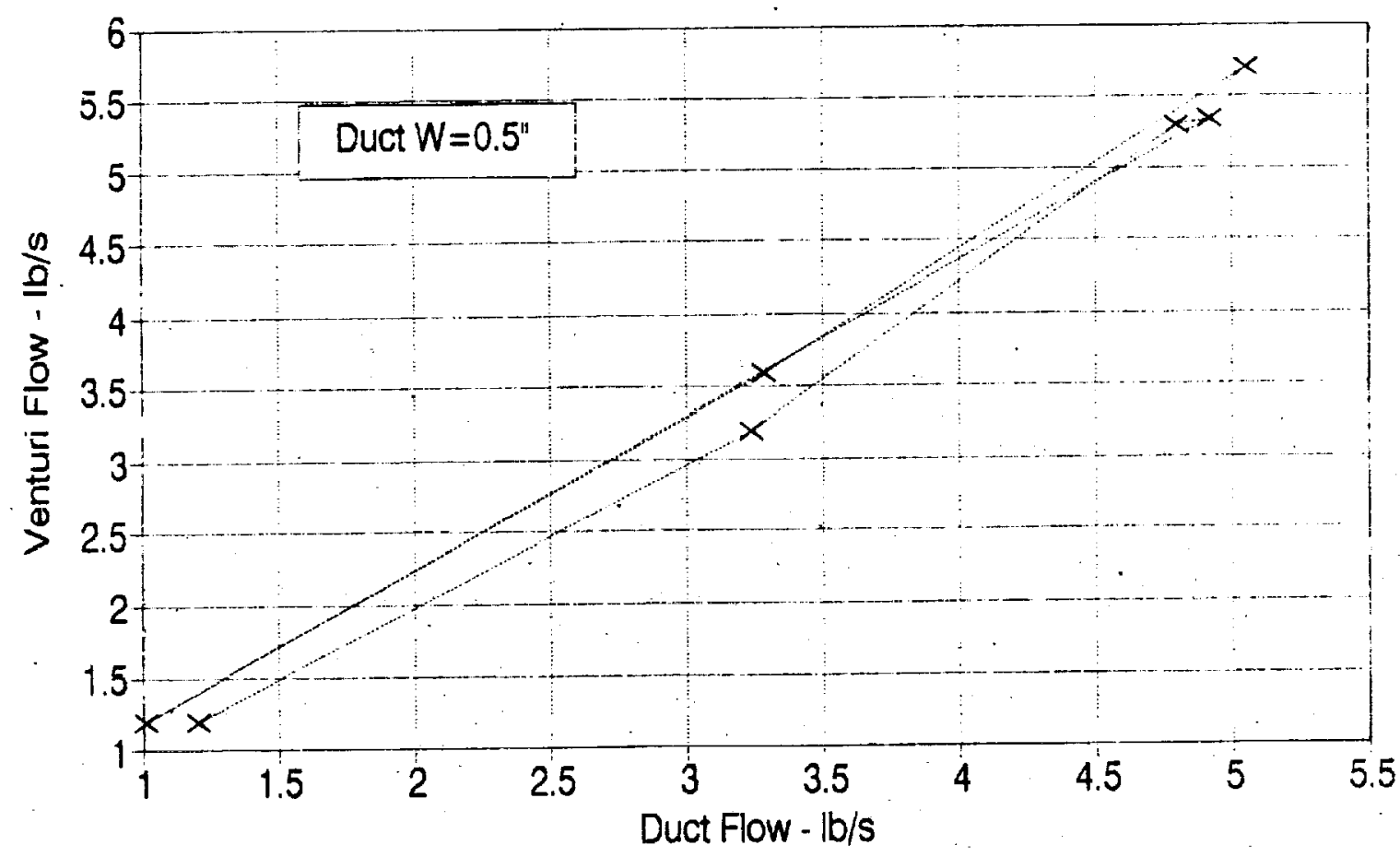

DUCT FLOW MEASUREMENTS

Venturi Tube vs Duct Pitot - 1" Width

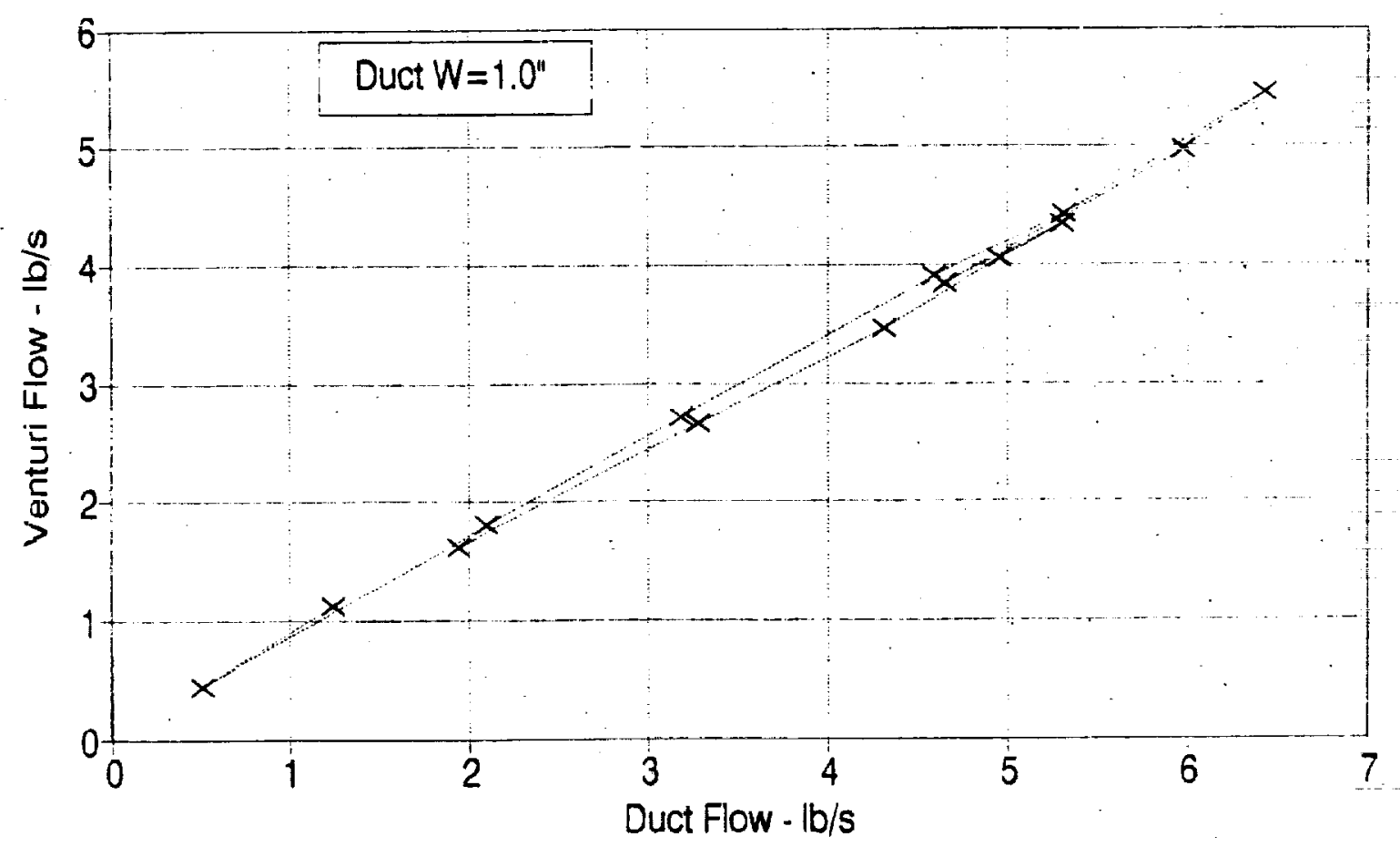

Figure B.4-2. Duct Air Flow Rates Correlations 


\section{DUCT FLOW EXPERIMENTS Flow Rate Correlations}

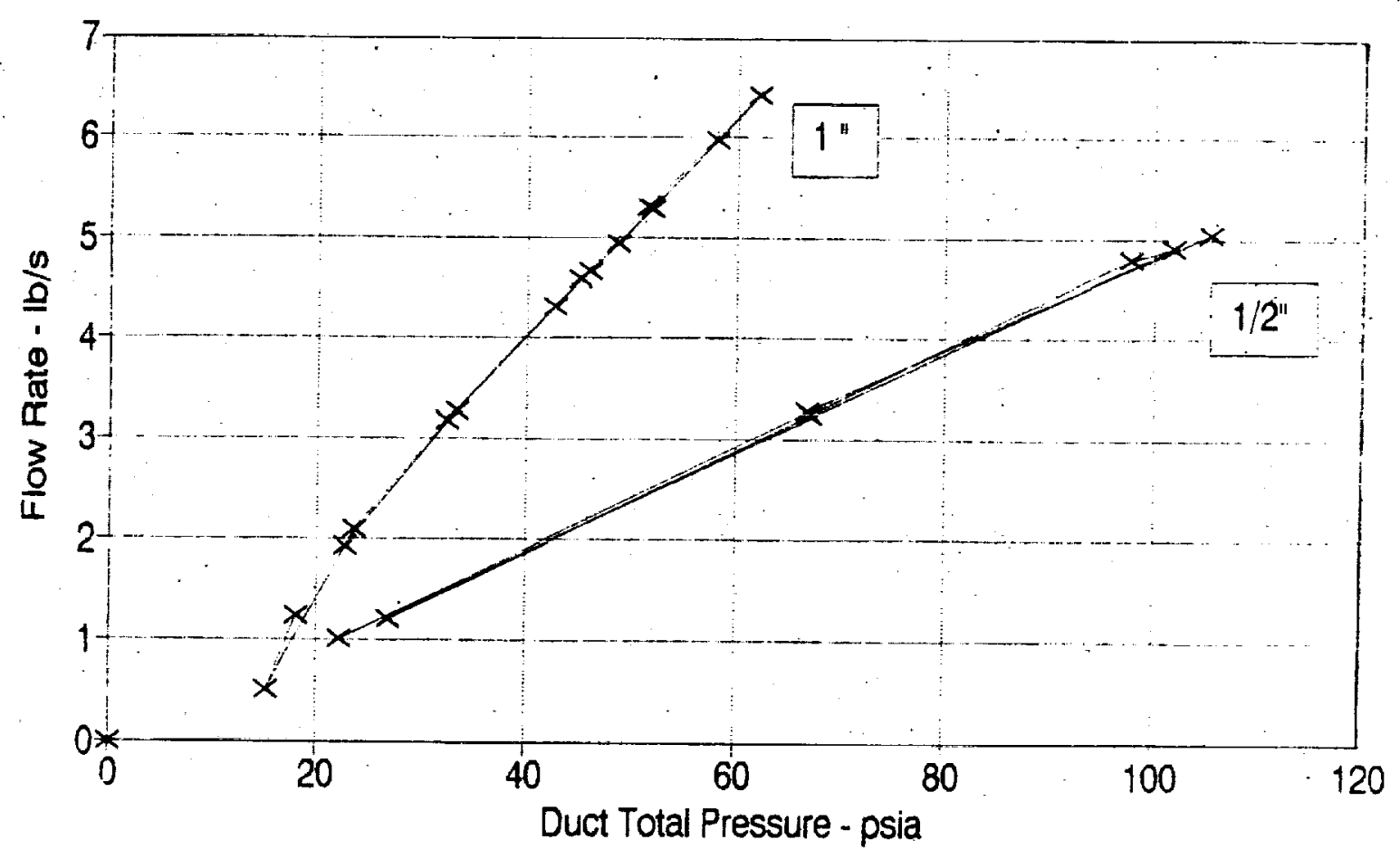

Figure B.4-3. Flow Rate correlations on Total Pressure 


\section{MUFFIIRS}

- A Pegured

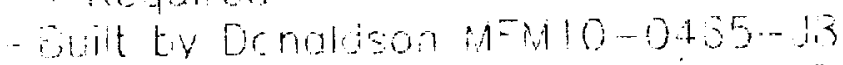

- Pubbust orom Petertit, aringe CA

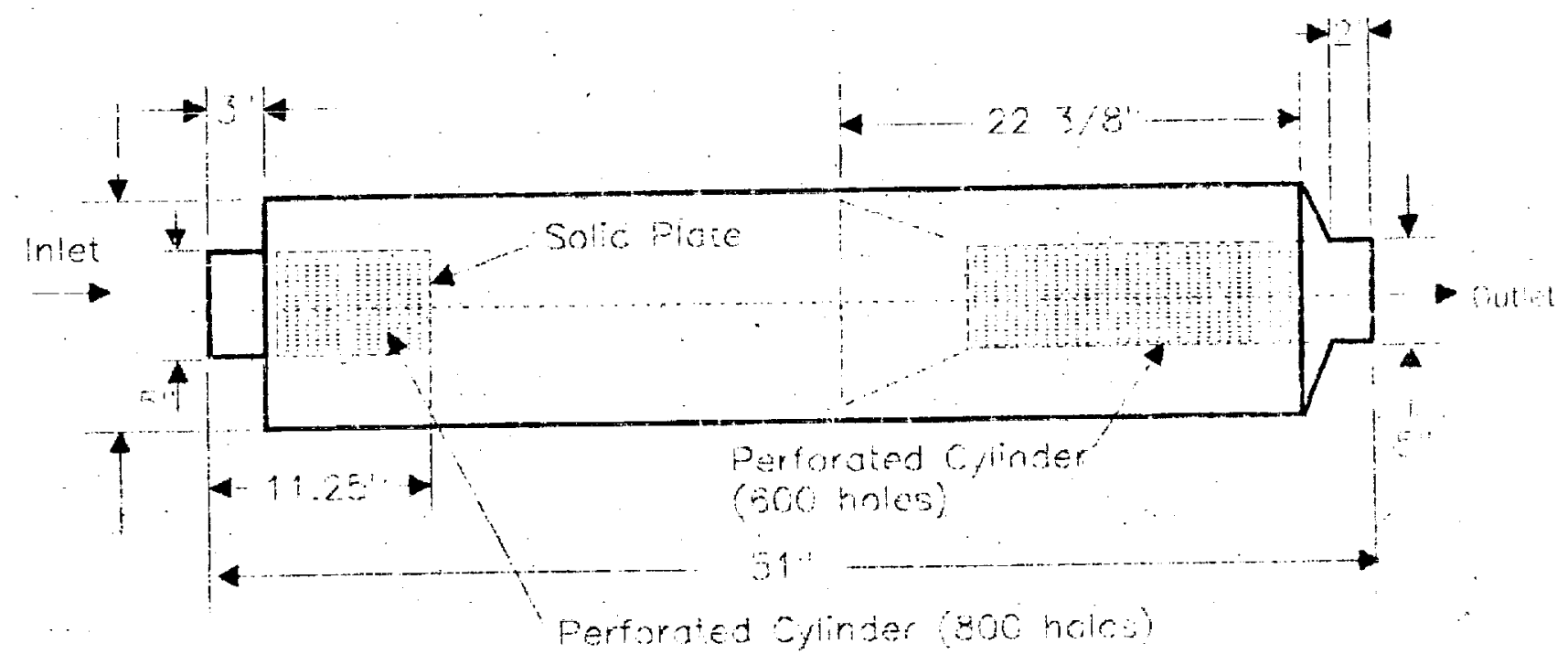

Figure B.4-4. Cross-section through a Muffler 


\section{DUCT FLOW EXPERIMENTS Total Pressure Correlations}

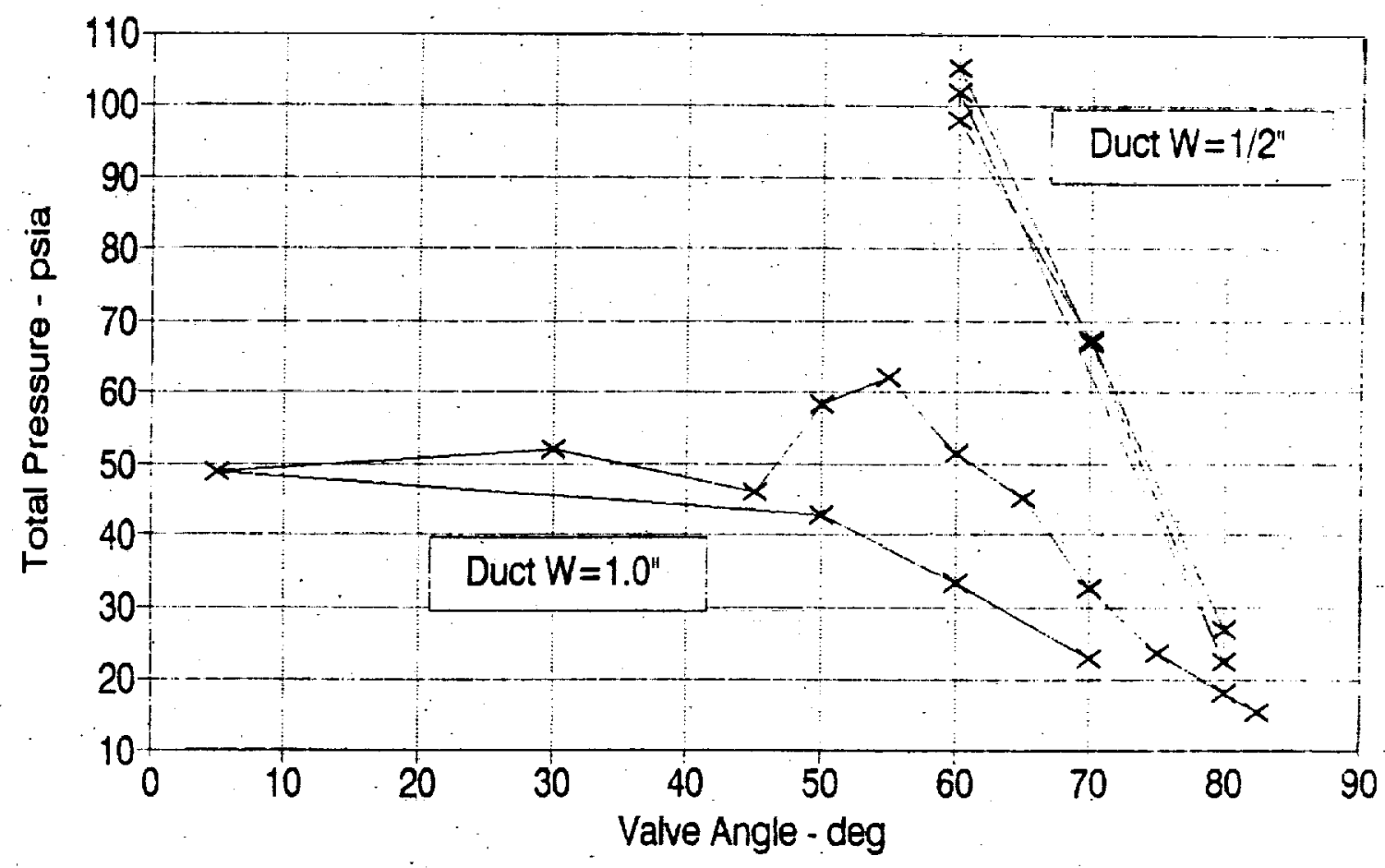

Figure B.4-5. Total Pressure Correlations 


\section{DUCT FLOW EXPERIMENTS Mach Number Correlations}

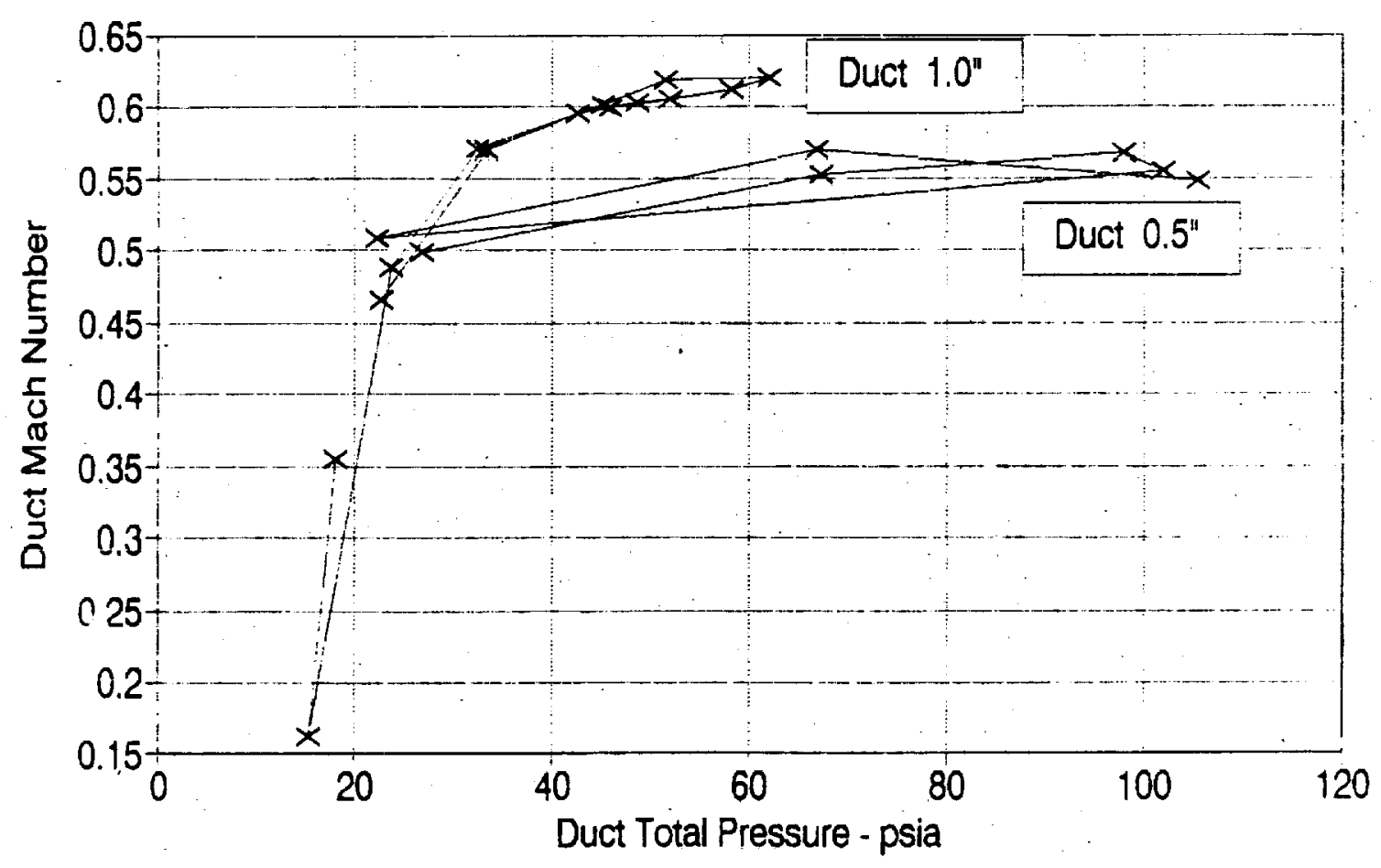

Figure B.4-6. Duct Mach Numbers 


\section{DUCT FLOW EXPERIMENTS Mach Number Correlations}

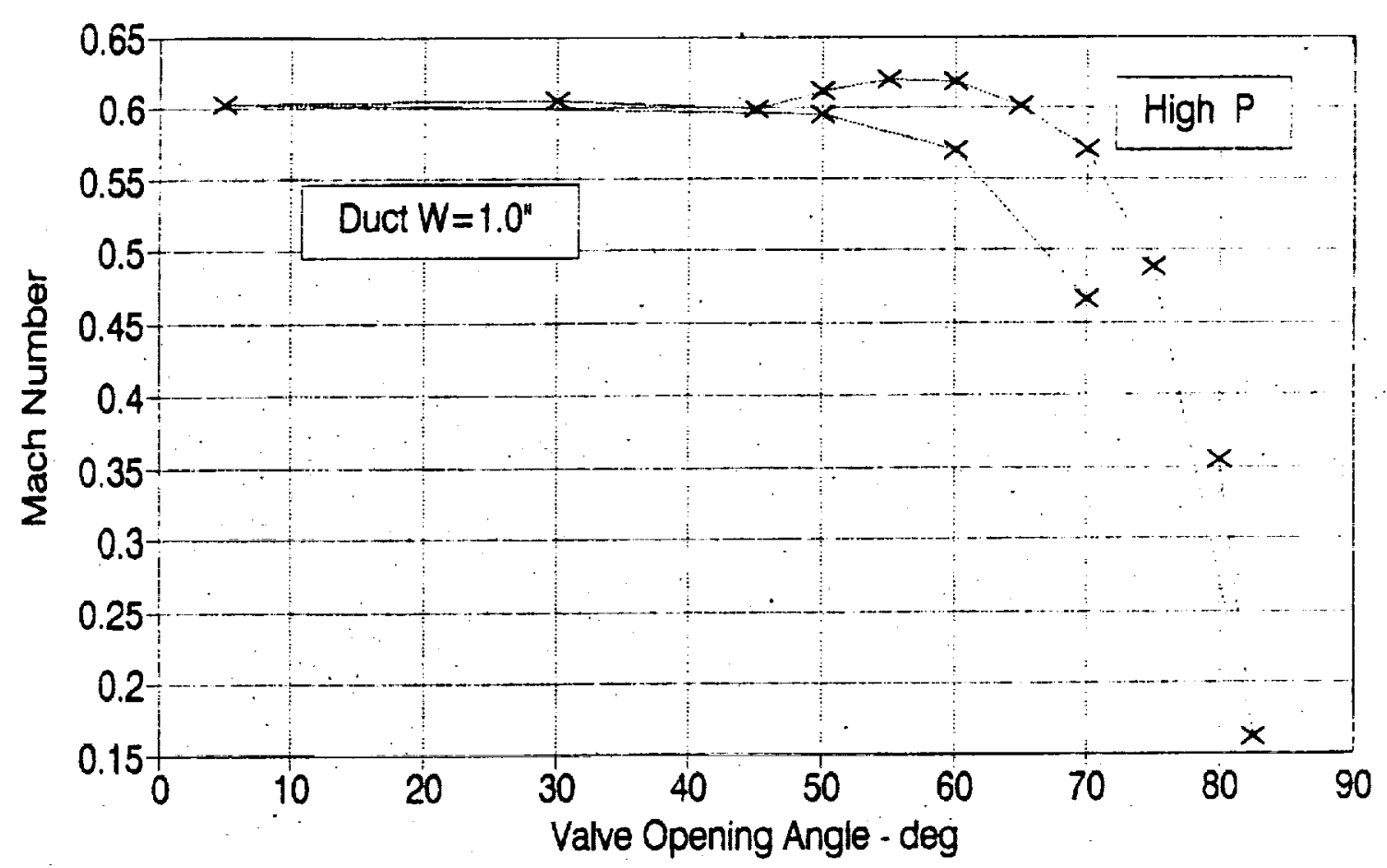

Figure B.4-7. Mach Number-Valve Angle Relations

Because of the problems with mixing and ignition, most of the experiments were performed with the valve angle around $80^{\circ}$. This means that in most cases the static pressures were only slightly above the ambient, and Mach numbers of the flow were less than 0.5. Occasional high injection frequency runs with greater valve openings were questionable because the duct pressure pulses did not seem to correlate with ignition or injection sequencing. 


\section{B. 5 Original Duct Tests}

Because of the difficulties connected with the development of detonation waves in the high speed flow duct, tests were performed in the original duct which was used in Reference 2 to determine the feasibility of developing transverse detonation waves in channel flows. The duct had a 2 " $x$ 12" cross-section and was 42" long. Air and propane were supplied at the closed end wall with the propane tube being bent $90^{\circ}$ so that the air and propane jets intersected. views of the duct showing the gas inlets and spark plugs are shown in Figure B.5-1. Propane was supplied from a 2.5" diameter, 48" long pipe which was filled to various pressures from the propane supply tank. Ignition was by continuous firing of spark plugs operated by a standard automotive ignition system. The pressure traces shown in Figure B.3-2 are interesting in that lower propane supply pressure produced higher duct pressures. Visual observations indicated that most of the explosions were taking place outside the duct. In the original experiments, great care was taken to adjust air and propane flow rates so that detonations occurred well within the duct. With such careful adjustments, pressure ratios of up to $12-13$ could be obtained while here the highest values were only $4: 1$ (approximately 45 psig).

It should be noted that the very low negative pressures are due to the overshoot of the transducers. It is also interesting to note that the 3 transducers which were in a field of 6" $x 12 "$ indicate identical pressures. The appearance of a second positive pressure pulse corresponds fairly closely to the fundamental organ pipe oscillation of the duct. 

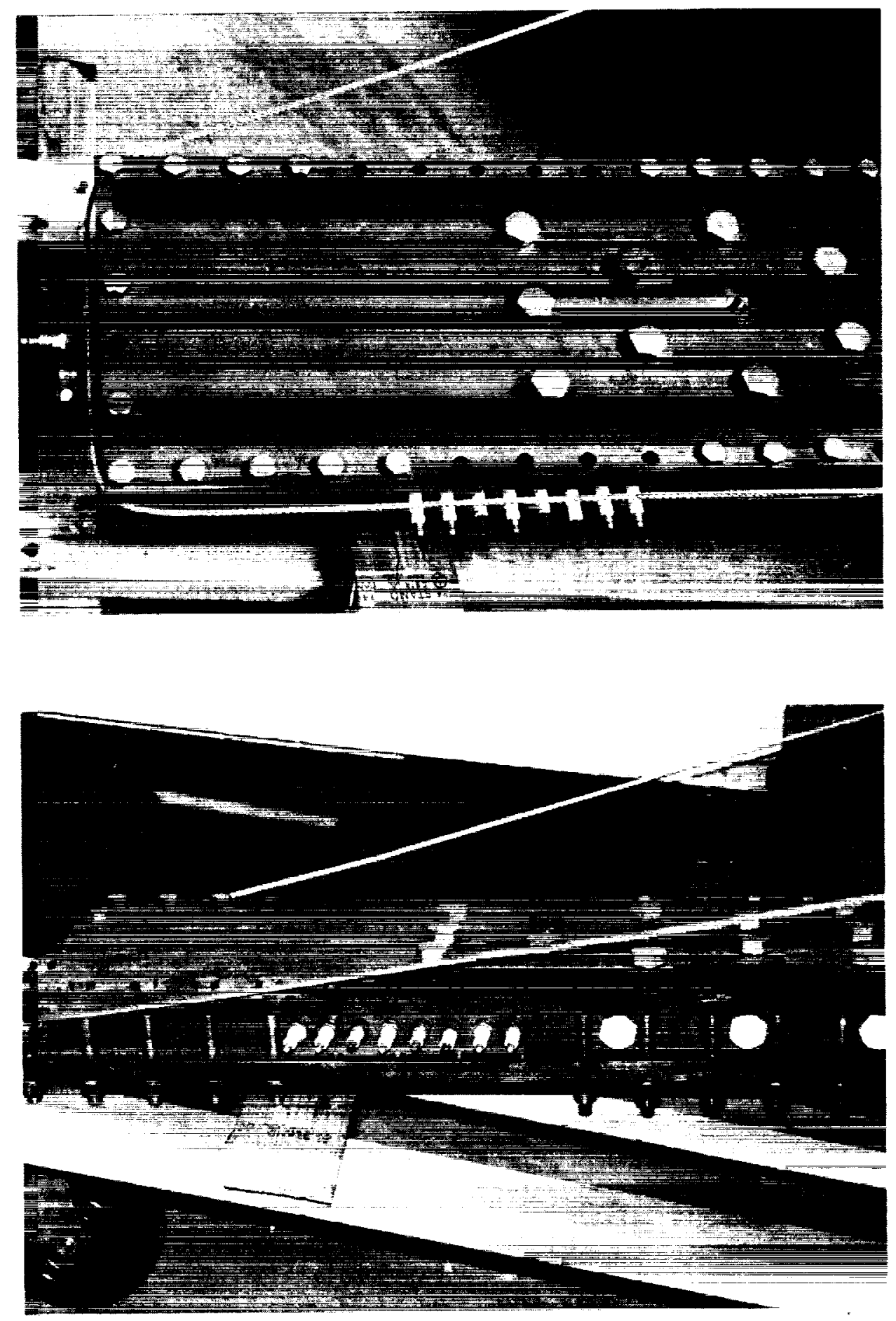

Figure B.5-1. Original Detonation Duct 


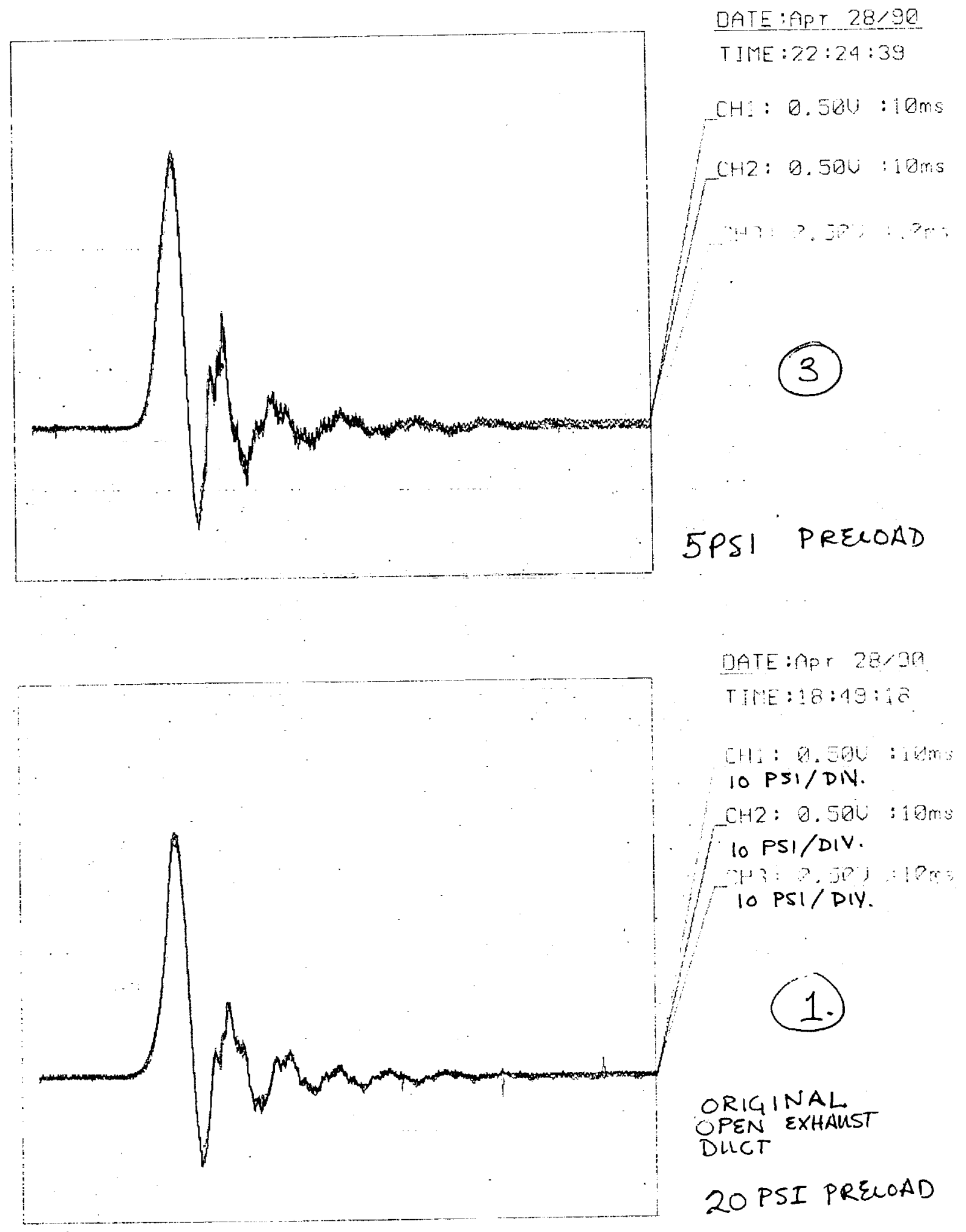

Figure B.5-2. Pressure Pulses in the original Detonation Duct B-19 


\section{B. 6 Valve Response}

The Omega valve shown here in Figure B.6-I was procured after it was determined that the fuel rates flow through the automotive injectors were too low.

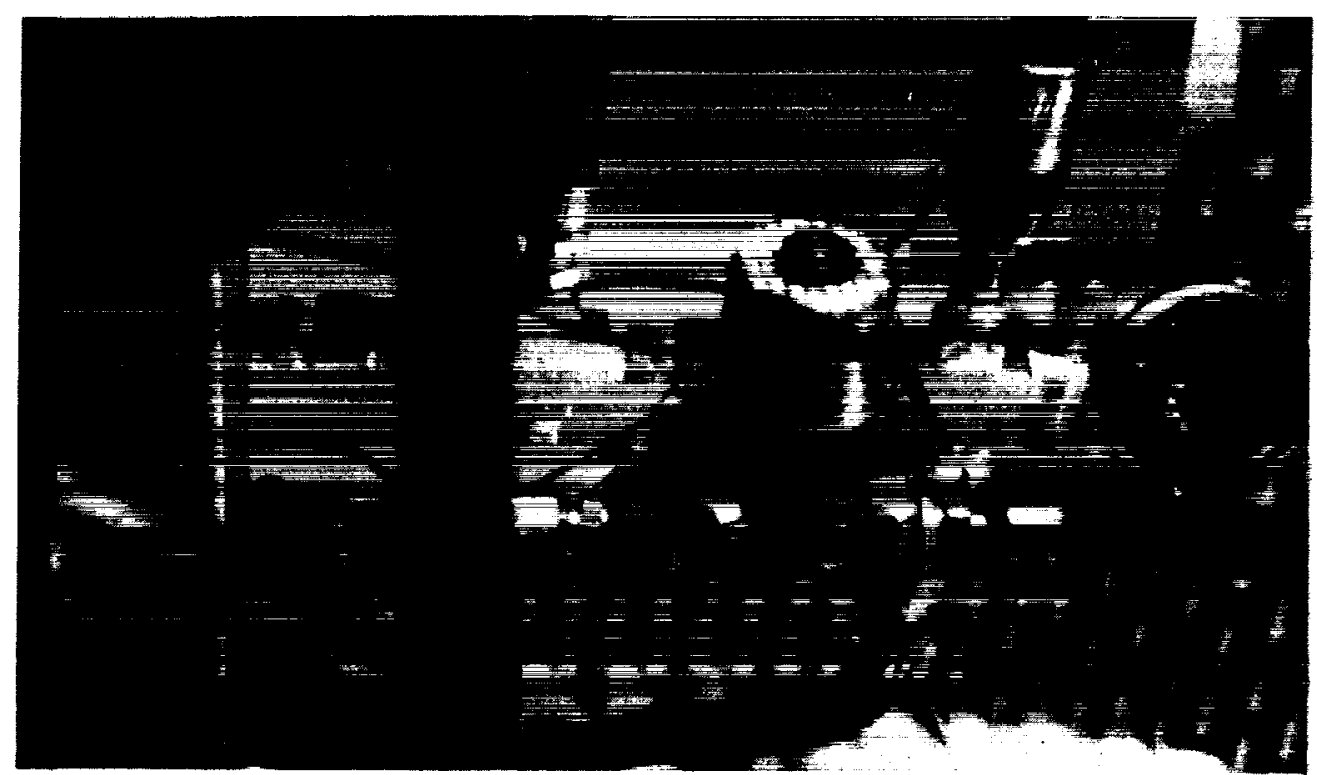

Figure B.6-1. Solenoid Valve Used to Inject Fuel

The valve response was tested by measuring the pressure in the fuel delivery line while the valve was cycled periodically up to its rated frequency of $50 \mathrm{~Hz}$. An example of a 20 Hz test with a $30 \%$ duty cycle is shown in Figure B.6-2.

It is seen that the valve remains open during a period of 3-4 times the expected open period, after it is nominally closed. This limited the tests to frequencies of $1-2 \mathrm{~Hz}$. 


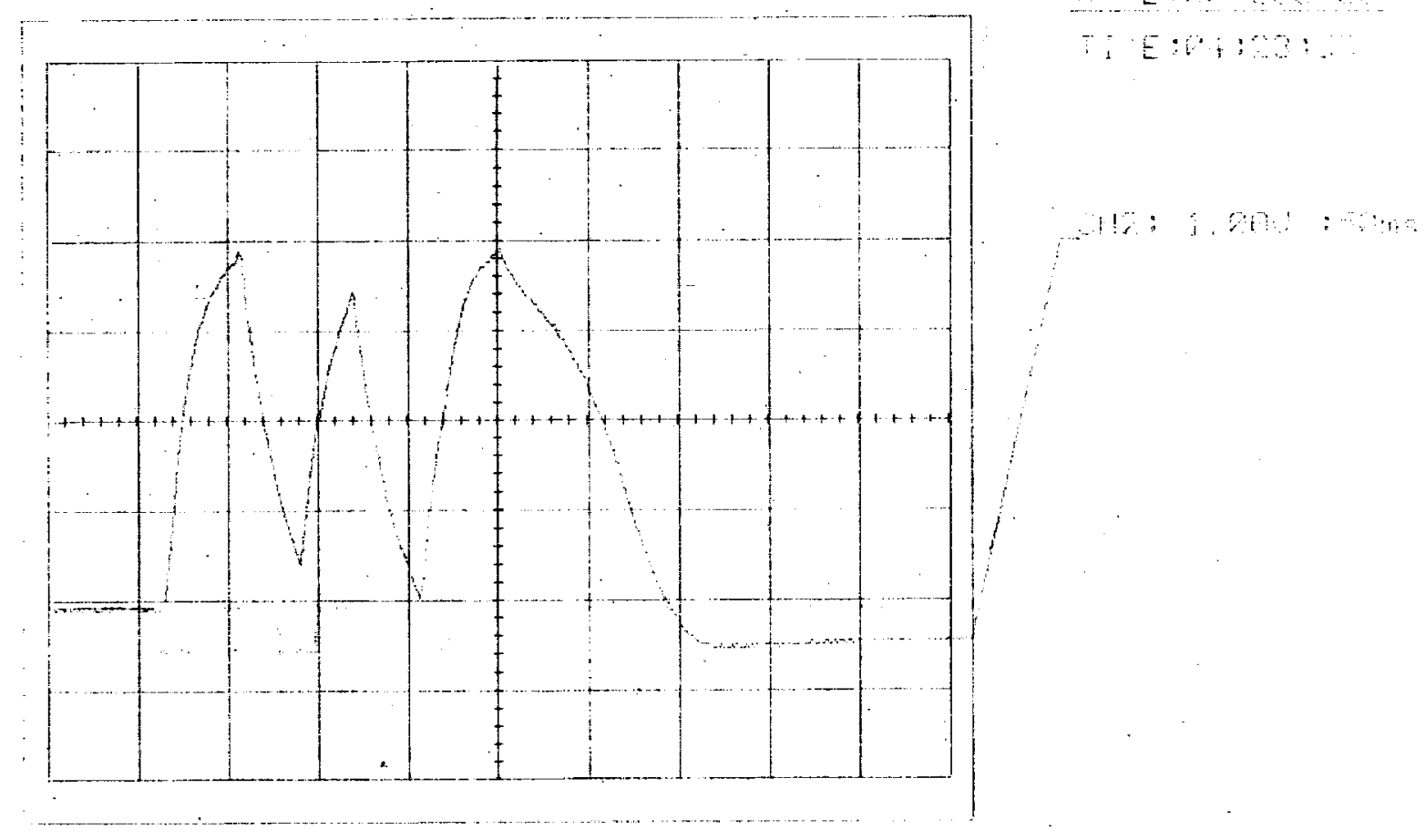

Figure B.5-2. Fuel Valve Response Test 


\section{B. 7 Combustion Bomb}

The apparently low detonation wave pressure necessitated a check of the combustion processes in a combustion bomb where the theoretical values are confirmed by a large number of experiments. A combustion bomb was constructed from a 1 ft length of 3" diameter plastic pipe with metal end-caps. Plastic was used to minimize heat losses. The combustion bomb is shown here in Figure B.7-1.

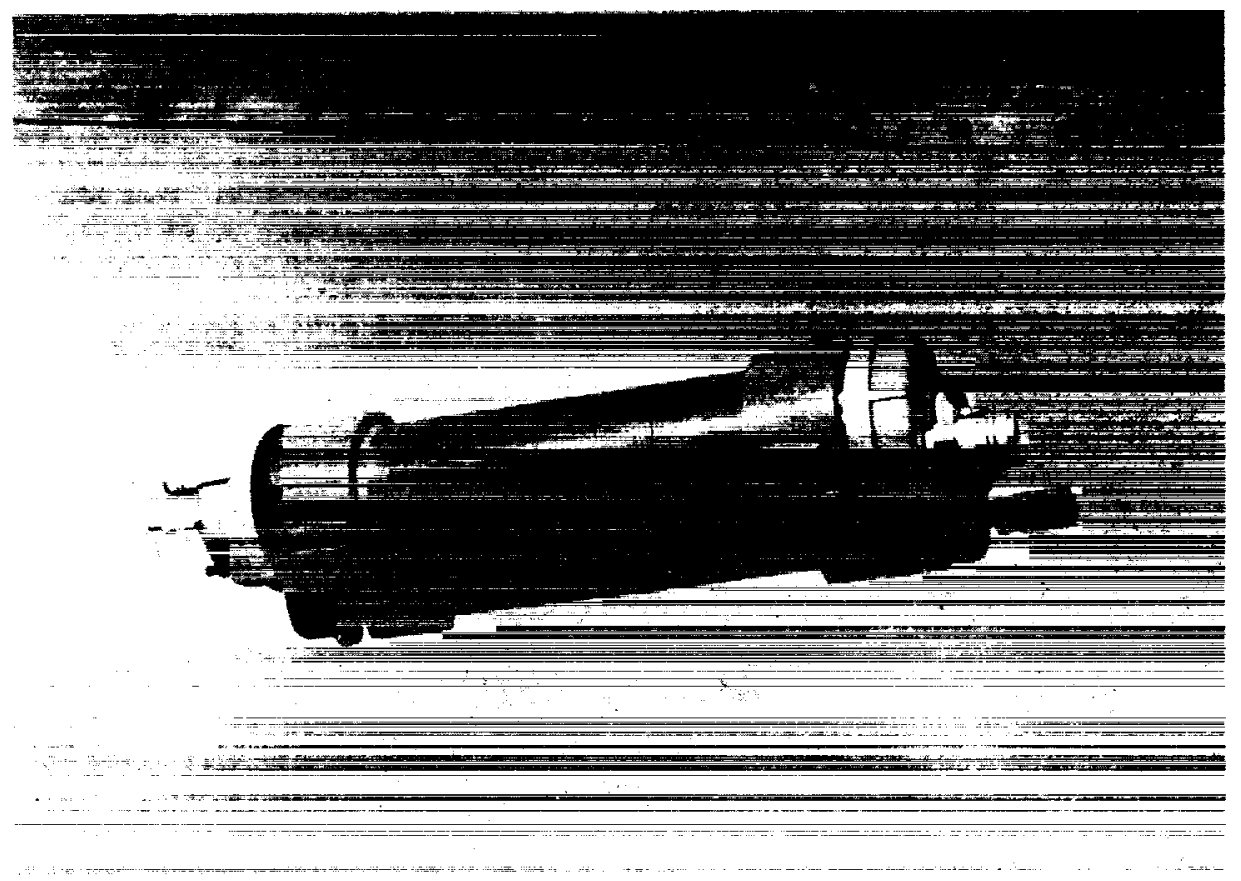

Figure B.7-1. Combustion Bomb

Some representative pressure traces are shown in Figure B.7-2, The initial pressure of the stoichiometric mixture was approximately $5 \mathrm{psig}$ and after ignition the recorded pressures were 180 psig and 234 psig for the PCB and validyne transducers respectively. These are pressure ratios of $10: 1$ and $12.7: 1$, but the latter is not reliable because the transient response of the validyne transducers was too slow for this type of testing. When twice the stoichiometric fuel/air ratio was used then the lower graph in Figure $B .7-2$ shows a pressure ratio of only approximately 4. Actually, this was quite representative of a large number of experiments with stoichiometric mixtures. 
The theoretical value for the pressure ratio in an isochoric propane-air combustion is about 10. This was not achieved in the combustion bomb, and in general, the pressure ratios were about half that value. Low values of around 4-5 were recorded in the flowing detonation duct and in the original duct, which had previously shown values of 8-12. The combustion bomb was purged with air and with propane-air mixture after each test so that the residual moisture on the walls was probably quite low. In the flowing duct, the molsture would be blown off the smooth walls so that it should not present any problems. A check with the California Air Resources Board revealed that commercial propane is at least $908 \mathrm{C}_{3} \mathrm{H}_{8}$ so that the quality of the fuel is fairly certain.

There is no rational explanation for the low pressures seen in the simple combustion bomb tests. 

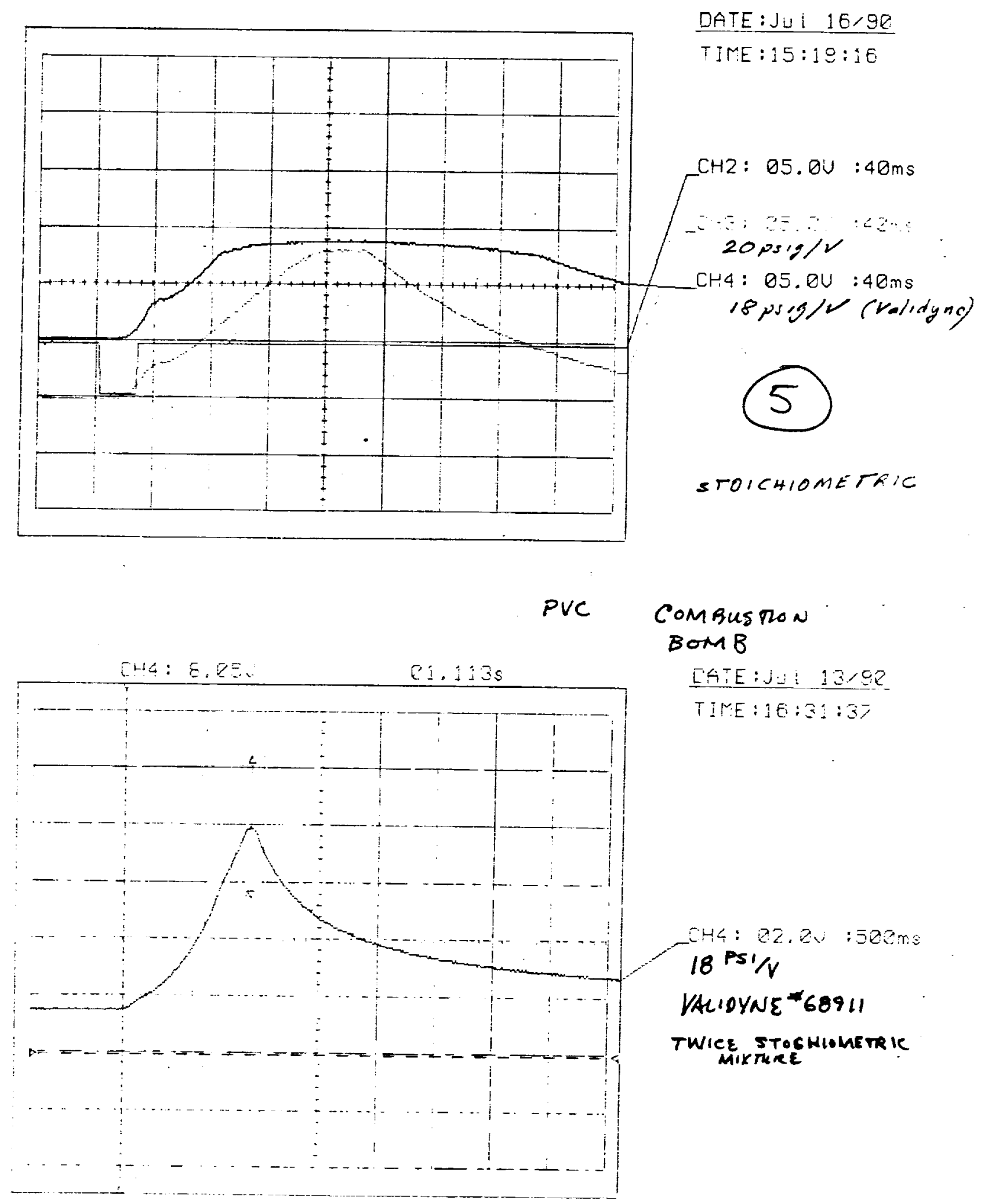

Figure B.7-2. Pressures After Isochoric Combustion 


\section{B. 8 Pressure Transducers Flame Tests}

Certain anomalies in the appearance of the pressure traces from the $\mathrm{PCB}$ and Kistler pressure transducers led to an investigation into their temperature stability. The local PCB representative (Dale/Dahl Associates) gave firm assurances that the transducers were temperature compensated and therefore stable. Kistler pressure transducers representatives could not offer any useful information. Inquiries at the $P C B$ factory yielded firm assurances that their transducers were not sensitive to temperature variations and exposure to flames. Preliminary tests of running a propane torch flame over the faces of the transducers showed that a trace resembling a pressure pulse could be produced quite easily. Further discussions with the PCB factory elicited the astonishing admission that flame tests had never been tried and our results were a complete surprise. Shortly afterwards, Dale/ Dahl Associates in PCB's name presented ISTAR Inc. with a roll of electrical tape and a tube of RTV to protect the transducer faces from the flames. Representative traces, produced by a rapid motion of a propane torch flame over the PCB transducers, with and without electrical tape cover, are shown in Figure B.8-1. It should be noted that the kistler 603L transducers exhibited an even greater sensitivity to exposure to flames. Because of scheduling demands, it was not possible to establish whether the exposure to flames caused spurious responses because of temperature effects or if the free electrons in the flame affected the charges on the piezoelectric elements.

The conclusion here is that the instrument manufacturers representatives know virtually nothing about their product and the manufacturers themselves do not test their instruments under conditions representative of the experiments for which the instruments are sold.

All the results reported here were obtained with electrical tape covering the piezoelectric elements of the transducers. 


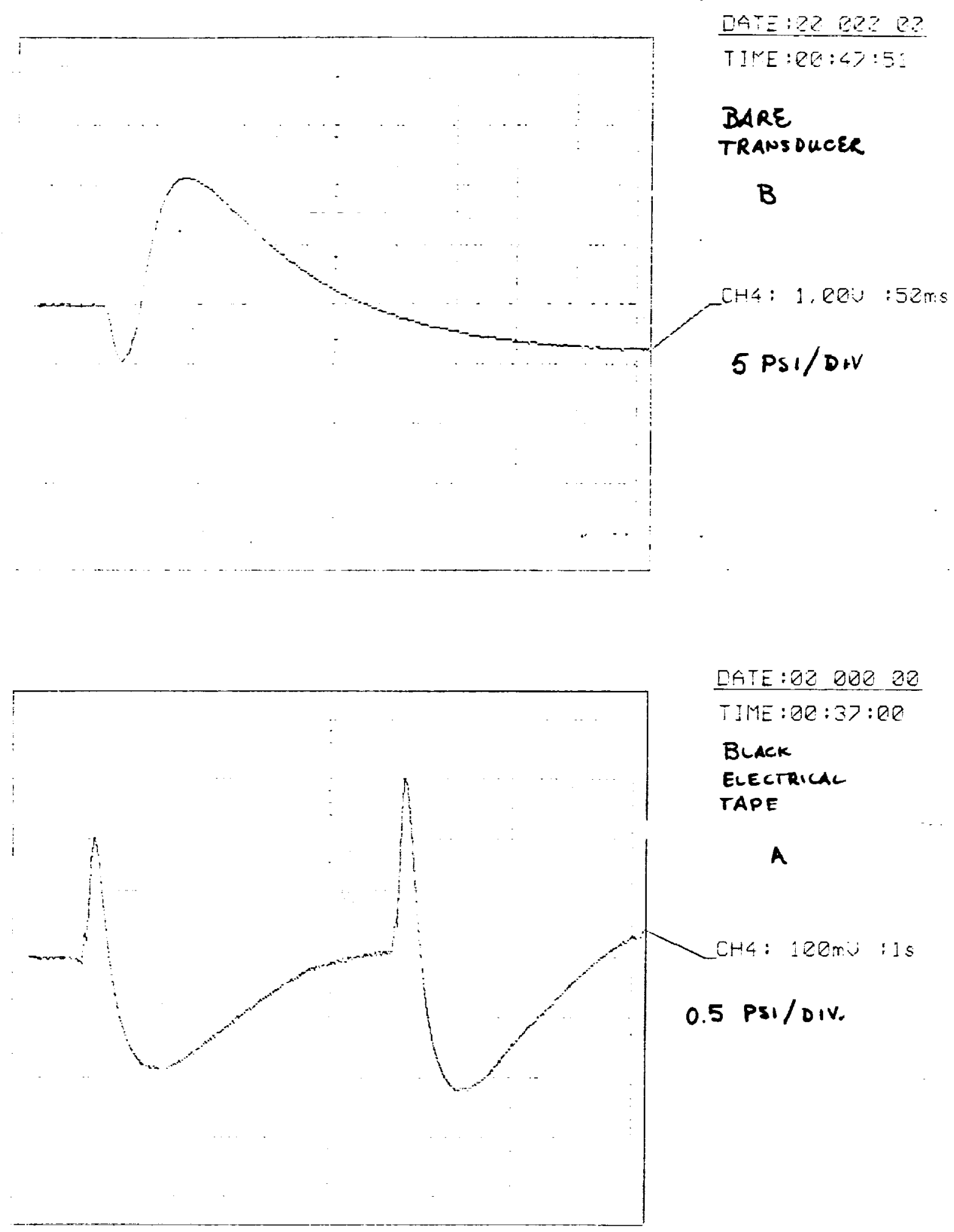

Figure B.8-1. Flame Exposure Tests of Pressure Transducers

$$
\text { B-26 }
$$




\section{APPENDIX C}

\section{DESIGN OF THE PROTOTYPE GAS GENERATOR UNIT}

It is intended to use the detonation ducts to process some part of the air leaving a relatively low pressure centrifugal or mixed-flow compressor at the front of the engine. For this reason, the detonation ducts are arranged around the circumference of the engine with the detonation waves moving normally to the axial flow and along the radil of the engine.

\section{c. 1 Prototype Design}

The general layout is shown in Figure $C .1-1$ in an axial section. In this case, very short inlet section is shown because originally a constraint was placed on the overall length of the device. The detonation ducts are in the central section which bolts to the inlet and exhaust sections through six-arm flanges. Also shown in the Figure is the divergence of the duct in the axial direction.

A detailed assembly drawing of the prototype duct was prepared under a subcontract by Korwin Advanced Technologies Co. Figure $\mathrm{C} .1-2$ shows a highly reduced drawing. A full set of full scale drawings was transmitted to the NASA program Manager, Dr. W. Rostafinski. The final design had an extended inlet section and had a length of 120 inches with a diameter of approximately 48 inches. Sections through the gas generator are shown in Figure $\mathrm{C} .1-3$. Although a six detonation duct prototype was designed, it was intended to use only 1 duct because of the very limited supply of compressed air. The intent was to inject liquid propane using automotive fuel injectors mounted in vertical arrays in the walls near the inlet to the detonation duct. Ignition was to be by means of spark plugs whose firing was directed by the injection-ignition control system.

The flanges which joined the inlet section and the exhaust duct to the central detonation ducts are shown in Figures $C \cdot 1-4$ and $C \cdot 1-5$ respectively. In the design shown here, bolts were used wherever possible to allow changes to be made with minimum expenditure in time and money. 


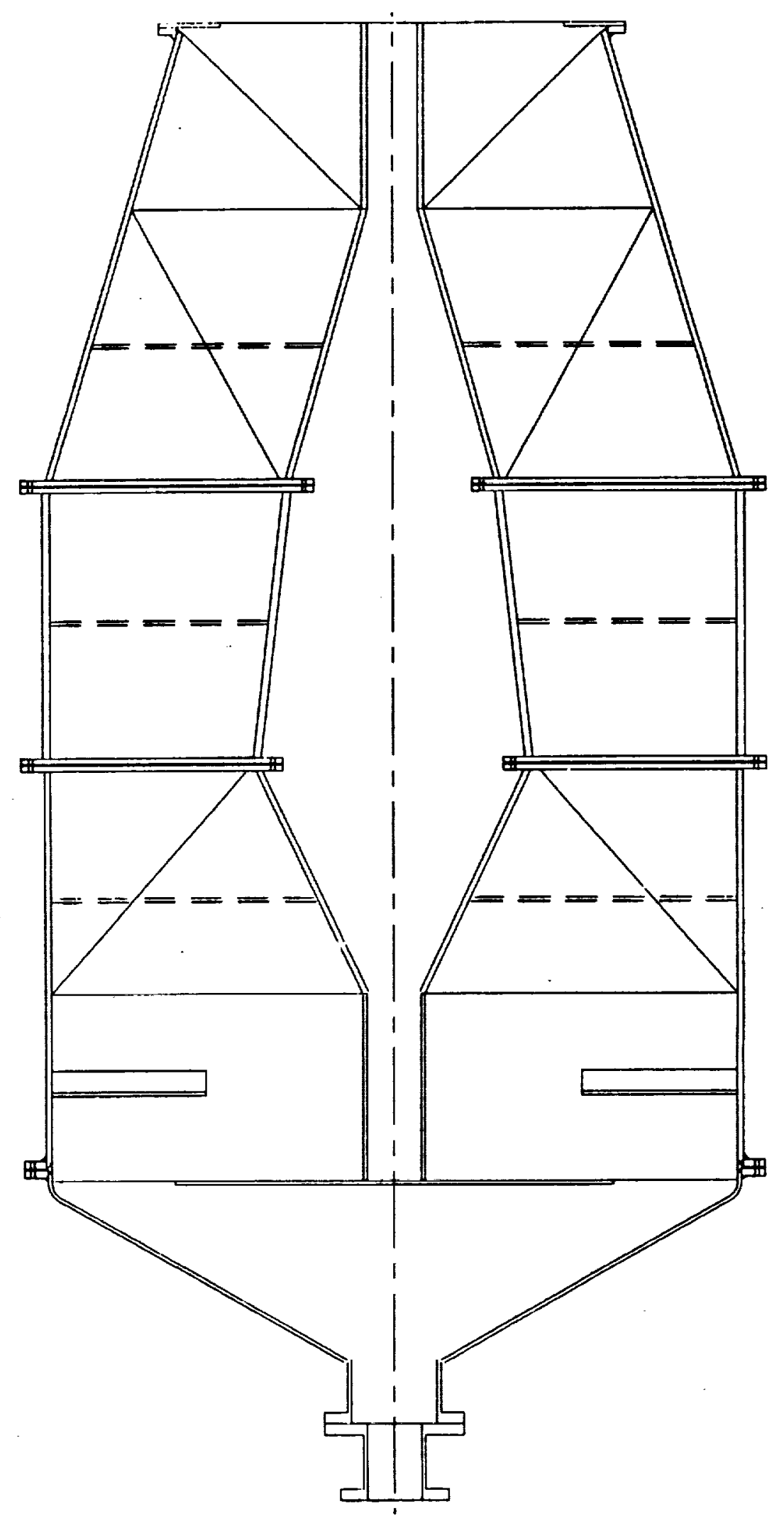

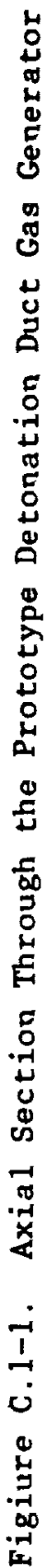

$$
c-2
$$


ORIGINAL PAGE IS

OF POOR QUALTY

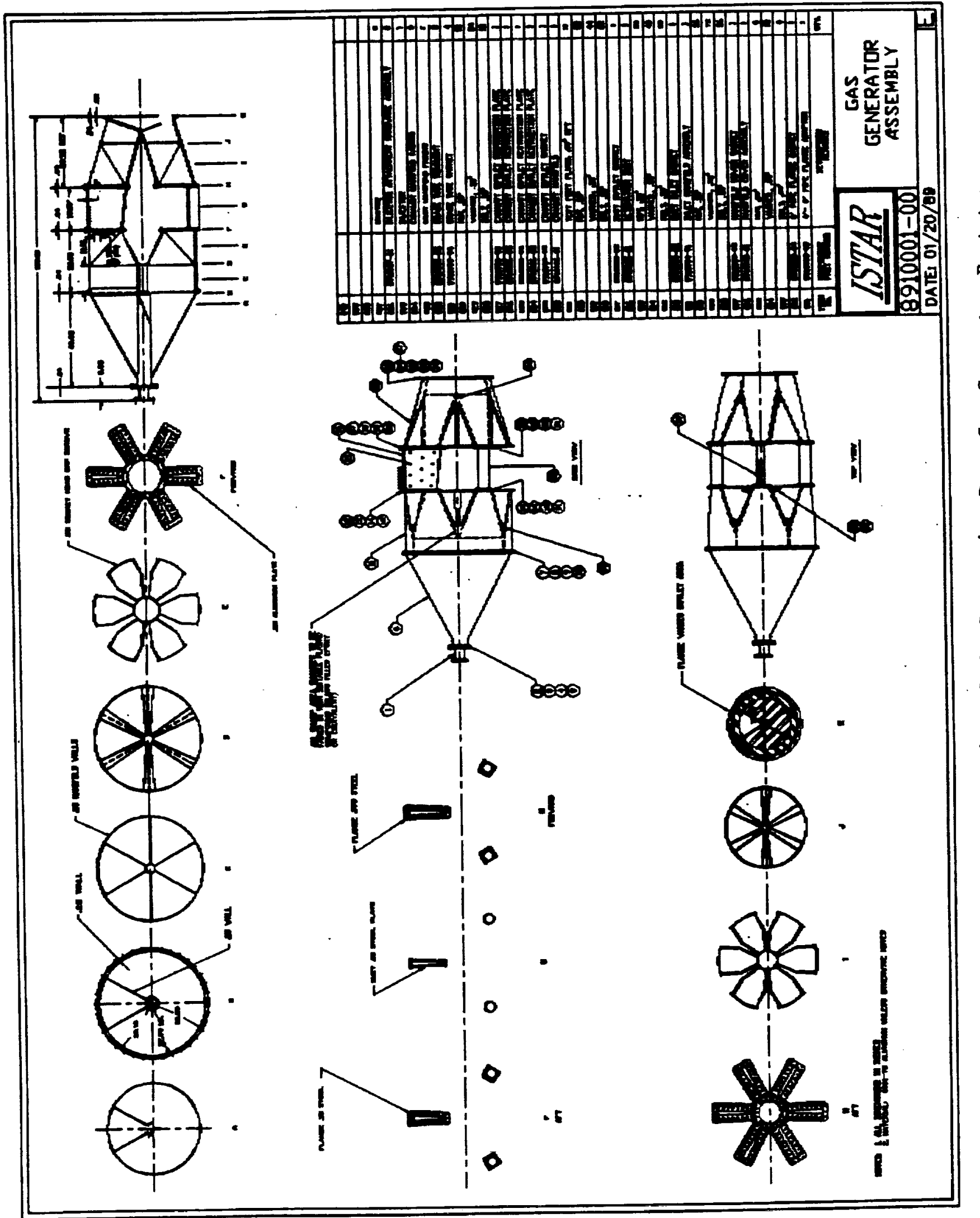

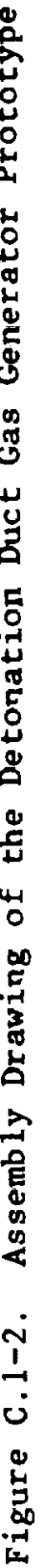




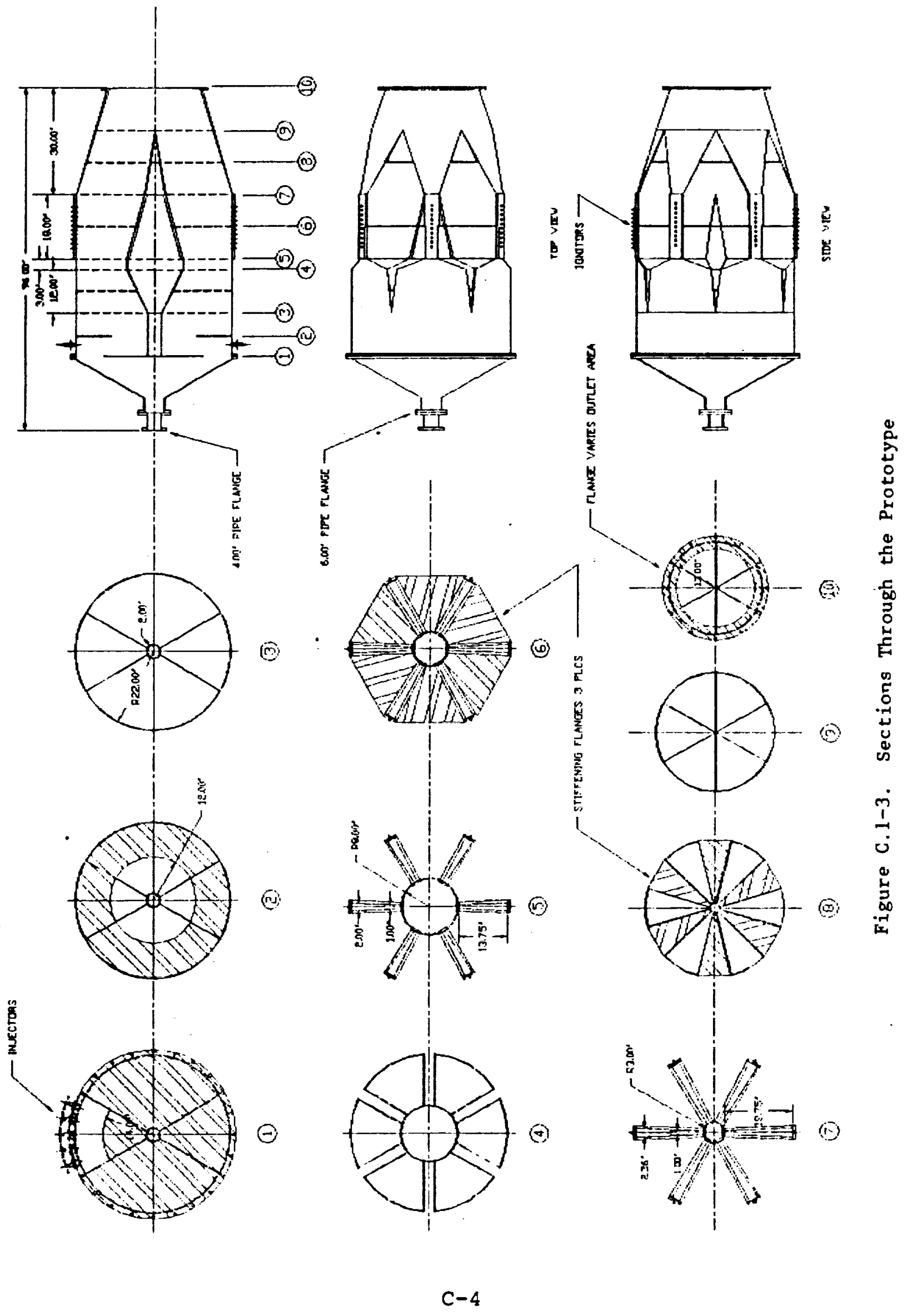




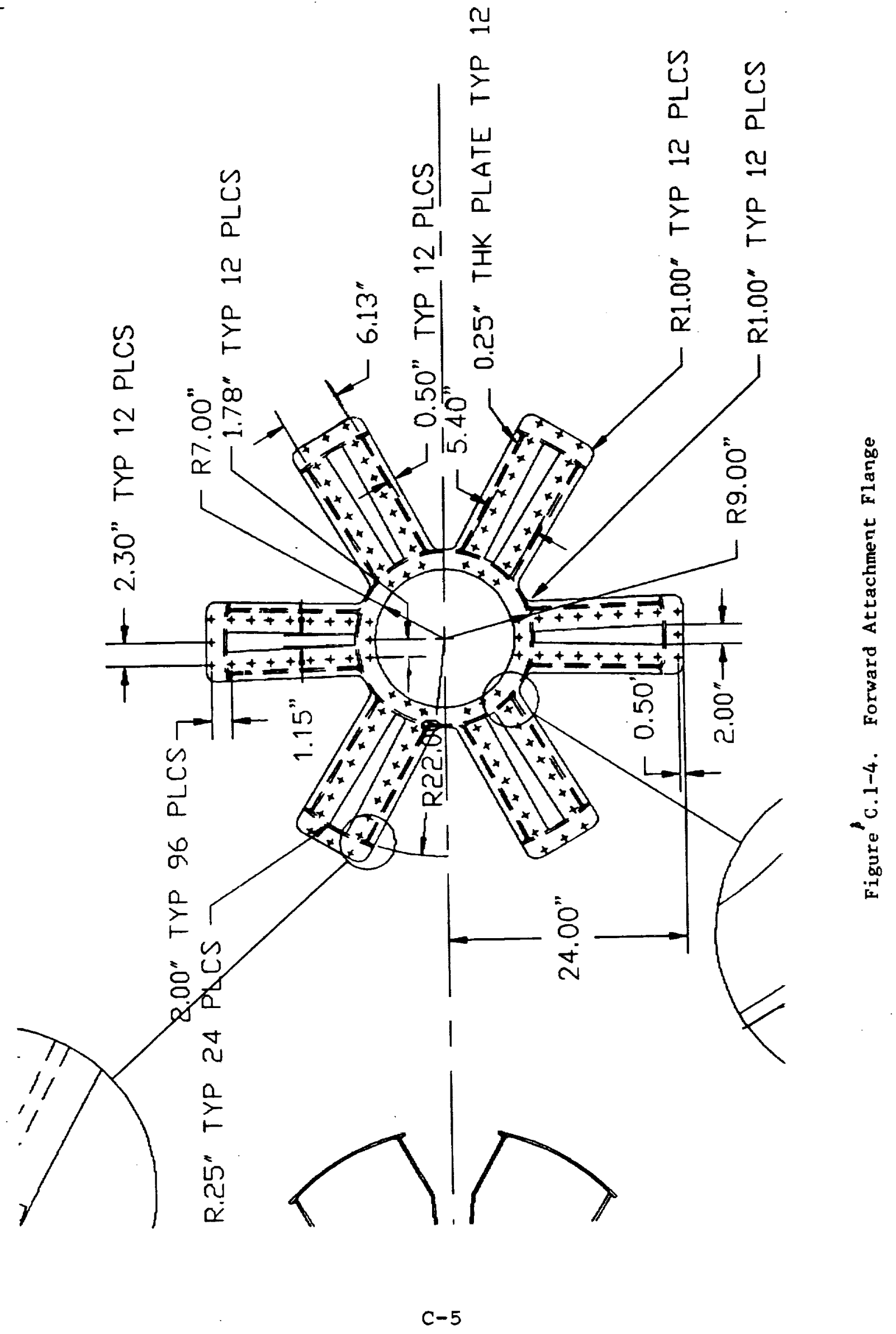




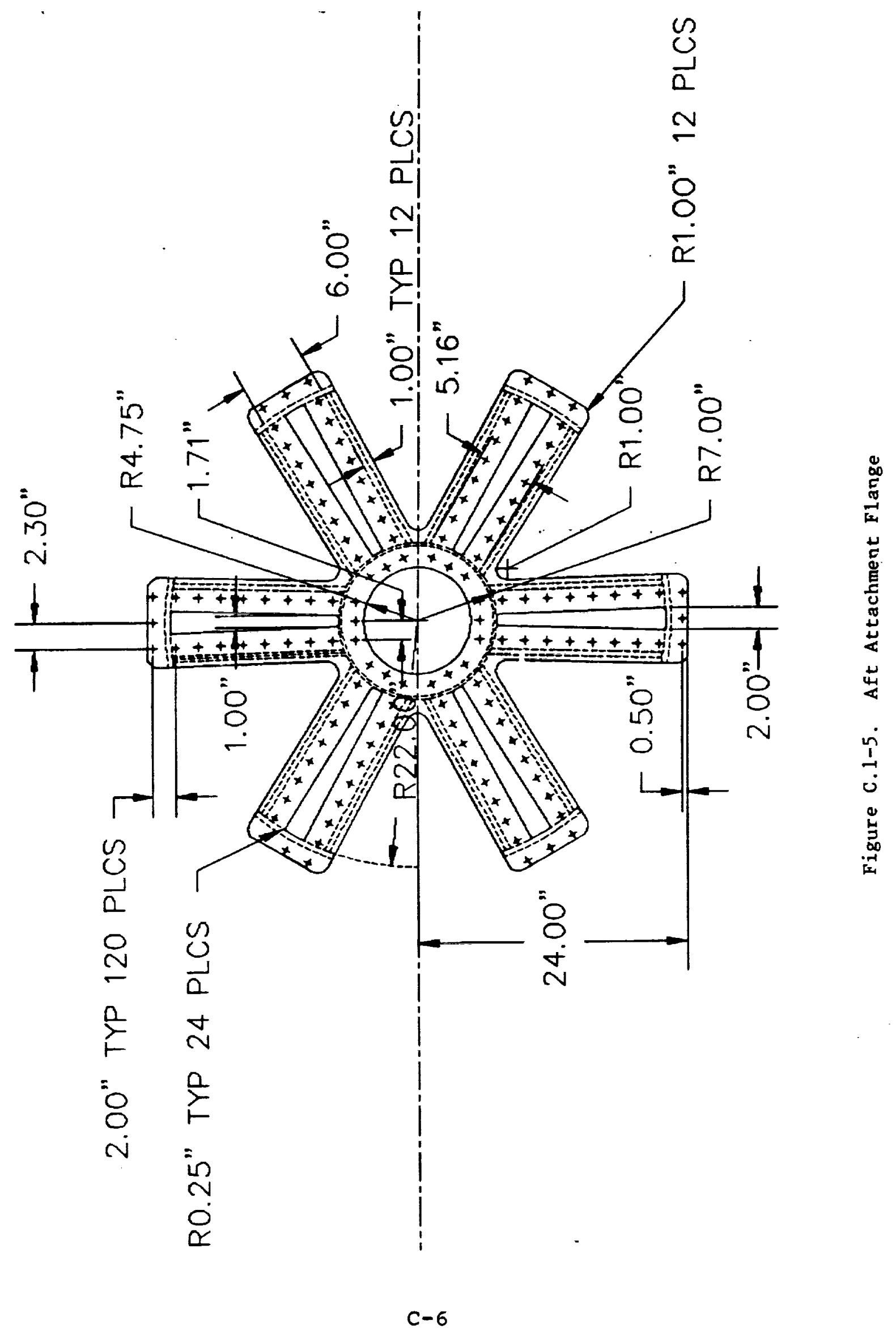




\section{2 Cost Estimates}

The preliminary fabrication drawings were shown for comments, suggestions, and critique to the following metal fabricators in the Los Angeles are:

FABRICATOR LOCATION

Atlantic Steel Western South Gate

Benner Sheet Metal

Anaheim

Carolina Rolling Co. South Gate

Hales Engineering

Camarillo

$J \& J$ Engineering

Gardena

Paramount Roll \& Forming

Santa Fe Springs

Sellars Products Inc.

Los Angeles

Tri-Models Inc.

Torrance

Wilcox Machine co. Bell Gardens
PERSONNEL

W. R. Burnham

A. Schroeder

J. Thornton

R. Hales

J. Donan

K. Moscrip

E.Iriana

P.A. Herzog

B. Murray
PRELIMINARY

COST ESTIMATE

$\$ 12-13,000$

$\$ 18-19,000$

$\$ 120-140,000$

$\$ 15-16,000$

$\$ 14-16,000$

$\$ 40,000$

$\$ 19,500$

on the basis of discussions, demonstrated experience and facilities, it was decided to send final drawings for firm bids to:

Benner Sheet Metal

Hales Engineering

Sellars Products Inc.

It should be noted that $J \& J$ Engineering claimed that they were doing comparable work for NASA and their incredibly high bid was in line with the bids accepted by NASA. 
The final drawings were assembled, a brief description was prepared and 3 vendors were invited to bid on the delivery of the assembled unit. The bids were in the range of $\$ 15,000$ to $\$ 22,500$. Further discussions with the vendors are necessary before a decision can be made.

\section{3 Model of the Prototype}

In the interests of assisting in the visualization of the prototype design, a $1 / 12$ scale model was constructed out of clear plastic. This is shown here in Figure c.3-1. The radial disposition of the detonation ducts around the circumference is clearly brought out by the red elements. The exhaust is extended to the central spine in the interests of rigidity. In the actual case, the exhaust would be terminated upstream at an appropriate exhaust area. 

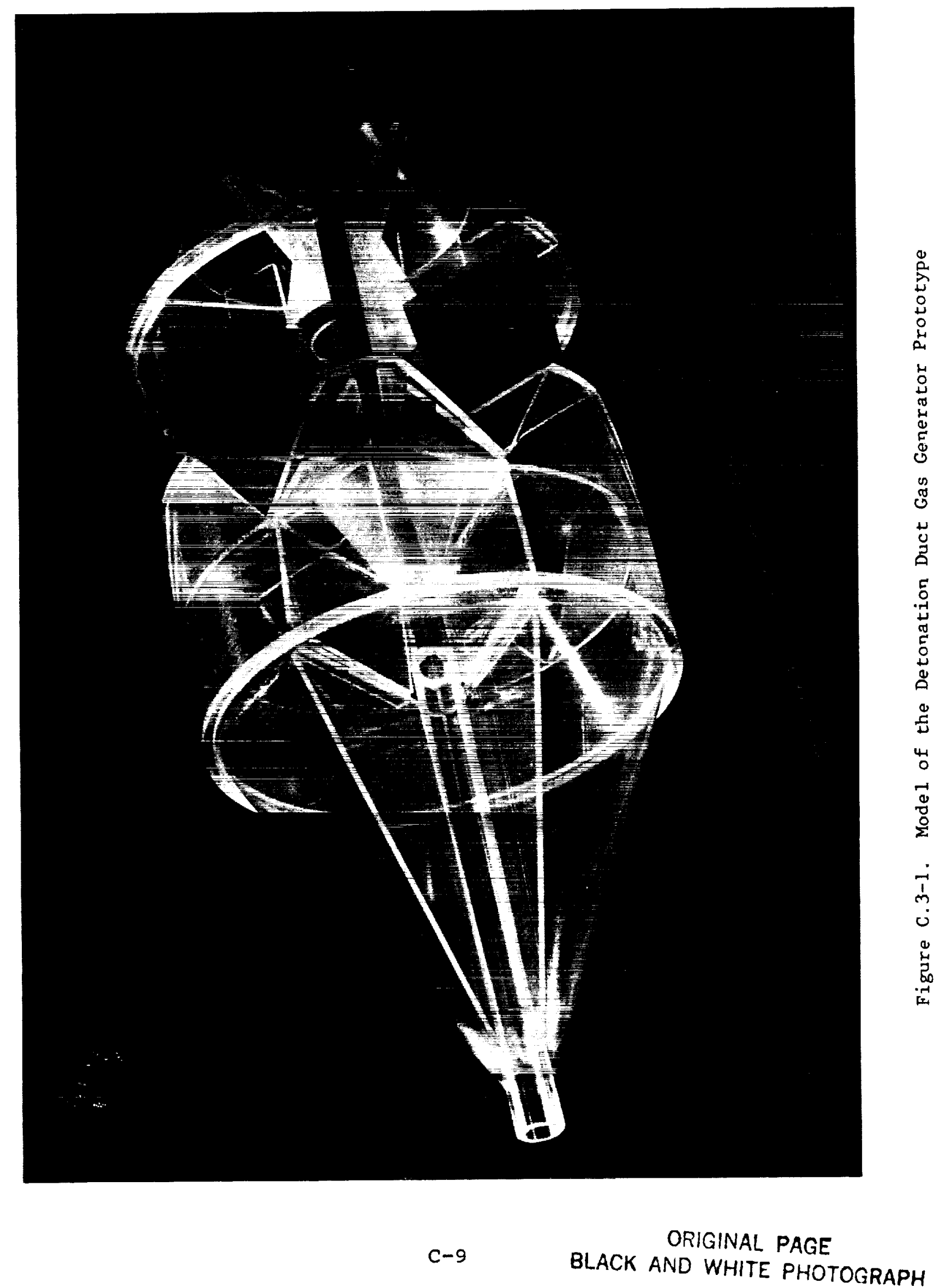
$-1-$ 
APPENDIX D

EXPERIMENTAL DATA

The experimental data, together with the principal parameters of each experiment, are summarized in the following tables. Other tests, which were performed in support of the principal experimental program, are presented elsewhere in the report.

The abbreviations in the column headings are as follows:

POS

Location of the pressure transducer which is shown in Figure D.I-I for the old duct. New duct locations are shown in Appendix $B$.

PRESS

Peak pressure on the first pulse, 'psig

PresPer

Period of pressure pulses, ms

InjPer

Injection period, ms

InjDur

Duration of the injection pulse, ms

IgnDel

Delay of ignition from start of the injection pulse

Tank Pr

Pressure in the air supply tank, psig

VIVeA

Angle of opening of the ball valve controlling the flow, degrees $\left(90^{\circ}\right.$ is fully closed)

COMMENTS

Remarks on the results. Full remarks are on the data base

The abbreviations in the headings for each run are:

B

Injection through the bottom plate

D

Deflector plate ahead of the injector

$F$

Front injectors only

L

Liquid propane injection

M

Middle injectors 


$\begin{array}{ll}\mathrm{n} & \text { Number of injectors } \\ \text { P } & \begin{array}{l}\text { Premixed air/fuel injection in conjunction with } \\ \text { liquid injection } \\ \text { Pre }\end{array} \\ \text { /P } & \text { Blocking plate in the duct inlet } \\ \text { T } & \text { Top injection } \\ \text { Tri } & \text { Triangular duct cross-section } \\ \text { V } & \text { Injection with solenoid valve }\end{array}$
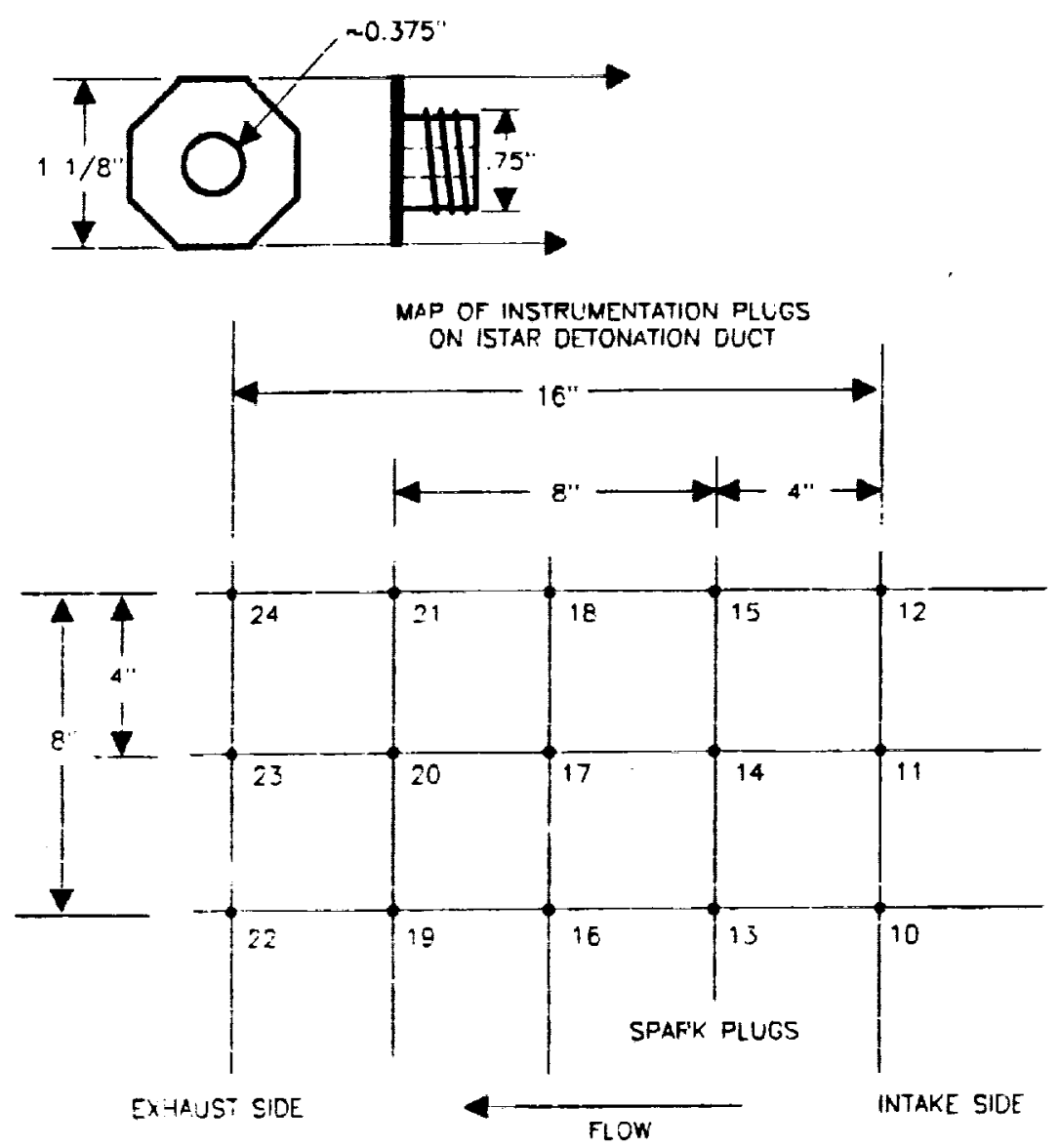
Figure D.1-1. Location of the Instrumentation
Ports in the old Duct

D-2 
NASA DETONATION DUCT GAS GENERATOR PROGRAM - PRESSURES

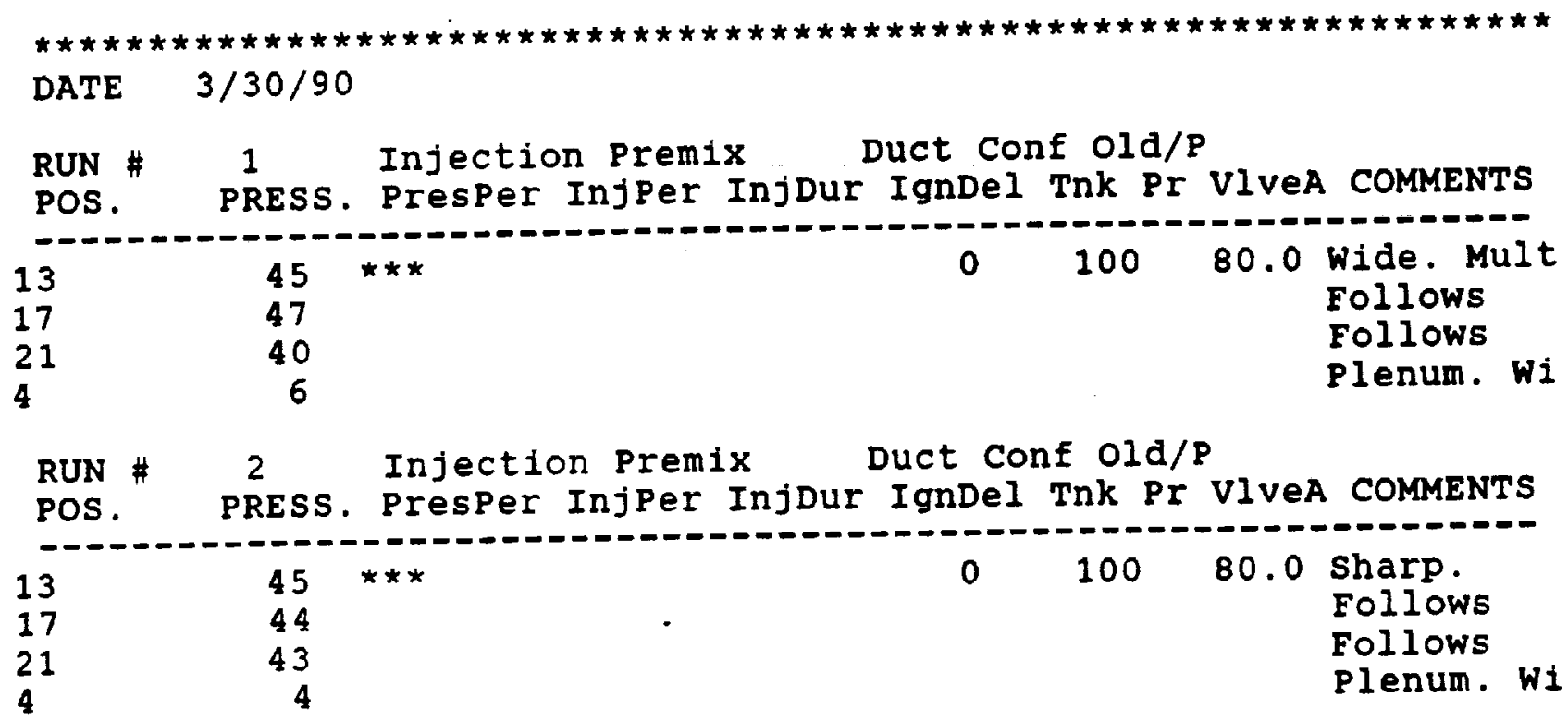

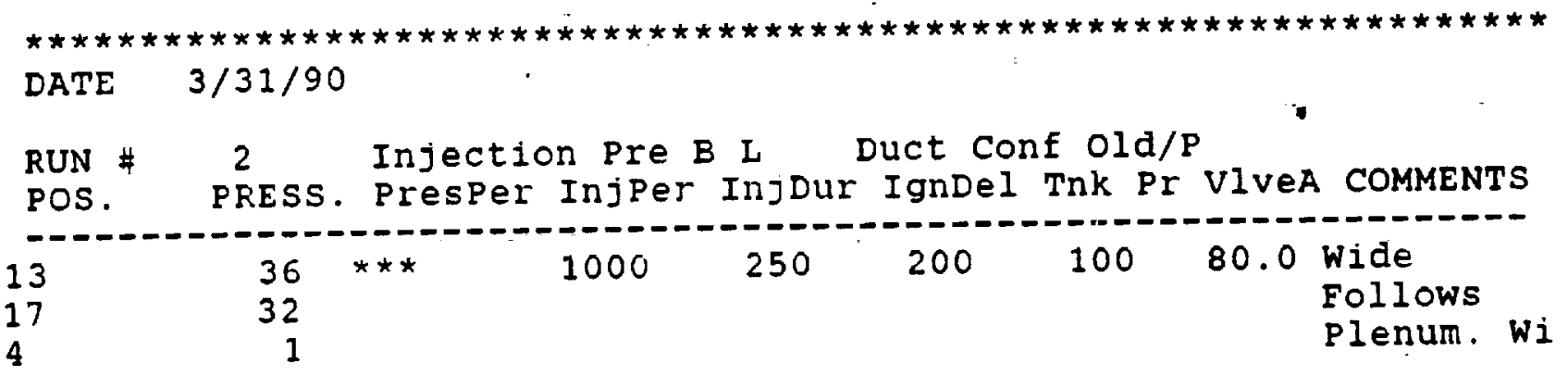

\begin{tabular}{|c|c|c|c|c|c|c|c|}
\hline $\begin{array}{l}\text { RUN \# } \\
\text { POS. }\end{array}$ & $\stackrel{4}{\text { PRESS. }}$ & $\begin{array}{l}\text { Injection Pre } \\
\text { Presper InjPer }\end{array}$ & InjDur & $\begin{array}{l}\text { Duct Cor } \\
\text { IgnDel }\end{array}$ & $\begin{array}{l}\text { nf old } / \mathrm{I} \\
\text { Tnk Pr }\end{array}$ & VIveA & $\mathrm{CO}$ \\
\hline $\begin{array}{l}13 \\
17 \\
21\end{array}$ & $\begin{array}{r}48 \\
48 \\
66 \\
4\end{array}$ & 1000 & 250 & 200 & 100 & 80.0 & $\begin{array}{l}\text { Wide } \\
\text { Identical } \\
\text { Sharp } \\
\text { Plenum. La }\end{array}$ \\
\hline
\end{tabular}

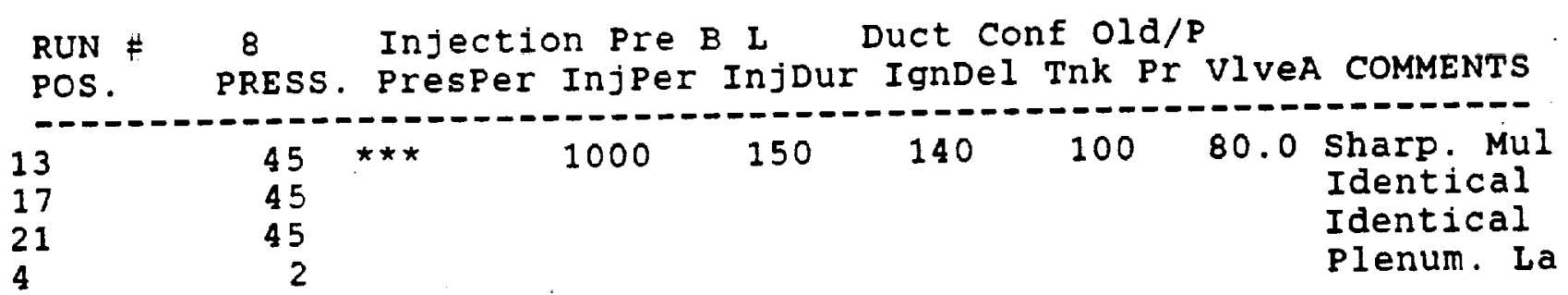

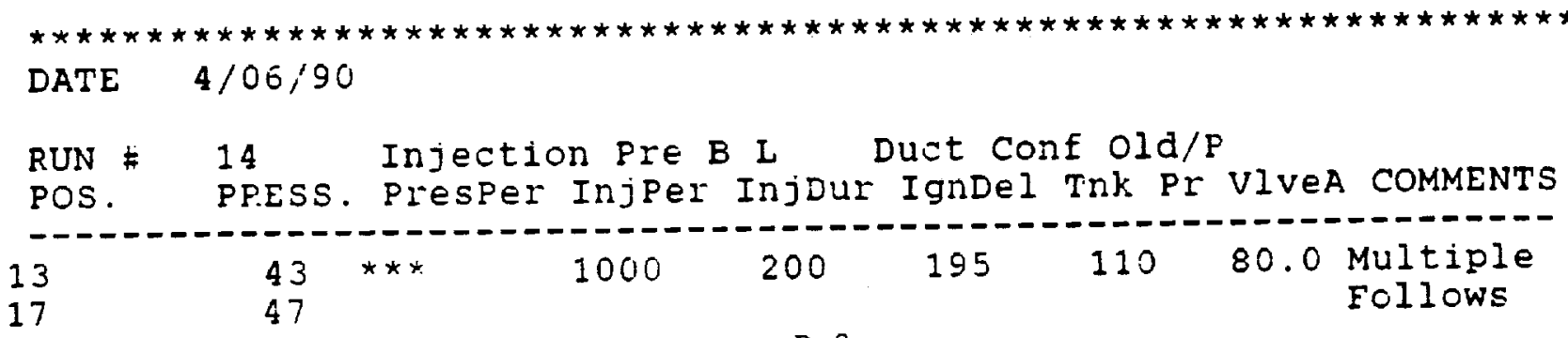


NASA DETONATION DUCT GAS GENERATOR PROGRAM - PRESSURES

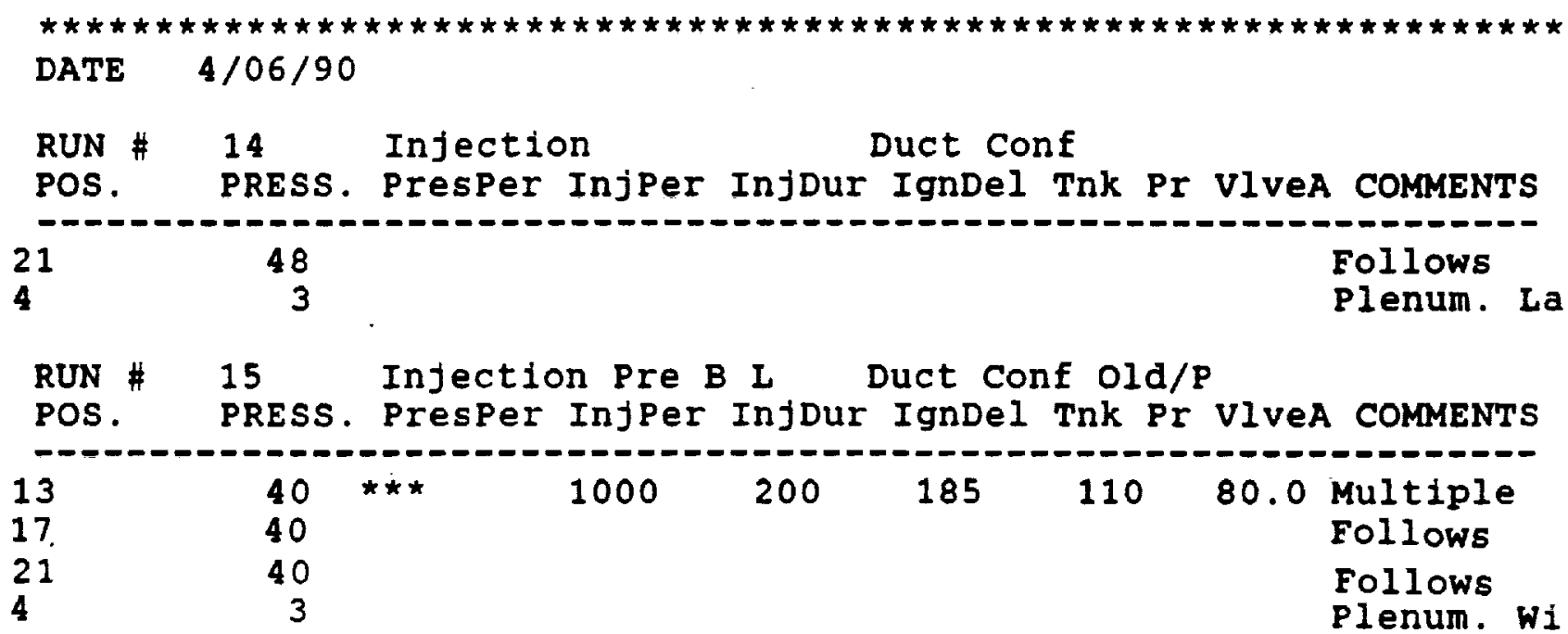

RUN \# 16 Injection Pre B L Duct conf Old/P POS. PRESS. PresPer InjPer InjDur IgnDel Tnk Pr VIveA COMMENTS

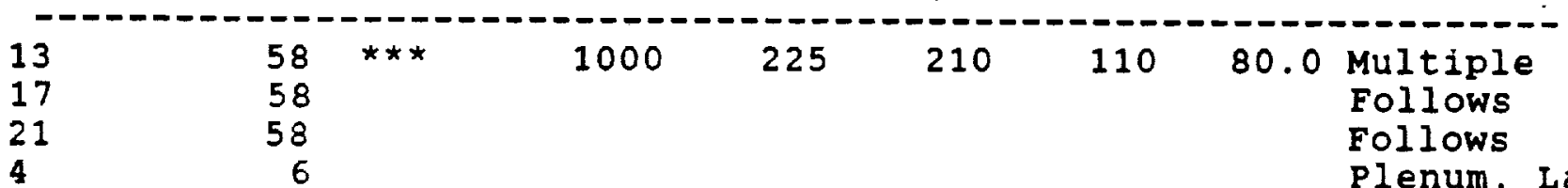

RUN \# 20 Injection Pre B L D Det Conf old/P POS. PRESS. PresPer InjPer InjDur IgnDel Tnk Pr VIveA COMMENTS

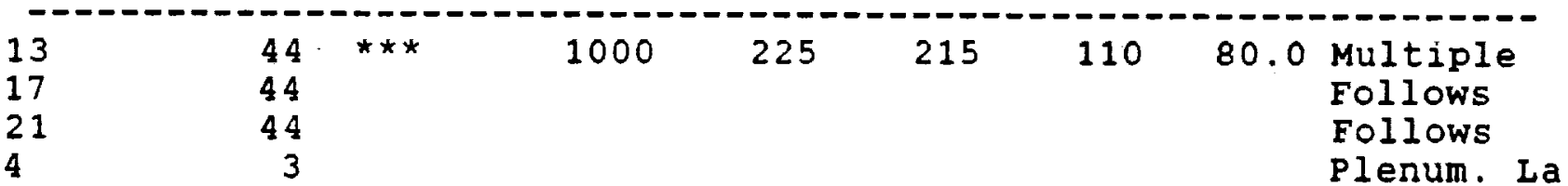

RUN $\# 21$ Injection Pre $B$ L Duct Conf old/P POS. PRESS. PresPer InjPer InjDur IgnDel Tnk Pr VIveA COMMENTS

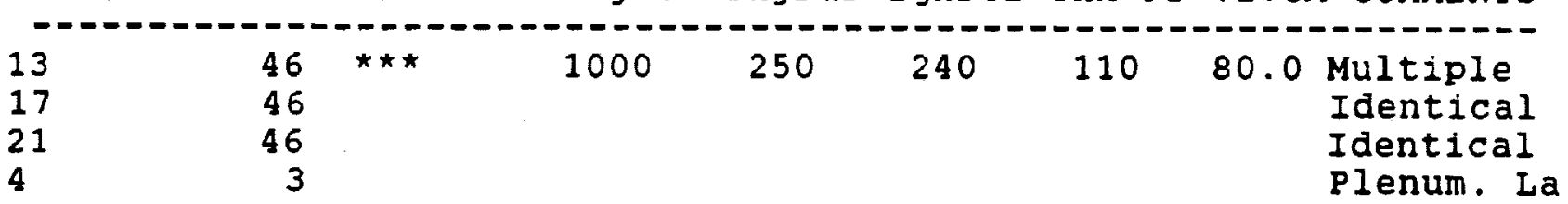

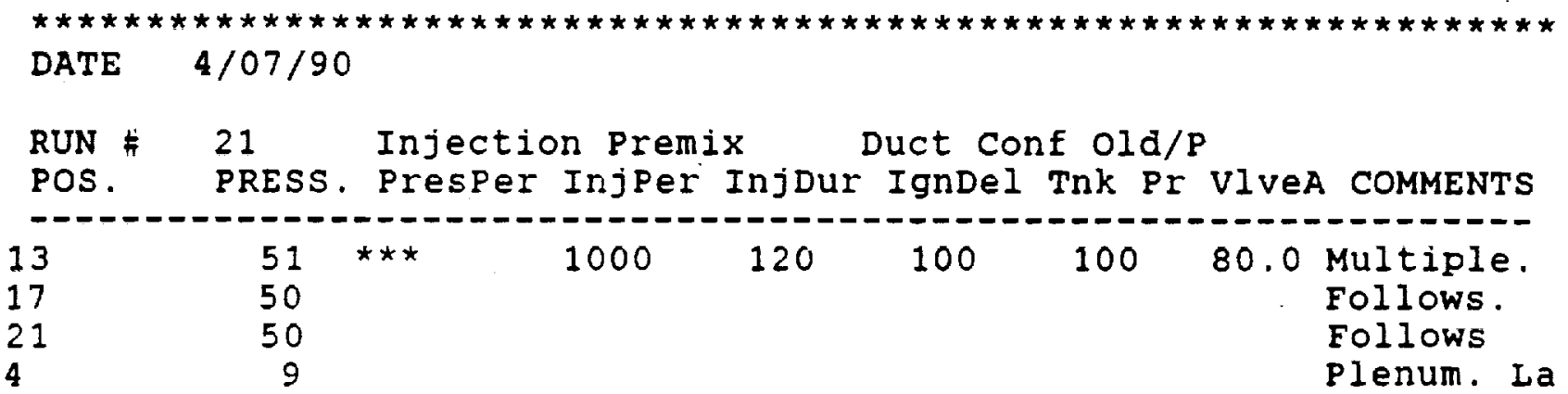


NASA DETONATION DUCT GAS GENERATOR PROGRAM - PRESSURES

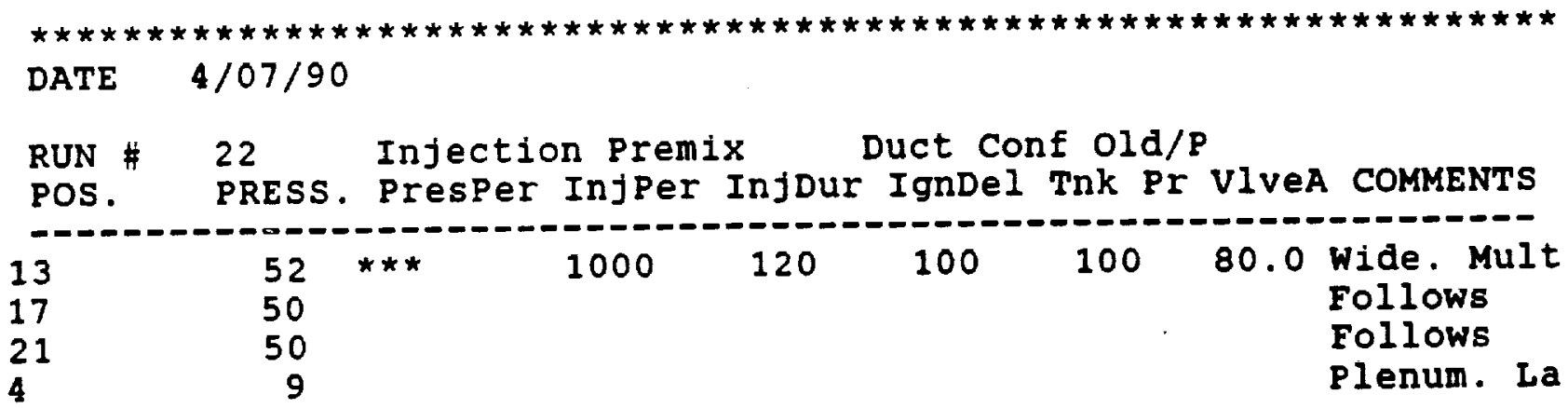

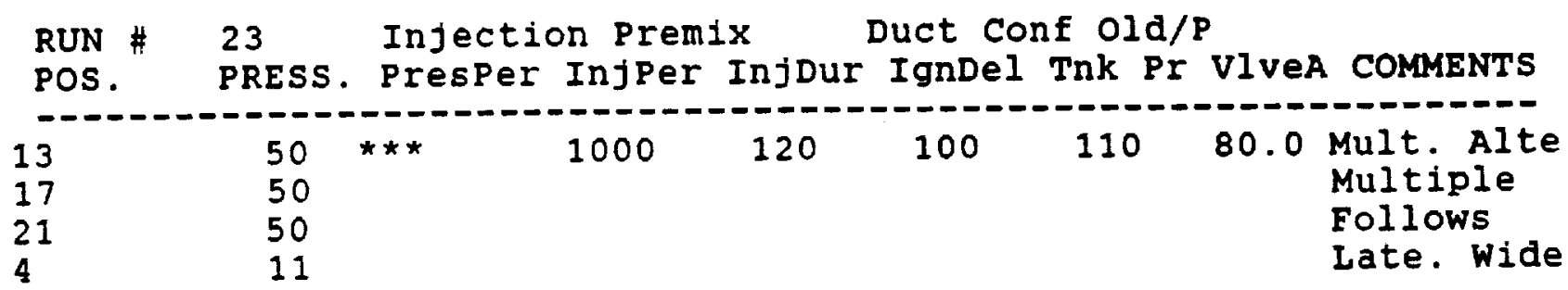

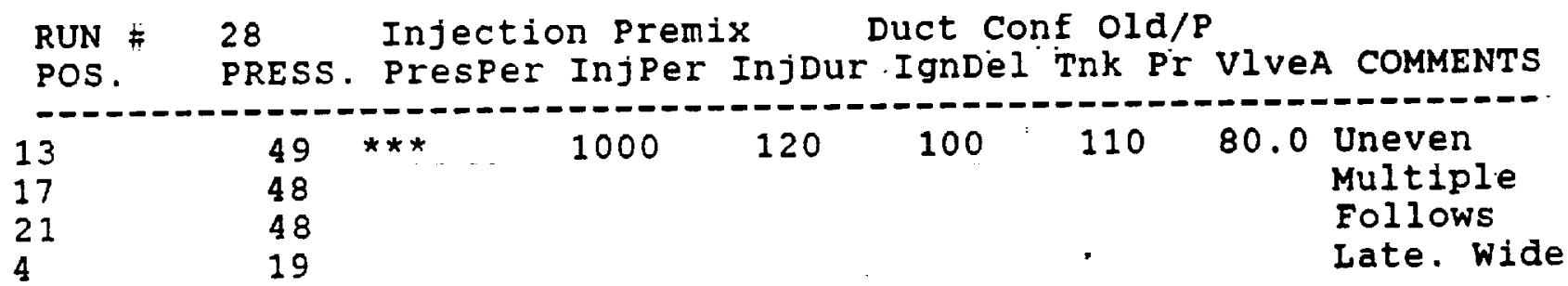

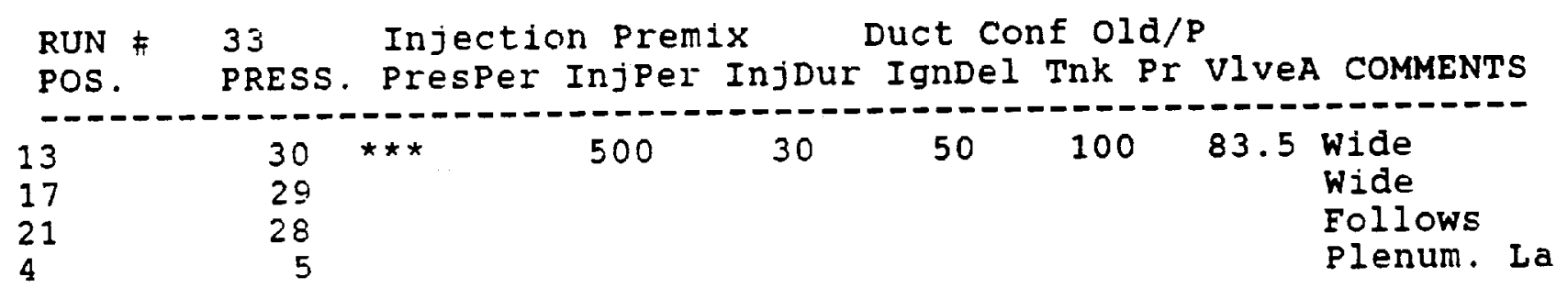

$\star \star \star * \star * * * * * * * * * * * *$
DATE $\quad 4 / 10 / 90$

\begin{tabular}{|c|c|c|c|c|c|c|c|}
\hline $\begin{array}{l}\text { RUN } \\
\text { POS. }\end{array}$ & $\begin{array}{l}11 \\
\text { PRESS. }\end{array}$ & $\begin{array}{l}\text { Injection Premis } \\
\text { Presper InjPer }\end{array}$ & ${ }_{\text {InjDur }}$ & $\begin{array}{l}\text { Duct Con } \\
\text { Igndel }\end{array}$ & $\begin{array}{l}\text { of old/F } \\
\text { Tnk Pr }\end{array}$ & VIveA & A COMMENTS \\
\hline $\begin{array}{l}3 \\
7 \\
21\end{array}$ & $\begin{array}{l}51 \\
49 \\
47 \\
11\end{array}$ & 1000 & 50 & 40 & 100 & 82.5 & $\begin{array}{l}\text { Wide. Miss } \\
\text { Follows } \\
\text { Follows } \\
\text { Plenum. La }\end{array}$ \\
\hline
\end{tabular}

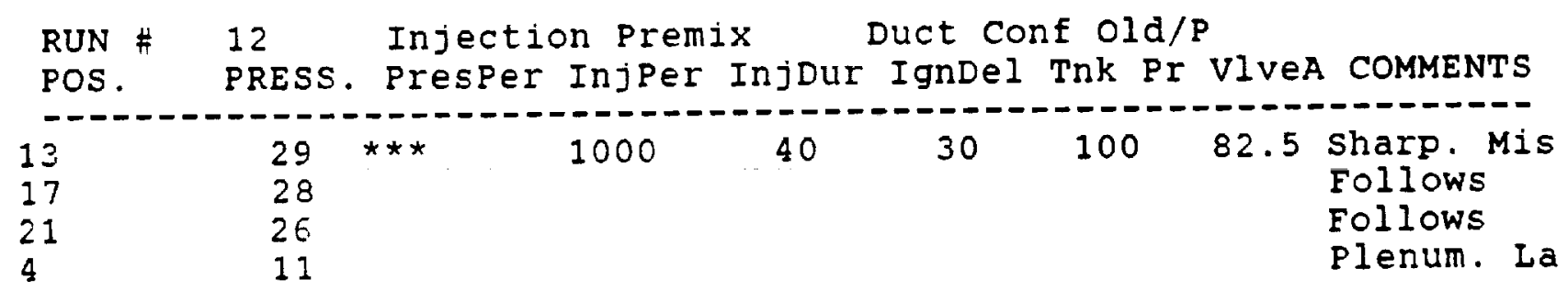


NASA DETONATION DUCT GAS GENERATOR PROGRAM - PRESSURES

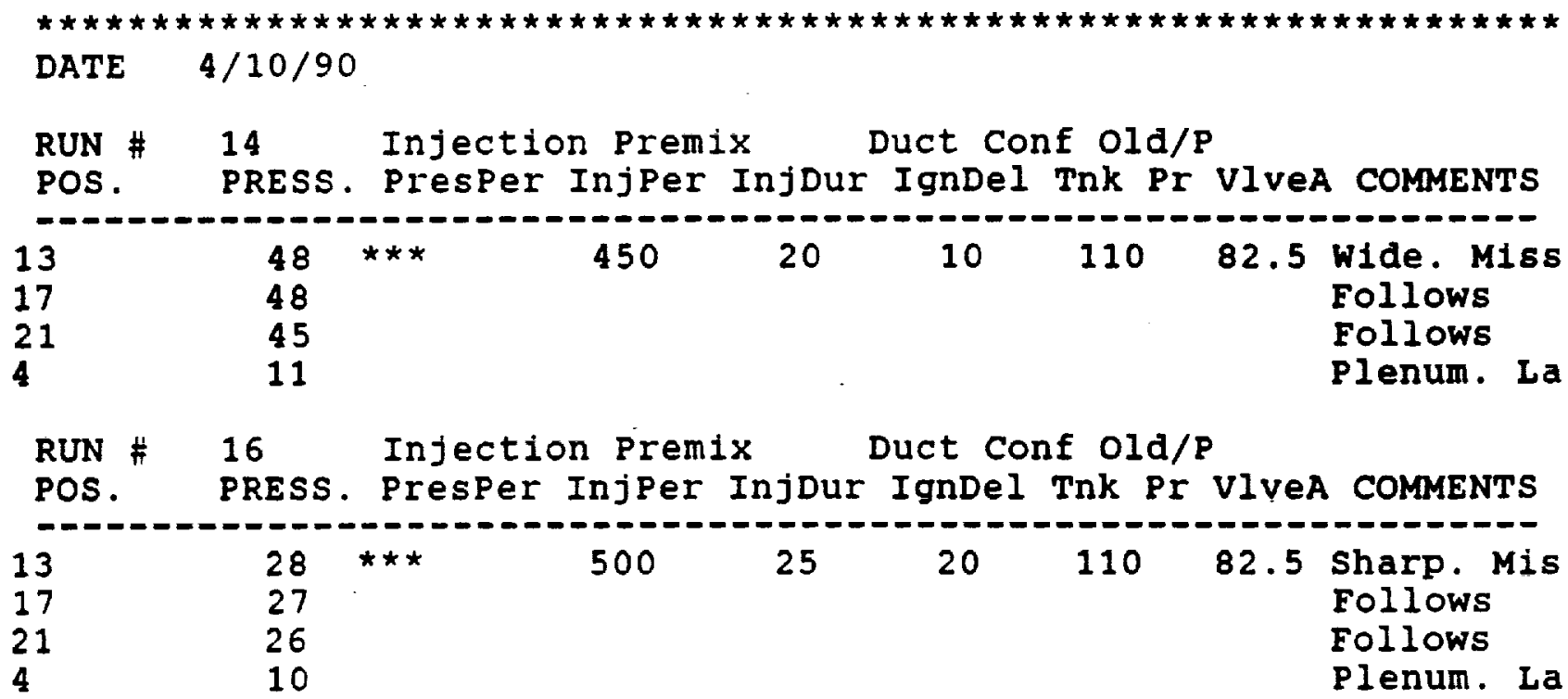

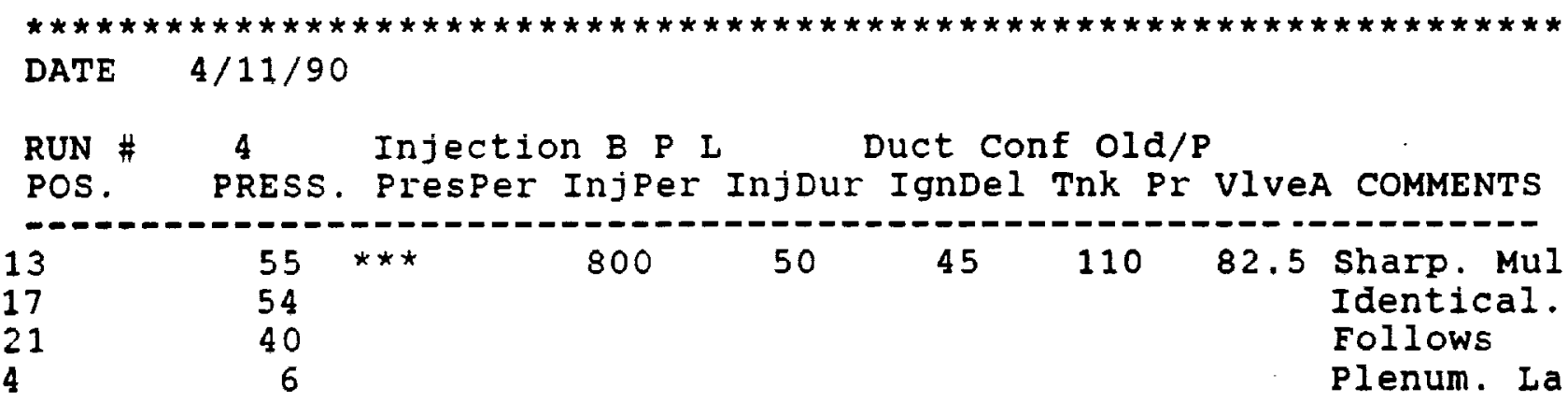

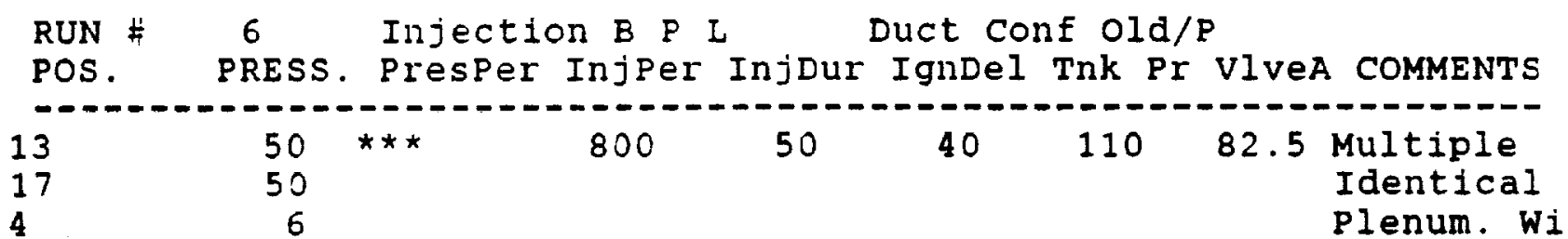

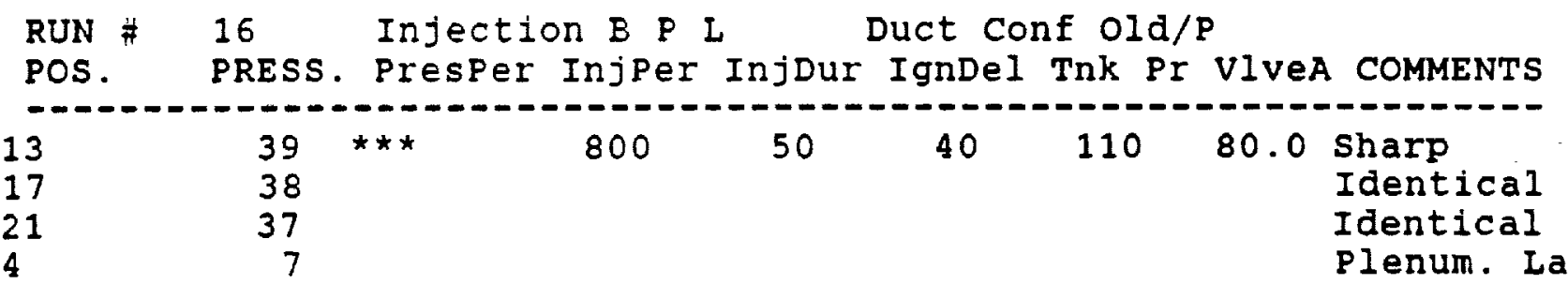

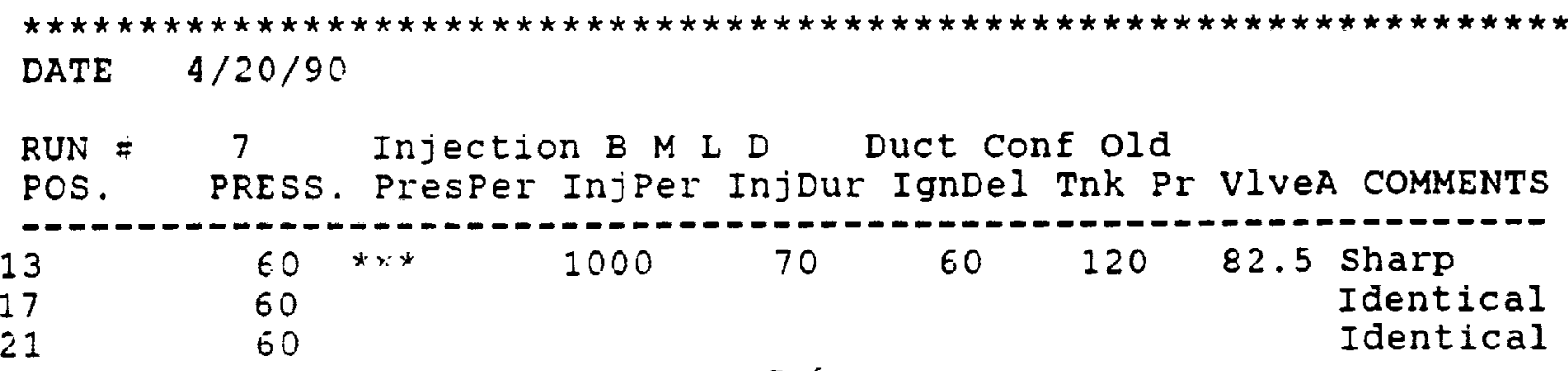


NASA DETONATION DUCT GAS GENERATOR PROGRAM - PRESSURES

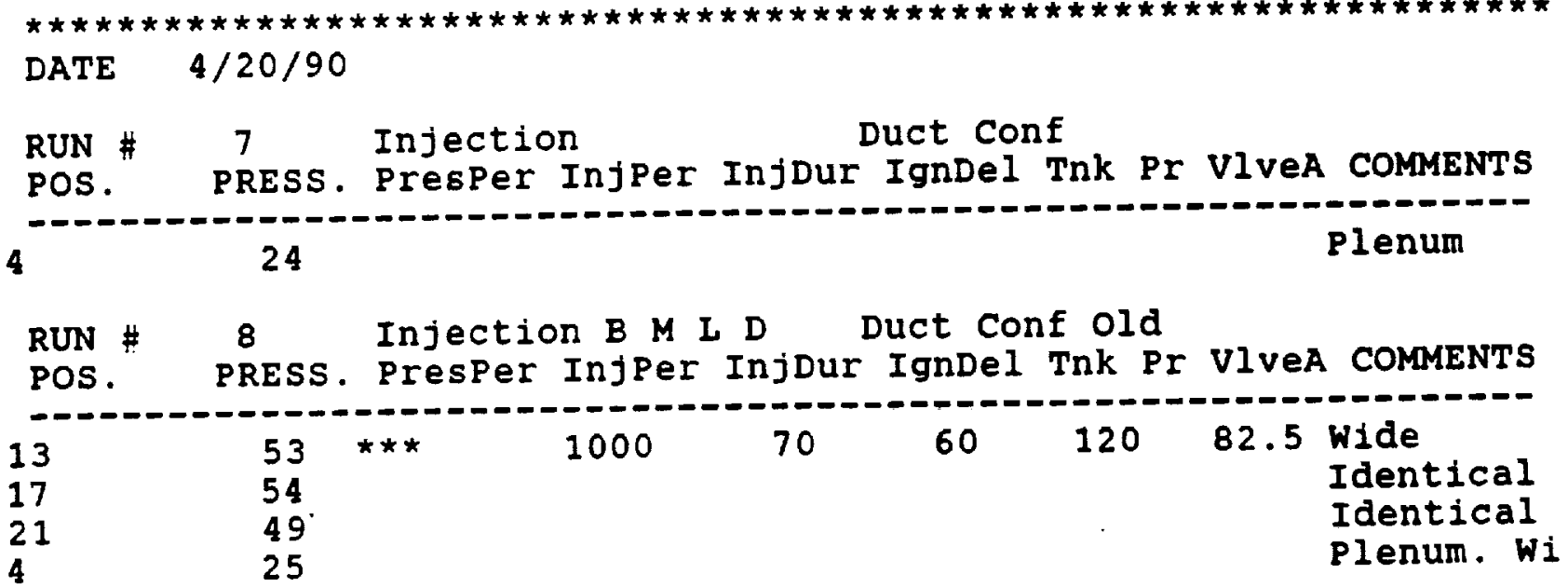

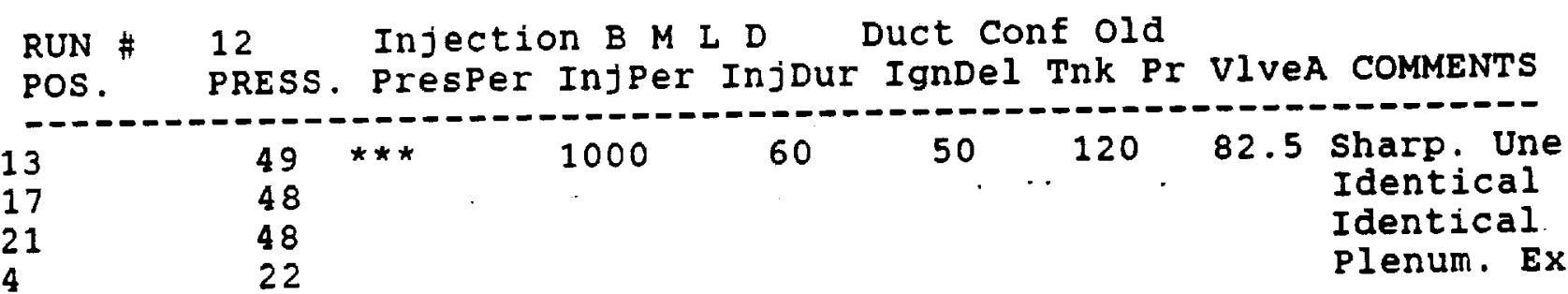

RUN $\Rightarrow 26$ Injection B M L D Duct conf old POS. PRESS. PresPer InjPer InjDur IgnDel Tnk Pr VIVeA COMMErTS

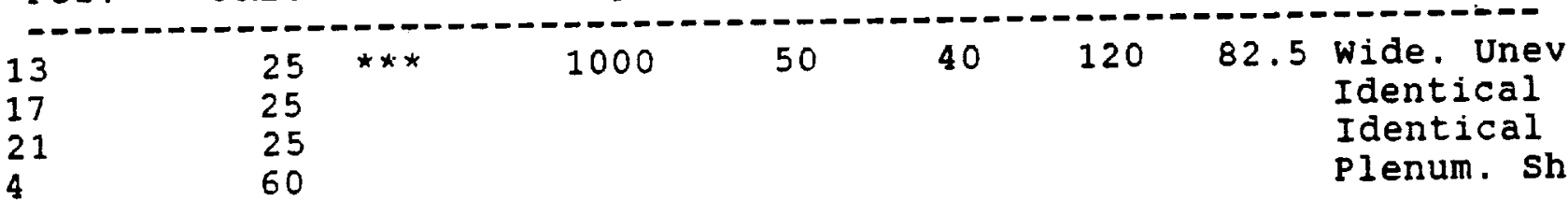

$\star \star * * * * \star \star * * * * \star * * *$
DATE $\quad 4 / 21 / 90$

\begin{tabular}{|c|c|c|c|c|c|c|c|}
\hline $\begin{array}{l}\text { RUN } \neq \\
\text { POS. }\end{array}$ & $\begin{array}{l}5 \\
\text { PRESS }\end{array}$ & $\begin{array}{l}\text { Injection } 2 \text { B I } \\
\text { Presper InjPer }\end{array}$ & $\begin{array}{l}\mathrm{L} \\
\text { InjDur }\end{array}$ & $\begin{array}{l}\text { Duct Cor } \\
\text { IgnDel }\end{array}$ & $\begin{array}{l}\text { Old/F } \\
\text { Tnk Pr }\end{array}$ & VIVeA & COMMENTS \\
\hline & $\begin{array}{r}38 \\
38 \\
38 \\
5\end{array}$ & $\star \star \star$ & 25 & 15 & 120 & 82.5 & $\begin{array}{l}\text { Double. sh } \\
\text { Identical } \\
\text { Identical } \\
\text { Plenum. Wi }\end{array}$ \\
\hline
\end{tabular}

\begin{tabular}{|c|c|c|c|c|}
\hline DATE & $5 / 05 / 90$ & & & \\
\hline $\begin{array}{l}\text { RUN } \\
\text { POS. }\end{array}$ & $\begin{array}{l}7 \\
\text { PRESS. }\end{array}$ & $\begin{array}{l}\text { Injection } \mathrm{T} \text { L } \mathrm{B} \mathrm{V} \\
\text { Presper Injper InjDur }\end{array}$ & $\begin{array}{l}\text { Duct conf old/P } \\
\text { IgnDel Tnk Pr VlveA }\end{array}$ & COMMENTS \\
\hline $\begin{array}{l}13 \\
17\end{array}$ & $\begin{array}{r}44 \\
43 \\
40 \\
6\end{array}$ & 1000 & $40 \quad 100 \quad 82.0$ & $\begin{array}{l}\text { Sharp } \\
\text { Identical } \\
\text { Late } \\
\text { Plenum. Ia }\end{array}$ \\
\hline
\end{tabular}




\section{NASA DETONATION DUCT GAS GENERATOR PROGRAM - PRESSURES}

\begin{tabular}{|c|c|c|c|c|}
\hline DATE & $5 / 05 / 90$ & & & \\
\hline $\begin{array}{l}\text { RUN \# } \\
\text { POS. }\end{array}$ & $\begin{array}{l}9 \\
\text { PRESS. }\end{array}$ & $\begin{array}{l}\text { Injection } T \text { L } B \text { Duct conf old/P } \\
\text { Presper InjPer InjDur IgnDel Tnk Pr }\end{array}$ & VlveA & COMMENTS \\
\hline $\begin{array}{l}13 \\
17 \\
21 \\
4\end{array}$ & $\begin{array}{l}56 \\
51 \\
49 \\
13\end{array}$ & $45 \quad 100$ & 82.5 & $\begin{array}{l}\text { Sharp } \\
\text { Follows } \\
\text { Follows } \\
\text { Late. Wide }\end{array}$ \\
\hline $\begin{array}{l}\text { RUN \# } \\
\text { POS. }\end{array}$ & $\begin{array}{l}10 \\
\text { PRESS. }\end{array}$ & $\begin{array}{l}\text { Injection } T \text { I } B \text { D Duct Conf old/P } \\
\text { Presper InjPer InjDur IgnDel Tnk Pr }\end{array}$ & VIVeA & COMMENTS \\
\hline $\begin{array}{l}13 \\
17 \\
21 \\
4\end{array}$ & $\begin{array}{r}44 \\
44 \\
39 \\
7\end{array}$ & 1000 & 82.5 & $\begin{array}{l}\text { Sharp. Nar } \\
\text { Identical } \\
\text { Follows } \\
\text { Plenum. La }\end{array}$ \\
\hline $\begin{array}{l}\text { RUN \# } \\
\text { POS. }\end{array}$ & $\begin{array}{l}12 \\
\text { PRESS. }\end{array}$ & $\begin{array}{l}\text { Injection } T \text { I } B \text { V Duct Conf old/P } \\
\text { Presper Injper InjDur IgnDel Tnk Pr }\end{array}$ & VIVeA & COMMENTS \\
\hline $\begin{array}{l}13 \\
17 \\
21\end{array}$ & $\begin{array}{r}42 \\
42 \\
43 \\
8\end{array}$ & 1000 & 82.5 & $\begin{array}{l}\text { Sharp. Mul } \\
\text { Identical } \\
\text { Follows } \\
\text { Plenum. La }\end{array}$ \\
\hline
\end{tabular}

\begin{tabular}{|c|c|c|c|c|c|}
\hline DATE & $6 / 04 / 90$ & & & & \\
\hline $\begin{array}{l}\text { RUN } \\
\text { POS. }\end{array}$ & $\begin{array}{l}13 \\
\text { PRESS. }\end{array}$ & $\begin{array}{l}\text { Injection } B \text { M L } \\
\text { Presper InjPer }\end{array}$ & $\begin{array}{l}\text { Duct Conf Tri } \\
\text { InjDur IgnDel Tnk Pr }\end{array}$ & VlveA & COMMENTS \\
\hline & $\begin{array}{l}35 \\
31 \\
30\end{array}$ & 570 & 50 & 82.5 & $\begin{array}{l}\text { Sharp } \\
\text { Follows } \\
\text { Identical }\end{array}$ \\
\hline
\end{tabular}

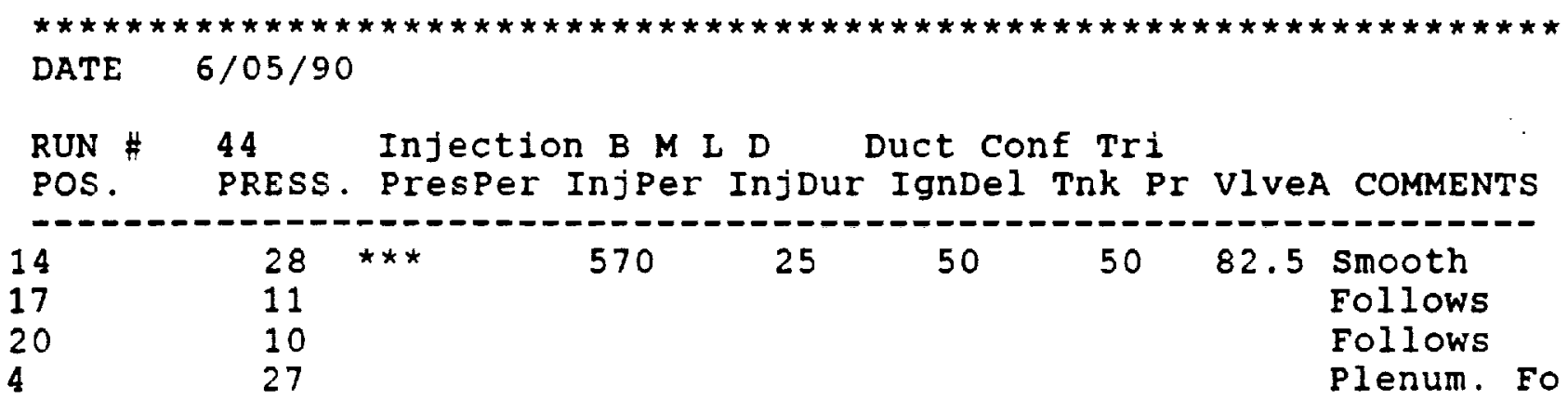




\section{NASA DETONATION DUCT GAS GENERATOR PROGRAM - PRESSURES}

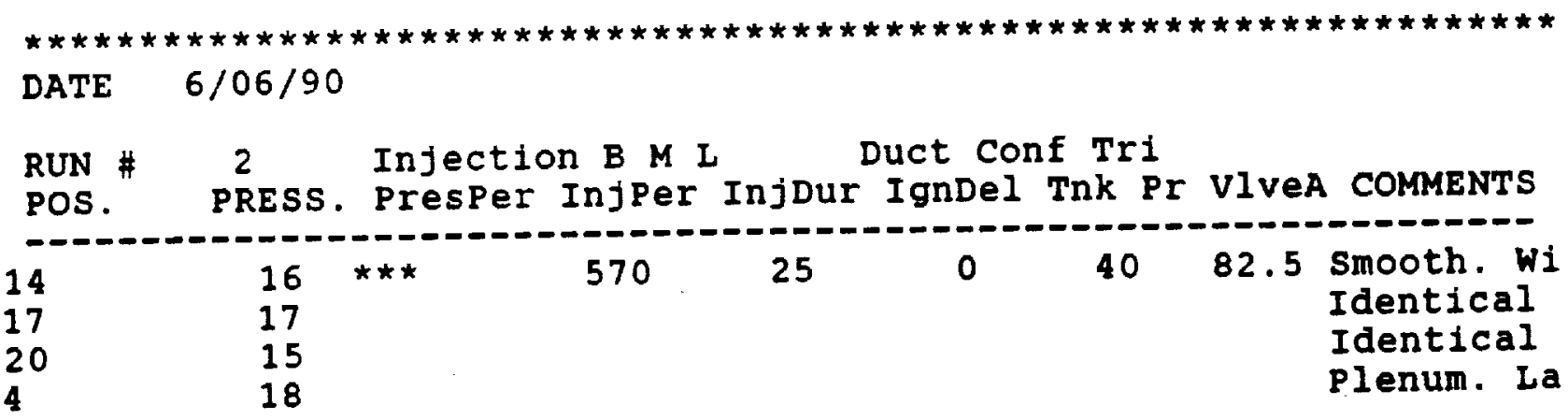

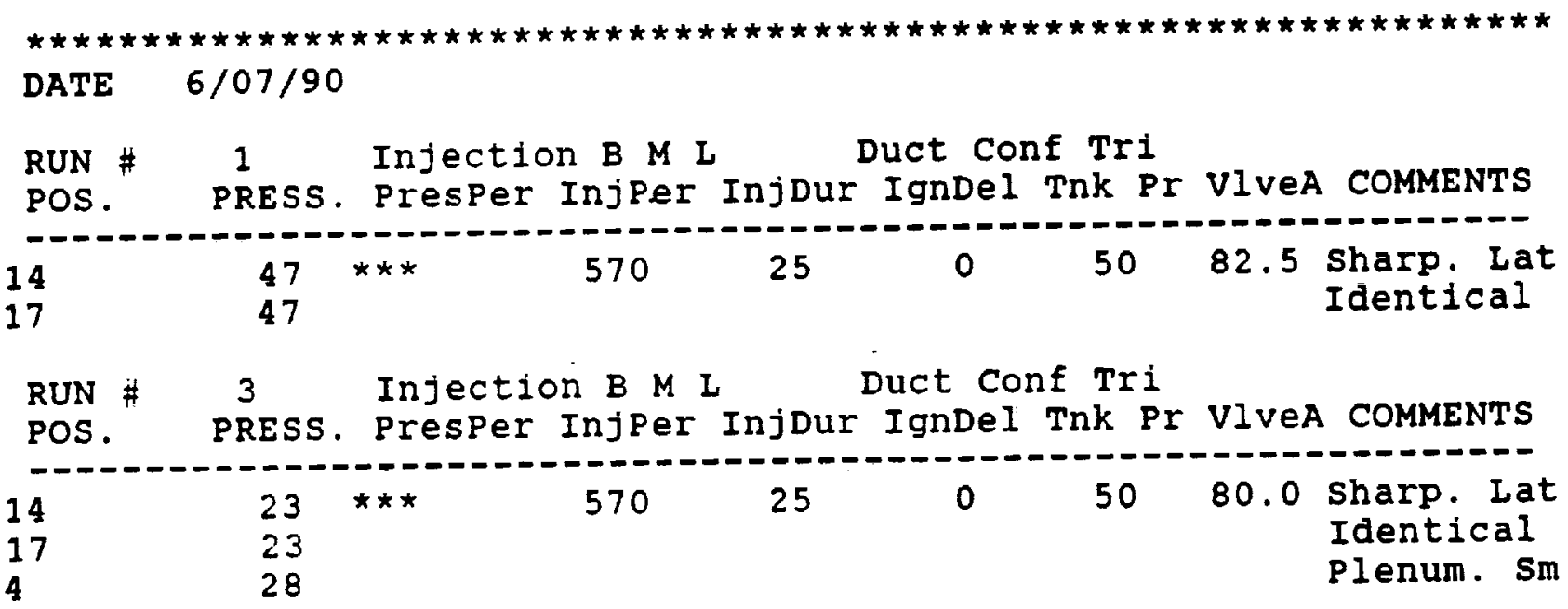

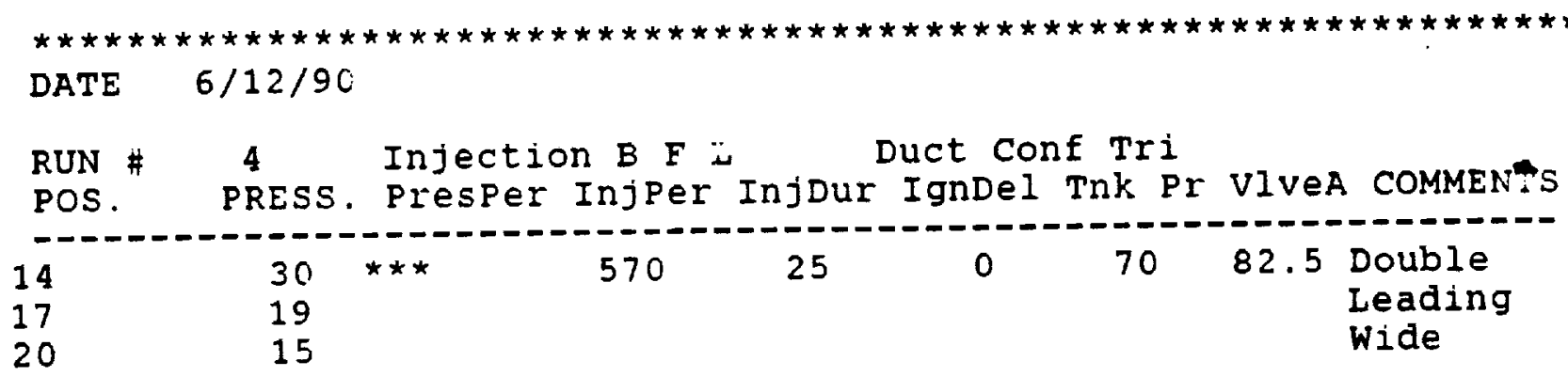

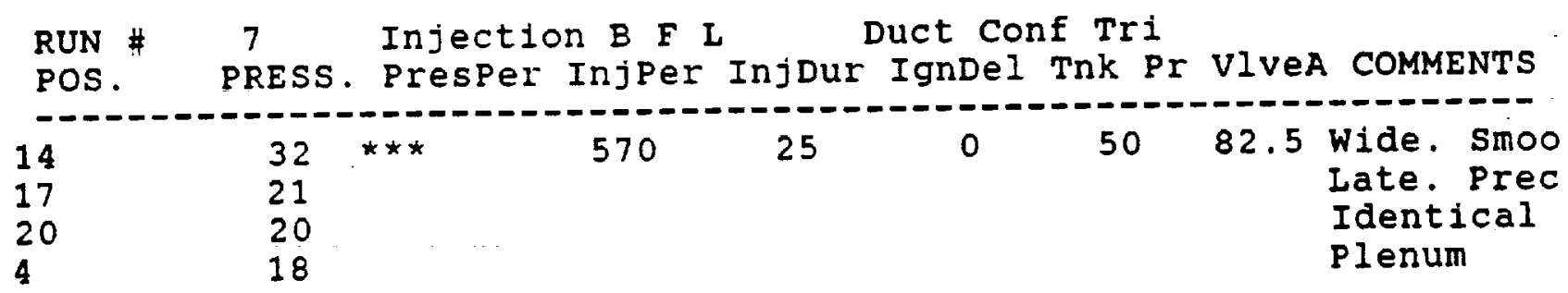

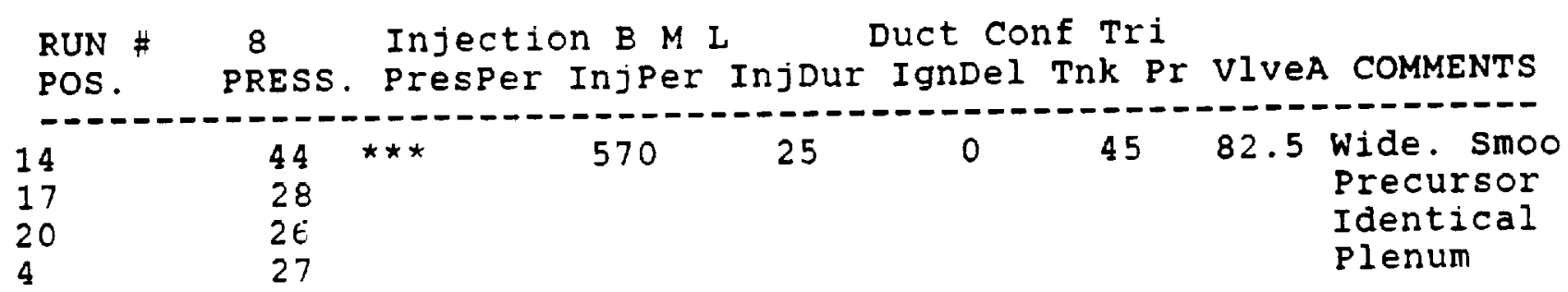


NASA DETONATION DUCT GAS GENERATOR PROGRAM - PRESSURES

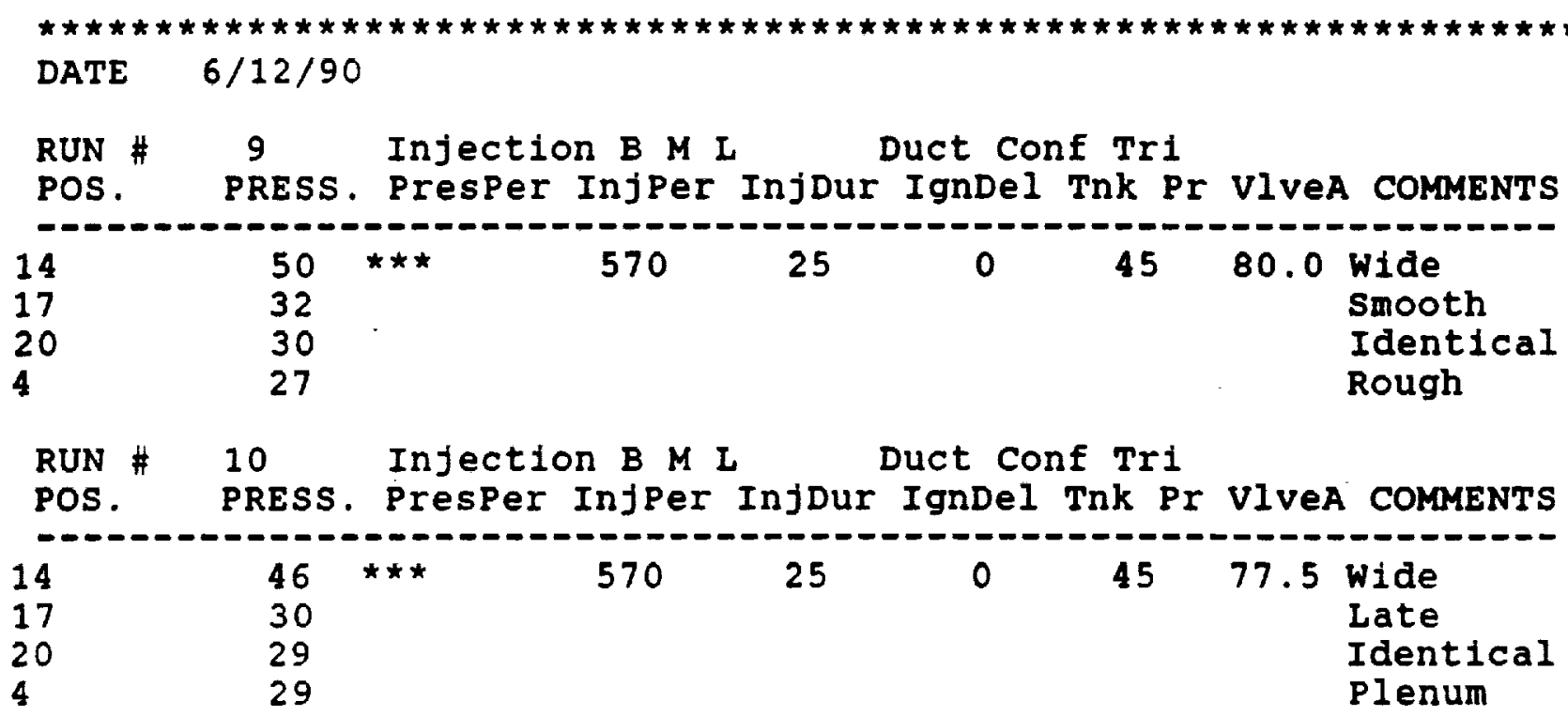

RUN $\# 11$ Injection B M L Duct Conf Tri

POS. PRESS. Presper InjPer InjDur IgnDel Tnk Pr VIveA COMMENTS

\begin{tabular}{|c|c|c|c|c|c|c|c|c|}
\hline $\begin{array}{l}14 \\
17 \\
20\end{array}$ & $\begin{array}{l}55 \\
33 \\
32 \\
28\end{array}$ & $\star * \star$ & 570 & 25 & 0 & 50 & 77.5 & $\begin{array}{l}\text { Smooth } \\
\text { Precurso } \\
\text { Identic } \\
\text { Plenum }\end{array}$ \\
\hline
\end{tabular}

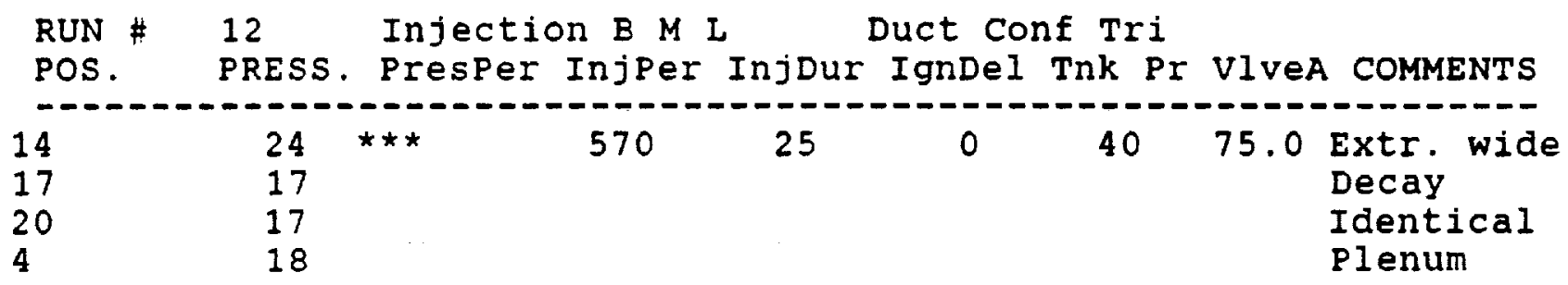

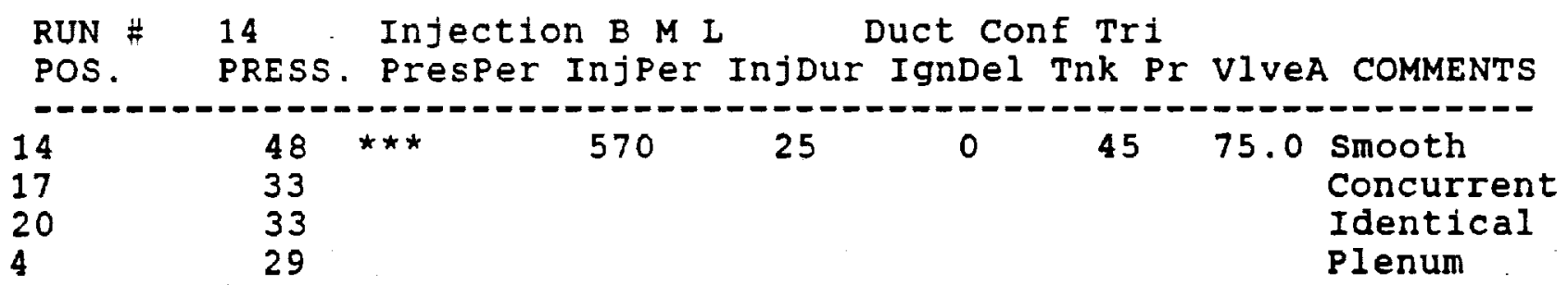

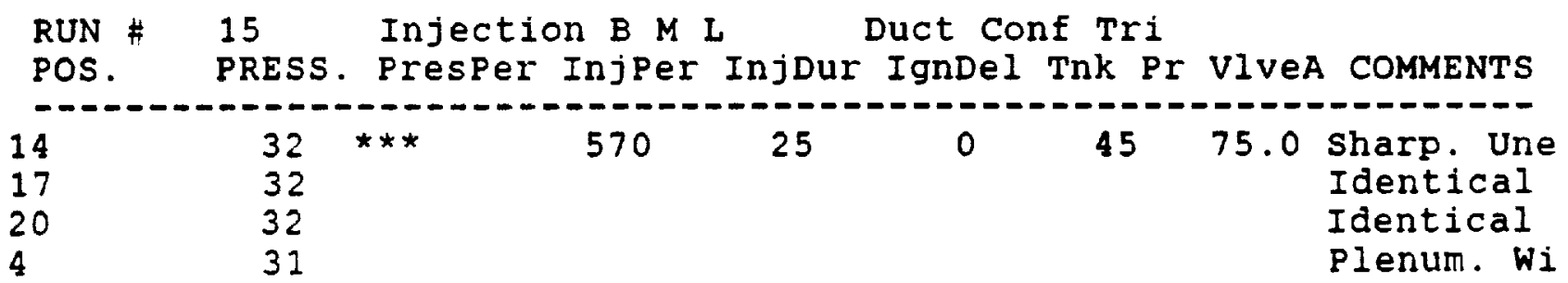


NASA DETONATION DUCT GAS GENERATOR PROGRAM - PRESSURES

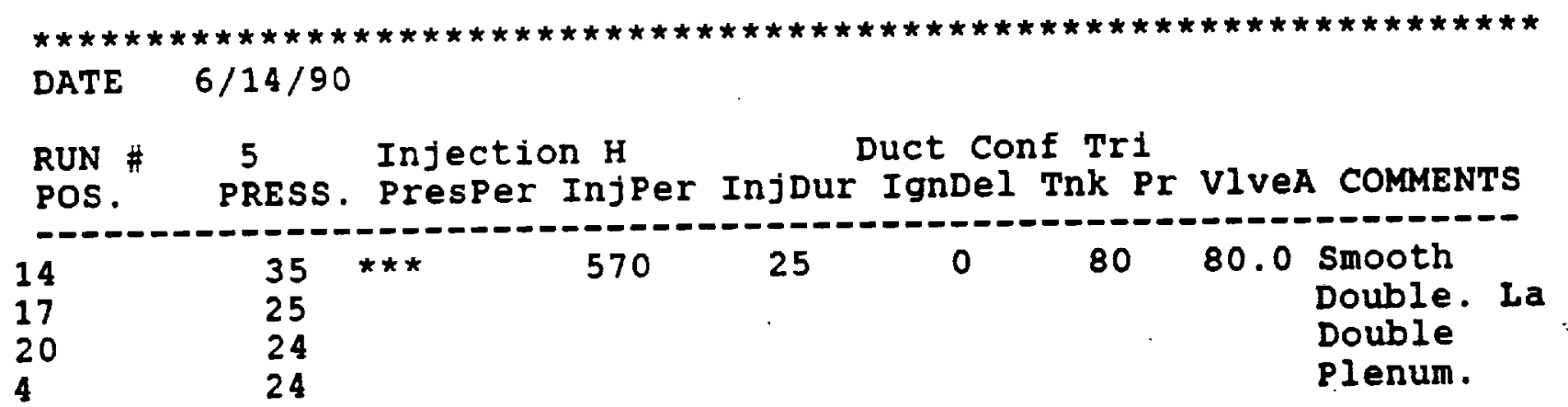

\begin{tabular}{|c|c|c|c|c|}
\hline DATE & $6 / 15 / 90$ & & & \\
\hline $\begin{array}{l}\text { RUN \# } \\
\text { POS. }\end{array}$ & $\begin{array}{l}1 \\
\text { PRESS }\end{array}$ & $\begin{array}{l}\text { Injection s I } \\
\text { Presper InjPer }\end{array}$ & $\begin{array}{l}\text { Duct Conf Tri } \\
\text { InjDur Igndel Tnk Pr }\end{array}$ & VIVEA COMMENTS \\
\hline $\begin{array}{l}14 \\
17 \\
20 \\
4\end{array}$ & $\begin{array}{l}52 \\
37 \\
37 \\
32\end{array}$ & $\star * *$ & $\begin{array}{ll}0 & 100 \\
. & \end{array}$ & $\begin{array}{ll}77.5 & \text { Sharp. } \\
& \text { Double } \\
& \text { Identical } \\
& \text { Identical. }\end{array}$ \\
\hline $\begin{array}{l}\text { RUN } \neq \\
\text { POS }\end{array}$ & $\begin{array}{l}6 \\
\text { PRESS. }\end{array}$ & $\begin{array}{l}\text { Injection } \\
\text { Presper Injper }\end{array}$ & $\begin{array}{l}\text { Duct Conf } \\
\text { InjDur IgnDel Tnk Pr }\end{array}$ & VIVEA COMMENTS \\
\hline $\begin{array}{l}14 \\
17 \\
4\end{array}$ & $\begin{array}{l}16 \\
15 \\
16\end{array}$ & 570 & 75 & $\begin{array}{cl}80.0 & \text { Late Ign. } \\
& \text { Leads } \\
& \text { Plenum }\end{array}$ \\
\hline $\begin{array}{l}\text { RUN \# } \\
\text { POS. }\end{array}$ & $\begin{array}{l}20 \\
\text { PRESS. }\end{array}$ & $\begin{array}{l}\text { Injection } \\
\text { Presper Injper }\end{array}$ & $\begin{array}{l}\text { Duct Conf Tri } \\
\text { InjDur IgnDel Tnk Pr }\end{array}$ & VIVEA COMMENTS \\
\hline $\begin{array}{l}14 \\
17\end{array}$ & $\begin{array}{l}34 \\
33 \\
31\end{array}$ & 570 & 100 & $\begin{array}{l}80.0 \text { Sharp. } \\
\text { Late. Conc } \\
\text { Plenum }\end{array}$ \\
\hline
\end{tabular}

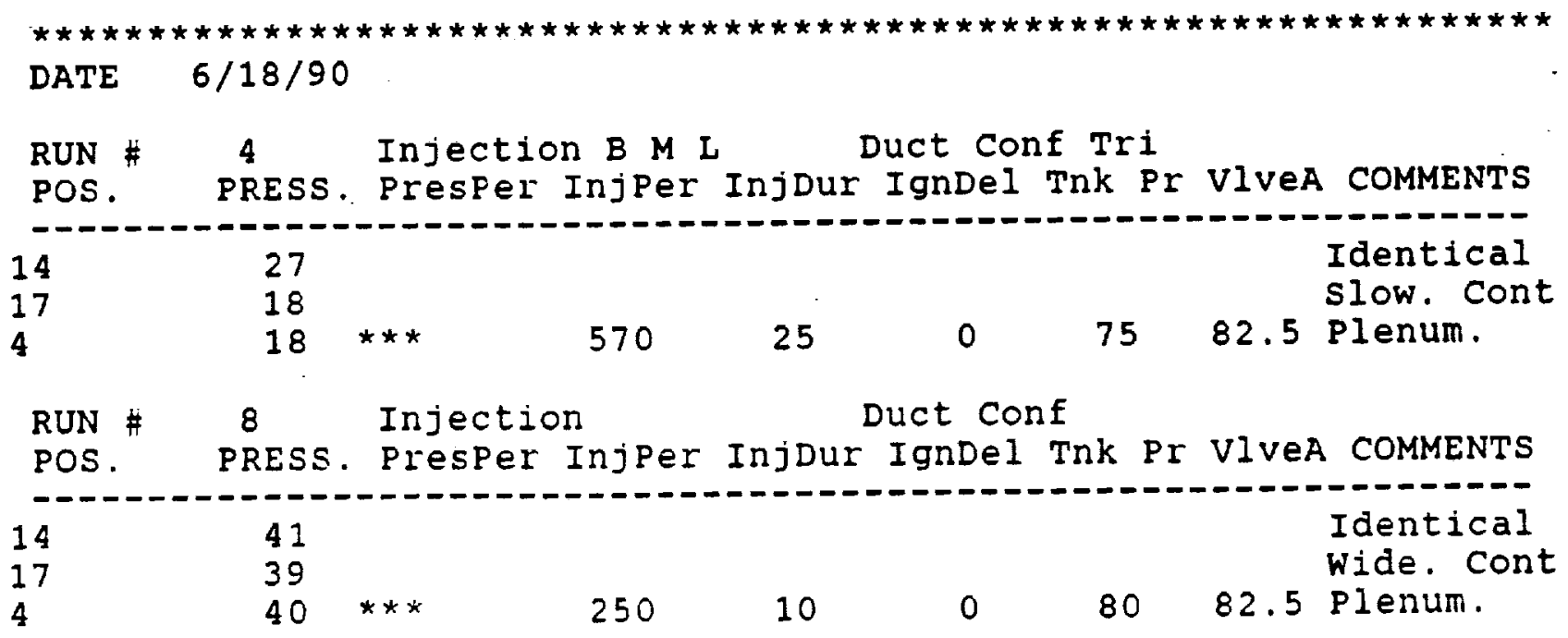




\section{NASA DETONATION DUCT GAS GENERATOR PROGRAM - PRESSURES}

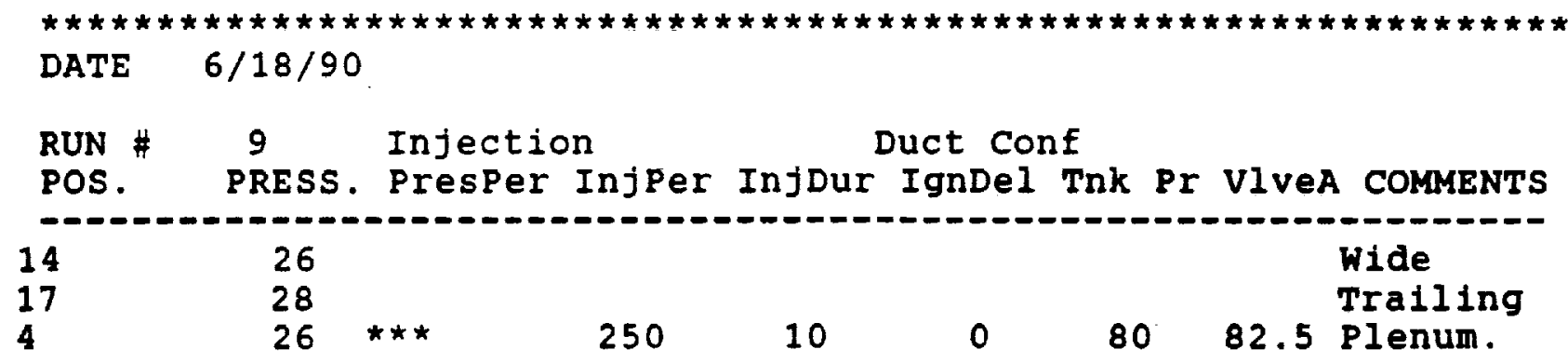

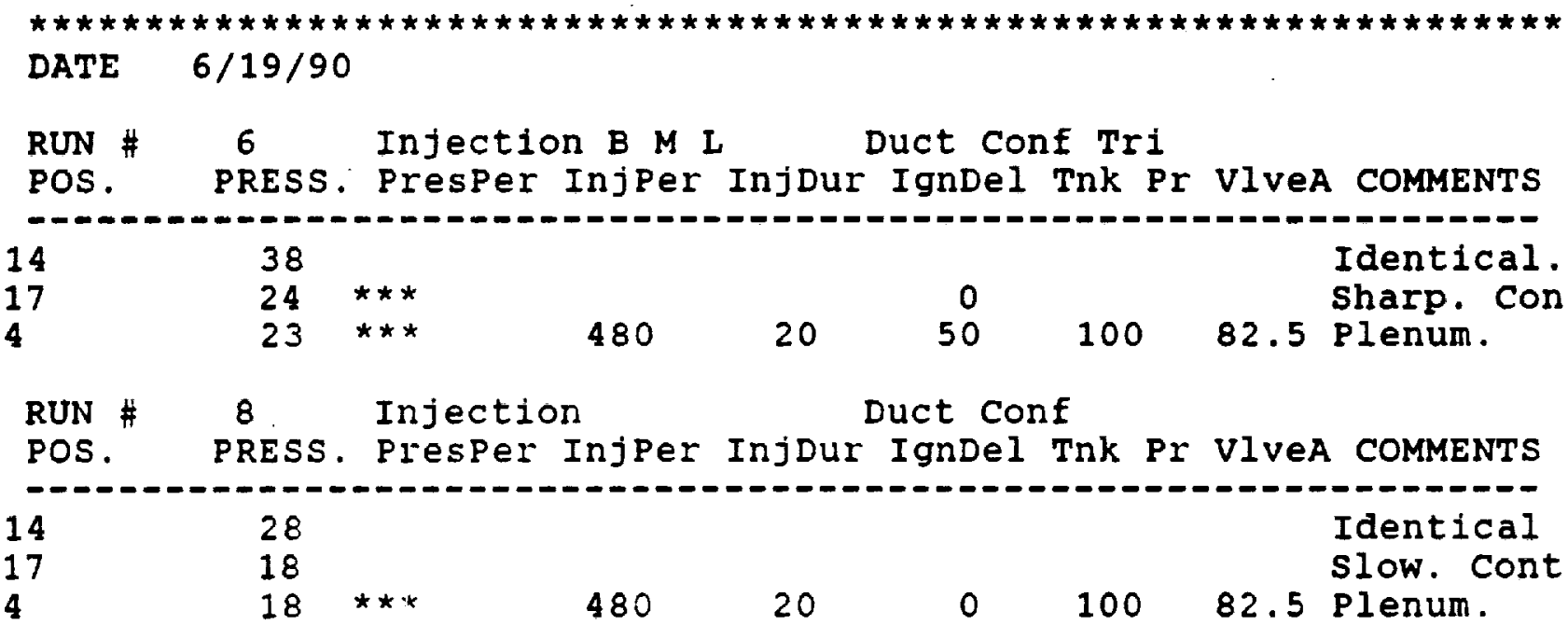

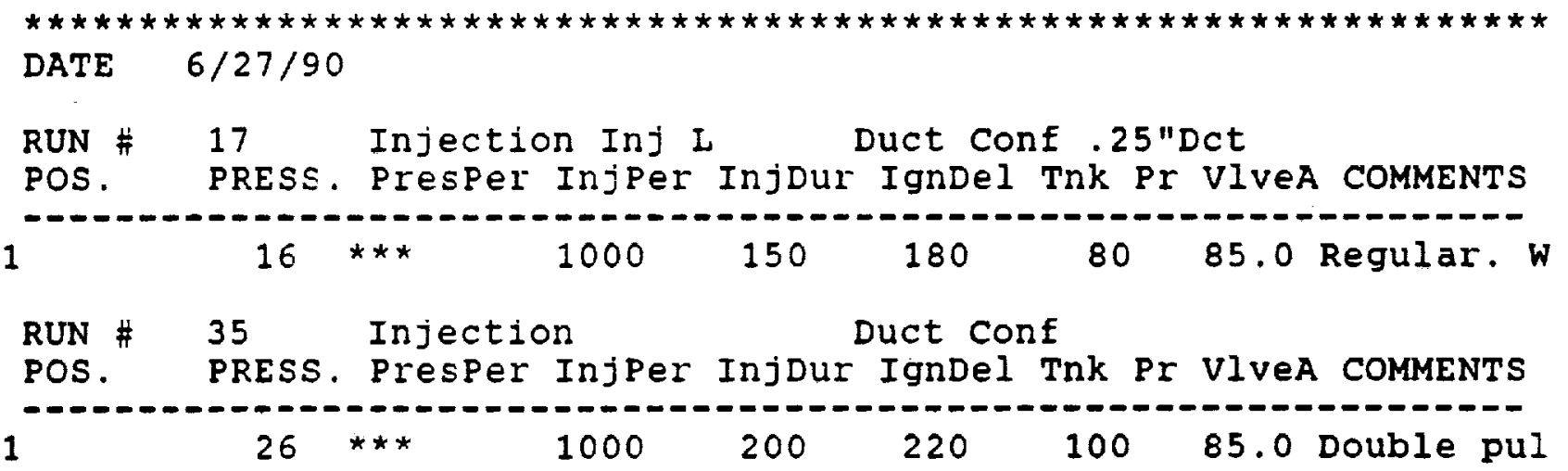

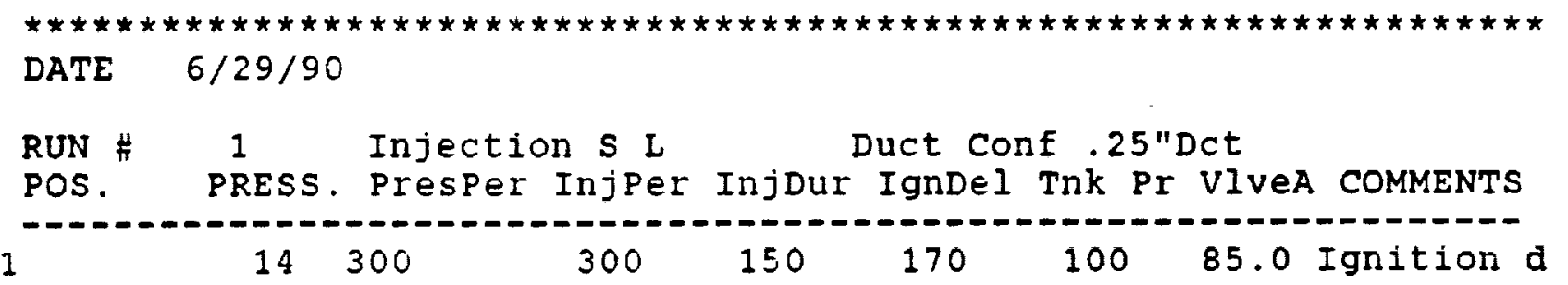


NASA DETONATION DUCT GAS GENERATOR PROGRAM - PRESSURES

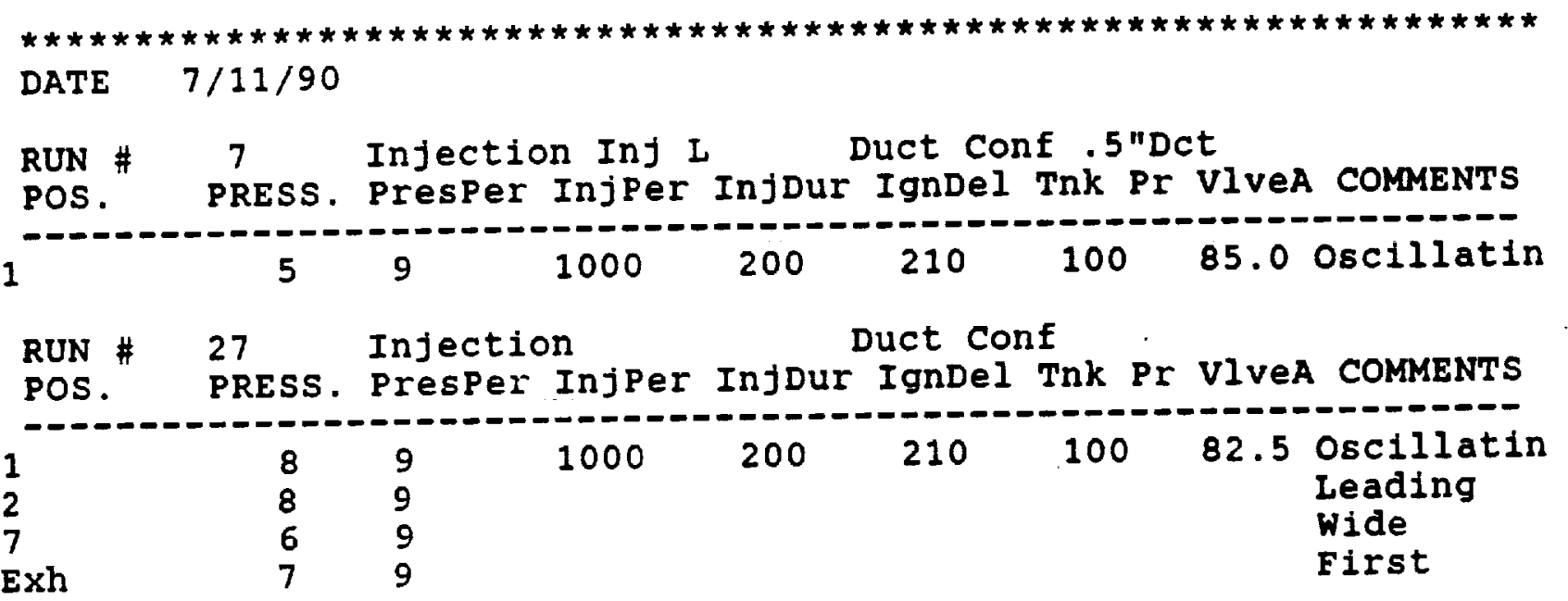

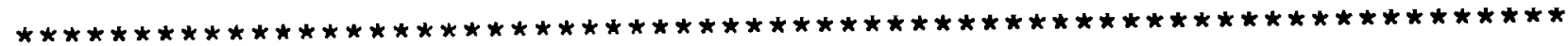

DATE $7 / 12 / 90$

RUN $\# 4$ Injection $S I$ Duct Conif . 5 "Dct

POS. PRESS. PresPer InjPer InjDur IgnDel Tnk Pr VIVeA COMMENTS

$104 * * * 40004300450$ slow rise

RUN \# 8 Injection Duct Conf

POS. PRESS. Presper InjPer InjDur IgnDel Tnk Pr VIveA COMMENTS

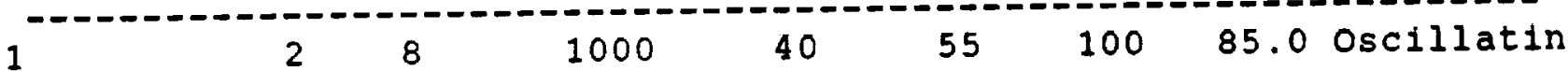

RUN \# 11 Injection Duct Conf

POS. PRESS. Presper InjPer InjDur Igndel Tnk Pr VIveA COMMEN.S

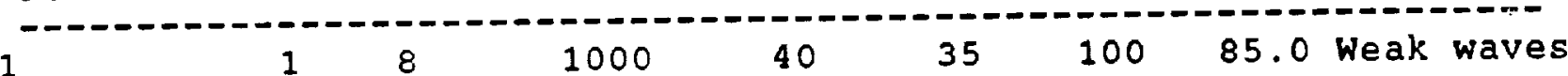

RUN \# 12 Injection Duct Conf

POS. PRESS. PresPer InjPer InjDur IgnDel Tnk Pr VIveA COMMENTS

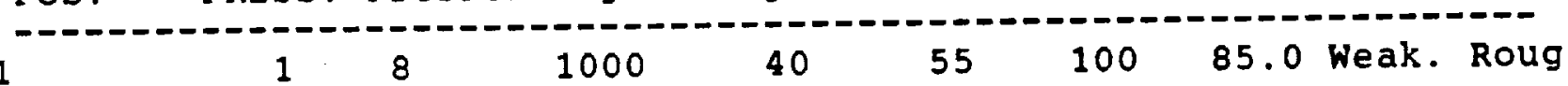

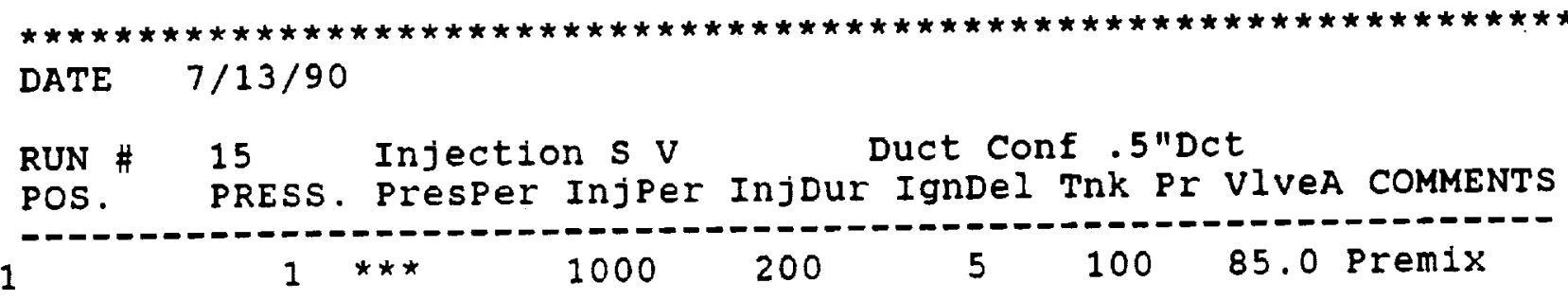


NASA DETONATION DUCT GAS GENERATOR PROGRAM - PRESSURES

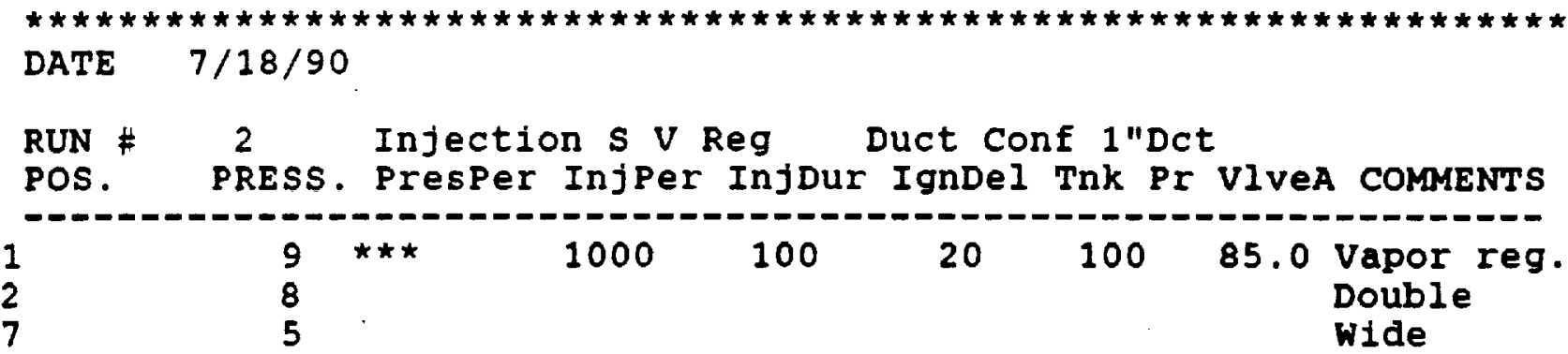

\begin{tabular}{|c|c|c|c|c|c|}
\hline $\begin{array}{l}\text { RUN \# } \\
\text { POS. }\end{array}$ & $\begin{array}{l}5 \\
\text { PRESS. }\end{array}$ & $\begin{array}{l}\text { Injection } \\
\text { Presper Injper }\end{array}$ & & $\begin{array}{l}\text { Duct conf } \\
\text { IgnDel Tnk Pr }\end{array}$ & VIVEA COMMENTS \\
\hline & $\begin{array}{l}21 \\
17 \\
14\end{array}$ & 1000 & 100 & 100 & $\begin{array}{l}85.0 \text { Liquid. st } \\
\text { Multiple } \\
\text { Wide }\end{array}$ \\
\hline
\end{tabular}

RUN $\# \quad 9$ Injection Duct Conf

POS. PRESS. Presper InjPer InjDur IgnDel Tnk Pr VIveA COMMENTS

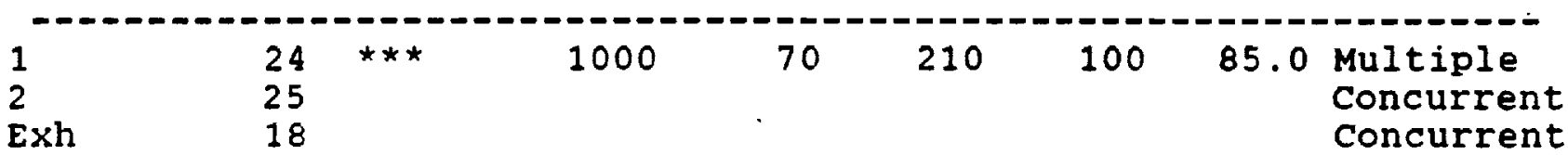

RUN \# 10 Injection Duct conf

POS. PRESS. ?resper InjPer InjDur IgnDel Tnk Pr VIveA COMMENTS -

\begin{tabular}{|c|c|c|c|c|c|c|c|c|}
\hline $\begin{array}{l}1 \\
2 \\
E \times h\end{array}$ & $\begin{array}{l}24 \\
24 \\
18\end{array}$ & $\star * *$ & 1000 & 70 & 210 & 100 & 85.0 & $\begin{array}{l}\text { Precursor } \\
\text { Concurrent }\end{array}$ \\
\hline
\end{tabular}

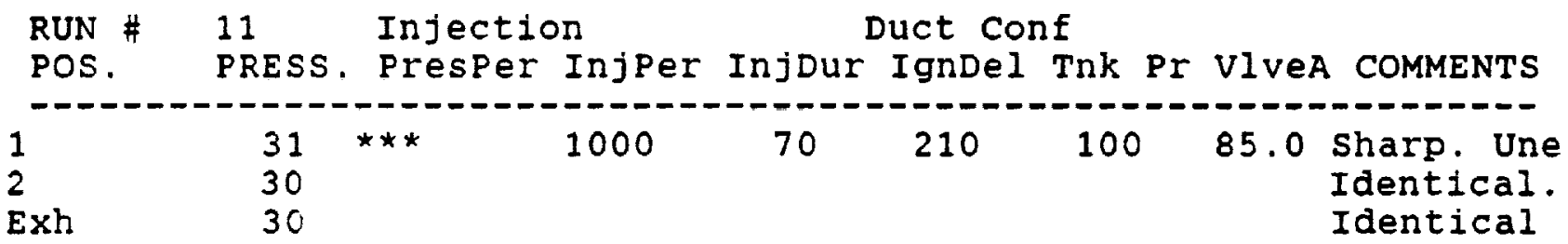

RUN \# 12 . Injection Duct Conf

POS. PRESS. Presper InjPer InjDur IgnDel Tnk Pr VIVeA COMMENTS

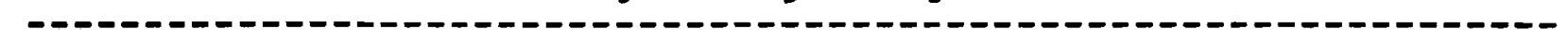

\begin{tabular}{|c|c|c|c|c|c|c|c|c|}
\hline $\begin{array}{l}1 \\
2 \\
\text { Exh }\end{array}$ & $\begin{array}{l}29 \\
30 \\
24\end{array}$ & $\star \star * *$ & 1000 & 70 & 210 & 100 & 85.0 & $\begin{array}{l}\text { Sharp. Une } \\
\text { Concurrent }\end{array}$ \\
\hline
\end{tabular}

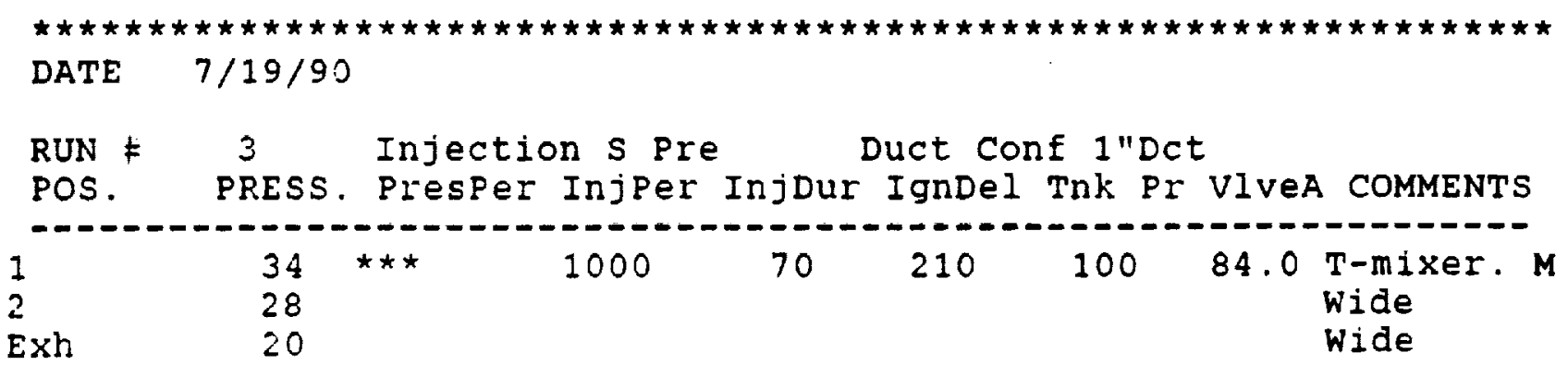




\section{NASA DETONATION DUCT GAS GENERATOR PROGRAM - PRESSURES}

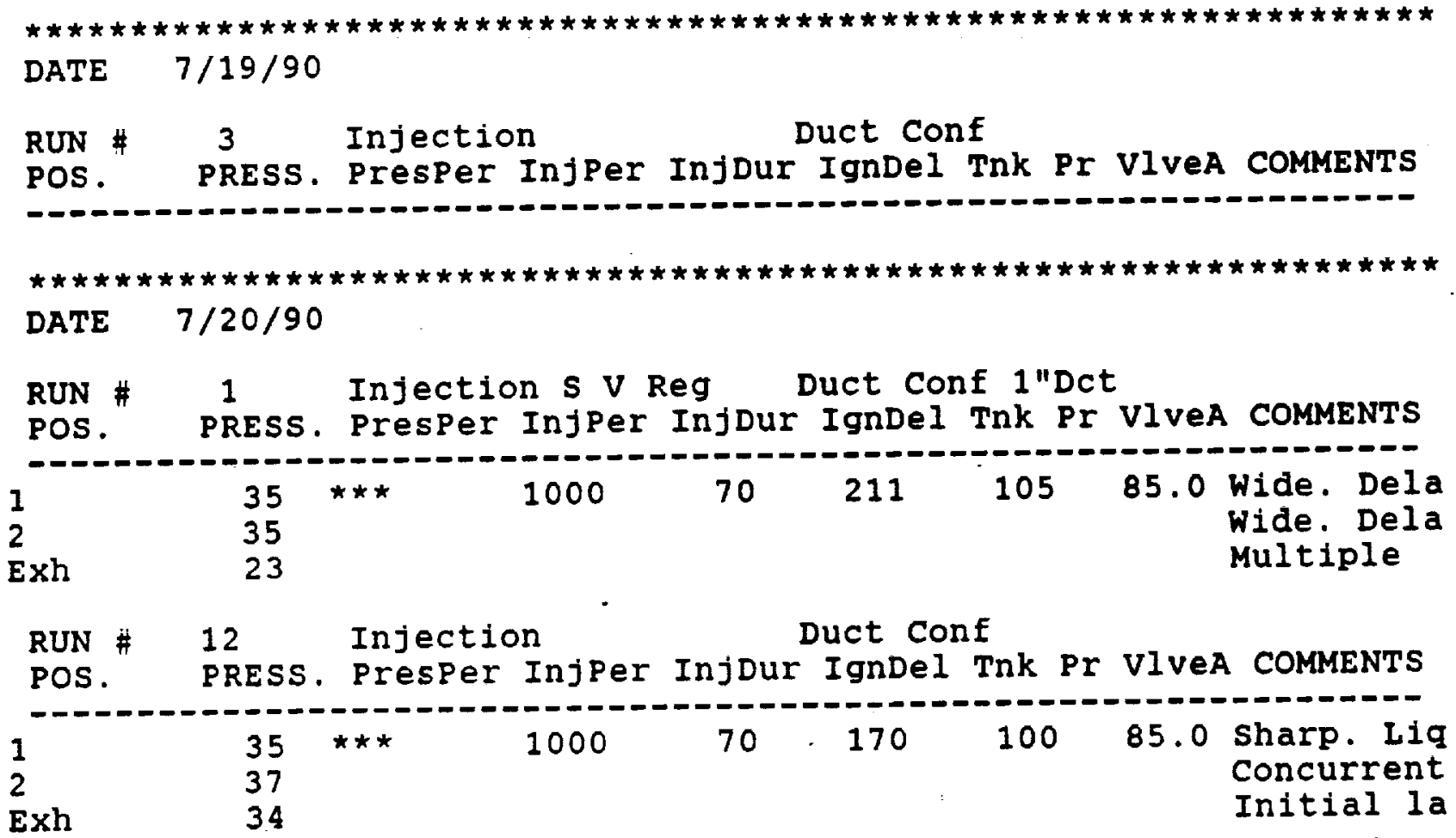

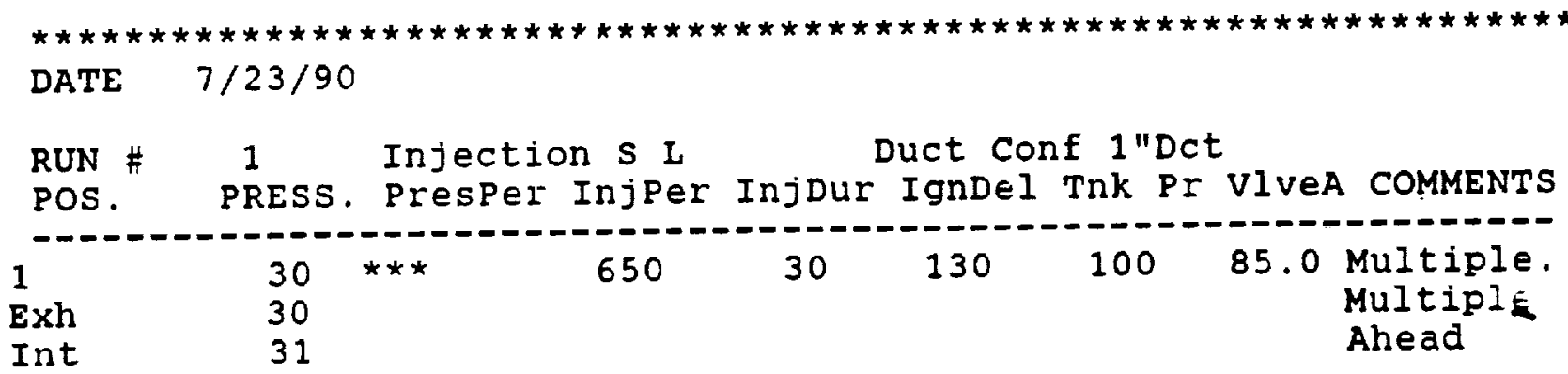

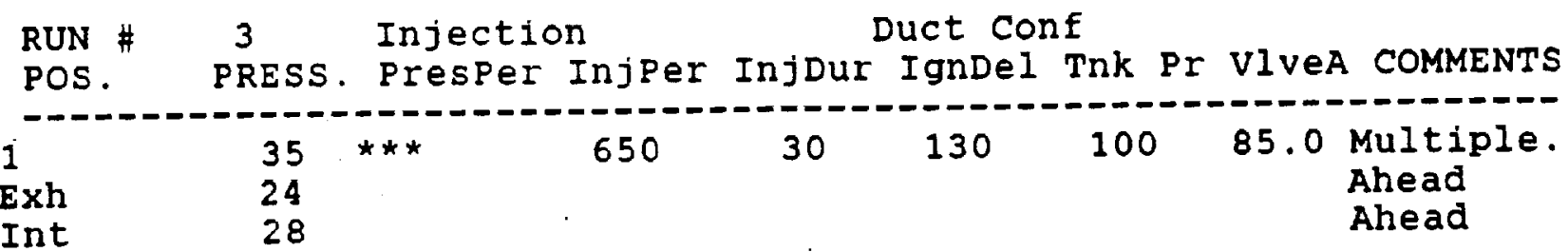

RUN \# 5 Injection Duct conf POS. PRESS. PresPer InjPer InjDur IgnDel Tnk Pr VIVeA COMMENTS

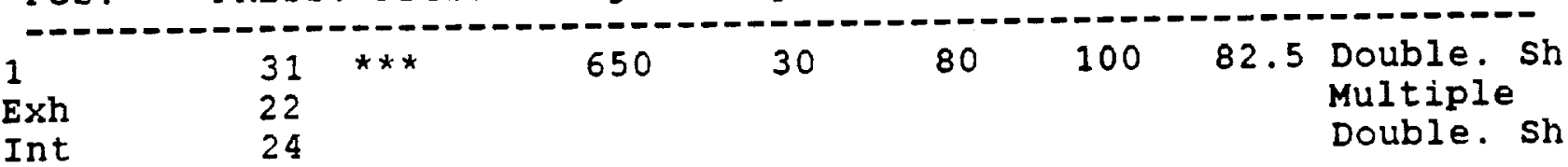

RUN \# 13 Injection Duct Conf

POS. PRESS. Presper InjPer InjDur IgnDel Tnk Pr VIVeA COMMENTS

\begin{tabular}{|c|c|c|c|c|c|c|c|c|}
\hline $\begin{array}{l}1 \\
\text { Exh } \\
\text { Int }\end{array}$ & $\begin{array}{l}31 \\
20 \\
26\end{array}$ & $\star * *$ & $\in 50$ & 30 & 60 & 90 & 80.0 & $\begin{array}{l}\text { wide. Port } \\
\text { wide. Earl } \\
\text { wide. Late }\end{array}$ \\
\hline
\end{tabular}


NASA DETONATION DUCT GAS GENERATOR PROGRAM - PRESSURES

\begin{tabular}{|c|c|c|c|c|}
\hline DATE & $7 / 23 / 90$ & & & \\
\hline $\begin{array}{l}\text { RUN \# } \\
\text { POS. }\end{array}$ & $\begin{array}{l}22 \\
\text { PRESS. }\end{array}$ & $\begin{array}{l}\text { Injection } \\
\text { Presper InjPer }\end{array}$ & $\begin{array}{l}\text { Duct Conf } \\
\text { InjDur IgnDel Tnk Pr }\end{array}$ & VlveA COMMENTS \\
\hline $\begin{array}{l}1 \\
\text { Exh } \\
\text { Int }\end{array}$ & $\begin{array}{l}24 \\
18 \\
21\end{array}$ & $\star \star \star$ & 30 & $\begin{array}{l}80.0 \text { Double. Po } \\
\text { Multiple. } \\
\text { Double. La }\end{array}$ \\
\hline $\begin{array}{l}\text { RUN \# } \\
\text { POS. }\end{array}$ & $\begin{array}{l}25 \\
\text { PRESS. }\end{array}$ & $\begin{array}{l}\text { Injection } \\
\text { PresPer InjPer }\end{array}$ & $\begin{array}{l}\text { Duct Conf } \\
\text { InjDur IgnDel Tnk Pr }\end{array}$ & VIVEA COMMENTS \\
\hline 1 & 23 & 200 & 151 & 80.0 Regular \\
\hline $\begin{array}{l}\text { RUN \# } \\
\text { POS. }\end{array}$ & $\begin{array}{l}26 \\
\text { PRESS. }\end{array}$ & $\begin{array}{l}\text { Injection } \\
\text { Presper Injper }\end{array}$ & $\begin{array}{l}\text { Duct Conf } \\
\text { InjDur Igndel Tnk Pr }\end{array}$ & VIVEA COMMENTS \\
\hline $\begin{array}{l}1 \\
\text { Exh } \\
\text { Int }\end{array}$ & $\begin{array}{l}52 \\
44 \\
42\end{array}$ & $\begin{array}{l}200 \\
200 \\
200\end{array}$ & 151 & $\begin{array}{l}80.0 \text { Very late } \\
\text { Concurrent } \\
\text { Sharp }\end{array}$ \\
\hline $\begin{array}{l}\text { RUN } \# \\
\text { POS. }\end{array}$ & $\begin{array}{l}27 \\
\text { PRESS. }\end{array}$ & $\begin{array}{l}\text { Injection } \\
\text { Presper Injper }\end{array}$ & $\begin{array}{l}\text { Duct Conf } \\
\text { InjDur IgnDel Tnk Pr }\end{array}$ & VIVEA COMMENTS \\
\hline $\begin{array}{l}1 \\
\text { Exh } \\
\text { Int }\end{array}$ & $\begin{array}{l}65 \\
45 \\
58\end{array}$ & 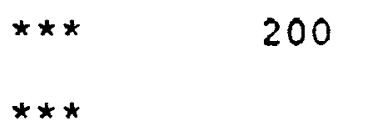 & 151 & $\begin{aligned} & 80.0 \text { Multiple. } \\
& \text { Wide } \\
& \text { Late-Ahead }\end{aligned}$ \\
\hline
\end{tabular}

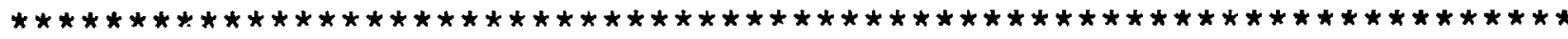
DATE $7 / 24 / 90$

RUN \# 6 Injection S I Duct Conf 1"DCt

POS. PRESS. Presper InjPer InjDur IgnDel Tnk Pr VIVeA COMMENTS

15 *** $200 \quad 30 \quad 150 \quad 75$ 80.0 Multiple.
\end{abstract}

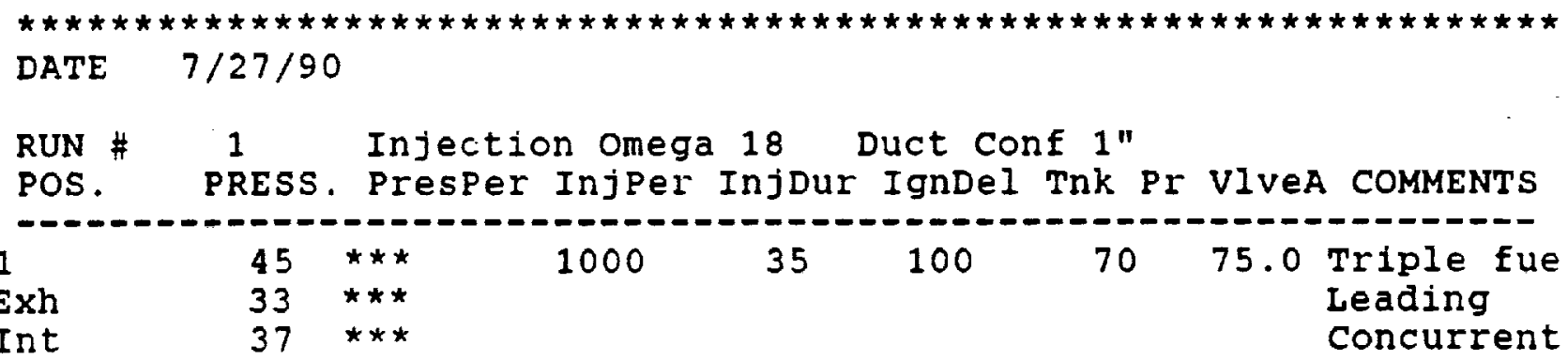

RUN \# 2 Injection Omega 18 Duct Conf $1 "$ POS. PRESS. PresPer InjPer InjDur IgnDel Tnk Pr VIveA COMMENTS

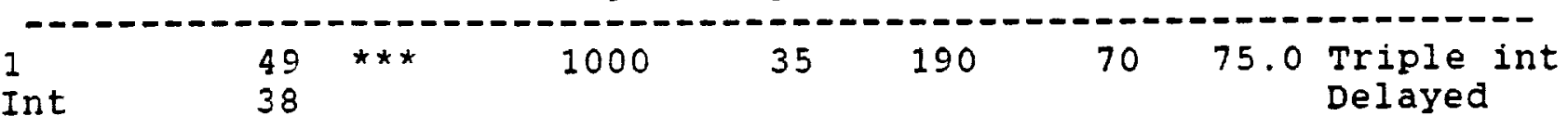




\section{NASA DETONATION DUCT GAS GENERATOR PROGRAM - PRESSURES}

\begin{tabular}{|c|c|c|c|c|}
\hline DATE & $7 / 27 / 90$ & & & \\
\hline $\begin{array}{l}\text { RUN \# } \\
\text { POS. }\end{array}$ & $\begin{array}{l}10 \\
\text { PRESS. }\end{array}$ & $\begin{array}{l}\text { Injection Omega } 18 \\
\text { Presper InjPer InjDur }\end{array}$ & $\begin{array}{l}\text { Duct Conf } 1 " \\
\text { IgnDel Tnk Pr }\end{array}$ & VIVEA COMMENTS \\
\hline $\begin{array}{l}\text { Exh } \\
\text { Int }\end{array}$ & $\begin{array}{l}58 \\
43 \\
48\end{array}$ & 1000 & 460 & $\begin{array}{r}75.0 \text { Sharp puls } \\
\text { Concurrent } \\
\text { Concurrent }\end{array}$ \\
\hline $\begin{array}{l}\text { RUN \# } \\
\text { POS. }\end{array}$ & 12 & $\begin{array}{l}\text { Injection Omega } 18 \\
\text { PresPer InjPer InjDur }\end{array}$ & $\begin{array}{l}\text { Duct Conf } 1 " \\
\text { Igndel Tnk Pr }\end{array}$ & VIVEA COMMENTS \\
\hline $\begin{array}{l}\text { xh } \\
\text { nt }\end{array}$ & $\begin{array}{l}45 \\
35 \\
37\end{array}$ & $\begin{array}{l}1000 \\
1000\end{array}$ & $\begin{array}{l}150 \\
150\end{array}$ & $\begin{aligned} 75.0 & \text { Sharp } \\
& \text { Leading } \\
& \text { Concurrent }\end{aligned}$ \\
\hline $\begin{array}{l}\text { RUN \# } \\
\text { POS. }\end{array}$ & $\begin{array}{l}15 \\
\text { PRESS. }\end{array}$ & $\begin{array}{l}\text { Injection Omega } 18 \\
\text { Presper InjPer InjDur }\end{array}$ & $\begin{array}{l}\text { Duct Conf } 1 " \\
\text { Igndel Tnk Pr }\end{array}$ & VIVEA COMMENTS \\
\hline xh & $\begin{array}{l}48 \\
40 \\
40\end{array}$ & $\star * \star$ & $150 \quad \cdots$ & $\begin{array}{ll}75.0 & \text { Multiple } \\
\text { Concurrent } \\
\text { Concurrent }\end{array}$ \\
\hline $\begin{array}{l}\text { RUN \# } \\
\text { POS. }\end{array}$ & 16 & $\begin{array}{l}\text { Injection Omega } 18 \\
\text { PresPer InjPer InjDur }\end{array}$ & $\begin{array}{l}\text { Duct Conf } 1^{\prime \prime} \\
\text { IgnD, I Tnk Pr }\end{array}$ & VlveA COMMENTS \\
\hline$\frac{1}{E \times h}$ & $\begin{array}{l}51 \\
40 \\
45\end{array}$ & 360 & 410 & $\begin{array}{l}75.0 \text { Triple fue } \\
\text { Concurrent } \\
\text { Concurrent }\end{array}$ \\
\hline
\end{tabular}

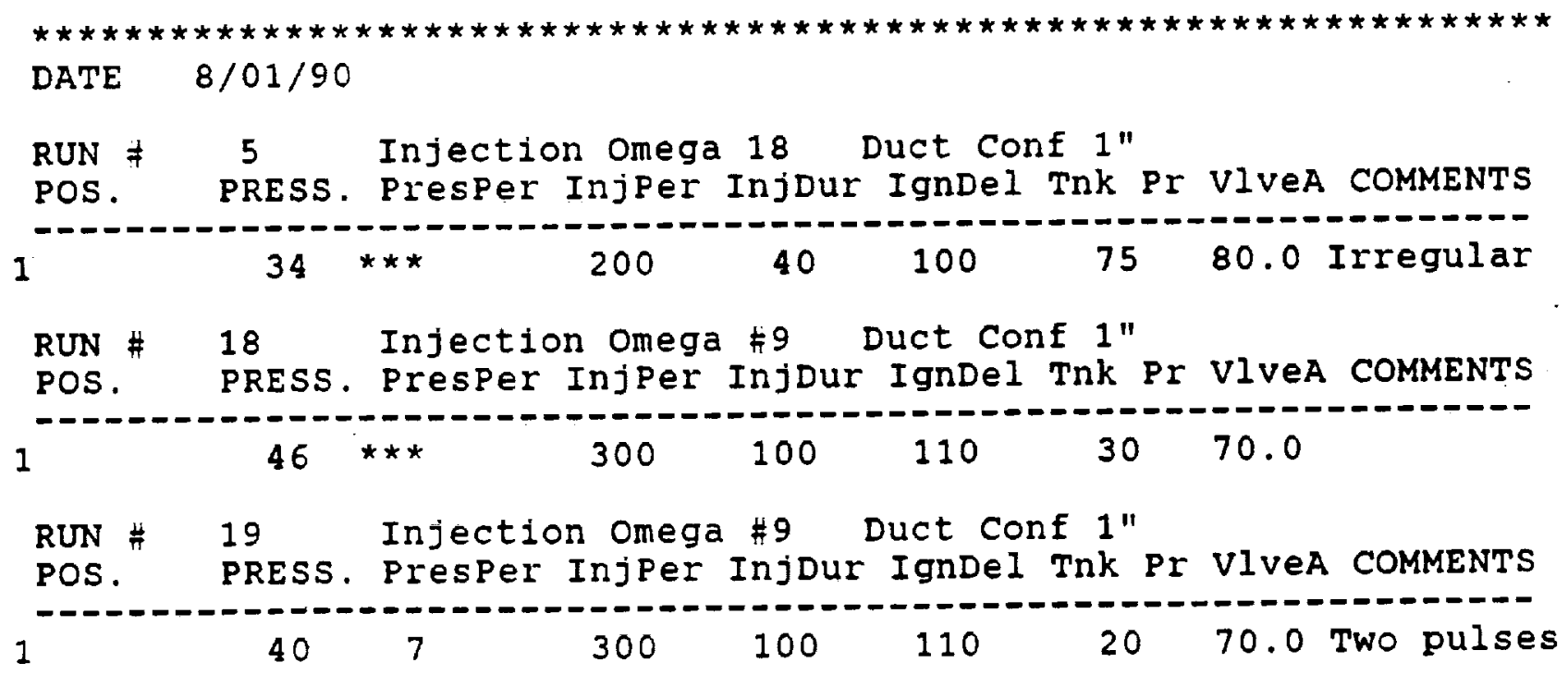




\section{NASA DETONATION DUCT GAS GENERATOR PROGRAM - PRESSURES}

\begin{tabular}{|c|c|c|c|c|}
\hline DATE & $8 / 03 / 90$ & & & \\
\hline $\begin{array}{l}\text { RUN \# } \\
\text { POS. }\end{array}$ & $\begin{array}{l}7 \\
\text { PRESS. }\end{array}$ & $\begin{array}{l}\text { Injection s L } \\
\text { Presper Injper }\end{array}$ & $\begin{array}{l}\text { Duct Conf 1"Dct } \\
\text { InjDur IgnDel Tnk Pr }\end{array}$ & VIVEA COMMENTS \\
\hline int & $\begin{array}{l}40 \\
30 \\
30\end{array}$ & $\begin{array}{l}500 \\
500 \\
500\end{array}$ & $\begin{array}{l}90 \\
90 \\
90\end{array}$ & $\begin{array}{l}80.0 \text { Sharp } \\
80.0 \text { Exc. Sharp } \\
80.0\end{array}$ \\
\hline
\end{tabular}

\section{RUN \# 10 Injection Duct Conf}

POS. PRESS. PresPer InjPer InjDur IgnDel Tnk Pr VlveA COMMENTS

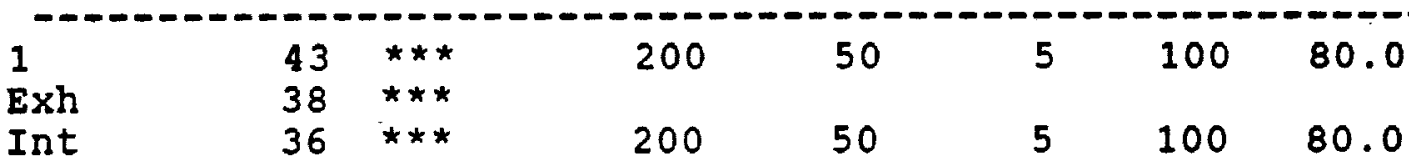

\begin{tabular}{|c|c|c|c|c|c|}
\hline $\begin{array}{l}\text { RUN - } \\
\text { POS. }\end{array}$ & $\begin{array}{l}19 \\
\text { PRESS. }\end{array}$ & $\begin{array}{l}\text { Injection } \\
\text { Presper Injper }\end{array}$ & Injour & $\begin{array}{l}\text { Duct Conf } \\
\text { IgnDel Tnk Pr }\end{array}$ & VlveA COMMENTS \\
\hline 1 & $\begin{array}{l}50 \\
30\end{array}$ & $\begin{array}{l}500 \\
500\end{array}$ & $\begin{array}{l}90 \\
90\end{array}$ & $\begin{array}{l}5 \\
5\end{array}$ & $80.0 \mathrm{Mult}$. \\
\hline
\end{tabular}

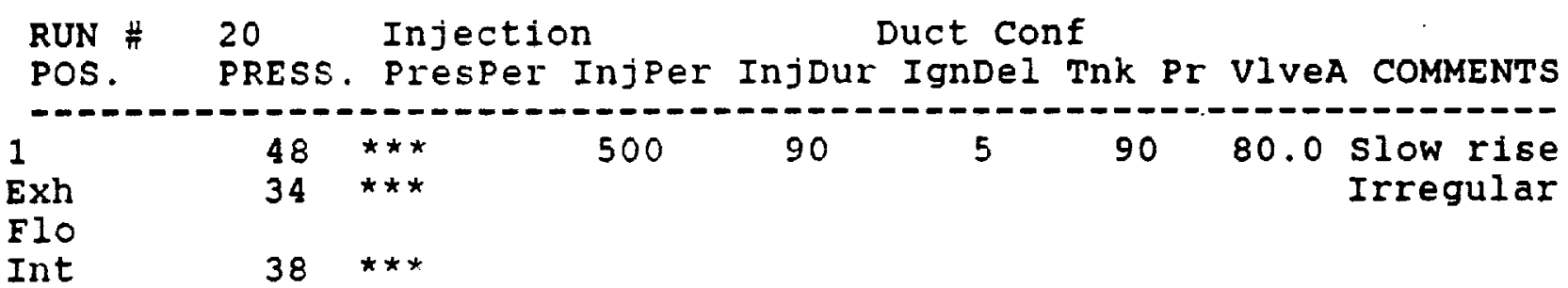

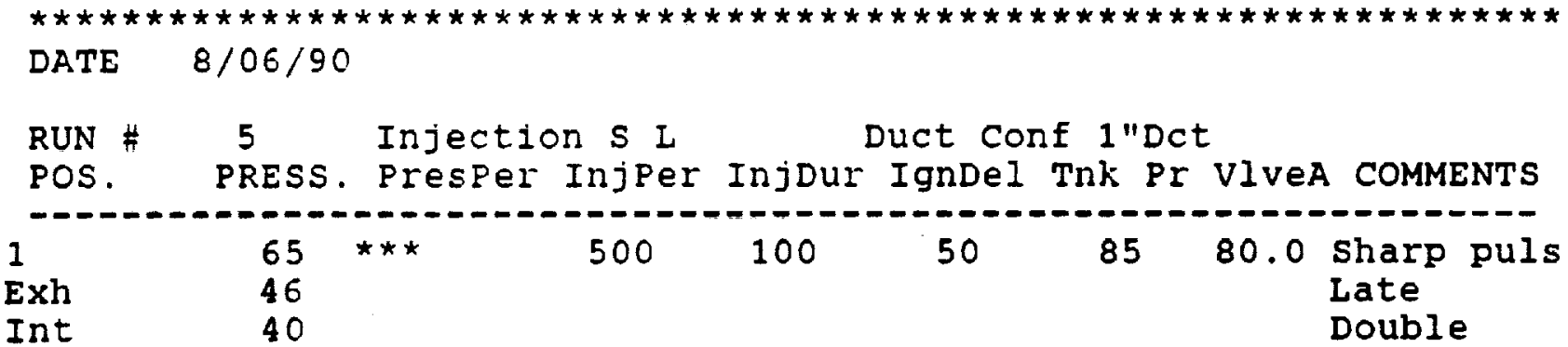

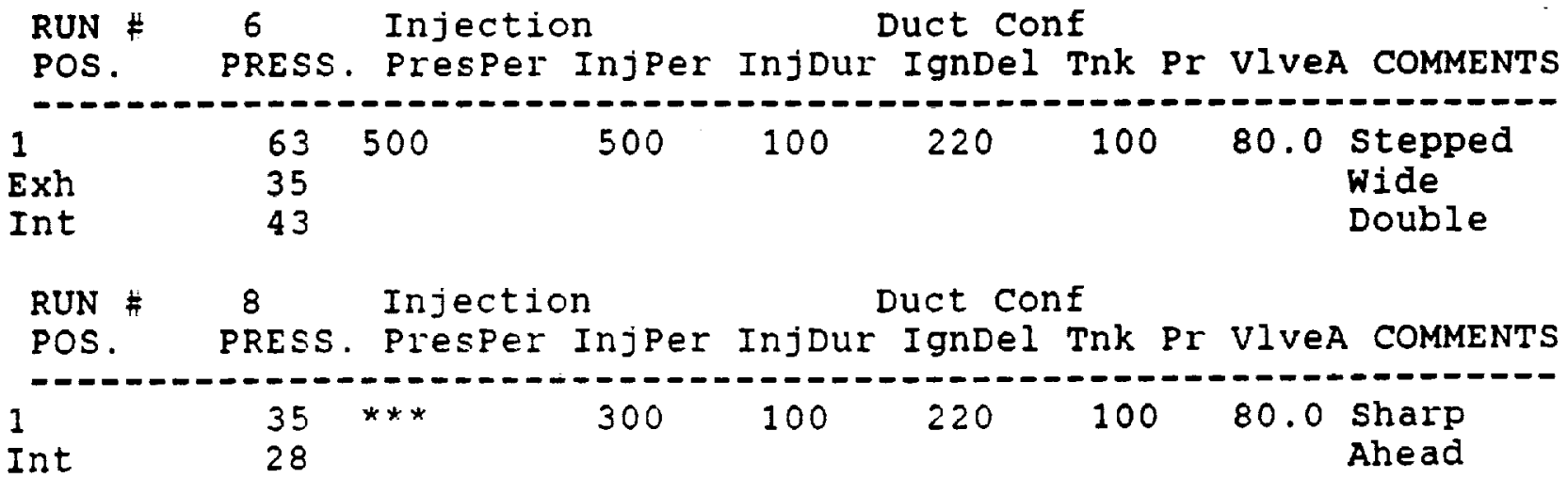




\section{NASA DETONATION DUCT GAS GENERATOR PROGRAM - PRESSURES}

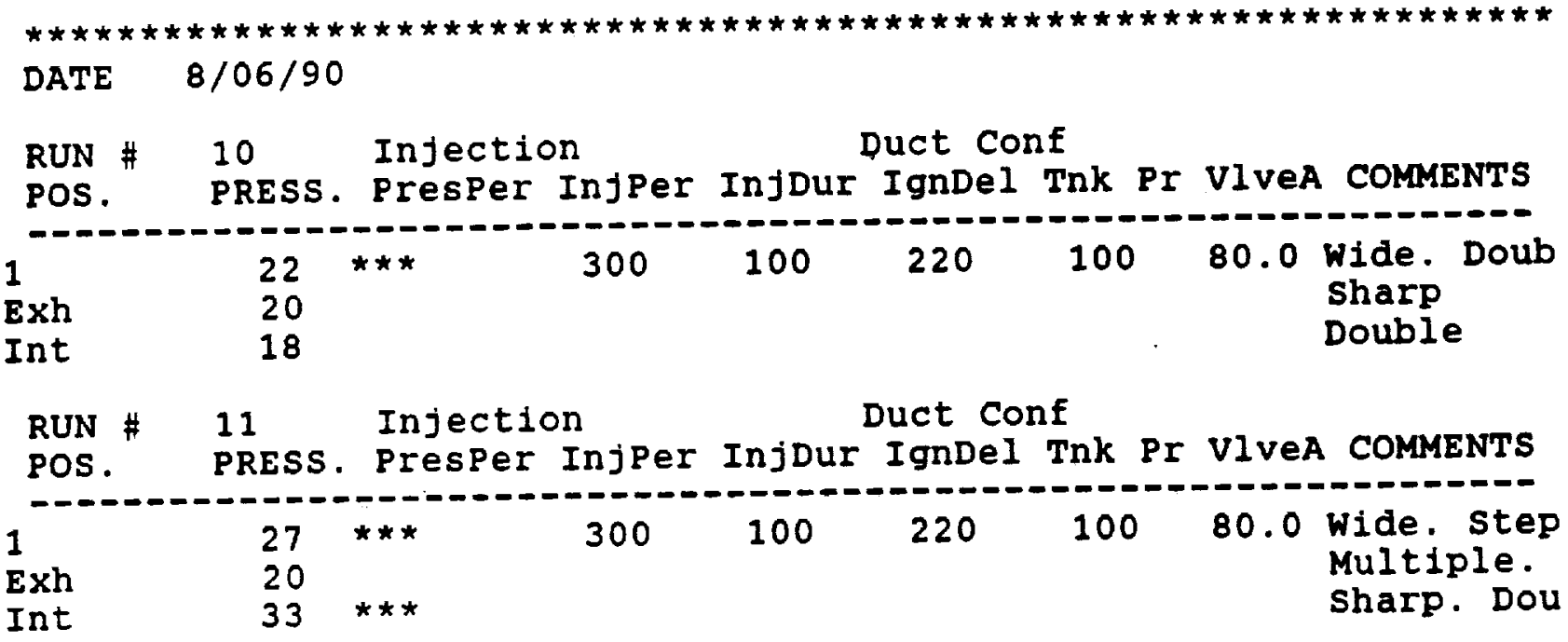

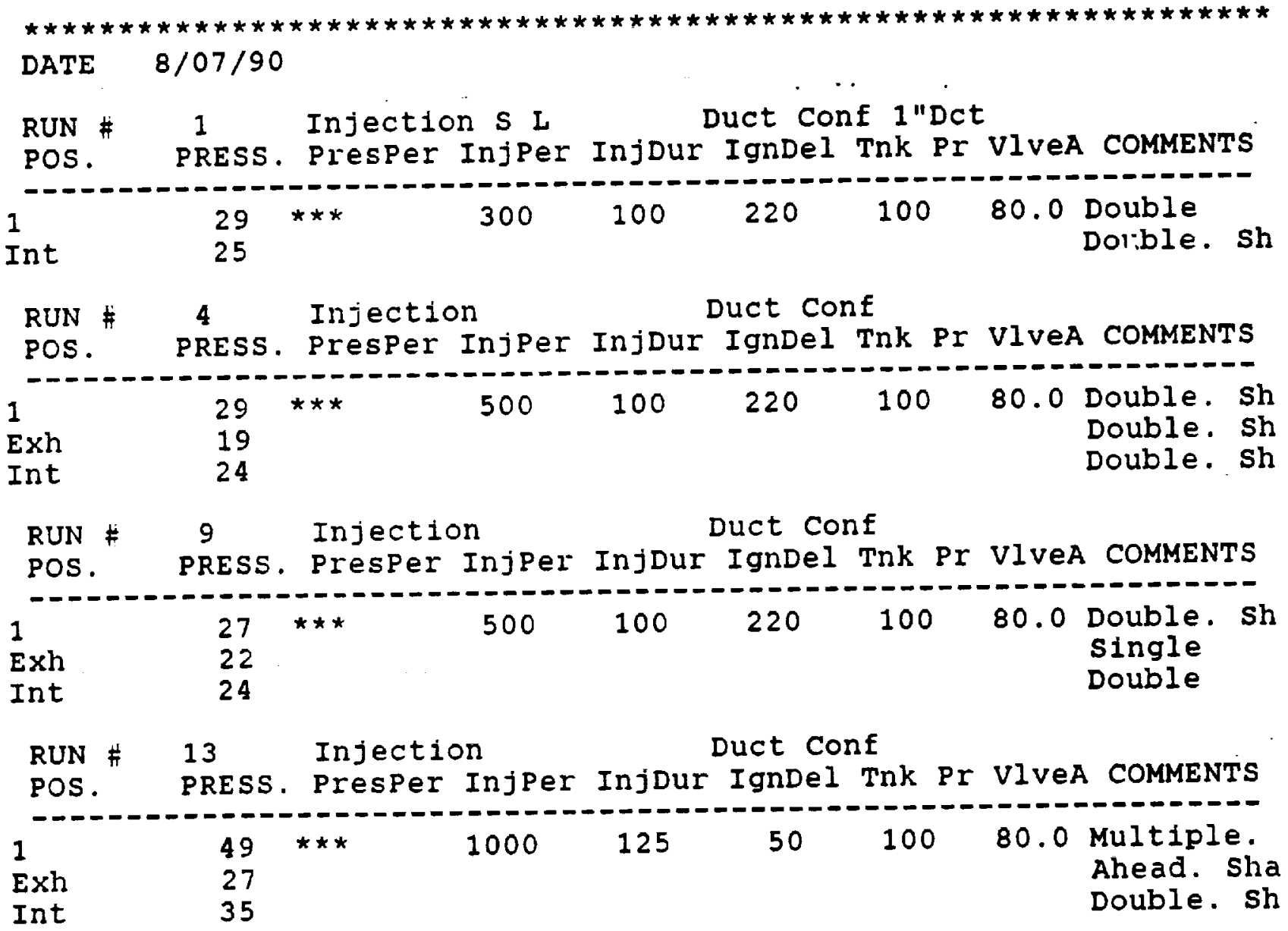

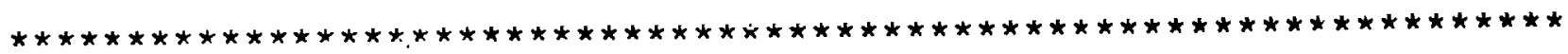
DATE $8 / 08 / 90$

RUN $\# \quad 1$ Injection $S$ I Reg Duct Conf 1 "DCt POS. PRESS. Presper InjPer InjDur IgnDel Tnk Pr VIVeA COMMENTS

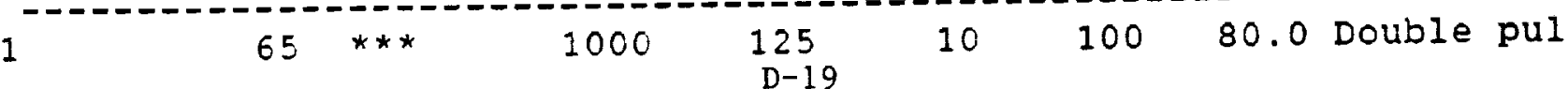


NASA DETONATION DUCT GAS GENERATOR PROGRAM - PRESSURES

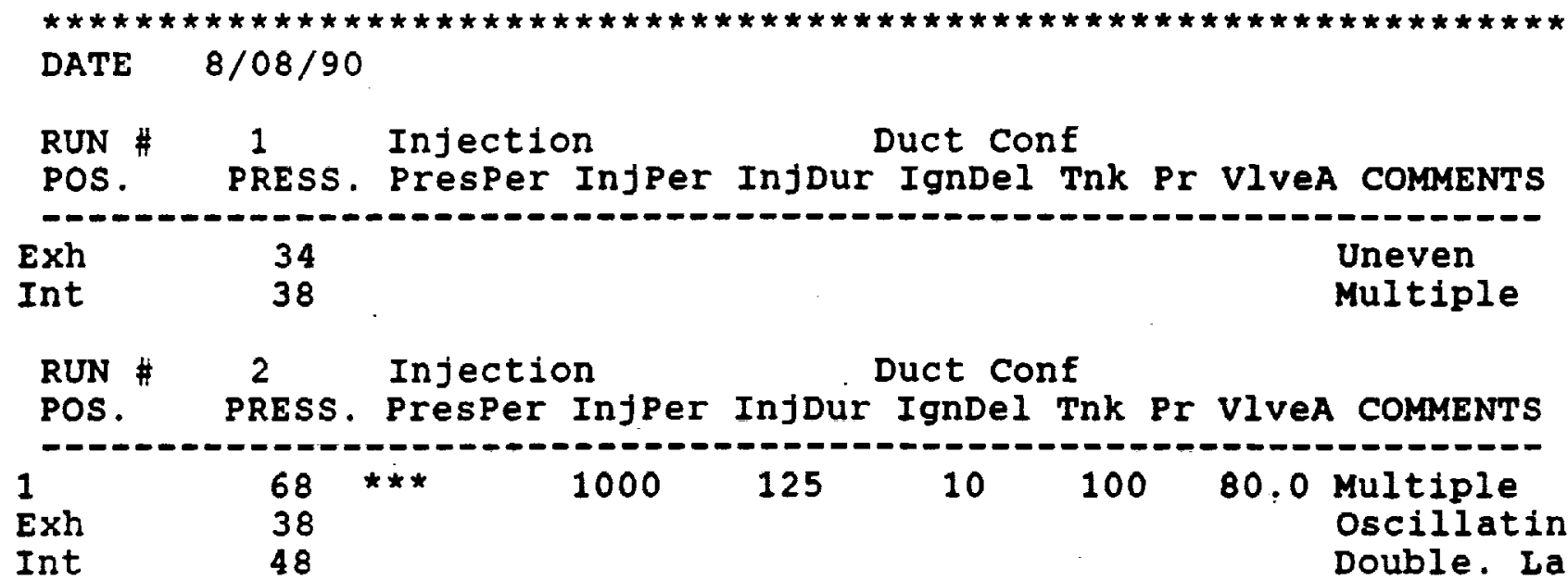

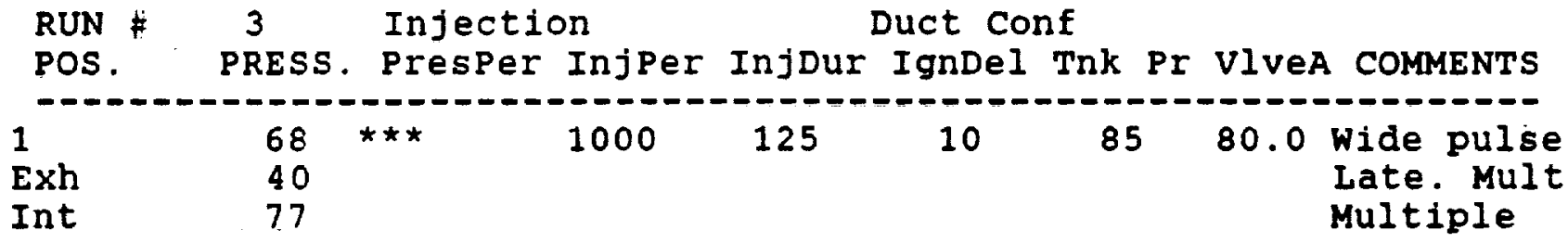

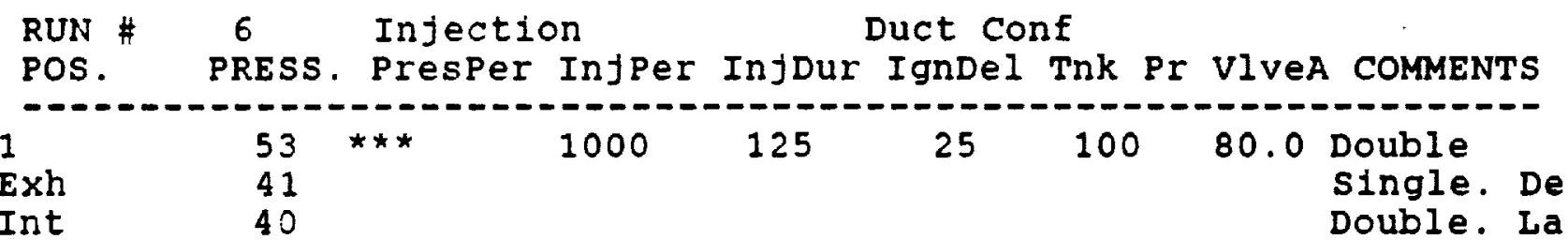

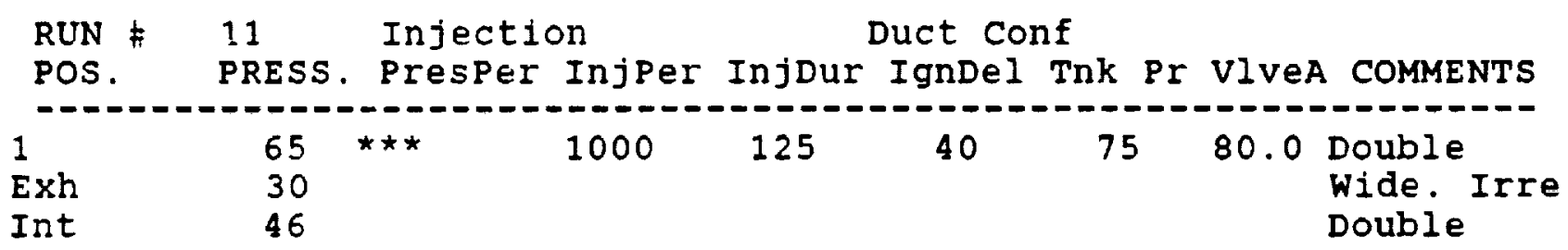

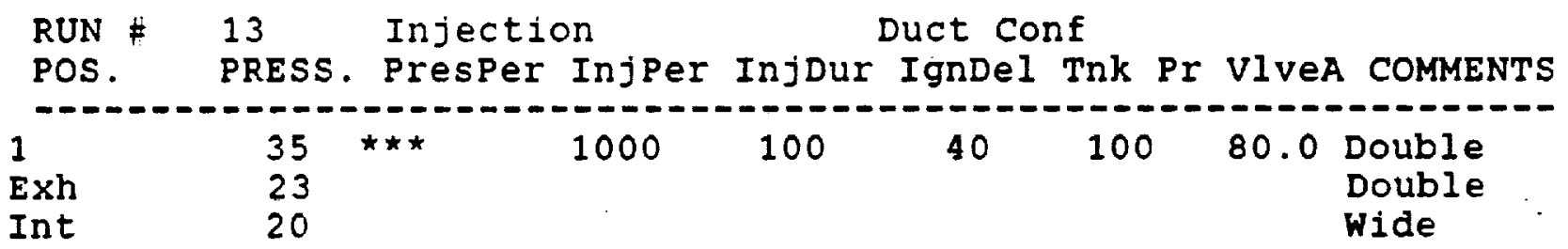

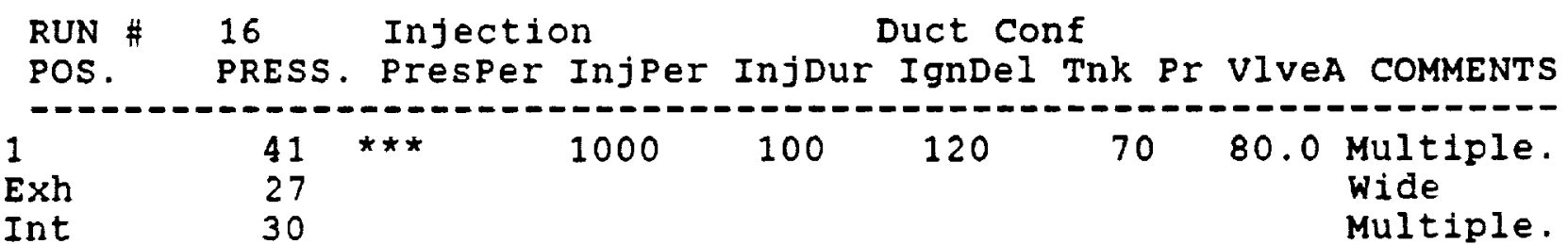

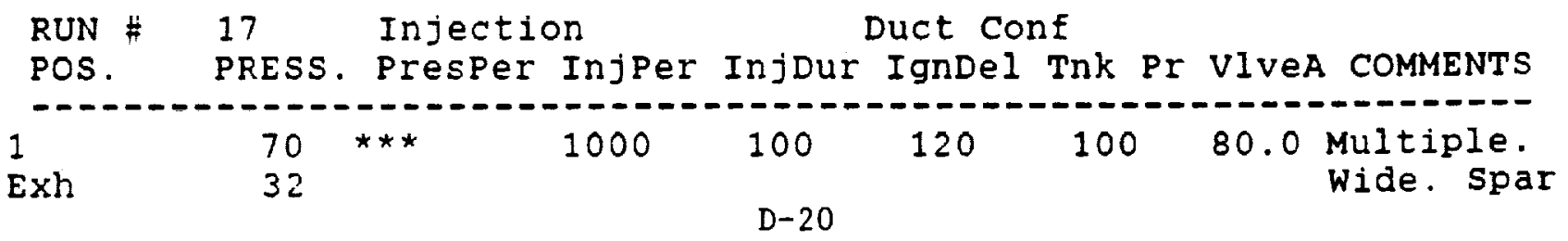




\title{
NASA DETONATION DUCT GAS GENERATOR PROGRAM - PRESSURES
}

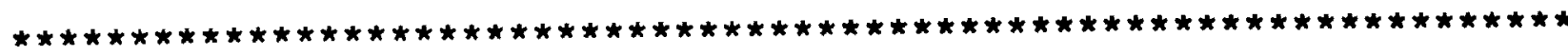

DATE $8 / 08 / 90$

RUN \# 17 Injection Duct Conf

POS. PRESS. PresPer InjPer InjDur IgnDel Tnk Pr VIveA COMMENTS

53

Multiple.
\end{abstract}

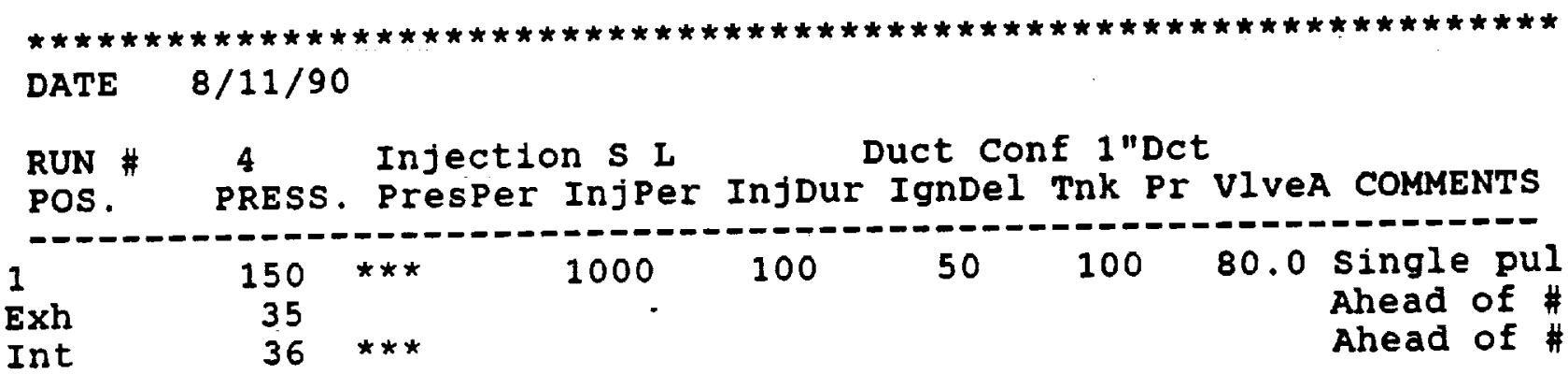

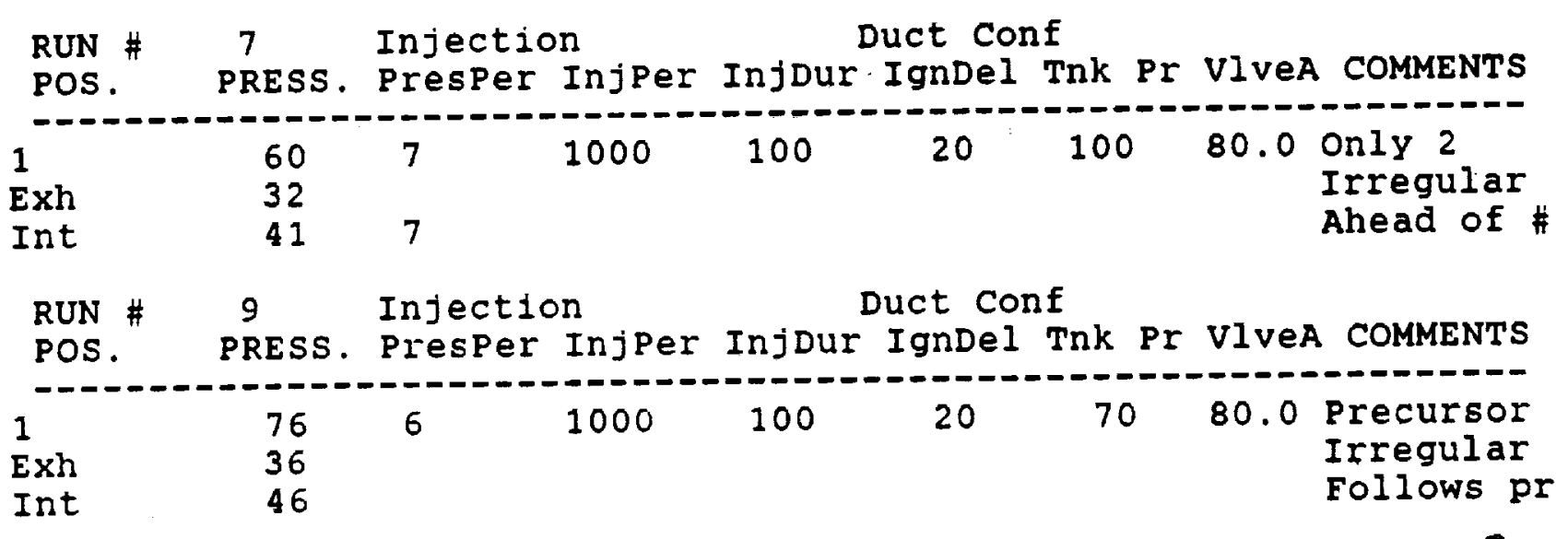

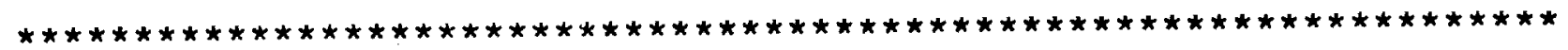

DATE $8 / 13 / 90$

RUN \# 19 Injection $S \mathrm{~L}$ Duct Conf 1 "DCt

POS. $\quad$ PRESS. PresPer InjPer InjDur IgnDel Tnk Pr vIveA COMMENTS

$1050 \quad 0 \quad 1000 \quad 100 \quad 225 \quad 50 \quad 80.0$ Wave veloc

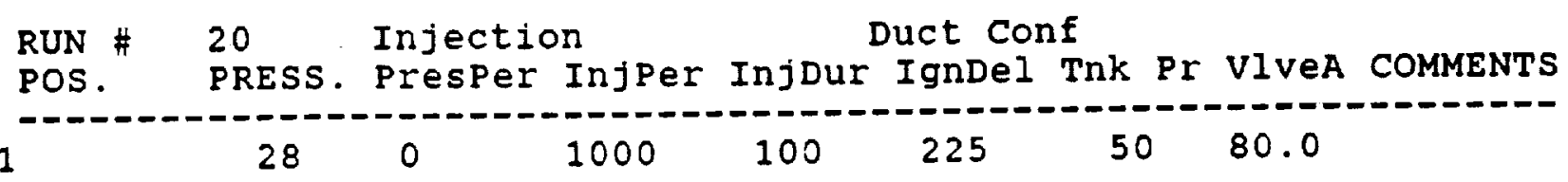

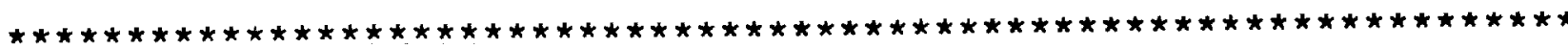

DATE $8 / 15 / 90$

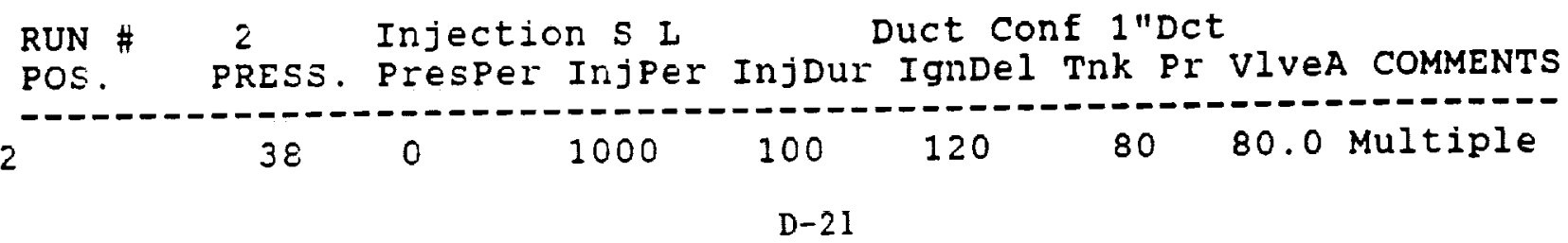


NASA DETONATION DUCT GAS GENERATOR PROGRAM - PRESSURES

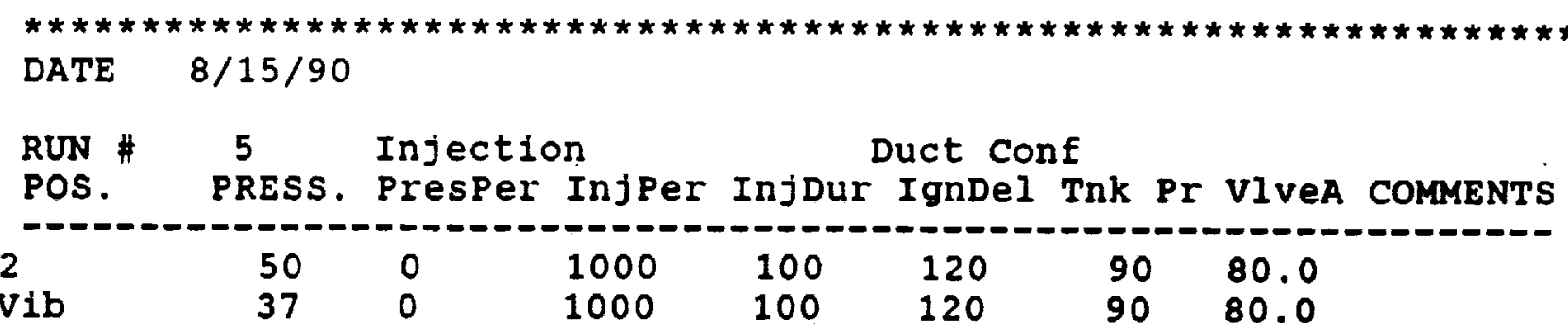

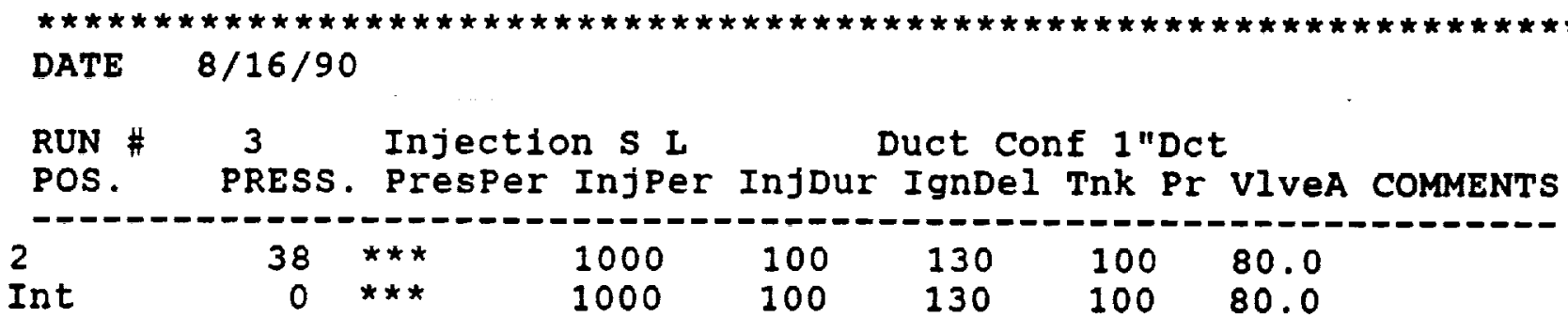

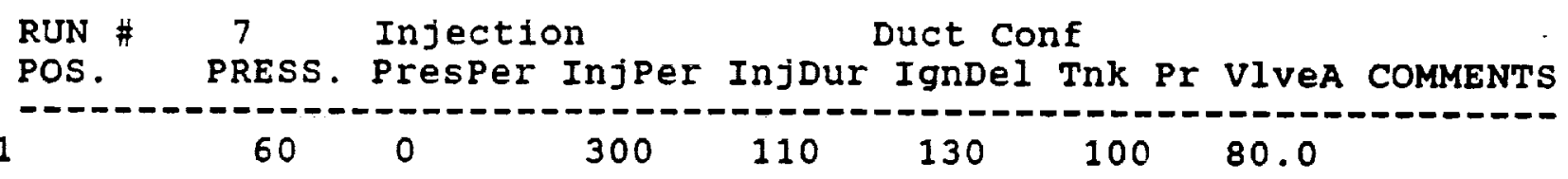

RUN \# $\quad 9$ Injection Duct Conf

POS. PRESS. Presper InjPer InjDur IgnDel Tnk Pr vIveA COMMENTS

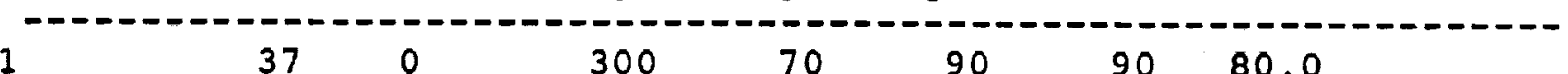

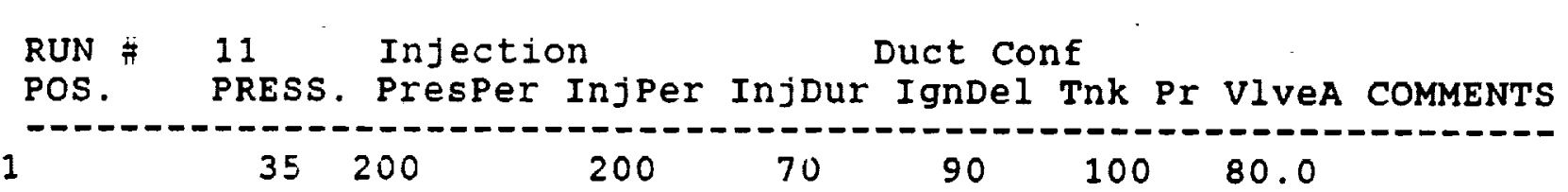

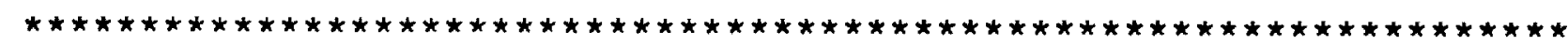
DATE $8 / 17 / 90$

RUN \# 7 Injection S L Duct Conf 1 "Dct POS. PRESS. PresPer InjPer InjDur IgnDel Tnk Pr VlveA COMMENTS

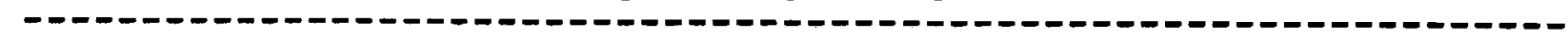

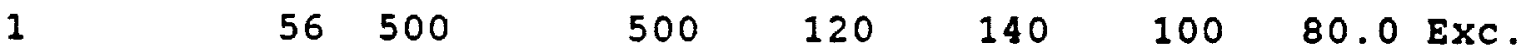
RUN \# 8 Injection
Duct Conf

POS. PRESS. PresPer InjPer InjDur IgnDel Tnk Pr VIveA COMMENTS

$152500 \quad 500 \quad 120 \quad 140 \quad 100 \quad 80.0$ Variable a

RUN \# 9 Injection Duct Conf

POS. PRESS. Presper InjPer InjDur IgnDel Tnk Pr VIVeA COMMENTS

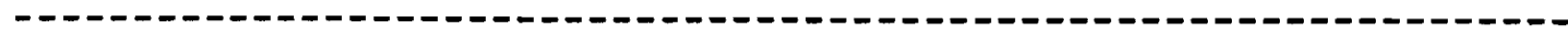

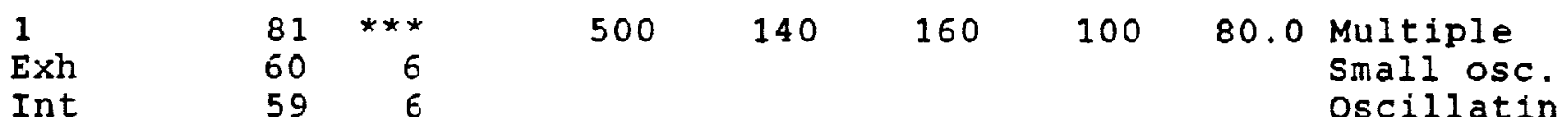




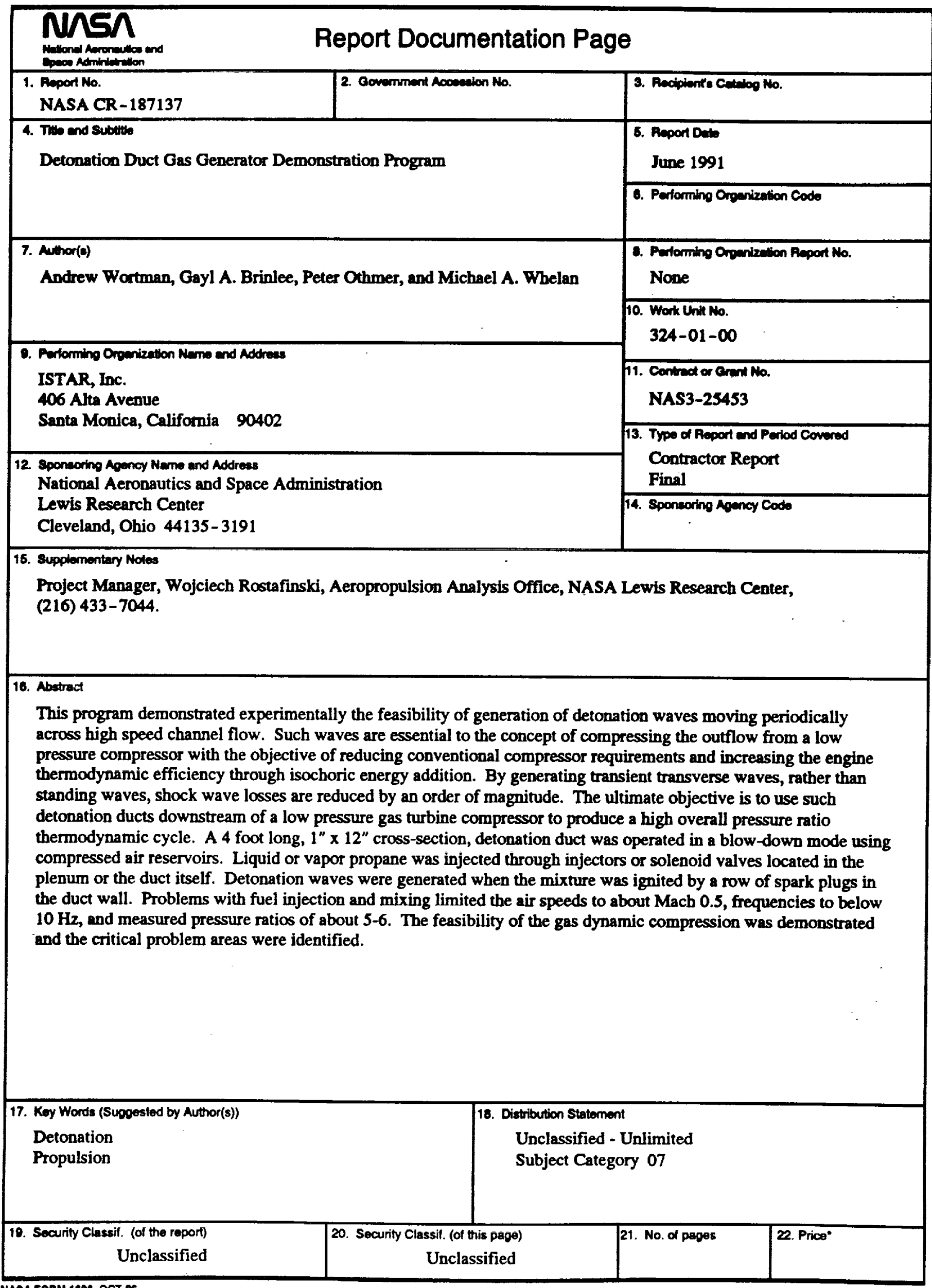

